TANZANIA

COUNTRY PROCUREMENT

ASSESSMENT REPORT

(CPAR)

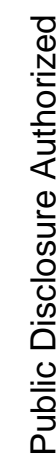

\author{
VOLUME II
}

MAIN REPORT AND ANNEXES

April 30, 2003

Operational Quality and Knowledge Services Africa Region 



\section{TABLE OF CONTENTS}

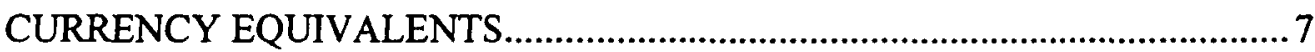

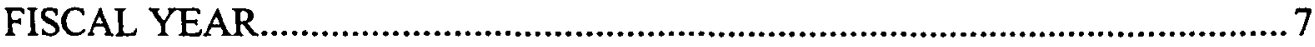

ABBREVIATIONS AND ACRONYMS ..................................................... 7

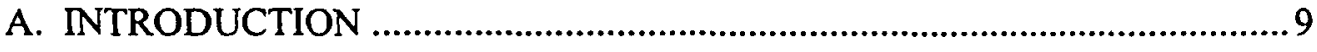

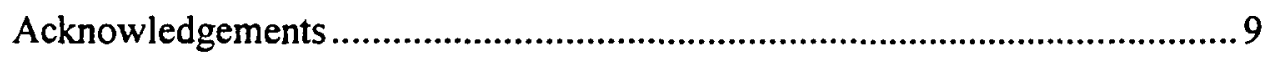

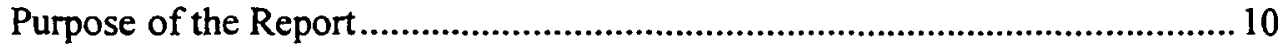

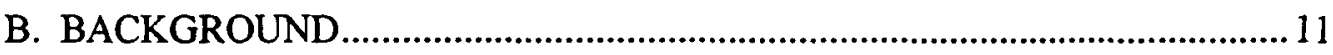

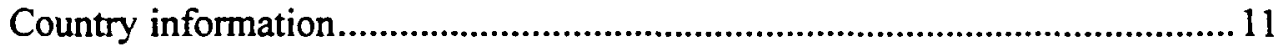

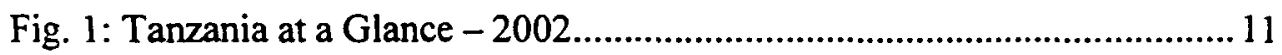

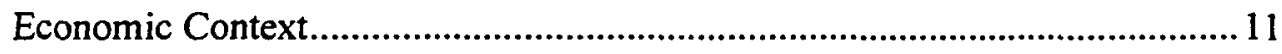

Bank Portfolio in Country ......................................................................... 12

Fig.2: Tanzania: Current Composition of World Bank Loan Portfolio ............... 13

C. MAIN FINDINGS AND ANALYSIS ....................................................... 14

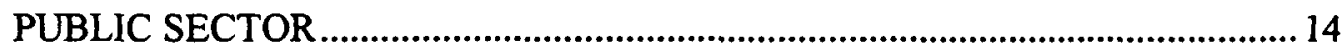

C.1. LEGAL AND REGULATORY FRAMEWORK .................................... 14

Existing legal and regulatory framework ................................................... 14

Legal Benchmark - Tanzanian Rules vs. International Standards .................... 15

Application of procurement rules - entities subject to regulation ................... 16

Methods of procurement and their conditions for use ...................................... 16

Fig. 3: Procurement thresholds .................................................................. 17

Publicity in procurement ................................................................................ 19

Pre-qualification and qualitative criteria ..................................................20

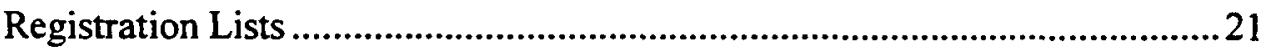

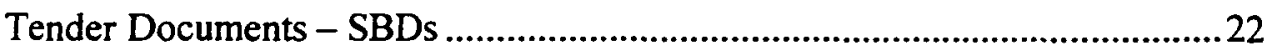

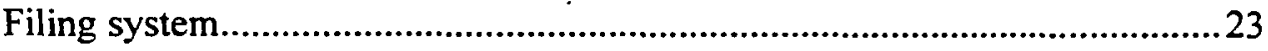

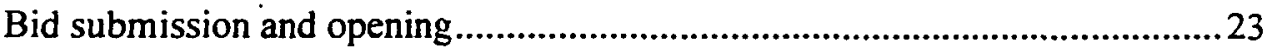

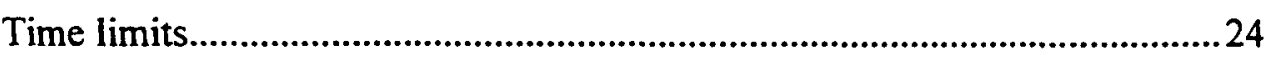

Fig. 4: Time limits within the procurement procedure ..................................25

Contract award procedure and criteria ..........................................................225

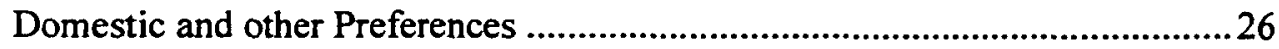

Negotiations: pre- and post contract negotiations.......................................22

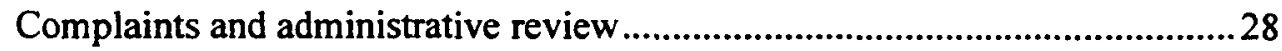

Other Legal Framework Issues ...............................................................29

Local Government Procurement.............................................................29

National Board for Materials Management Act vs. Public Procurement Act .... 30

Defence and security Procurement ..............................................................30

Legal Framework - conclusion ............................................................... 31

Summary of Legal Framework Recommendations ........................................ 31

C. 2. PROCEDURES AND PRACTICES ..................................................... 32 
Procurement Planning - Release of Funds ................................................. 32

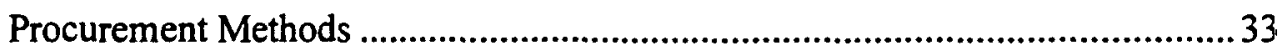

Publicity and transparency in procurement .................................................. 34

Pre-qualification and qualitative criteria .......................................................34

Tender Documents - Standard Bidding Documents....................................... 34

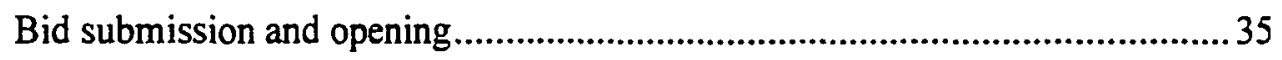

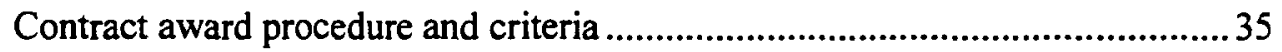

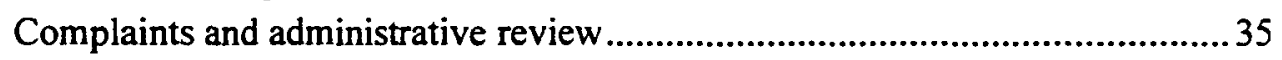

Summary of Recommendations for Procedures and Practices .......................... 37

Monitoring and Contract Management ........................................................38

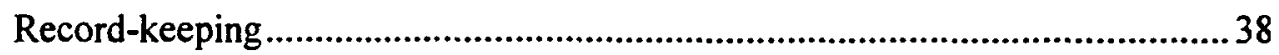

Variations and post-contract negotiations ...................................................38

Enforcement and monitoring compliance ......................................................39.

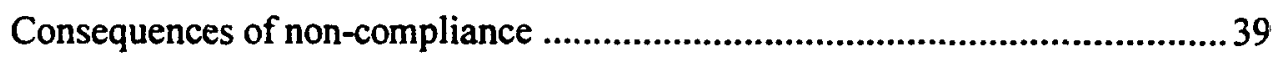

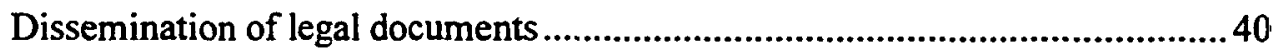

Recommendations for Monitoring and Contract Management ........................40

C.3. ORGANISATION AND RESOURCES ................................................. 41

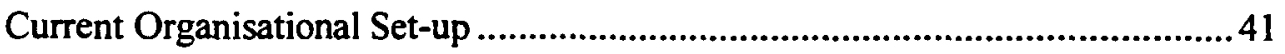

Role of the Central Tender Board..............................................................4 41

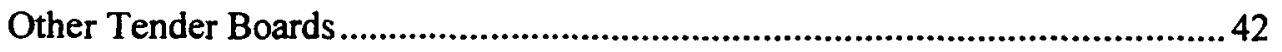

Fig. 5: Thresholds for procuring entities....................................................4 43

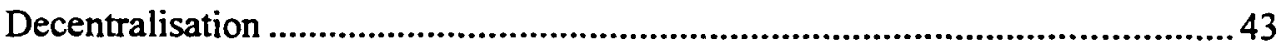

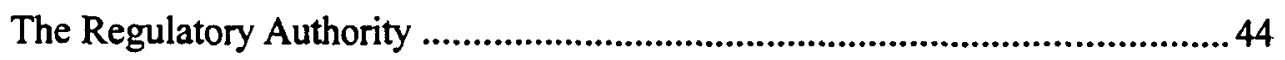

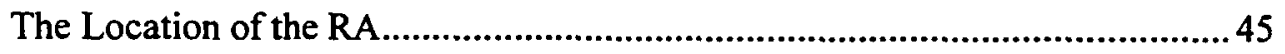

Establishment and Strengthening of Procurement Management Units .............46 46

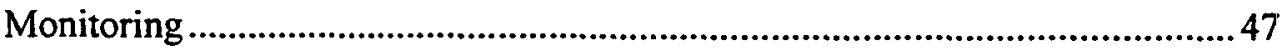

Securing information flow to the RA....................................................4 47

The monitoring role of the RA vis-à-vis local government .............................48 48

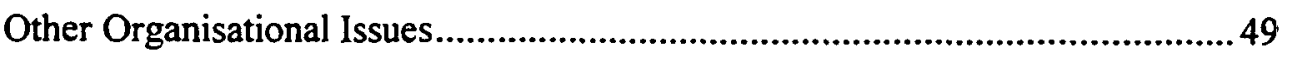

The Public Procurement Appeals Authority................................................ 49

Local government procurement ............................................................50

Utilising the advantage of scale ..............................................................5 52

Information dissemination regarding the RA and the PPAA .........................55

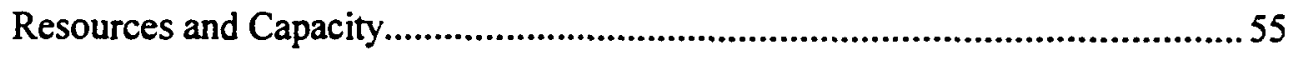

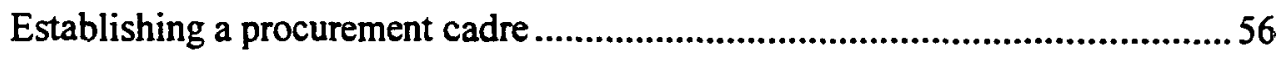

Up-grading and certification of procurement professionals..........................55

Fig. 7: Number of Supplies Officers in the public service ..............................57

Public Service Pay and Pay Reform ............................................................5

Selective Accelerated Salary Enhancement .................................................6 60

Capacity Building Measures...................................................................61 61

Fig. 8: Overview of Procurement Training Institutions ................................. 63 


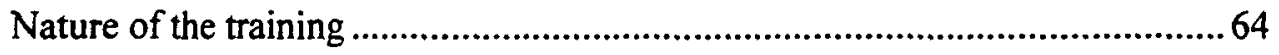

Summary of Recommendations Regarding Organisation and Resources..........65

C. 4. AUDIT AND ANTI-CORRUPTION MEASURES .................................67

Corruption in Procurement .......................................................................67

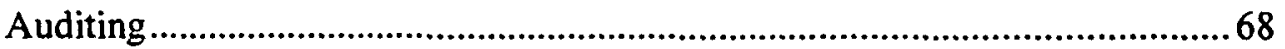

Institutional Set-up for Fighting Corruption in Procurement ..........................69

Fig. 9: Mandate and functions of key oversight institutions ......................... 70

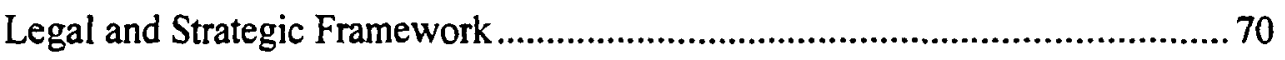

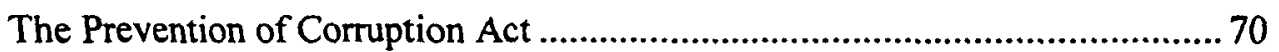

The National Anti-Corruption Strategy and Action Plans ........................... 71

Review of Anti-Corruption sector strategies ............................................. 72

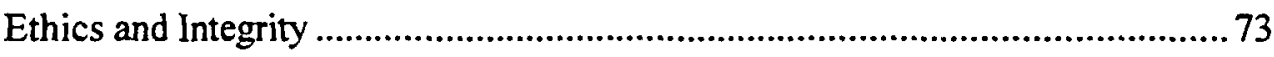

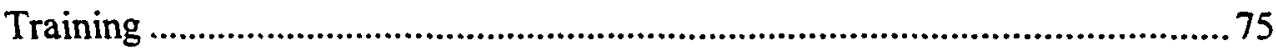

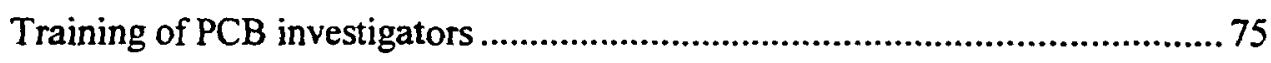

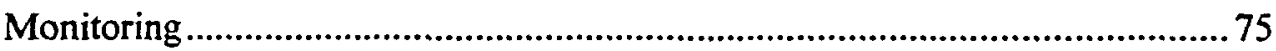

Monitoring public procurement .............................................................. 75

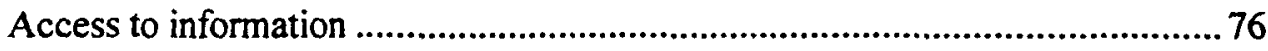

Building capacity of NGOs ............................................................... 76

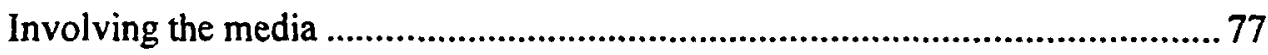

Introducing whistleblowing mechanisms....................................................78

Performance Indicators to Monitor Corruption in Procurement........................ 79

Summary of Recommendations for Audit and Anti-Corruption Measures ........81

C. 5. PUBLIC SECTOR MANAGEMENT PERFORMANCE ............................82

Performance of the Public Procurement System .......................................... 82

Value of procurement ............................................................................. 82

Public Sector Reform Programmes.............................................................8 82

Status of Public Financial Management...................................................... 84

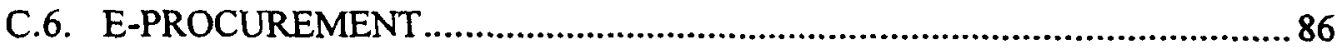

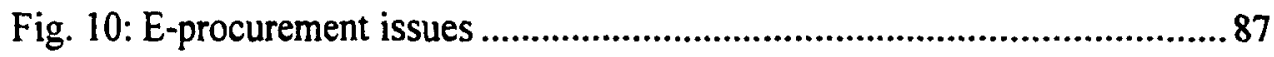

Fig. 11: Features and complexity of e-procurement systems .........................8 87

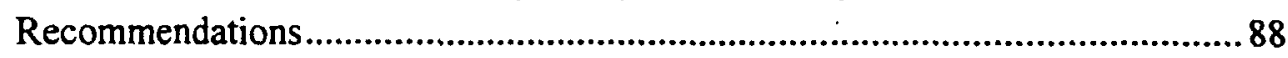

C. 7. PERFORMANCE ON BANK-ASSISTED PROJECTS...............................90 90

Choice of procurement method and advertisement ...................................... 90

Tender Openings..................................................................................91

Bid- and performance security...............................................................91

Pre-Qualification Documents: .................................................................91

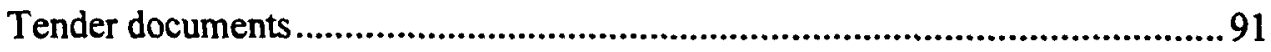

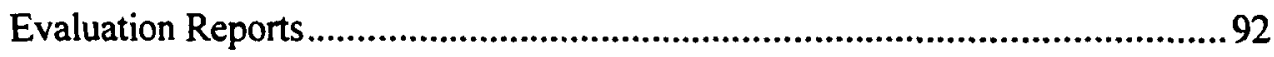

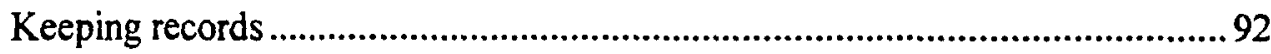

Timeliness......................................................................................92

Recommended Supervision Plan .....................................................93 


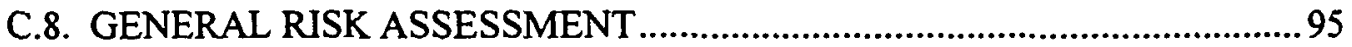

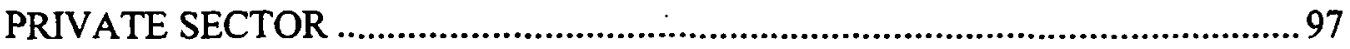

C.9. TRADE PRACTICES AND CUSTOMS ................................................99

Trade Policies and Conditions in General .................................................97

Custom Practices and Authorities in General..............................................98

Import Procedures and Practices................................................................. 99

Fig. 12: Annual TRA Customs Dept. Revenue Collection .............................. 100

Fig. 13: TRA Customs Department Annual Revenues .................................... 10 1.

C.10. COMMERCIAL PRACTICES AND PROCUREMENT .......................... 102

Fig. 14: Gross domestic product by sector (mainland) .................................. 102

Fig. 15: Tanzania: External Trade .............................................................. 103

Regulation of Competition and Conditions of Doing Business in Tanzania ...... 103

Fig. 16: Commercial Banks Lending rates for year 2002 .............................. 104

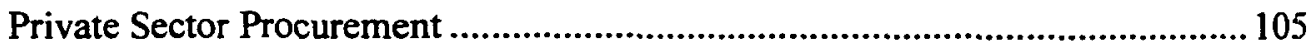

C.11. PRIVATE SECTOR PERFORMANCE................................................ 106

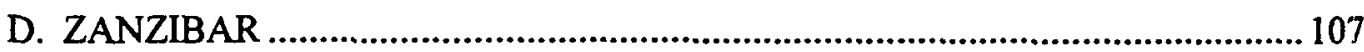

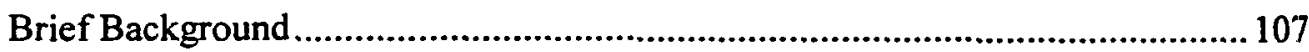

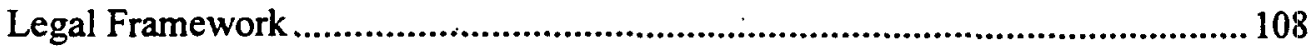

Procedures and Practices ........................................................................... 109

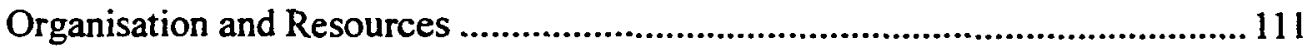

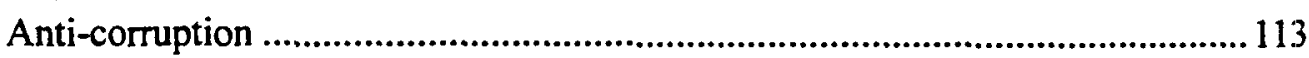

The Private Sector in Zanzibar .................................................................114

Fig. 17: Gross domestic product by sector (Zanzibar)..................................... 115

Import and Export Procedures and Practices..................................................115

Summary of Recommendations for Zanzibar.................................................116

E. RECOMMENDED ACTION PLAN ......................................................... 117

Measures to be the Taken by the Government ............................................... 117

Measures to be Taken by the Bank and Other Financiers................................ 117

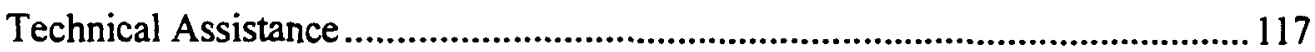

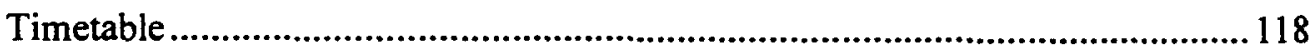

Funding Procurement Reform .................................................................118

Monitoring and Follow-up Plan.............................................................118

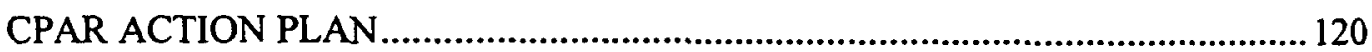

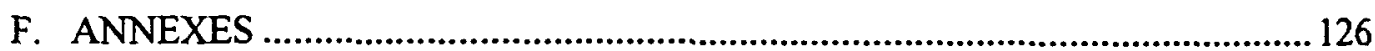




\section{LIST OF ANNEXES}

$\begin{array}{ll}\text { Annex I } & \text { List of People Met } \\ \text { Annex II } & \text { List of Documents Consulted } \\ \text { Annex III } & \text { List of Task Force Members/Government Procurement Task Force } \\ \text { Annex IV } & \text { Detailed Breakdown of Supplies Officers in Public Service } \\ \text { Annex V } & \text { Anti-Corruption Initiatives } \\ \text { Annex VI } & \text { NACSAP Action Plan for Public Procurement } \\ \text { Annex VII . } & \text { Checklist Comparing National Competitive Bidding Procedures } \\ & \text { And World Bank Policy }\end{array}$

\section{FIGURES}

Figure 1. Tanzania at a Glance - 2002

Figure 2. Tanzania: Current Composition of World Bank Loan Portfolio (as of June 30, 2002, amounts in USD Million)

Figure 3. Procurement thresholds

Figure 4. Time limits within the procurement procedure

Figure 5. Thresholds for procuring entities

Figure 7. Number of Supplies Officers in the public service

Figure 8. Overview of Procurement Training Institutions

Figure 9. Mandate and functions of key oversight institutions

Figure 10. E-procurement issues

Figure 11. Features and complexity of e-procurement systems

Figure 12. Annual TRA Customs Dept. Revenue Collection - Budget Vs Actual 1997 to 2000

Figure 13. TRA Customs Department Annual Revenues

Figure 14. Gross domestic product by sector (mainland)

Figure 15. Tanzania: External trade

Figure 16. Commercial Banks Lending rates for year 2002

Figure 17. Gross domestic product by sector (Zanzibar) 


\title{
CURRENCY EQUTVALENTS
}

(Exchange Rate on April 15, 2002)

\author{
Currency Unit $=$ Tanzanian Shilling (Tshs) \\ USD $1=1,050.00$ Tshs
}

\section{FISCAL YEAR}

July 1 - June 30

\section{ABBREVIATIONS AND ACRONYMS}

$\begin{array}{ll}\text { AfDB } & \text { African Development Bank } \\ \text { ATIP } & \text { Accountability, Transparency and Integrity Program } \\ \text { BoT } & \text { Bank of Tanzania } \\ \text { CAS } & \text { Country Assistance Strategy } \\ \text { CED } & \text { Chief Executive Director } \\ \text { CFAA } & \text { Country Financial Accountability Assessment } \\ \text { CSD } & \text { Civil Service Department } \\ \text { GS } & \text { Government Stores } \\ \text { CSD } & \text { Civil Service Department } \\ \text { CTB } & \text { Central Tender Board } \\ \text { CTBA } & \text { Central Tender Board Act } \\ \text { DI } & \text { Destination Inspection } \\ \text { DIS } & \text { District Administrative Secretary } \\ \text { EOI } & \text { Expression of Interest } \\ \text { EU } & \text { European Union } \\ \text { EUD } & \text { EU Procurement Directives } \\ \text { FY } & \text { Financial Year } \\ \text { GDP } & \text { Gross Domestic Product } \\ \text { GGCU } & \text { Good Governance Coordination Unit } \\ \text { IBRD } & \text { International Bank for Reconstruction and Development } \\ \text { ICB } & \text { International Competitive Bidding } \\ \text { ICS } & \text { Integrated Controller System of the World Bank } \\ \text { IDA } & \text { Intemational Development association } \\ \text { IFMAP } & \text { Integrated Financial Management Accountability project } \\ \text { IMS } & \text { Information Management System } \\ \text { IMWG } & \text { Inter-Ministeral Working Group } \\ \text { IPR } & \text { Independent Procurement Review } \\ \text { JICA } & \text { Japanese International Cooperation Agency } \\ \text { LCC } & \text { Local cost compensation } \\ \text { LGRP } & \text { Local Govemment Reform Programme } \\ & \end{array}$




\begin{tabular}{|c|c|}
\hline MBA & Master of Business Administration \\
\hline MDA & Ministries, Departments, and Agencies \\
\hline MSD & Medical Stores Department \\
\hline MoF & Ministry of Finance \\
\hline MSA & Medical Stores Department Act \\
\hline NACSAP & National Anti-Corruption Strategy and Action Plan \\
\hline NAO & National Audit Office \\
\hline NBMM & National Board for Materials Management \\
\hline NBMMA & National Board for Materials Management Act \\
\hline $\mathrm{NCB}$ & National Competitive Bidding \\
\hline NCC & National Construction Council \\
\hline NGO & Non-Governmental Organisation \\
\hline OPP & Office for Public Procurement \\
\hline OWI & Oversight and Watchdog Institutions \\
\hline PCB & Prevention of Corruption \\
\hline PEA & Post Entry Audit \\
\hline PER & Public Expenditure Review \\
\hline PFMRP & Public Financial Management Reform Programme \\
\hline PIF & Performance Improvement Fund \\
\hline PMUs & Procurement Management Units \\
\hline PPA & Public Procurement Act \\
\hline PPAA & Public Procurement Appeals Authority \\
\hline PPB & Procurement Professionals Body \\
\hline PPTS & Public Procurement Training Strategy \\
\hline PQ & Pre-Qualification \\
\hline PRS & Poverty Reduction Strategy \\
\hline PRSC & Poverty Reduction Support Credit \\
\hline PS & Permanent Secretary \\
\hline PSI & Pre-shipment Inspection \\
\hline PSRP & Public Service Reform Programme \\
\hline QCBS & Quality and Cost Based Selection \\
\hline RAS & Regional Administrative Secretary \\
\hline RA & The Regulatory Authority \\
\hline RFQ & Request for Quotation \\
\hline SASE & Selective Accelerated Salary Enhancement \\
\hline SME & Small and Medium Sized Enterprises \\
\hline SBDs & Standard Bidding Document \\
\hline TAP & Tax Administration Project \\
\hline TB & Tender Board \\
\hline Tl & Transparency International \\
\hline TNA & Training needs assessment \\
\hline ToT & Training of Trainers \\
\hline TRA & Tanzania Revenue Authority \\
\hline UML & United Nations Model Law for procurement/ UNCITRAL \\
\hline UNCITRAL & United Nations Commission for International Trade Law \\
\hline VAT & Value Added Tax \\
\hline WB & World Bank \\
\hline WBG & World Bank Guideline \\
\hline WTO & World Trade Organisation \\
\hline
\end{tabular}





\section{A. INTRODUCTION}

1. This report, which updates the CPAR of September 1996, presents the findings and recommendations of two World Bank missions: a preliminary mission from July 8-12 and August 5-9, 2002; and a main mission' from November 19 to December 6, 2002.

2. Concurrently with the CPAR, an Independent Procurement Review (IPR) was being carried out by Global Procurement Consultants Limited (GPCL) ${ }^{2}$ of India as a sub-contractor to PLS RAMBOLL Management A/S. The IPR provided direct input to the CPAR.

3. To assist and guide the CPAR, the Government of Tanzania established a Task Force comprising several ministries, local government representatives, parastatals, the private sector, as well as a representative from the Government of Zanzibar. The taskforce is chaired by the Secretary of the Central Tender Board (CTB) Mr. Nkinga. ${ }^{3}$

4. A draft report was discussed at a workshop organised by the Government of Tanzania in Dar es Salaam on 27-28 January 2003. During this workshop, members of the Task Force, representatives from regional and local government authorities, and a number of development partners discussed and agreed this report, including its key findings and recommendations. To benefit from the momentum of the workshop it was decided to streamline the Task Force enabling it to carry forward the reform of the public procurement system. It was further decided that new terms of reference for the Task Force shall be developed focussing on the implementation of the recommendations coming out of the workshop.

\section{Acknowledgements}

5. The mission is grateful for the cooperation it received from the Govemments of Tanzania and Zanzibar and all organisations visited. In particular, the mission would like to thank the members of the Government Task Force for their full and proactive commitment to the CPAR mission, participation in key meetings and, in particular, for the comprehensive dialogue, which

\footnotetext{
'The mission was led by Mr. Rogati Kayani (Lead Procurement Specialist), and included representatives from the Government of Tanzania, Mr. Pascal Tegwa (Senior Procurement Specialist) from the World Bank Tanzania Country Office as well as a consultant team from PLS RAMBOLL Management A/S of Denmark lead by Mrs. Mette S. Lassesen (Procurement organisation, procurement capacity, and anti-corruption) and consisting of Mr. Soren Staugaard Nielsen (Legal framework, procedures and practices) and Mr. Claus Thomsen (Trade and private sector). In addition a group of local consultants were engaged: Dr. Laurent Shirima (Legal framework, procedures and practices), Mr. Oltesh Thobias (Trade and private sector), and Professor Awadhi Mawenya (Anti-comuption). ${ }^{2}$ Headed by Mr. R. Rajappa and including Mr. A. K. Kolsur and Dr.Masaburi (local consultant).

${ }^{3}$ Please refer to Annex III for a full overview of the Task Force members
} 
they entered into with the mission, to discuss the issues identified by the assessment and to develop the recommendations presented in this report.

6. In addition, the mission would like to thank the Danish Government Trust Fund for financing parts of the mission and the AfDB, DANIDA, DFID, JICA, SDC, SIDA, USAID and the EU for providing valuable contributions in discussion during the various stages of the CPAR process.

\section{Purpose of the Report}

7. The World Bank undertakes assessments of the procurement environment, covering both public and private sectors in borrowing member countries on a systematic basis. The objective of the assessment is to determine the compatibility of national procurement law and practices with the principles of economy and efficiency and with international procurement practices. The findings and recommendations of this work not only helps the Bank ensure that sound procurement practices are followed in the projects that the Bank finances, but also enables it to provide valuable feedback to member countries regarding the strengths and weaknesses of their public procurement systems. This enables member countries to improve the transparency of the procurement process and enhance the efficiency of public spending. 


\section{B. BACKGROUND}

\section{Country information}

8. The United Republic of Tanzania is a union of two countries, mainland Tanganyika and Zanzibar (consisting of the islands of Zanzibar and Pemba). The country covers a land area of $945,000 \mathrm{sq} . \mathrm{km}$. and its population at the end of 2001 was estimated at 34.5 million. A summary is captured in Table 1 below.

Fig. 1: Tanzania at a Glance -2002

\begin{tabular}{|l|l|}
\hline Population & 34.45 million \\
\hline Surface area & 945 thousand sq km \\
\hline Population growth & $3 \%$ (annually) \\
\hline Life expectancy (years) & 44 \\
\hline Population below national poverty line & $35 \%$ \\
\hline GNI per Capita & 270 US\$ \\
\hline GDP & 9.1 billion US $\$$ \\
\hline
\end{tabular}

Source: World Development Indicators Database

9. Tanzania has two governments, the Union Government and the Zanzibar Government. The mainland is wholly governed by the Union Government, while Zanzibar is mainly governed by the Zanzibar Government with the Union Government taking care of some government affairs including security and foreign affairs. Procurement in the mainland is governed by the 2001 Procurement Act and Regulations while Zanzibar is governed by its own Rules and Regulations. The CPAR will review the two systems separately.

\section{Economic Context}

10. Tanzania, with a per capita income of USD 270 , is one of the poorest countries of the world. The economy is heavily dependent on agriculture (primarily, coffee, cotton, tea, cashew nuts, sisal, maize, rice, wheat, cassava, and tobacco), which accounts for about 50 percent of GDP, provides 85 percent of exports, and is by far the largest employer. Topography and climatic conditions, however, limit cultivated crops to only a small fraction of the land area. Industry accounts for some 15 percent of GDP and is mainly limited to processing agricultural products and light consumer goods. Tanzania's macroeconomic performance has continued to improve during 2000 and 2001 (Annexes 1 to 3). The annual growth rate increased to 4.9 percent in 2000 and rose to 5.6 percent in 2001, despite the negative effects on commodity prices and tourism of the slowdown in the world economy. The rise in growth during 2001 was led by relatively strong performance in agriculture, mining, and wholesale and retail trade. Good rainfall and improved 
markets, particularly for food crops in the neighbouring countries have combined to raise agriculture growth to an estimated 54.5 percent 2001 . The mining sector growth remained strong at 12.3 percent raising its overall contribution to GDP to 2.5 percent from negligible levels five years ago. Wholesale and retail trade (including tourism) grew at 7 percent. Industry (manufacturing, utilities, construction, transport and communication) grew at an average of nearly 6 percent posting improvements in all sub-sectors over 1999 and 2000 except for construction, which had peaked earlier during the height of investment in gold mining. The overall growth rate for 2002 is projected to rise further to 5.9 .

11. The Country Assistance Strategy (CAS) for Tanzania focuses on higher economic growth, poverty reduction and institutional reforms to improve governance. It conforms with Govemment's main strategic directions - adherence to macro stability, increased private sector participation in the economy, a renewed emphasis on rural development and improved delivery of social services. It also supports the Government's desire to enter into new relationships with partners, based on the phased switching from projects to programs for a more effective and efficient use of aid resources. In supporting these objectives, the CAS suggests a lending program which will be increasingly geared towards operations with a direct bearing on poverty and strengthening of social sector programs, in a shift from the earlier emphasis on infrastructure development. Pursuant to this shift from projects to programs, a Poverty Reduction Support Credit (PRSC) is being prepared to support the Government's poverty reduction strategy (PRS). In shifting from projects to programs, the Bank's focus in ensuring fiduciary compliance is also shifting from dealing with specific projects to dealing with reforms of nationwide procurement systems. The work on the CPAR will be closely linked to the work already done on Country Financial Accountability Assessment (CFAA) and ongoing Public Expenditure Review (PER).

12. Governance: Tanzania has initiated comprehensive reforms to improve economic governance. Reforms in the area of public financial management include the implementation of an integrated financial management system, the adoption of an inclusive Public Expenditure Review/Medium Term Expenditure Framework process, and the revision of the public finance management and the public procurement systems. Following up on the recommendations of the Warioba report which documented deeply entrenched corruption in the public sector, a national action plan for the control of corruption as well as sector specific anti-corruption plans are being implemented. The impact of these anti-corruption measures has already been seen as demonstrated by an improvement in the relative position of Tanzania on the Transparency International's Corruption perception index for 2001.

\section{Bank Portfolio in Country}

13. The Bank disbursed about USD 1,644 million of International Development Association (IDA) resources to Tanzania through projects and operations that exited the portfolio between 1991 and 2002. It has greatly expanded its support - both financial and knowledge sharing - to the country. New commitments in the last fiscal year, Financial Year (FY) 2002 amounted to 
USD 396 million. The Bank's net commitment to Tanzania at the beginning of FY03 was USD 1,233.0 million (second highest, after Ethiopia, in the Africa Region of the Bank). One of the challenges for both the Government of Tanzania (GoT) and the Bank is to ensure that this momentum is maintained, followed through on project implementation, on disbursements, and on dialogue with all stakeholders.

Fig.2: Tanzania: Current Composition of World Bank Loan Portfolio (as of June 30, 2002, amounts in USD Million)

\begin{tabular}{|c|c|c|c|c|c|}
\hline Project & $\begin{array}{l}\text { Approval } \\
\text { date }\end{array}$ & $\begin{array}{l}\text { Closing } \\
\text { date }\end{array}$ & $\begin{array}{l}\text { Age } \\
\text { (year) }\end{array}$ & $\begin{array}{l}\text { Net commit- } \\
\text { ment }\end{array}$ & $\begin{array}{l}\text { Total } \\
\text { disbursed }\end{array}$ \\
\hline \multicolumn{6}{|l|}{ ESSD } \\
\hline Lake Victoria Environment Project & $07 / 30 / 1996$ & $06 / 30 / 2004$ & 5.92 & 15.1 & 8.8 \\
\hline National Agric. Extension Project II & $07 / 11 / 1996$ & $12 / 31 / 2002$ & 5.97 & 31.1 & 23.5 \\
\hline River Basin Management Project & $07 / 11 / 1996$ & $12 / 31 / 2003$ & 5.97 & 26.3 & 17.1 \\
\hline Tanzania Agric. Research Project II & $01 / 29 / 1998$ & $06 / 30 / 2003$ & 4.42 & 21.8 & 11.7 \\
\hline Forest Conservation Management Project & $02 / 26 / 2002$ & $12 / 31 / 2007$ & 0.34 & 31.1 & 0.0 \\
\hline Lower Kihansi Management Project & $07 / 03 / 2001$ & $12 / 31 / 2006$ & 0.99 & 6.3 & 0.4 \\
\hline \multicolumn{6}{|l|}{ Infrastructure } \\
\hline Railways Restructuring Project & $06 / 13 / 1991$ & $12 / 31 / 2002$ & 11.05 & 64.7 & 64.3 \\
\hline Second Integrated Roads Project & $04 / 07 / 1994$ & $06 / 30 / 2004$ & 8.24 & 106.7 & 53.5 \\
\hline Urban Sector Rehabilitation Project & $05 / 23 / 1996$ & $06 / 30 / 2004$ & 6.11 & 105.0 & $\overline{72.6}$ \\
\hline Songo Songo Gas Dev. \& Power Gen. & $10 / 09 / 2001$ & $03 / 31 / 2006$ & 0.72 & 183.0 & 7.8 \\
\hline Rural Water Supply Project & $03 / 20 / 2002$ & $06 / 30 / 2006$ & 0.26 & 26.0 & 0.0 \\
\hline \multicolumn{6}{|l|}{ Finance and PSD } \\
\hline Financial Institutions Dev. Project II & $08 / 31 / 1999$ & $12 / 31 / 2003$ & 2.83 & 27.5 & 9.1 \\
\hline Privatization and PSD Project & $12 / 14 / 1999$ & $09 / 30 / 2004$ & 2.55 & 45.9 & 9.0 \\
\hline Public Service Reform Project & $12 / 02 / 1999$ & $12 / 31 / 2004$ & 2.58 & 41.2 & 7.6 \\
\hline Rural and Micro-finance Services & $08 / 26 / 1999$ & $12 / 31 / 2003$ & 2.85 & 2.0 & 0.4 \\
\hline Tax Administration Project & $03 / 30 / 1999$ & $12 / 31 / 2004$ & 3.25 & 40.0 & 10.0 \\
\hline Regional Trade Facilitation & $04 / 03 / 2001$ & $06 / 30 / 2011$ & 1.24 & 24.8 & 3.8 \\
\hline \multicolumn{6}{|l|}{$\mathrm{HDN}$} \\
\hline Health Sector Development Program & $06 / 15 / 2000$ & $12 / 31 / 2003$ & 2.04 & 22.0 & 6.5 \\
\hline Human Resource Development Program & $10 / 07 / 1997$ & $12 / 31 / 2005$ & 4.73 & 20.9 & 17.2 \\
\hline Primary Education Dev. Program & $10 / 09 / 2001$ & $10 / 31 / 2004$ & 0.72 & 150.0 & 50.0 \\
\hline Tanzania Social Action Fund & $08 / 22 / 2000$ & $06 / 30 / 2005$ & 1.85 & 60.0 & 13.9 \\
\hline \multicolumn{6}{|l|}{ PREM } \\
\hline PSAC 1 & $06 / 15 / 2000$ & $06 / 30 / 2003$ & 2.04 & 191.4 & 67.8 \\
\hline
\end{tabular}

Source: Tanzania, Draft Country Portfolio Performance Review, February 2003, by the Government of Tanzania and the World Bank 



\title{
C. MAIN FINDINGS AND ANALYSIS
}

\author{
PUBLIC SECTOR
}

\section{C.1. LEGAL AND REGULATORY FRAMEWORK}

\section{Existing legal and regulatory framework}

14. The United Republic of Tanzania is a union of two countries, mainland Tanganyika and Zanzibar (consisting of the islands of Zanzibar and Pemba). Tanzania has two governments, the Union Government and the Zanzibar Government. The mainland is wholly governed by the Union Government, while Zanzibar is mainly governed by the Zanzibar Government with the Union Government taking care of some government affairs including security and foreign affairs. Procurement in the mainland is governed by the 2001 Procurement Act and Regulations while Zanzibar is governed by its own Rules and Regulations. The CPAR will review the two systems separately.

15. Local Government authority (district, town, municipal, and city councils) are placed outside the line ministries under the control of the Local Government Authority under The President's Office. The line ministries simultaneously maintain their own representation at local level. The Public Finance Act (2001) forms the legal basis for public expenditure. The following main legal instruments govern public procurement in Tanzania.

16. Public Procurement Act (PPA) and Regulations: The PPA was enacted in July 2001 replacing all previous procurement legislation, which was at that time spread out in several different acts and other legal instruments. ${ }^{4}$ Subsequently in 2001, the Regulations were issued in two parts: 1) Procurement of Goods and Works Regulations, ${ }^{5}$ and 2) Public Procurement (Selection and Employment of Consultants). ${ }^{6}$ In mid-November 2002, the Central Tender Board (CTB) issued a set of standard documents and guidelines. The PPA covers procurement carried out by both central government and local authorities, though for the latter case, specific Local Government Regulations are to be issued under the Local Government Finances Act.

17. Anti-Corruption Legislation: The Prevention of Corruption Act (1971) with subsequent changes and amendments serves together with the Organized Crime Control Act (1984) as the basis for the establishment of the Prevention of Corruption Bureau (PCB) in 1990 with authority for monitoring and prosecuting malpractice in public procurement.

\footnotetext{
${ }^{4}$ Some of the most important pieces of legislation that have now in part been replaced by the PPA are the Financial Memorandum (on local government authority procurement), the Medical Stores Department Act, and the National Board of Materials Management Act.

${ }^{5}$ Government notice No. 138 published 13/07/01. Where nothing else is stated in this report the term Regulations refer to these.
} 
18. Public Service Act: The Public Service Act (2002) with subsequent amendments and the supporting Employment Ordinance and Security of Employment Act establish the Public Service Commission responsible for human resource management in the public sector.

\section{Legal Benchmark - Tanzanian Rules vs. International Standards}

19. With the introduction in 2001 of PPA, Tanzania has taken a very profound step of reforming the entire legal framework of public procurement. The PPA was created on basis of the UNCITRAL model law on procurement, with considerable technical assistance from donors with an aim to upgrade the legal framework to international standards.

20. The following benchmark seeks to compare the present legal framework for procurement in Tanzania with selected internationally recognized procurement regimes. The benchmark is focused on a number of key issues recognized as important for a sound procurement system. The key issues are described in general terms to determine whether the internationally accepted principles are present and adequately implemented in the legislation. As the practical issues may vary between the different sectors when procuring goods, works and services, the benchmark will focus on the common application of these principles. For the sake of comparison, three different procurement regimes have been selected. They each pose a different approach to regulating public procurement, but all share the same basic values of transparency and accountability leading the way to more value for money in public procurement:

- The World Bank Guidelines (WBG) for procurement under International Bank for Reconstruction and Development (IBRD) loans and IDA credits ${ }^{7}$

- The United Nations UNCITRAL Model Law on public procurement (UML) ${ }^{8}$

- The EU procurement directives (EUD) ${ }^{9}$.

${ }^{6}$ Government notice No. 137 published 13/07/01

7 The World Bank Guidelines for procurement under IBRD loans and IDA credits (WBG) are an example of procurement regulations enforced by a large global donor organisation. These guidelines are designed for use as a prerequisite to loan agreements in which the World Bank is part. The purpose of the guidelines are to "... ensure that the proceeds of any loan are used only for the purposes for which to loan was granted, with due attention to considerations of economy and efficiency and without regard to political or other non-economic influences or considerations". Besides being internal guidelines regulating procurement undertaken with the use of funds made available by the World Bank, the guidelines are also an atempt to codify the essence of best practice regarding procurement and thus obtaining the goals mentioned above. It is therefore the policy of the World Bank to apply the principles of the guidelines not only to procurement financed wholly or in part by World Bank loans but also to seek a general compliance within the receiving country of these principles.

${ }^{8}$ The United Nations UNCITRAL Model Law on procurement of goods, construction and services (UML) was adopted by the United Nations Commission for International Trade in 1994. The Model Law is by UNCITRAL described as an answer to "...inefficiency and ineffectiveness in the procurement process, patterns of abuse, and the failure of the public purchaser to obtain adequate value in retum for the expenditure of public funds". It is the explicit purpose of the Model Law to promote transparency, objectivity and efficiency thereby curbing corruption and abuse in the procurement of public goods. In contrary to other international regulations the Model Law is purpose built to suit the needs of development countries whose economies are in transition, such as Tanzania. 


\section{Application of procurement rules - entities subject to regulation}

21. The PPA in Article 2 aims to cover all procuring entities, defined as "ministry, government department, agency, parastatal organisation, a regional or a local authority", with some important exceptions. Parastatals are covered by the PPA only if mentioned by name in the regulations and if they receive government subsidy. A parastatal organised as a private company, but with the government as a majority shareholder, would thus fall outside this category. This leaves open the possibility of a part of the public administration, or a public utility, being branched out and thus outside the coverage of the PPA, even though the public, through government ownership of shares, still remains in control of the activity. This is an issue that especially affects a country such as Tanzania, which historically has had a very large public sector, but now are deregulating and developing the private sector as a key player in society. The present situation where the PPA covers a parastatal, only while it receives public subsidy, also appears very difficult to enforce. The aim of the Regulation is to solve this issue by including in the first schedule a list of all the public entities that are subject to the PPA. Strangely a number of parastatals, which do not receive government subsidy, are in fact included on the list. ${ }^{10}$

- EUD: The EU directives on this issue has taken the view that the legal framework must be applicable if the activity in question is under public control, whether that control is through ownership of shares or by any other means. The underlying principle being that all activities carried out in the public interest should abide by the same rules.

- UML: The UNCITRAL Model Law is basically identical to the PPA in this respect.

Recommendation: The rules regarding application of the PPA on parastatals should be clarified by amending the PPA to cover all parastatals.

22. The PPA operates with competitive tendering as the main method for procurement of goods, works and services. Guided by the thresholds published as part of the Regulations, the procuring entity can use International Competitive Bidding (ICB), National Competitive Bidding (NCB), Restricted Tendering, Competitive Quotations, Single Source Procurement, and Minor

\footnotetext{
${ }^{9}$ The European Union directives on procurement (EUD) have for over a decade now been the national regulations regarding the public procurement of goods, services and public works in the member states of the European Union. The four main directives are on a number of points supplemented by other regulations issued by the European Commission, the organisation trusted with the enforcement of the directives. As a directive only under certain circumstances can be applied directly by courts in the member states, all member states have by law enacted the directives in their respective legal frameworks. The European Union has for political reasons divided the rules governing procurement in to four different sets of regulations addressing the procurement of goods, services, public works and public supply. For a large part, the directives contain parallel sets of rules for each sector, with some major exemptions. The European Commission has in 2001 put forward a proposal for a new unified procurement directive, scheduled for implementation in 2004 at the earliest.

${ }_{10}$ This contradiction was also noticed by the National Board of Material Management (NBMM) in its comments of July 2002 on the PPA
} 
Value Procurement. However the Regulations Article 80(4) allows for the procuring entity to "select an appropriate alternative method of procurement" in "any case where tendering would not be the most economic and efficient method of procurement..." The alternatives available are single source, direct contracting (goods and works) and force account, all with specific conditions attached. While the approach of offering different procurement methods for different types and sizes of contracts provides for an efficient system, the provision that allows the procuring officer, at his discretion, to apply the alternatives opens an avenue of non-transparency and potential abuse. Such delegation of authority does put increased demand on the quality of the CTB as an oversight authority.

- UML: Open Tendering, with or without pre-qualification is the main procuring procedure for all procurement of goods and works under the UNCITRAL law. The open tendering procedure includes all the major features of an international procurement system such as public advertisement of tender notice and exclusive criteria for both pre-qualification and selection of bidders.

- WBG: The ICB method is the mainstay of the procuring procedures available for WB financed projects. The WBG contains a comprehensive set of guidelines securing both transparency by advertisement and equality by uniform criteria of selection.

23. The thresholds that determine the available procurement methods are listed in schedules to the Regulations:

Fig. 3: Procurement thresholds

\begin{tabular}{|c|c|c|c|}
\hline Procurement method & Characteristics & Goods & Works \\
\hline $\begin{array}{l}\text { International competitive } \\
\text { tendering }\end{array}$ & $\begin{array}{l}\text { Tender advertised internationally or } \\
\text { nationally only. Mandatory if } \\
\text { payment is in foreign currency. }\end{array}$ & No limit & No limit \\
\hline competitive & Tender advertised nationally only. & $\begin{array}{l}\text { Up to Tshs } \\
800,000,000\end{array}$ & $\begin{array}{l}\text { Up to Tshs } \\
1,600,000,000\end{array}$ \\
\hline Restricted tendering & $\begin{array}{l}\text { Tender documents issue to restricted } \\
\text { number of potential bidders. } \\
\text { Requires one of the following } \\
\text { conditions: } \\
\text { - prior pre-qualification or goods of } \\
\text { specialized nature } \\
\text { - works offered by limited number of } \\
\text { contractors } \\
\text { - urgent need } \\
\text { - other exceptionally reasons. }\end{array}$ & $\begin{array}{l}\text { Up to Tshs } \\
400,000,000\end{array}$ & $\begin{array}{l}\text { Up to Tshs } \\
800,000,000\end{array}$ \\
\hline $\begin{array}{l}\text { Competitive } \\
\text { (shopping) }\end{array}$ & $\begin{array}{l}\text { Price quotations sought from at least } \\
\text { three suppliers. } \\
\text { Requires approval by tender board } \\
\text { and one of these conditions: }\end{array}$ & $\begin{array}{l}\text { Up to Tshs } \\
80,000,000\end{array}$ & $\begin{array}{l}\text { Up to Tshs } \\
200,000,000\end{array}$ \\
\hline
\end{tabular}




\begin{tabular}{|c|c|c|c|}
\hline & $\begin{array}{l}\text { - no supplier would have commercial } \\
\text { interest in tendering for all goods } \\
\text { - goods readily available } \\
\text { - local or international purchase } \\
\text { possible. }\end{array}$ & & \\
\hline Single Source Procurement & $\begin{array}{l}\text { Direct contracting with one supplier. } \\
\text { Requires a letter of invitation and } \\
\text { one of these conditions: } \\
\text { - urgent need } \\
\text { - one contractor available for works } \\
\text { - contractor has undertaken similar } \\
\text { works or is mobilised } \\
\text { - extension of works satisfactory } \\
\text { conducted by the same contractor. }\end{array}$ & $\begin{array}{l}\text { No limit, but } \\
\text { must be } \\
\text { justified }\end{array}$ & $\begin{array}{l}\text { Up to Tshs } \\
800,000,000\end{array}$ \\
\hline Minor Value Procurement & $\begin{array}{l}\text { Direct contracting with one supplier } \\
\text { without letter of invitation }\end{array}$ & $\begin{array}{l}\text { Tshs } \\
2,500,000\end{array}$ & $\begin{array}{l}\text { Tshs } \\
8,000,000\end{array}$ \\
\hline Procurement method & \multicolumn{2}{|l|}{ Characteristics } & $\begin{array}{l}\text { Services and } \\
\text { Consultancy }\end{array}$ \\
\hline Competitive selection & \multicolumn{2}{|c|}{$\begin{array}{l}\text { Advertisement and invitations for submission of } \\
\text { expressions of interest, leading to formation of short- } \\
\text { list. }\end{array}$} & No limit \\
\hline $\begin{array}{l}\text { Competitive proposals (quality } \\
\text { and cost based selection }\end{array}$ & \multicolumn{2}{|c|}{ Competitive process among 5-7 invited consultants. } & $\begin{array}{l}\text { Up to Tshs } \\
150,000,000\end{array}$ \\
\hline $\begin{array}{l}\text { Single Source Procurement or } \\
\text { Direct Contracting }\end{array}$ & \multicolumn{2}{|c|}{$\begin{array}{l}\text { Requires one of following conditions: } \\
\text { - natural continuation of previous work } \\
\text { - rapid selection essential } \\
\text { - very small assignments } \\
\text { - one firm qualified or with experience of exceptional } \\
\text { worth. }\end{array}$} & $\begin{array}{l}\text { Up to Tshs } \\
150,000,000 \\
\text { and must be } \\
\text { justified }\end{array}$ \\
\hline Minor Value Procurement & \multicolumn{2}{|c|}{$\begin{array}{l}\text { Where the need for preparing and evaluating } \\
\text { competitive proposals is not justified. A selected firm } \\
\text { is invited to negotiate contract. }\end{array}$} & $\begin{array}{l}\text { Tshs } \\
2,500,000\end{array}$ \\
\hline
\end{tabular}

24. When reviewing the thresholds, it should be noted that initiating a tender process carries costs, such as those used for advertising and monitoring. To support the principle of value for money, the procurements for which tendering is mandatory must have a size that warrants these costs. ${ }^{11}$

25. There appeared to be widespread acceptance of the current level of the thresholds for selection of procurement method. On the other hand, the procuring entities visited were equally in agreement that the procedures and especially approvals contained in the tendering methods are cumbersome and a barrier for effective procurement. This however is caused by the internal thresholds for approval described in the decentralisation section of this report.

\footnotetext{
"Many procuring entities met by the mission and the National Construction Council in its survey of the PPA, have complained about disproportional costs of advertising.
} 
26. The present procurement methods available are in line with international standards and the thresholds for their application appear balanced. It is important that the CTB makes future use of its option to annually regulate the thresholds in accordance with inflation and the general needs of the public sector. The access to different procurement methods in the Regulations contain a large number of conditions which are difficult to evaluate and which could appear as loopholes that allow procuring entities to avoid open tender methods, if adherence to rules is not monitored closely.

\section{Publicity in procurement - advertisement of tenders and time for bid preparation}

27. Equal opportunity for all in the bidding process is one of the central features of a sound and transparent procurement system. Such opportunity is only achieved by making all potential bidders aware of tenders. The PPA Article 37 demands for a procuring entity to prepare and advertise a tender notice before carrying out any of the open tendering procedures ${ }^{12}$ available. The content of the tender notice is not described in the PPA. However the Regulations Article 99 describe minimum requirements for an invitation to tender and it is understood from the Regulations that this invitation could serve a dual purpose as tender notice. Noticeably it is not a minimum requirement that the tender notice describes the applicable award criteria. The means of publicizing the notice are described in the PPA being publication in at least two newspapers of national circulation, and for international tendering, publication in at least one international paper or journal. There is no requirement for publication of notices in the Gazette, nor is there a procurement joumal or any other consolidated collection of current procurement notices. Bidders are thus forced seek their information through a number of different sources, including different regional newspapers, notice boards and personal contacts.

28. Contract awards are mandatory to publish in the Gazette, with the name of the successful tenderer, the contract amount and the date on which the contract was awarded. The Regulations ${ }^{13}$ allow both the public and bidders conditional access to information contained in the mandatory procurement protocol.

- WBG: All tenders subject to the ICB tendering method must be advertised in the Development Business. In addition a Specific Procurement Notice shall be made in both national and intemational papers of relevance.

- UML: A general rule of mandatory advertisement of all tenders is included in the model law. The enacting state may chose to insert the name of its official gazette as the primary means of advertisement and also allowing for secondary legislation concerning the exact form of the advertisement.

\footnotetext{
${ }^{12}$ National Competitive Tendering and Intemational Competitive Tendering

${ }^{13}$ Regulations Article 20(2) and Article 20(3)
} 
- EUD: All tenders must be advertised in the Official Journal of the European Communities. The procuring entity may in addition chose to advertise locally or nationally providing the information given in all media are the same so as to prevent discrimination of suppliers/contractors.

29. The introduction of a dedicated government-financed procurement journal would address both the issue of high advertising costs and provide the potential bidders with one single source of information. Frequent publication is essential for the journal to become a real alternative to other means of advertising. Such a journal should be published weekly and with daily advertisements on the government web-site. ${ }^{14}$ Publication in the journal should be mandatory for all notices that are currently advertised according to the PPA and Regulations. Thus eliminating the need for a specific threshold for advertisement in the joumal. However, recognizing that a large part of the public will seek their information through the newspapers, a double system of mandatory advertisements in both the newspapers and the Public Procurement Journal could be upheld for high value national tendering and all international tendering where the comparable costs of advertisement are negligible.

Recommendation: A central government financed monthly Procurement Journal for publication of all procurement-related advertisements should be established.

\section{Pre-qualification and qualitative criteria}

30. The PPA does not have a clause calling for mandatory pre-qualification, but only states that a procuring entity "may engage in pre-qualification proceedings". The Regulations in Articles 15, 16 and 81 call for the procuring entity to "consider pre-qualifying" and describes the provisions if pre-qualification is carried out. Mandatory use of prequalification for example in all complex tenders and/or tenders with a value above 5 billion Tsh, should greatly increase the use of prequalification.

31. Neither the PPA nor the Regulations include any mandatory qualitative criteria. Article 13.3 of the newly issued "Standard tendering documents on procurement of goods" provide some guidance on eligibility criteria listing that the tenderer must have the "financial, technical and production capability necessary to perform the contract". No further explanation is given as to how these criteria can be applied in practice. The document further points to the criteria mentioned in the tender documents, underlining the fact that the criteria used for qualitative selection are very much at the discretion of the procuring officer.

32. The Standard Bidding Documents (SBDs) recently issued by the CTB include a "Standard Pre-qualification Document" for procurement of works through international competitive tendering which does contain examples of eligible qualification criteria. Furthermore the Standard Pre-qualification Document contain list of advantages and disadvantages of pre-qualification to assist the procurement officer in making the right decision. The lack of general mandatory

\footnotetext{
${ }^{14}$ An electronic version of this journal on the Internet is discussed in the e-procurement section of this report.
} 
qualification criteria does however provide opportunity for the application of non-transparent local criteria.

- EUD: The procurement method of restricted tendering demands the following of a strict prequalification procedure under the EUD. Restricted tendering may be the method of choice at the discretion of the procuring entity. The criteria allowed to be applied when selecting suppliers for short listing are all listed in the EUD. In addition the EUD contains provisions for the length of the pre-qualification procedure, a minimum of 5 suppliers to be short-listed and rules of advertisement. Not all qualified suppliers have a right to bid as a limit to the number of bidding suppliers can be set by the procuring entity. The inclusion on a general pre-qualification list must not substitute the specific evaluation that a supplier is entitled to for each application for pre-qualification.

- WBG: Recognises the need for pre-qualification in complex procurement, but leaves it to the discretion of the procuring entity as to when pre-qualification should be used. When pre-qualification is used certain criteria listed in the WBG must be applied and advertisement of invitation to pre-qualify is mandatory. All eligible suppliers must be pre-qualified. The inclusion on a general pre-qualification list must not substitute the specific evaluation that a supplier is entitled to for each application for prequalification.

- UML: Detailed regulation of pre-qualification proceedings is included in the UML. An exclusive list of allowed criteria for pre-qualification are listed and all other criteria that might be applied by the procuring entity are banned. The inclusion on a general pre-qualification list must not substitute the specific evaluation that a supplier is entitled to for each application for pre-qualification.

33. Domestic or local preference is not possible in the qualification process, but only by applied price preferences during award.

Recommendation: The access to pre-qualification according to the PPA is adequate, however, the Regulations and Standard Bidding Documents should provide further guidance as to when prequalification is applicable, including a mandatory demand for pre-qualification in appropriate situations.

\section{Registration Lists}

34. According to PPA Article 20, bidders in works, goods, services and consultant tenders, must all be registered with an "appropriate current professional body". 15 Specifically in works procurement this system has unwanted consequences. The system of registration lists applies fully to all domestic bidders while international bidders are allowed post-register, pending award of a contract. ${ }^{16}$ The mandatory registration lists leads to bidders being evaluated twice by qualitative

\footnotetext{
${ }^{15}$ These are established by law such as the Contractors Registration Act (1997), Engineers Registration Act (1997) and Architects and Quantity Surveyors Registration Act (1997). While the Contractors Registration Board monitors the qualifications of companies, the other registration boards bear more resemblance to professional societies of individuals.

${ }^{16}$ This is contrary to the previous Contractors Registration Act bylaws, which demanded pre-registration even for foreign bidders. The National Construction Council has remarked that the new post-registration is difficult to enforce.
} 
criteria, first by the board that administers the list and later during the actual tender. A system of mandatory registration seeks to ensure the quality and capacity of the bidders, but also creates a barrier to market access for new suppliers and upholds an unnecessary double qualification procedure. In addition, registration system may: (i) limit competition; and (ii) be a source of rents. It should however be recognized that procuring entities with low capacity to perform proper prequalification are relying on the registration as their main method of assessing the qualifications of potential bidders. From discussions with the private sector and at the workshop ${ }^{17}$ it appeared that the different classes, indicating different levels of capacity, that are currently in use, provides for an inefficient and inflexible system. While the requirement for registration can be justified for national competitive bidding it is not recommended for international competitive bidding. However, a contractor may be required to register before a contract is executed. In using these lists it is important to ensure that they are updated because many times the information on these lists is not current. Another issue concerning the use of the registration lists is the way in which potential bidders are picked from the list. This is described in the practices section.

- UML, EUD and WBG: Contains a list of exclusive criteria for pre-qualification. The WGG states: "Pre-qualification shall be based entirely upon the capability and resources of prospective bidders to perform the particular contract satisfactorily..." Neither allows the use of a general qualification list as a condition for tender.

Recommendation: Registration could be made a prequalification condition for NCB but for ICB it should be upheld as mandatory only for contract signature in accordance with international practice.

\section{Tender Documents - SBDs}

35. The PPA Article 39 requires the procuring entities to use the "appropriate standard model in tender documents". A set of SBDs was only issued in mid- November 2002 by the CTB. The SBDs issued by the CTB comprise of:

- Procurement of Goods through international competitive bidding

- Procurement of Health Sector Goods

- Standard requests for proposals (Consultants)

- Standard Pre-qualification Document for procurement of works

- Procurement of works through national competitive bidding

- Procurement of works - smaller contracts.

36. These SBDs are all mandatory, but the CTB have at the time of writing (April 2003) not yet distributed the documents among the ministries, let alone the local government authorities and districts.

\footnotetext{
${ }^{17}$ Held in Dar Es Salaam 27. and 28. January 2003 to discuss the recommandations of this report.
} 
37. The PPA allows for procuring entities to use SBDs issued by donor organisations even for government-funded procurement. This has been a common practice until now. Specifically for works procurement the National Construction Council has developed a set of SBDs and an accompanying "code of procedure" which are in widespread use. ${ }^{18}$ Since the SBDs issued by the CTB are mandatory they will replace all previously issued documents issued by the National Construction Council (NCC) and will prohibit the use of donor documents on government-funded projects. ${ }^{19}$ A review of the newly issued SBDs reveals their close similarity with Donor SBDs on which they are in part based. The essential features of SBDs are all there. The primary concern is whether the procuring entities have the capacity to utilize these quite comprehensive documents.

- EUD: Holds no specific regulation concerning the content of tender documents.

- WBG: Standard World Bank bidding documents (SBDs) are mandatory.

- UML: Contains minimum requirements for the content of tender documents.

Recommendation: Support the distribution and enforcement of the newly developed SBDs issued by the CTB. Support distribution with accompanying capacity building

Filing system

38. According to PPA Article 30(1), a protocol recording procurement proceedings, all decisions taken and the reasoning behind those decisions must be kept for a 5-year period by both the procuring entity and the approving tender board ${ }^{20}$. The Regulations Article 20 contains a comprehensive list of information and documents that must be included in the protocol. The mandatory information to be recorded includes names of bidders, qualifications and evaluations of bidders and bids and any exceptions to the general provisions that have been applied. The procurement protocol in its present form is a powerful prerequisite for proper enforcement of the rules, provided that the maintaining of protocol itself can is enforced.

- UML, EUD and WBG: All require procurement protocols maintained and filed for future reference.

Recommendation: Existing rules on procurement documentation are adequate, but must be supported by proper enforcement.

\section{Bid submission and opening}

39. The PPA Article 42 contains provisions on bid submission and opening. In addition the Regulations Article 107 lists a number of specific mandatory demands for the bid submission and opening process. The most important are:

\footnotetext{
${ }^{18}$ The NCC have in addition developed and distributed Standard Tendering Procedure for Local Government and Standard Agreements and Conditions of Contracts, etc.

${ }_{19}$ Donor documents can still be used on donor-funded projects because of the general exception in PPA Article 4

${ }^{20}$ The National Records and Archives Act contains similar provisions covering the entire public sector?
} 
- A locked tender box must be used for storing tenders until opening

- Tenders received late must be rejected

- Tenders must be opened immediately after the deadline for submission

- Tenders must be opened in public

- Tenderers' names and prices shall be announced at the opening session

- Attempts of wrongful influence must result in rejection.

- EUD: Bids must be submitted to address stated in the notice for tender, but otherwise no special regulations govern the submission of bids and their opening.

- WBG: Bids must be opened promptly after the deadline for submission. Public bid opening with the participation of the bidders is mandatory.

- UML: Bids must be opened at a time specified in the tender documents. Public opening with the participation of the bidders is mandatory.

The existing rules on bid submission and opening are largely in accordance with international standards. The issue of compliance and enforcement is covered in the Procedures and Practices section.

The existing rules on bid submission and opening are adequate, but must be supported by proper enforcement.

\section{Time limits}

40. The PPA does not contain any time limits for the different steps of the procurement process. The given time for preparing bids is described in the PPA and the Regulations as "sufficient time", but the Regulations Article 102 calls for a minimum tender period of 45 calendar days increasing to 90 calendar days for complex works tenders and according to the Regulations Article 85(7), when using the competitive quotations (shopping) method of procurement a period of minimum 45 days shall be given to prepare tenders. A period of 45 days for preparation of a shopping bid seems to defy one of the main purposes of using this method, which is speed.

41. The Regulations (Goods and Works) Fourth Schedule contains a list of the procurement steps with attached minimum/maximum time limits: 
Fig. 4: Time limits within the procurement procedure

\begin{tabular}{|c|c|c|}
\hline & $\begin{array}{l}\text { Time } \\
\text { (Weeks) }\end{array}$ & $\begin{array}{l}\text { Total Elapsed } \\
\text { (Weeks) }\end{array}$ \\
\hline 1. Finalise specifications, OR Consultancy: & & $(\operatorname{Min} . /$ Max. $)$ \\
\hline Define and agree terms of reference & $2 / 4$ & $2 / 4$ \\
\hline la Obtain Donor Agency approval & 4 & \\
\hline 2. Preparation of tender documents & 2 & $4 / 6$ \\
\hline $\begin{array}{l}\text { 3. Approval of tender document by } \\
\text { Purchasing Committee or Tender Board }\end{array}$ & 2 & $6 / 8$ \\
\hline 3a Donor agency approval & 4 & \\
\hline 4. Advertise and issue tender & 2 & $8 / 10$ \\
\hline 5. Return of bids and tender opening & $6 / 9$ & $14 / 19$ \\
\hline 6. Evaluation of bids & 3 & $17 / 22$ \\
\hline (with clarifications) & (6) & \\
\hline $\begin{array}{l}\text { 7. Examination and approval by tender } \\
\text { board }\end{array}$ & 2 & $19 / 24$ \\
\hline 7a Review and approval by donor agency & 4 & \\
\hline 8. Notification of award to successful bidder & 1 & $20 / 25$ \\
\hline 9. Award of contract & 2 & $22 / 27$ \\
\hline $\begin{array}{l}\text { (Ministry of Justice and Constitutional } \\
\text { approval, if required) }\end{array}$ & (4) & $(26 / 31)$ \\
\hline
\end{tabular}

42. These limits however appear only as guidelines for procurement planning without foundation in the PPA itself. Lack of mandatory time limits, like a limit on the period between bid submission and award of contract, before re-tendering is called for, opens opportunity for collusion and corruption. A limit on award of contract of $\mathbf{3 0}$ days from submission, before specific approval for extension must be sought from the relevant tender board, would target the issue of drawn out award processes that the mission identified as a general problem. Otherwise the limits contained in the Regulations appear balanced, but should be made mandatory, with a clear risk of re-tendering when not adhered to.

Recommendation: Mandatory time limits for the main steps in the procurement process should be established, and the existing time limits should be reviewed to ensure that these are actually supporting the purpose of combining transparency with efficiency.

\section{Contract award procedure and criteria}

43. The PPA specifies that the procuring entity must ensure equal treatment of bidders in processing bids and awarding the contract. The PPA does not specify eligible award criteria other than "evaluated cost" for goods and works procurement. On consultant procurement the procuring entity can choose between criteria based on cost, technical quality or a combination. Adequate guidance on use of the evaluated cost criteria and rules of calculation can be found in the Regulations and in the SBDs issued by the CTB. Bracketing, by banning bids with a value below or above a certain amount is not permitted. The terms of contract must be approved by the 
Attomey General before the procuring entity is authorized to enter into such contract. ${ }^{21}$ This $^{2}$ sometimes leads to delays in the procurement process.

- EUD and UML: Exclusively two criteria are allowed for contract award. The criteria are: 1) Lowest price only, 2) Economically most advantageous.

- WBG: Contains a variant of the economically most advantageous criteria as the WBG states that contract can only be awarded to the bid that is (i) substantially responsive to the bidding documents; and (ii) to offers the lowest evaluated cost.

44. The available award criteria are adequate and in line with international practices, and are supported with guidelines on their application.

Recommendation: While the available award criteria are adequate the issue of delay of approval by the Attorney General could be addressed by increasing the capacity of the Attorney Generals office.

\section{Domestic and other Preferences}

45. The PPA Article 22 allows the procuring entity to apply a margin of preference in awarding contract to Tanzanian bidders. This domestic preference can be maximum $10 \%$ for International Competitive Tendering of works and requires a number of conditions to be met, mainly to insure that foreigners do not misuse this rule through ownership or joint ventures with local companies. For goods and services ICB, the maximum margin of preference is $15 \%$ for locally manufactured goods and related services.

46. For service contracts there is an opportunity to prepare a shortlist comprising entirely of Tanzanian consultants if the value is below a certain threshold and no foreign firm have expressed interest. For procurement of goods, works and services that are exclusively funded by the government and under a threshold, the PPA Article 23 furthermore demands that bidding is reserved for "local persons or firms". The Regulations Article 93 gives a wide access for the procuring entity to change and adapt the procurement procedures and give preference to local communities, if this is "in the interest of project sustainability, or to achieve certain specific social objectives". There are no specified thresholds for access to this discretionary preference system. While domestic preference arguably supports capacity building at the local levels, a more efficient method of building capacity is through the design of tender packages so that they appeal to local suppliers. Such packages would for instance have bid securities which are affordable to the local contractors and the minimum qualifying criteria such annual gross turnover could be set to a level which local bidders are able to participate.

- WBG: Domestic preference is allowed in certain situations, but only through application of transparent measure of preference in calculating the best bid. When works are procured the preferred country must also have a GNP pr. capita below a certain level.

\footnotetext{
${ }^{21}$ This is a normal feature of a procurement system, but a number of procuring entities have complained that the process of legal approval constitutes one of the major bottlenecks in the system.
} 
- UML: A margin of domestic preference is allowed when applying contract award criteria, but only if transparent and with the approval of the procuring authority.

- EUD: Domestic preferences are forbidden.

47. Where procurement of goods is exclusively government funded, the procuring entity must procure from the Government Stores (GS), unless the items are not available or only available at prices above marked prices. Recommendations regarding the reform of GS are provided in the chapter on Organisation and Resources.

Recommendation: Maintain availability of domestic preference at the present margin of preference, which is in accordance with international standards. Consider a targeted monitoring campaign to assess whether the domestic preference system is in fact promoting local companies. Issue more specific rules on the exceptions contained in Regulations Article 93 to prevent any misuse of access to deviations. Issue guidelines as to how local capacity can be built through the proper design and scope of tender packages.

\section{Negotiations: pre- and post contract negotiations}

48. Negotiations between bid submission and contract award are allowed as long as they do not "substantially alter the original terms of reference or the terms of the contract". A total ban on negotiations forms one of the comerstones in the principle of equal treatment of bidders. In the light of this, the conditional access to negotiations in the PPA hinders effective enforcement of the ban, and creates confusion as to the limits of the ban on negotiations.

49. Negotiations after contract award leading to alterations and amendments are banned according to PPA Article 58, unless the alteration is to the benefit of the Government or the alteration has been endorsed by the approving authority. The PPA in this respect fails to recognize the issue of equal treatment of bidders. A substantial alteration in an already signed contract is in its substance comparable to pre-contract negotiations. If collusion between procuring entity and bidder takes place, it is very difficult to discern whether a post-contract alteration is in fact a result of illegal pre-contract negotiations.

- WBG: Alterations of bids after submission, whether through negotiations or not, are not allowed. Only minor clarifying changes in the bids are allowed after submission.

- UML: Outside the specific situations mentioned above the UML contains a strict ban on negotiations between the procuring entity and the bidder after bid submission.

- EUD: Only in negotiated procedures with very limited use are post-bid negotiations allowed. In all other cases a strict ban on post-bid negotiations is in place. This ban extends to a ban on all unclear or 
incomplete terms that might lead to negotiations of contract and in fact discriminating suppliers not included in the negotiations.

Recommendations: An effective ban on both pre- and post-contract negotiations should be introduced. As a short-term alternative measure, rules defining when a contract is considered substantially altered and defining the difference between post-contract negotiations and legal variations could be disseminated.

\section{Complaints and administrative review}

50. Access to a complaints mechanism is available to bidders and other parties in the procurement process, but not to the general public. The PPA establishes a three-tier system of administrative review for aggrieved bidders. The first, and mandatory, step in complaining is by lodging a request for administrative review with the procuring entity. Secondly the bidder may refer the case to the CTB for decision. Thirdly a procedure before the Public Procurement Appeals Authority (PPAA) can be initiated provided that certain conditions are met. Finally judicial review by the courts is available. The members of the PPAA are public officials with a high court judge serving as chairman. The PPAA was, at the time of writing (March 2003) not yet established in practice.

51. Once a contract has entered into force, the procuring entity is barred from entertaining complaints regarding the tender that led to that contract. The PPA does not describe the remedies available to the procuring entity or the CTB, but only states that the matter is subject to "administrative decision". Remedies available to the PPAA range from a declaration of the applicable rules to suspension of proceedings, annulment of any decisions, and termination of proceedings. A very significant exemption to this rule is the fact that a contract that has entered into force cannot be annulled. This leaves the entire complaints procedure without its most potent remedy, namely that of annulment and forced re-tendering.

- EUD: Each member state is obliged to form an independent body of control and judicial. This body may be administrative or in the form of a competent court. On the supranational level, the European Commission has the administrative task of control and policymaking but also has the authority to bring cases against member states before the European Court.

- WBG: No regulations regarding the right to administrative review or special judicial treatment of complaints.

- UML: A complete system of judicial review is included in the UML. First a right to administrative review by the administrative body that the complaint is directed at. Secondly a right to appeal to a special administrative body which is equipped with expertise in the area of public procurement and has at its disposal a number of legal remedies including revision of an unlawful decision, annulment of an unlawful decision combined with payment of compensation. Thirdly, access to the civil courts for trial. 
52. For a complaints system to function properly it is essential that complaints are actually filed, and that the complaints authority has access to the relevant information. As discussed in the Procedures and Practices section of this report, there can be a number of reasons why wellfounded complaints are nevertheless not filed. One of the main reasons is the fear of blacklisting. Many countries have introduced a whistleblower facility to counter this issue. A whistleblower facility entrenched in the Regulations, would allow the public to initiate investigations into procurement cases and should enable both bidders and the general public to initiate such investigations anonymously. To prevent misuse however, the filing of complaints should incur a modest fee and be limited to entities or persons with a substantiated legal interest in the case.

Recommendation: Establish the Public Procurement Appeals Authority. Introduce a whistleblower facility, and allow business associations to complain on behalf of their members. Ensure adequate remedies. Annulment and re-tendering must be real options for all tenders when a material breach of procedure occurs.

\section{Other Legal Framework Issues}

\section{Local Government Procurement}

53. Traditionally procurement under the Presidents Office of Regional Administration and Local Government and carried out by the local government authorities (district, town and municipal councils) have been governed by different rules than procurement in the central government. With the enactment of the PPA, the sections in the former Financial Memorandum issued under the Local Government Finance Act governing procurement in the local government, was revoked. While the PPA calls for specific local government procurement regulations to be issued under the Local Government Finance Act, such regulations have at the time of writing not yet been issued. The PPA is therefore presently directly applicable to local government procurement.

54. The local government regulations were gazetted on March 15, 2003, supported by a draft Procurement Manual for Local Government Authorities. The dregulations are in two volumes:

1. The Local Government (Procurement of goods and works) regulations

2. The Local Government (Selection and employment of consultants) regulations.

These regulations are drafted on the basis as those at the central level. The main procurement methods and processes are very similar to those in the Regulations governing central administration and parastatals. ${ }^{22}$

\footnotetext{
${ }^{22}$ A significant difference appears in the thresholds for application of the single source procurement method on works, where the Local Authority Regulations draft only allows single source up to a maximum of Tshs 80,000 versus the 800,000 allowed at central level.
} 
55. Since the local government regulations contain the provisions guiding the composition of the local authority tender boards, the present situation is that the composition prescribed by the old, now void, Financial Memorandum is still applied even though the procurement itself is covered by the new PPA. According to the Financial Memorandum the politically elected councillors are members of the tender board. This issue is covered elsewhere in this report. However, the new regulations entirely remove councillors from the procurement process.

Recommendation: Disseminate the new Local Government Regulations.

National Board for Materials Management Act vs. Public Procurement Act

56. The National Board for Materials Management Act (NBMMA) oversees the standard and conduct of the supplies officers who previously were exclusively responsible for conducting procurement as an integrated function of stores management. With the enactment of the PPA the procurement function has now gained a legal framework of its own and this has raised questions as to the relationship between the NBMMA and the PPA.

57. It has been the view of the NBMM, that the NBMMA on certain issues, such as procurement being exclusively reserved for supplies professionals, would supersede the PPA. It is however clear from the PPA Article 76 that it renders void all previous rules on procurement that are in contradiction to the PPA. As a consequence, the procurement professionals mentioned in the PPA are not by law required to be supplies officers, but as recommended in this report should be replaced with certified procurement professionals. The dissemination of this message to the various entities and its practical implementation is discussed in the Organisation chapter of this report.

\section{Defence and security Procurement}

58. A specific issue concerns procurement carried out by the Ministry of Defence and the security forces under the Ministry of Home Affairs. The PPA Article 2 contains a special exception for "military equipment and supplies for the Defence Forces" and "equipment and supplies of arms and ammunition" for the intelligence and security services, the police and prison authorities. The exception of sensitive procurements from the general procurement rules is a common feature of most procurement regimes, and is accepted under the UNCITRAL Model Law. Even though the PPA could be more precise on its description of the differences between the two types of procurement, this weakness could be corrected by simple guidance by the CTB.

59. The Ministry of Defence have established two tender boards, in principle dealing with respectively sensitive and non-sensitive procurement. The sensitive procurement is carried out by a tender board under the Defence and Security Committee under the Office of the President and the non-sensitive procurement is carried out by the Military Tender Board. Even though the Military Tender Board is by virtue of its non-sensitive operations covered by the PPA, it has not 
been included in the schedule to the Regulations listing all entities with tender boards. Thus a state of confusion exists as to the status of the Military Tender Board and to some degree also regarding the correct splitting of procurement between sensitive and non-sensitive articles.

Recommendation: The Regulations should be amended to reflect the existence of the Military Tender Board. The CTB should offer guidance to the tender boards as to the correct division between sensitive and non-sensitive procurement. The non-sensitive procurements should be subject to the PPA.

\section{Legal Framework - conclusion}

60. The legal framework for public procurement in Tanzania is in transition. While some very important steps in the right direction have been taken with the introduction of the procurement Act, there remain some large outstanding issues, particularly concerning local government procurement, access to complaints mechanism and dissemination of legal texts. Overall, and compared to other countries in the region, the legal framework for public procurement is updated and adequate. The single most important issue is that of dissemination and proper application of the rules contained in the legal framework. After a period of carving out the new rules, the country must now focus on making those rules work.

\section{Summary of Legal Framework Recommendations}

Short term:

- Disseminate Local Government Authority Regulations

- Support the distribution and enforcement of the newly developed Standard Documents issued by the CTB.

- Establish the Public Procurement Appeals Authority.

- Introduce necessary amendments to the PPA to establish the Regulatory Authority (from the Organisation and Resources section)

Long term (requiring amendments to legal instruments)

- Introduce a whistleblower facility

- Ensure adequate remedies for misprocurement.

- Establish mandatory time limits for the main steps in the procurement process and review existing time limits

- Introduce an effective ban on both pre- and post-contract negotiations 


\section{2. PROCEDURES AND PRACTICES}

\section{Procurement Planning - Release of Funds}

61. Procurement planning is essential for public procurement to achieve one of its major goals of providing value for money. Without proper planning, tenders fail to meet the real requirements of the public, timeframes are missed, costs increase and opportunities for economy of scale are missed. The Regulations Part V and specifically Article 63 contain a detailed list ${ }^{23}$ of mandatory requirements for procurement planning before tenders are floated. Applicable for the local government, the local government procurement manual contains a similar requirement for procurement planning.

62. However, the good intentions of the regulations are compromised by the poor dissemination of the Regulations, poor or non-existent enforcement and most importantly by the manner in which funds are released. The general practice witnessed by the mission was that besides minimal budgeting exercises, no actual procurement planning is taking place for government funded projects. Even those few procurement units that actually perform procurement planning fail to acknowledge the very important point that procurement planning is a dynamic exercise where plans are constantly updated to reflect the needs of the procuring entity and the marketplace for those specific requirements.

63. From the IPR exercise, cases have been noted where the engineer's estimate for civil works is at variance with the contract award and in most of the cases 40 to $50 \%$ higher than the lowest competitive bid. This may be due to lack of cost data bank and ad hoc application of weight to account for remote locations and unreasonable construction period assumed. In Goods contracts, usually no budgetary provisions are indicated, and as such procurement is mostly on approval, taken on need basis.

64. The quarterly release ${ }^{24}$ of funds that is common makes it very difficult for the procuring entities to plan beyond the next quarter, in practice crippling all attempts of effective procurement planning ${ }^{25}$.

\footnotetext{
${ }^{23}$ The list includes time and cost estimates, grouping or splitting of packages and choice of procurement method.

${ }^{24}$ A Budget Ceiling Committee, chaired by the Permanent Secretary of MoF, comprising the Divisional Commissioners, Accountant General, the TRA and Bank of Tanzania (BoT), determines the release of funds.

${ }^{25}$ According to the CFAA (2001) "Improvements in resource programming have meant that variance between budget allocations and outturns has been reduced across government, and releases to priority sectors are now broadly consistent with the expenditure programme. However, non-priority sectors continue to experience shortfalls in releases, particularly at the beginning of the fiscal year."
} 
Recommendation: It is recommended that the existing requirements for procurement planning are enforced, and that the present lack of capacity to implement the comprehensive requirements is addressed by making extensive guidance and standard forms available to the procuring entities. CTB to develop standard planning forms. In order to develop correct cost estimates, a centralized computerized cost data bank on works and goods, could be developed and maintained by the Regulatory Authority for reference and periodic updating by a qualified quantity surveyor.

\section{Procurement Methods}

65. Within the ministries, the impression the mission got was that some of the major procurers notably the Ministry of Works (including TANROADS) and the Ministry of Education is well aware of the PPA and its principle of selection of procurement method based in part on the value of the contract. This certainly also applies to the tenders being brought before the CTB which is seen as a strong enforcer of the PPA. It is however still a widespread practice to base the choice of procurement method on whichever seems appropriate, on the discretion of the accounting officer. This practice often leads to use of the competitive quotation or single source methods, even for procurements with a value above the set thresholds.

66. In the local government administration, the situation is another. Since none of the visited districts in November 2002 were aware of the PPA being enacted in 2001, they were still using the former procurement rules in the Financial Memorandum. Based on these now defunct rules the district tender boards often apply the "request for quotations" method with open tendering being almost exclusively used on donor funded projects where this is a donor requirement.

67. When using the competitive quotation (shopping) method, procuring entities often pick the three minimum bidders from an internally maintained list of potential bidders or directly from the lists maintained by the registration boards. None of the procurement units visited by the mission was able to provide any explanation as to how the three invited bidders are chosen from amongst all the potential bidders on the list. This practice is contrary to the Regulations on use of restricted tendering and provides ample opportunity for abuse. Nevertheless this practice is widespread.

68. Especially in local government the splitting of tenders to avoid having to seek the approval of the CTB, which is regarded as a cumbersome and time-consuming process, is common, despite the outright ban on this practice in the PPA. To a certain degree the splitting of tenders is also a result of the present budgetary process and the uneven disbursement of funds. 


\section{Publicity and transparency in procurement \\ - advertisement of tenders and awards}

69. It is the impression that open tender procedures are in fact advertised as stipulated. Any abuse of the procurement process takes place in the previous steps of selecting the applicable procurement method, where splitting and so called urgent needs leads to use of quotation and shopping method where tender would have been appropriate. Especially in local government procurement there seems to be a quite widespread practice of not advertising in newspapers, because of the cost involved, but only by posting notices on the tender notice board maintained by each tender board. Though the Regulations require that international community is notified through their respective embassies and trade commissions, tender advertisement are often restricted to local newspapers and East African papers. It is noted from the IPR, that in the absence of such publicity in many ICB tenders, the same set of contractors (including foreign) have been participating in most of the Works contracts.

70. As there is no central media for advertisement of tender or award notices the practices are scattered and the requirement for advertisement difficult to enforce. By introducing a Procurement Journal $^{26}$ the bidders would gain access to a central source of information and the costs of advertisement could be brought down. Contract award notices are very seldom published, even though this is a requirement in the PPA. The procuring entities cite lack of knowledge of the rules and excessive cost for advertising as reasons for this practise. Even more disturbing is the fact that bidders often are not informed of the fate of their bid, until a contract has been signed, thereby effectively cutting bidders off from initiating an otherwise justified complaint process.

Recommendation: Enforce requirement for advertisement of tenders in generally available media. Establish a procurement journal.

\section{Pre-qualification and qualitative criteria}

71. Pre-qualification is not mandatory, but its application relies on the professional judgement of the procurement officer. Because of low capacity to utilize the rather complex rules, this often leads to pre-qualification not being carried out at all, even in complex works tenders where its application is paramount. In many cases, specifically in works procurement, the procuring entity relies solely on the bidders registration status with one of the registration boards for its assessment of the bidders qualifications. In such cases the bidders are not qualified according to their specific qualifications for the project tendered, but only on more vague general qualifications.

\section{Tender Documents - Standard Bidding Documents}

72. The SBDs in use can roughly be divided into two groups: (1) Those based on donor SBDs, especially World Bank; and (2) Those issued by the National Construction Council for works procurement. From the IPR the mission learned that often in case of shopping of goods, verbal

\footnotetext{
${ }^{26}$ Combined with an electronic version accessible through the Internet.
} 
quotations have been invited or brief requests for proposals issued, lacking basic information like last date for submission of quotes, specified parameters, method of evaluation, delivery time, terms of payment etc. Bidding documents are often very poorly prepared and fail to reflect the actual needs of the procuring entity. The main reason for this is the low capacity in the procurement units and lack of knowledge of the new legal instruments. This again leads to poor quality of technical specifications and the need for negotiations, which again opens an opportunity for collusion and breach of the principle of equal treatment of bidders.

\section{Bid submission and opening}

73. From the IPR it is noted that in some of the contracts reviewed, time allotted for bid submission from date of tender availability is kept lower than the recommended one in the regulations. This results in less response and non-participation. However the rest of the bid opening procedures (such as bid opening on the date and time specified, rejection of bids received after the stipulated time, recording the name of bidder, and read out prices, verification of bid security along with the details such as value, form, validity, etc.) are recorded and minutes of bid openings prepared. In some cases of shopping procedures where selection by three quotations has been followed, enquiry is over the phone or through an undated, unsigned letter of enquiry, without any last date for submission mentioned. The mission was informed of several instances of breaches of confidentiality and collusion between the procuring entity and bidders, leading to competitors bids being revealed before the official opening and bidders allowed to replace their own tender. These practices are all in blatant conflict with existing rules, and underlines the urgent need for an authority to effectively enforce the rules.

\section{Contract award procedure and criteria}

74. Evaluation reports are generally of poor quality. In many cases award criteria other than those listed in the bidding documents are applied. The evaluation reports reviewed by the IPR do generally not analyse the evaluation parameters of equipments, offered work methodology, personnel capability and experience, etc., adequately in detail.

\section{Complaints and administrative review}

75. It is the impression that bidders very rarely complain over discrepancies in the procurement process. Given the gap that presently exist between the legal framework and the actual practices, the reason for the lack of complaints is certainly not that procurement is carried out by the book, but rather that the bidders find it unfruitful to complain. This is true for complaints directed against the procuring entity itself, but also for complaints directed at the CTB, of which there are very few $w^{27}$. Based on information from the private sector the major reasons for this situation are:

- Unclear procedures of complaint: Even though the PPA is quite clear as to the process of complaint the act is not widely known, and the consensus seems to be that personal relations with

\footnotetext{
${ }^{27}$ In the period 1 Jan. 2002 until I Dec. 2002, the CTB received a total of 2 formal complaints, although the CTB assisted in a number of cases, which were settled without a formal ruling.
} 
people tend to create more results. Thus complaints are lodged at senior officials (even though these may reside in a different ministry), the Prevention of Corruption Bureau (PCB), the Auditor General, etc. The path of complaint established in the PPA needs to heighten its credibility and the first step would be to establish the Public Procurement Appeals Authority mentioned in the act.

- Lack of enforcement: Even though there are huge discrepancies between the law and actual practices, the management in both ministries and in the local government expressed a relaxed attitude towards the enforcement of existing rules. Monitoring and review of procurement process is only done upon receipt of a complaint, which again very rarely happens. The mission did not hear of a single example of punishment being handed out for misprocurement, except in clear cases of corruption. This attitude towards enforcement cannot help but give the bidders the impression that complaining has no real consequence or impact, regardless of the formal outcome of the complaint.

- Lack of adequate remedies: The PPA does not supply the option of annulment of the procurement contract if this contract is in force. The complaining bidder, once the contracts wrongfully awarded is in place, has no other option than to seek economic damages. Since the burden of proof can be very difficult to lift for an aggrieved bidder it becomes a futile exercise to complain.

76. The PPA Article 61(7) requires all bidders involved in corrupt practices to be registered by the CTB and banned from participating in public tenders for a period of ten years. The CTB does currently not have such a list. The individual procuring entities can maintain their own exclusion list according to PPA Article 60(3)(b). Official blacklists are not in use, but several of the procuring entities interviewed, especially amongst local government, expressed clearly that contract award in part was based on their previous experience with the bidders, without this being indicated in the tender documents.

77. The suppliers and contractors are invariably afraid of disputes, for survival in the industry. This is in spite of the fact that arbitration clauses are provided in the tender documents ${ }^{28}$.

\footnotetext{
${ }^{28}$ A case in point is one of a bidder for a works contract in a roads project who was evaluated as non-responsive, due to the fact that a litigation case with the government was ongoing and the contractor did not mention this in his proposal.
} 


\section{Summary of Recommendations for Procedures and Practices}

\section{Short term}

- The requirement for advertisement of tenders in generally available media should be enforced with an aim to increase market access and transparency until the procurement journal is operational.

- Enforce existing rules on application of pre-qualification to ensure that accounting officers realistically consider the advantages that pre-qualification provides.

- Securing the integrity of the bid opening process in accordance with existing rules by stepping up the number of audits targeted at the physical and organisational measures that the procuring entities have taken to ensure proper handling of the bid-opening process.

- Correct use of award criteria should be enforced through audits and strengthening of the quality of evaluation reports.

- Introduce credible complaints mechanism, by strengthening the complaints handling ability of the CTB and establishing the PPAA to provide a functioning avenue of complaints for bidders.

\section{Medium term}

- A strengthening of the general quality of procurement planning should be pursued through monitoring and capacity building, with an aim to bring procurement plans up to the standards required by existing rules.

- Guidelines for selection of bidders for quotations should be issued to strengthen enforcement of the existing rules of equal treatment of bidders.

\section{Long term}

- Establish a government-funded, monthly-issued, procurement journal. The journal should be paper-based but also available through the Internet.

- Consider mandatory pre-qualification for certain tenders to enforce the proper use of prequalification. 


\title{
Monitoring and Contract Management
}

\begin{abstract}
Record-keeping
78. Even though the PPA clearly stipulates a demand for proper and comprehensive record keeping, the experience by the mission is that files are missing and incomplete. This does not seem to be an issue confined to the procurement files, but is rather the result of generally poor filing systems in the public sector ${ }^{29}$. The enforcement of the already existing rules on proper record keeping is lax, and it seems without any real consequence to the accounting officer that a file, or parts of it, can go missing. In the local government the problem seems to be partly caused by lack of resources leading to necessary copies for the file not being made.
\end{abstract}

\section{Variations and post-contract negotiations}

79. The contract documents ${ }^{30}$ often permit acceptable percentages of variations, and such variations get covered under Contingencies provided for in the contract sum. These variations/amendments are expected to take place during the course of contract period arising out of unforeseen needs, change of design due to problems encountered at site, and extra scope of services in the consultants' activities due to extension of time arising out of delays.

80. Generally however variations are not a frequent occurrence, with the exception being local government procurement where the mission was informed that variations often are negotiated, resulting in material differences from the original specifications, without this leading to retendering. The procurement units themselves cite poor planning, poor specifications and the timeand cost consuming tender process as the main reason for this situation. The Auditor-General reported some cases of variations, especially in large roads projects, leading to substantially larger payments than budgeted. These cases were allegedly not caused by lack of knowledge of the rules, but were clear cases of corruption, which were allowed to flourish due to lack of monitoring by the responsible authority.

Recommendations: Variations and alterations should be kept to a minimum as variations reflect poorly on planning, design, estimations and execution of the tender. To achieve this "minimum variations" status, choice of consultants, and selection of procurement / project monitoring personnel has to be done with lot of care and judgment. In large civil works, operation of bonus clause could be an incentive to discourage extension of time. Also, discount being offered by the bidder and accepted by the client can be kept aside as a form of bonus, for better performance. Where the contractor's rates in works are noted to be lower than the Engineer's estimate, additional performance guaranty against these rates can be called for to discourage contractor's post-contract negotiations to make up for the losses he may incur against such low rates. Whenever extension in the time period is granted, it should be ensured that the performance guaranty is kept valid till the end of new defects liability period or warranty period.

\footnotetext{
${ }^{29}$ The Records and Archives section in the ministries has been supported by DFID through the Records Management Project, which provides technical assistance to the section, and is expected to continue until 2004.

${ }^{30}$ In works procurement the contract documents are often based on the standard documents provided by NCC. The new mandatory SBDs issued by the CTB for works (National Competitive Tenders) should replace these and also contain provisions for variations in Art. 39.1
} 


\section{Enforcement and monitoring compliance}

81. On all major steps of the procurement process, the mission witnessed a gap between the existing legal framework and the practices followed. The reasons for this are multiple, but it is a common feature of all procurement entities visited, that monitoring and enforcement of existing rules is almost non-existing. This is the case for procurement at both central and local levels, as well as in the parastatals.

82. According to the PPA, the CTB is tasked with monitoring and enforcement but for many reasons, understaffing being a major one, nothing is happening. Not even basic statistical information, such as a breakdown of all procurement in Tanzania by sectors and choice of procurement method, is collected and available. Without such basic information it is evident that the CTB is unable to fulfil its enforcement obligations, even if the staff was available. The central media for public procurement notices that also form one of the recommendations of this report would be a key factor in establishing useful statistics. The present CTB is satisfied with trying to cope with the day-to-day tasks of approving tenders presented by lower ranking tender boards, and have in practise given up on the tasks of monitoring compliance and enforcing the rules. Furthermore, enforcement of the PPA and the supporting Regulations within the local authorities is also non-existent. ${ }^{31}$

Recommendations: Establish a strong program of monitoring and enforcement, with specific annual goals for the volume monitored and the number of cases of mi-procurement uncovered. Introduce changes in legal framework to allow CTB to not only to monitor but also to enforce rules in the local authorities.

\section{Consequences of non-compliance}

83. On interviewing numerous public employees, it was clear to the mission that noncompliance with existing rules were disclosed and discussed in a very open-minded manner by the accounting officers. To some extent this is evidence to the general attitude towards the problem of non-compliance. Neither management nor individual officers prioritise compliance and there certainly is no fear of audits or punishment.

84. According to the PPA Part VI non-compliance with the PPA and its supporting Regulations can lead to criminal proceedings against that individual. Furthermore under the public employment rules disciplinary action can be taken. The cases of this actually happening are few and mostly confined to cases where actual corruption has taken place. The legal prerequisites for establishing an efficient system of audits and handing out the punishments that will serve as deterrent are there. It is now up to the CTB to utilise those legal instruments.

${ }^{31}$ The conclusions concerning poor compliance with existing rules, caused in part by poor monitoring and enforcement is supported by previous studies such as the World Bank Country Financial Accountability Assessment (2001), which recorded the same issues on compliance with rules for financial management. 


\section{Dissemination of legal documents}

85. In the recent years the legal framework for procurement in Tanzania has seen the enactment of the Public Procurement Act in July 2001, the subsequent issue of the Regulations on both goods, works, services and consultants for central government in 2001, the issuing of new standard documents in 2002, and in the local government the upcoming Regulations for local government procurement to be issued in early 2003. These legal documents all introduce profound changes in the way procurement is carried out. With the introduction of the PPA the country is challenging the practices, which have developed around the principle of procurement as a by-product of stores-management. These practices, inspired by the British system, date back to colonial times and thus are well entrenched in the public service.

86. With the new legislation providing such a radical change, of course, this puts extra strain on the demands for dissemination of legal texts and guidance for the procuring entities. The mission experienced a general gap between the existing legal framework, and the practices in the public sector. The severity of this issue range from line ministries implementing ad hoc measures in contradiction to the Regulations to the fact that none of the district tender boards visited were even aware of the PPA having been enacted over one year earlier.

Recommendation: Proper and urgent dissemination of legal documents namely the PPA and the supporting Regulations, together with the necessary capacity building at all levels of the public administration is of paramount importance for the development of an efficient public procurement system.

\section{Recommendations for Monitoring and Contract Management}

\section{Short term}

- Enforce existing rules on proper record keeping

- Increase quality in specifications to reduce need for variations

- Establish deterrence by enforcing existing rules on punishment for misprocurement

\section{Long term}

- Establish awareness of legal framework. Execute a general program of monitoring, audit and enforcement, with specific annual goals. 



\section{C.3. ORGANISATION AND RESOURCES}

\section{Current Organisational Set-up}

87. Public procurement decisions in Tanzania are currently made by the CTB; ministerial tender boards; regional administration tender boards; district tender boards; local government tender boards; and parastatal tender boards. In addition to these institutions, there are other relevant organisations such as: the Attorney General, who is responsible for prosecuting breaches of the Procurement Act; the Auditor General who responsible for auditing all procurement transactions; and the Prevention of Corruption Bureau (PCB), which investigates corruption related offences. Also relevant are the Government Stores (GS), responsible for procurement of a variety of goods for all central government entities; and the Central Medical Department (CMD), which is responsible for the procurement and distribution of medical supplies..

\section{Role of the Central Tender Board}

88. The CTB is composed of a Chairman, currently the Permanent Secretary (PS) of the Ministry of Finance, and six members: representatives from the Ministry of Finance; Ministry of Agriculture \& Food; Ministry of Industry and Trade; Ministry of Works (two persons); and Ministry of Water and Livestock Development. The chairman and the members of the CTB are all appointed for a three-year period. The CTB is assisted by the Secretariat of the Board headed by the Executive Secretary, who is appointed by the President. The Executive Secretary attends all meetings of the CTB but does not have voting rights on any decisions. Currently the CTB Secretariat consists of five people, including the Executive Secretary. The employment of additional four staff members have been approved but not initiated.

89. The most urgent problem is the dual role of the CTB currently maintaining both executive and regulatory powers. According to the Procurement Act, the CTB has the following functions:

\section{Regulatory}

- Oversee and monitor the conduct of procurement by the various entities

- Advice the Government on procurement policy

- In cooperation with local and international organisations, supervise the management and training of a cadre of procurement specialist staff within the civil service.

\section{Executing}

- Approve the issue of tenders or the use of alternative methods

- Execute tenders

- Review and approve tenders. 
90. This mix of powers and functions contributes to an unstable situation, whereby the CTB on one hand participates in the procurement procedure by issuing, executing and approving tenders and on the other hand monitors the same procedures. This leads to a situation where the CTB in reality monitors its own deeds, which is contradictory to all established principles of separation between executive and regulatory powers. It ultimately leads to the CTB losing authority and credibility as a regulatory body. The executive role of the CTB also leads to lack of accountability and responsibility at the level of the ministerial tender boards and the ministerial Accounting Officers. Under the current system, the Accounting Officer is fully accountable for the budget but not for procurement with a value above the threshold for CTB approval under that budget.

Recommendation: The Public Procurement Act of 2001 should be amended with the purpose of relieving the CTB of its executing responsibilities and consolidate it as a regulatory body (Regulatory Authority) responsible for oversight and monitoring of the entire procurement process

\section{Other Tender Boards}

91. The establishment of tender boards (TBs) in ministries, departments and agencies (MDAs) is regulated in the PPA. They include:

Ministry and independent departments' T.Bs with the following members: the Accounting Officer (chairman); the Chief Accountant of the Ministry; the heads of not more than four key departments; the director of procurement or a procurement specialist of the Ministry; a director from another ministry, who shall be appointed by the MoF.

Regional TB: the Regional Administrative Secretary (RAS) (chairman); the Regional Accounting Officer; the regional education officer; the engineer whose speciality is under consideration in the tender board; the regional health specialist; the regional trade officer; a procurement specialist from the line ministry.

District TB: the District Administrative Secretary (DIS) (chairman); the Regional Accounting Officer; a government officer appointed by the DIS, who is specialist in the goods, works, or services procured; a procurement specialist from the line ministry; a Government officer appointed by the RAS.

The Parastatal TB comprising eight members appointed by the Chief Executive Director (CED): the CED (chairman); the head of the procurement or purchasing department; four heads of departments; two members from outside the parastatal organisation. 
92. The PPA also establishes the local government authority TBs. According to the latest Regulations ${ }^{32}$ for local government procurement, the local government tender board consists of: the Council Director (chairman); the Council Treasurer; The head of the department for which the procurement is to be done; the District Administrative Secretary; two other heads of departments or units who may be appointed by the Council Director.

93. The PPA Regulations determine the thresholds for the various procuring entities ${ }^{33}$ :

Fig. 5: Thresholds for procuring entities

\begin{tabular}{|l|l|l|l|}
\hline \multirow{2}{*}{ Organisation } & \multicolumn{3}{|c|}{ Limit in million Tshs and type of contract } \\
\cline { 2 - 4 } & Works & Goods & Services \\
\hline Ministry TB & 450 & 270 & 90 \\
\hline Executive Agency TB & 200 & 120 & 40 \\
\hline Regional TB & 100 & 60 & 20 \\
\hline District TB & 50 & 30 & 10 \\
\hline Independent Government Department & 50 & 30 & 10 \\
\hline Local Government TB & Unlimited & Unlimited & Unlimited \\
\hline Parastatal TB (examples): & & & \\
Tanzania Electricity Supply Company & 18 & 10,8 & 3,6 \\
Tanzania Railways Corporation & 22,5 & 13,55 & 4,5 \\
\hline
\end{tabular}

Source: PPA Regulations

\section{Decentralisation}

94. As mentioned above, the present situation provides for a CTB, with extensive executive powers, including powers to approve all tenders above the thresholds provided for in the PPA and its Regulations. However, these thresholds laid upon lower-level tender boards are generally perceived as too low. For ministries for example, the amount, which can be procured for without CTB approval must not exceed 450 million TShs for works contracts ${ }^{34}$ and 270 million TShs/ 90 million TShs for goods and services contracts respectively. Rather than increasing the thresholds across the board, it is suggested that the procurement be completely decentralised to the ministerial level, leaving the CTB as a purely regulatory and monitoring body in line with the recommendation above.

95. The advantages of full decentralisation can be summarised as:

- Greater accountability at the Ministry level and for the Accounting Officers, who would not only be responsible for the budget but also for all procurement under that budget

\footnotetext{
${ }^{32}$ A mentioned above in the Legal Framework chapter, the Regulations have just been gazetted.

${ }^{33}$ The Regulations establish thresholds for 101 different organisations.

${ }^{34}$ Procurement of Goods and Works Regulations, Second Schedule, litra a).
} 
- More efficient procurement, as the CTB would not serve as a bottleneck in the procurement process.

Example: Full decentralisation in Uganda

Uganda fully decentralised its procurement function to ministries about two years ago, and has subsequently experienced marked improvements in the efficiency of the procurement process. Simultaneously, the Central Tender Board was reformed into a regulatory and policy body.

96. The potential risks, which have to be proactively addressed, are: (i) potential decentralisation of corruption; and (ii) lack of oversight and coordination. However, these risks may be mitigated by combining decentralisation with the establishment of a well-resourced regulatory body that monitors compliance and with powers to sanction violators of the laid down procedures. A prerequisite for this is to secure the information flow from the ministerial tender boards to the CTB and thereby ensure that proactive rather than reactive monitoring can be conducted. Also, decentralisation of the entire procurement portfolio to the ministerial level must be followed with substantial capacity building of the ministerial tender boards. Mechanisms for introducing these measures are described in further detail below.

It is recommended that all execution of procurement should be decentralised to MDAs and parastatals, while simultaneously maintaining and strengthening the Regulatory Authority. This will make Accounting Officers directly accountable for procurement, as they are currently accountable for the budget.

\section{The Regulatory Authority}

97. The Regulatory Authority (RA) will be a policy and regulatory body. It will also be vested with strong monitoring powers, allowing it to monitor all stages of the procurement process, from procurement planning to contract management, i.e. the entire procurement cycle. The RA should have the following tasks:

- Monitoring the public administration and the procurement environment in order to implement proactive and/or corrective measures when necessary. The monitoring shall ensure that rules and procedures are adhered to and should specifically focus on the enforcement aspects. Thus, in order to the RA to serve as a credible oversight body, particular focus must remain on applying remedial measures when non-compliance with the legal framework is identified.

- Forging policies for the future of procurement. The RA will be the foremost advisor to the Government on matters of public procurement. Thereby the extensive knowledge gathered by the RA as a result of its monitoring tasks will benefit the future legal initiatives concerning public procurement. 
- As an instrument of administrative review the RA will be the second level of complaint for a bidder, consultant or contractor complaining of a violation in procurement proceedings. The path of complaint according to the proposed procurement law has three levels, the first being the entity responsible for the purchase, the second is the RA applying the principles of transparency and non-discrimination set forth in the law, and the third level is the PPAA, which is described in the Public Procurement Act, but not yet established. Over time when the RA has been able to exercise the necessary authority over the administration the need for administrative review should decline as the procuring entities become aware that their own treatment of complaints will be overturned by the RA if the regulations are not strictly adhered to.

- The regulatory responsibilities of the RA includes the issuing and updating of regulations regarding thresholds for application of the procurement rules, usage of domestic preference, calculation of contract value and others mentioned in the Public Procurement Act. As the RA draws its authority from the Act only areas defined in the Act will be subject to regulations issued by the RA. No administrative body has the authority to change or amend the law outside these defined areas. This is the sole prerogative of the National Assembly as the legislative body.

- Capacity building. The RA shall oversee and coordinate activities aimed at enhancing procurement capacity at all levels of Government. This includes coordination and cooperation with independent training institutions tasked with the implementation of tailored training activities.

- Information dissemination. The RA shall be responsible for coordinating all information efforts aimed at enhancing the knowledge of the procurement system in general and of procurement decisions in particular.

\section{The Location of the RA}

98. The current CTB is located within the $\mathrm{MoF}^{35}$, and while the Executive Secretary is appointed by the President the rest of the CTB members are appointed by the MoF. ${ }^{36}$ Until now, the MoF has been well-placed to discharge the functions of the executive body to enforce the procurement legislation, as it is an established ministry with the authority vis-à-vis other ministries of the Government. However, experience in other countries has shown that in some cases a line ministry of government may invariably lack the independence needed to oversee a country's public procurement system, as it is subject to pressures from politicians and from other ministries. Thus, the question is, whether the RA should remain affiliated to the MoF, or whether another organisational set-up should be devised. Different models for the organisational set-up have been chosen by different countries:

\footnotetext{
${ }^{35}$ PPA, Article 5.

${ }^{36}$ PPA, First Schedule, Article 1
} 


\section{Example:}

In Poland, which is often cited as an example of good procurement reform, the oversight and regulatory function is conducted by the Office for Public Procurement (OPP): The OPP reports directly to the Government and the Chairman of the OPP, whose rank is equivalent to that of a Deputy Minister of Government, is directly responsible to the Prime Minister. In line with this, the Chairman of the OPP is appointed and may be dismissed by the Prime Minister.

99. In the case of Tanzania it is suggested that the RA be established as an autonomous body reporting directly to Minister of Finance and not as present to the PS of the MoF. By maintaining the RA under the auspices of the Minister of Finance, the RA will benefit from the strength and political influence of the MoF vis à vis other ministries. In addition, the MoF is the coordinator of the major reform efforts and will also be a key player in procurement reform. ${ }^{37}$ Thus, by maintaining links between the RA and the MoF, the necessary momentum for procurement reform is best ensured

It is recommended that the $R A$ be established as an autonomous body reporting directly to Minister of Finance.

\section{Establishment and Strengthening of Procurement Management Units}

100. Several of the procuring entities at central government level visited by the mission have established supplies units headed by a certified materials management professional. However, actual Procurement Management Units (PMUs) are currently not in place. The Regulations of the PPA presupposes the existence of PMUs. Thus, according to the Fifth Schedule of the Regulations, the CTB shall conduct a capacity rating and certification of the PMUs. In line with the decentralisation and the establishment of a professional procurement cadre, as described in detail below, the already existing supplies units should be transformed into regular PMUs. The PMUs will provide support and secretariat services to the decentralized tender boards, and will be responsible for the process aspects of procurement, including but not limited to:

- General co-ordination especially within ministry, department or agency

- Organise development of technical specifications ${ }^{38}$

- Prepare bid documents

- Organise advertisement

- Issue bid documents

- Organise communication with bidders

- Issue bid receipts and keep bids till opening date

\footnotetext{
${ }^{37}$ The MoF is the coordinator of the Poverty Reduction Support Credit, which will most likely serve as the main instrument for financing procurement reform.
} 
- Arrange public bid opening sessions

- Participate in bid evaluation as determined by the tender board

- Prepare evaluation reports

- Prepare draft contracts

- Present the result of a tendering procedure to the tender board for approval

- Arrange contract signature

- Manage the procurement process during contract execution

- Maintain proper records for the whole procurement process.

It is recommended that the supplies units be transformed into regular procurement management units (PMUs) headed by qualified procurement experts. The PMUs should provide support and secretariat services to the decentralized tender boards as described above.

\section{Monitoring}

\section{Securing information flow to the $R A$}

101. To ensure comprehensive monitoring of the procurement process by the $R A$, the reform will need to establish sound and efficient information mechanisms and procedures between the RA and all the procuring entities. This focus on the information flow should ensure that the RA can carry out its monitoring role in a pro-active manner and not only react to already implemented procurement decisions.

102. It is advised that an information sharing model be developed ensuring early and continued flows of information from the procuring entities to the RA. Ideally such a model should entail an early warning mechanism allowing the RA to carry out reviews of planned and ongoing procurement and not merely finalised procurement processes. The information sharing and early warning should be united in an Information Management System (IMS) tailored specifically for the Tanzanian setting. To facilitate efficient monitoring by the RA, the IMS should include the following features:

- Intelligence gathering, i.e. systematised reporting to the RA by procuring entities providing information at various stages of the procurement process

- Information matching, allowing the RA to match information and identify high risk procurement jobs

- Targeting - where the RTCB based on the risk assessment, conduct targeted early review of certain high risk procurement jobs

\footnotetext{
${ }^{38}$ The PMU should be able to use technical specialist for the development of technical specifications in agreement with the buyer/Ministry. However, the responsibility for ensuring the quality must still rest with the PMU and the tender board.
} 
- Information sharing, ensuring that information is shared among all relevant parties and thereby enhancing transparency and accountability.

103. The risk assessment part of the IMS could focus on obtaining and matching information regarding certain procurement jobs, for example procurement jobs:

- of large value

- within specifically corruption prone sectors, such as construction

- within procuring entities with weak capacity

- etc.

In addition to information provided by the procuring entities, the RA should also rely on and share information with the civil society organisations engaged in monitoring procurement processes.

104. The monitoring of the RA will be carried out towards the following:

- The ministerial tender boards

- Specialised tender boards (military tender board, police tender board, etc.)

- Regional administration tender boards

- District tender boards

- Local government authority tender boards

- Parastatal tender boards

- Medical Stores department ${ }^{39}$.

It is recommended that an Information Management System (IMS) ensuring a proper information flow to the $R A$ be developed. The IMS should be designed to enable procurement risk assessment and allow the $R A$ to conduct targeted monitoring.

The monitoring role of the $R A$ vis-à-vis local government

105. The Public Procurement Act of 2001 stipulates that in relation to local government authorities, the CTB shall "study the conduct of procurement by local authorities with a view of ensuring the full compliance by them with their established procurement system." The Act further stipulates that the CTB shall "advise local government authorities on all matters regarding procurement and the efficient operation of their established procurement system and make such recommendations as it deems fit. ${ }^{40}$ From the wording of the law, the current monitoring role of the CTB vis-à-vis local government authorities is relatively weak. In comparison, the CTB is mandated to "oversee and monitor" the conduct of procurement by ministries and other procuring entities. The mission identified several shortcomings in the overall monitoring and auditing of the local government procurement. Thus at present there is virtually no monitoring taking place neither by the President's Office/Regional and Local Government nor by the CTB.

\footnotetext{
${ }^{39}$ The Medical Stores Department shares features with the GS. However, the GS are not included here as the present report recommends that the GS be closed. See the section on "Utilizing the advantage of scale" below.
} 
106. As part of an overall focus on strengthening monitoring of public procurement, there will be an increased need for strengthening the institutions, which will carry out the monitoring functions. As suggested above, the RA should become a strong and focussed monitoring entity, and adequate resources should be allocated to this extent. Rather than building up extensive monitoring capacity at both the RA and within the President's Office/Regional and Local Government, it is suggested that the RA be empowered to directly monitor local government procurement, and that RA be empowered to intervene at all stages of procurement carried out by local government authorities. This further falls into line with the recommendation above in the legal framework chapter suggesting that one uniform legal framework for procurement be introduced for both central and local government.

Recommendation: The $R A$ should be given full monitoring and supervisory powers regarding the procurement carried out by local government authorities.

\section{Other Organisational Issues}

\section{The Public Procurement Appeals Authority}

107. According to the PPA Article 65, a PPAA shall be established in the Ministry of Finance. The PPAA shall have a High Court Judge as chairman and four other members appointed by the Minister of Finance. These four members shall have knowledge and experience in public procurement, finance, commerce, business administration or law and shall be from institutions having no direct vested interest in public procurement. ${ }^{41}$ As explained above in the legal framework chapter, the CTB constitutes the second tier in a three-tier administrative complaints system with the procuring entity constituting the first address of appeal and the PPAA the third. Final recourse may be sought in the court system. It is suggested that the RA maintain this role within the appeals system.

108. However, in consequence of the relocation of the CTB and the establishment of the RA as an autonomous body, the PPAA should also be detached from the MoF. The RA could maintain the secretary function of the PPAA. The PPAA should have members appointed by the MoF, by the Procurement Professionals' Body (PPB) ${ }^{42}$, and by the private sector. The latter measure is important to ensure that private sector complainants, i.e. the bidders, maintain the impression that the PPAA is a fair and credible review authority.

\footnotetext{
${ }^{40}$ PPA, Article 7, litra b (i) and (ii).

${ }^{41}$ PPA Article 66, 1 litra (a) and (b).

42 The PPB is described in more detail in the section below on "Up-grading and certification of procurement professionals"
} 
It is recommended that the membership of the PPAA be amended to include representatives from the private sector and from the Procurement Professionals' Body (to be established). The members of the PPAA should be appointed as an urgent measure and the PPAA made operational to provide a functioning and credible review body. The PPAA should be administrative rather than judicial and therefore the chairman does not have to be a high court

\section{Local government procurement}

109. During the visits to various local government entities, the mission witnessed a widespread use of the now void Financial Memorandum. Until the new Regulations are made operational by the President's Office/ Regional Administration and Local government there will remain a gap regarding the applicable and operational framework. As a result of the legal inconsistency and general lack of information dissemination regarding the legal framework, a number of inadequacies were identified: inadequate advertising of tenders, excessive use of quotation method and application of non-transparent selection processes, lack of transparency regarding contract award including lack of publication of contract awards, undue political influence on contract award especially by councillors sitting on the tender boards, and lack of oversight and procurement audits by local government authorities.

110. The presence of councillors on the local government tender boards has been an issue of extensive discussion within the local government reform process. ${ }^{43}$ All the local government tender boards visited were constituted according to the now void 1997 Local Government Authority Financial Memorandum ${ }^{44}$, which prescribes that the local government tender board be composed of members of the District Finance Committee, who are all elected members of the Council. Although the Executive Director and Heads of Departments participate in the tender board meetings, they do so on an advisory basis, and the councillors are not obliged to take heed of the technical advice provided by the executive representatives. The mission was informed that award decisions are often made on political grounds, and thus many of the decisions made by the local government tender boards are perceived as biased and questionable.

111. Some of the councillors met, maintained that the presence of councillors on the local government tender boards is justified due to the councillors knowledge of the local conditions and the local market. However, most councillors also agreed that the same argument may be used against having councillors on the tender boards, as many councillors depend on the local business community for campaign funds and therefore may be perceived as being biased towards certain local interests.

\footnotetext{
${ }^{43}$ The Local Government Reform Programme has organised a set of workshops focusing particularly on local government procurement on 29-30 July 2002 and 10 December 2002. During these workshops the issue of political representation on the local government tender boards were discussed at length.
} 
112. In the view of the mission, procurement is an executive function, which should be carried out without political interference. Politicians are responsible for approving the budget and supervising its implementation, but should not be involved in the executive role of dispersing the funds. Thus, the oversight role of the councillors is compromised, when they, as in the present situation, are also involved in the execution of the budget provisions through procurement. The mission was pleased to know that the latest draft of the local government procurement regulations (now gazetted) excludes councillors from the local government tender boards.

113. Another issue calling for immediate attention is the complete lack of monitoring and audit of local government procurement. None of the districts visited had had their procurement processes audited, despite the many indications that irregularities are frequent. As an aspect of the monitoring element, the mission identified no examples of local community involvement in the monitoring of local public procurement. This mirrors the similar situation at central government level, where civil society monitoring of the procurement processes is completely missing. As described further below in the chapter dealing with anti-corruption, measures for civil society monitoring of public procurement by local government can and should be vested within the larger anti-corruption monitoring effort.

114. The problems identified with respect to local government procurement will be partly alleviated by the new local government regulations. However, other issues of equal importance must be addressed, and one of these is the general lack of eapacity for conducting sound procurement at the local government level. A major task persists in introducing the new legal framework to all relevant parties involved in the procurement process, including the local communities and local civil society. Beyond mere introduction all officials involved directly in the procurement process, from members of the tender boards to those officials responsible for contract follow-up and contract management must be trained so that they are able to fully use and abide with the new legal and procedural framework. The issue of building capacity within public procurement is further described below.

- It is recommended that the President's Office/Regional Administration and Local Government disseminate the new Regulations as soon as possible.

- While strengthening the monitoring role of the RA towards local government procurement, it is also suggested that specific initiatives encouraging civil society/local community monitoring of the procurement processes be established. These initiatives should build on ongoing and planned monitoring initiatives in relation to the National Anti-Corruption Strategy and Action Plan.

\footnotetext{
44 The Memorandum is void according to Article 76 of the PPA, which revokes all laws, regulations or rules relating to public procurement enacted prior to the PPA.
} 


\section{Utilising the advantage of scale}

115. At present the Government uses the advantage of scale when procuring through the Government Stores (GS) and Medical Stores Department (MSD). Both the GS and the MSD are perceived as ineffective and not meeting demands from the public entities.

116. Procurement from $\mathbf{G S}^{45}$ is regulated in the PPA Article 24, which determines that when financial resources are exclusively provided by a Tanzanian public body, a procuring entity shall procure from the GS any item included in the approved current Stores Catalogue unless such items are not available at higher prices than current market prices. Before procuring elsewhere, the procuring entity must obtain a certificate of non-availability from the GS. Also, the GS shall periodically publish in the Gazette and in the local newspapers of wide circulation the names and quantities of items available in the stores catalogue. The mission learned that neither the requirement of non-availability certification nor the requirement of publication is followed by the GS.

117. In the FY01/02 the GS had a turnover of Tshs 6.77 billion, while the total requirements for the GS amounted to Tshs 44.6 billion. The Ministry of Works TB is responsible for the tenders of the GS. The GS currently employ app. 120 people in Dar es Salaam and 15 people in each of the 19 regional branches. The employees include accountants, supplies officers, administrators, and others. The mission learned that the procedures for obtaining supplies from the GS can be divided in two main groups: obtaining fuel and obtaining other supplies. For the fuel, Government entities deposit an amount with the GS at the beginning of the Financial Year, for which the GS then procure, and the Government entities can then draw fuel supplies on that basis. As for other items, procurement is undertaken upon request from the Government entities. The GS procure on the basis of forecasts based on previous years' procurement. For items other than fuel, the GS receive evolving funds. The GS are usually able to obtain fuel at lower prices than market prices, however, for other items, the GS are usually not competitive.

118. According to the GS, they lack sufficient funds to procure internationally, which leaves the GS highly dependent on the local market. There have been instances of suppliers colluding during tender procedures, whereby the cited prices for all eligible bidders were above market prices, and in such instances the GS decide to cancel the tender. When inquiring among the suppliers, the GS were told that the demand for bid security and the costs of obtaining these through the local banking system had lead to the increased price. The lack of funds has also lead to a situation, where the GS are relying heavily on credit measures, and this might sometimes determine the supplier.

119. During a meeting with the GS, the management agreed that the current set-up is not functioning in a satisfactory manner. The GS are obliged to supply all levels of government, but

\footnotetext{
${ }^{45}$ The GS is in this report synonymous with the Store operated by the Ministry of Works. However, additional stores are operated by the Ministry of Water (Maji Stores) and the Ministry of Livestocks (Veterinary Stores).
} 
have neither the funds, nor the organisational capacity to do so. The lack of funds has lead to a situation, where the GS cannot tender internationally, and as a result is too reliant on the local market. Also, poor infrastructure, for instance lack of transport vehicles, has lead to deterioration of the supply channels from the GS centre in Dar es Salaam and to the regions. Thus, at regional level, the local GS branches are often out of stock, forcing the authorities there to procure locally in an often even less competitive market. As a result, most government entities have stopped relying on the GS and have introduced their own procurement measures for items, which should be procured by the GS. The only item, which the GS are still able to procure and provide at competitive prices, is fuel. Overall, however, it is obvious that the present set-up of centralised procurement and storage pose a barrier to a cost effective and value for money oriented procurement system, and the mission suggest that an effective "zero storage system" be introduced.

\section{Example: The use of framework agreements in Denmark}

With a total staff of 34, the National Procurement Ltd. in Denmark provides services to the public sector in Denmark with the defined goal to secure the public sector savings and benefits through better prices, safer purchases and more efficient working processes. The core service of the company, which is owned jointly by the Association of Local Municipalities and The Ministry of Finance, is a voluntary subscription arrangement offering public organisations advantageous purchasing terms and conditions among an assortment of specially selected products and services. In return, the suppliers get an attractive possibility to sell their products and services to the public sector on a contractual basis. By tendering large framework agreements, the company offers easy access to the economies of scale for its customers, who by their subscription acquire only an option to buy. Only when the list prices appear advantageous will the subscribers access the framework agreements and contract directly with the suppliers. The subscription arrangement is accessible to the subscribers in a paper edition as well as electronically. Through a new electronic procurement network all public-purchasing routines can now be accessed from the office PC. The system is accessible for $\mathbf{8 0 - 9 0 , 0 0 0 ~ e m p l o y e e s ~ i n ~ t h e ~ s t a t e , ~ c o u n t i e s ~ a n d ~ l o c a l ~ g o v e r n m e n t s . ~ T h e ~}$ number of framework agreements is 80 - all in all equivalent to some 2 billion line items. More than 8500 public organisations subscribe, and there are 250 suppliers on framework agreements, several with distributors, totalling more than 1200 order addresses in Denmark. Total turnover in 2001 was USD 600 million.

120. The scope of the MSD is regulated in the Medical Stores Department Act (MSA) of $1993 .{ }^{46}$ The MSA, Article 3 establishes the MSD as an autonomous department within the Ministry of Health. The MSA, Article 4 outlines the functions of the MSD, including to "develop, maintain and manage an efficient and cost-effective system of procurement, storage and distribution of such approved drugs and other medical supplies required for use by the public health services", and to "implement work plans and programmes approved by the Board in relation to the procurement and supply of approved drugs". The MSA, Article 16 establishes the Medical Tender

\footnotetext{
${ }^{46}$ The full title of the Act is: "An Act to establish the Medical Stores Department for the procurement, storage and distribution of medical supplies and to provide for other matters connected or incidental to the establishment and management of the department" of 22 September 1993.
} 
Board, which is responsible for advertising, receiving and opening of all tenders for the purchase of pharmaceuticals and other supplies and for appointing appropriate suppliers.

121. The MSD procures drugs, medical supplies, equipment, vaccines, medical kits and special products. During the FY00/01 the MSD procured for a total of some Tshs 18,783 billion worth of supplies and in the FY01/02 the total procurement volume amounted to Tshs 25,2 billion. ${ }^{47}$ The methods used were a mixture of International Competitive Bids, Restricted Tenders and Emergency Orders. The MSD procures drugs by generic name, mainly from foreign suppliers and according to international accepted standards. At the same time, however, the MSD actively encourages the participation of local drug manufacturers in procurement. About $90 \%$ of MSD orders fall within the category of International Competitive Bids. This has helped considerably to reduce the prices of pharmaceuticals and related products.

122. For the MSD, the current system implies that the MoH deposits funds with the MSD, which will then procure in line with specifications developed by the $\mathrm{MoH}$ and subsequently forward the supplies directly to the various $\mathrm{MoH}$ entities. This system has been chosen deliberately due to previous experience of the local $\mathrm{MoH}$ entities not using the funds released for the purpose intended. Thus, prior to the establishment of the MSD, there were widespread complaints of misuse of funds evidenced by severe scarcity of supplies or low quality supplies, especially at district level. Under the current system, the MSD regularly supply the local MoH entities with medical kits containing a selection of the most commonly used medical supplies. This practice has to some extent alleviated the previous scarce supply situation. However, several of the district medical officers, with whom the mission spoke, still complain that the drugs supplied are not sufficient, and there are also examples of expired supplies being delivered or that the delivery does not match the needs of the local community. If drugs are not available from the MSD or can be obtained at lower prices locally the local health entities are allowed to procure at the local market. Though, in reality this very rarely happens since the funds have been deposited with the MSD and the local MoH entities rarely have additional funds at their disposal.

123. Thus, the current system, which has been developed with extensive financial and technical support from DANIDA, also serves as a budget control mechanism, allowing the $\mathrm{MoH}$ to ensure that the funds allocated to medical supplies are used for procurement of these supplies. Due to these previous deficiencies in district procurement of medical supply, the MSD is also supposed to serve as a quality assurance mechanism, though interviews at local level suggest that this objective is not fully met.

124. In light of the extensive resources invested in the current MSD procurement system, and the previous negative experiences with (extensively) decentralised medical procurement, the mission agree that this set-up should be kept for the medium term. It is, however, recommended that the

\footnotetext{
${ }^{47}$ Figures provided by the MSD.
} 
long-term objective should be to decentralise the medical procurement along the same lines as for the GS.

It is suggested that the Government of Tanzania introduce the mechanism of framework agreements as a method of maintaining advantages of volume while reducing disadvantages of centralised storage and distribution. In doing so it is important to pay careful attention to the tendering process and the award of the framework agreements. In addition it is recommended to close the GS and establish a new slim procurement unit within central government, which will be responsible for the tendering and management of the framework agreements.

\section{Information dissemination regarding the $R A$ and the PPAA}

125. As mentioned above, the mission identified widespread shortcomings in the general knowledge about the PPA, which was enacted more than a year ago. The lack of knowledge was especially noticeable at the local government level. Very few among the people interviewed were familiar with the appeals options provided in the PPA, and the mission was not able to identify any recent instances of appeals or complaints being lodged. It became apparent that the lack of complaints and appeals lodged is closely connected to the lack of information about the appeals option, as well as a general lack of trust in appeals leading to remedial action.

126. After reforming the CTB and setting up the PPAA, a first step should therefore be to design and initiate a nation wide information campaign targeting central and local government, parastatals as well as the international and national business community and informing all these about the new institutional set-up, its implications, and paying particular attention to the appeals system.

It is recommended that a nationwide information campaign be organised. The campaign shall aim at informing all parties involved in procurement, including the private sector, of the new institutional set-up. The campaign shall in particular provide information about the appeals system and the remedies provided.

\section{Resources and Capacity}

127. Lack of capacity is the single most important issue in the sector, and all of the interlocutors with whom the mission met, cited lack of capacity and skilled personnel as a great impediment to conducting sound procurement. With decentralisation and the creation of properly staffed procurement units in each procuring entity the demand for skilled procurement staff will undoubtedly rise. 
128. The procurement capacity of the various procuring entities varies greatly. Some ministries like the Ministry of Works and large parastatals like TANROADS have quite extensive experience with procurement through many years of procuring under donor funded projects. While the staff undertaking procurement in these entities are not fully familiar with the PPA, they are generally very skilled in the use of the procurement rules of the various donors, and as most donor rules are built on the World Bank framework, which also serve as the model for the PPA, the knowledge gap in need to be bridged is not large for this group. For other ministries, who do not have prior experience with donor-funded procurement, the capacity gap to be bridged is greater. Likewise for the regional administration procurement.

129. At the local government level, the procurement capacity is dimmutive, and there is a great need for a quick yet carefully planned intervention. As mentioned above, none of the districts visited were familiar with the 2001 PPA, and procurement was generally conducted by applying now void rules and to a large extend upon the discretion of the politically dominated local tender board. Provided this report's recommendations regarding local government are followed, the procurement will be left to the executive level of the local government authorities, and there will be a need for introducing sound procurement principles and training of relevant staff within all local government entities.

\section{Establishing a procurement cadre}

130. A first step should be the introduction of a cadre of qualified procurement officials. At the moment procurement is mainly carried out by certified supplies officers without adequate procurement training. On the whole, procurement is not viewed as an established profession and does not present an attractive career path, and from this follows the overall lack of incentive schemes for procurement professionals. This situation stands in the way of establishing the necessary capacity for proper procurement in compliance with existing rules. The mission discussed this matter with the leadership of the Civil Service Department (CSD) of the President's Office, which was positive towards the introduction of a specialised procurement cadre within the civil service career system.

131. The introduction of a specialised procurement cadre should be vested within the ongoing Public Service Reform Programme (PSRP). Over the past years a comprehensive job-evaluation and re-grading exercise for public employees has been conducted. The exercise has been geared to identify the extent of career stagnation by technical and professional staff, unearth inequities and disparities in job-grading and salary levels, and update the schemes of service. The establishment of a procurement cadre should be conducted as part of this larger exercise. Two main issues must be addressed when introducing a new cadre within the civil service system: One is the upgrading and certification of procurement professionals, the other is the placement of the cadre within the on-going public service pay reform. Both these issues are discussed further below. 


\section{Up-grading and certification of procurement professionals}

132. Currently the CSD operate with the category of supplies staff placed within a six-level framework:

- Principal Supplies Officer I

- Principal Supplies Officer II

- Senior Supplies Officer

- Supplies Officer I

- Supplies Officer II

- Supplies Assistant.

133. There are currently 901 supplies officers employed within the public service. ${ }^{48}$ As illustrated by the figure below, the majority of the supplies officers are working within central government MDAs, with less representation at the regional and district level. For a detailed breakdown of number of employees within each of the six categories and salary levels, please refer to Annex III.

Fig. 7: Number of Supplies Officers in the public service

\begin{tabular}{|l|l|}
\hline Public service entity & Number \\
\hline Central Government MDAs & 657 \\
\hline Regions & 38 \\
\hline Districts - Central Government funded & 174 \\
\hline Districts - Locally funded & 32 \\
\hline Total & 901 \\
\hline
\end{tabular}

134. The certification of supplies officers is currently conducted by the National Board for Materials Management (NBMM), which is a body under the Ministry of Works. In the certification, the NBMM is guided by the National Board for Materials Management Act (NBMMA) of May 1981, which also determines that only persons authorised by the NBMM may be employed as supplies officers. ${ }^{49}$ The NBMMA defines materials management as "the effective and economic co-ordination of (a) stock identification, classification and coding; (b) inventory control and provisioning, including procurement and stock verification; (c) storehouse layout and organisation; (d) preservation and packing; and (e) handling transport and distribution" ${ }^{50}$ Clearly, materials management is not compatible with the notion of procurement in the traditional sense as encompassing all stages of procurement from procurement planning to contract management and monitoring. Also, the focus of the NBMM has up until now been on purchase of goods and has not included procurement of civil works and consultancy services.

\footnotetext{
${ }^{48}$ Statistics provided by the CSD

${ }^{49}$ Part IV of the NBMMA.

${ }^{50} \mathrm{Part} I$ of the NBMMA.
} 
135. Thus, the challenge will be to organise the transition from mere materials management to full-fledged procurement. Ideally the CSD supplies staff category should be replaced with a category of procurement officers, and this category should be recognised within the public service meritocracy on the same level as other professionals, such as administrators, accountants, etc. Thus, a regular career path for procurement specialists should be introduced. In doing so, it will be necessary to introduce a new certification scheme. Such a scheme should not be unduly rigid, but should ensure that those working as procurement specialists possesses the necessary skills and experience. A minimum requirement should be full knowledge and understanding of the PPA and Regulations, and familiarity with the practical implications of the legal framework. In some instances, the requirements can be met by recognising as procurement specialists those public officials, who have extensive experience with donor-funded procurement. This category of professionals will need upgrading with respect to the PPA, but as the principles of the PPA are largely identical with the principles applied by most donors, the need for up-grading will be less. In other instances there will be a need for more systematic training and re-certification. This will be the case for the large number of supplies officers, who have mainly worked with this limited aspect of procurement and have not been exposed to procurement in the fullest sense.

136. The establishment of a fully recognised procurement cadre will lead to the discharging of some of the functions and privileges currently held by the Materials Management profession. The PPA indirectly recognises this by defining a procurement expert as "a person who is engaged in a profession, occupation or calling in which recourse to procurement is directly or indirectly involved and has such knowledge and experience of the practice of procurement". Thus the PPA does not limit the notion of a procurement specialist to a certain profession, but puts emphasis on the actual and practical skills of the specialist in question.

137. Recognising that materials management is merely a limited aspect within the larger public procurement framework, it is suggested that a new procurement professional body (PPB) be established. This body should be tasked with the promotion of the new procurement cadre and should replace the NBMM as the certifying body for professionals working with procurement. The PPB should also be responsible for procurement training in close cooperation with the RA. The establishment of the PPB might be carried out by way of transforming the current NBMM, and the mission learned that the NBMM is already contemplating a change in focus as well as in name - to the "National Board of Procurement and Supplies. However, the mission would stress the importance of ensuring that a truly new organisation and vocation is created and that it is not merely a question of "pouring new wine in old bottles". 
- The mission recommends that a new cadre of procurement specialist replace the supplies officers within the public service system to the widest possible extent. This should be done gradually while phasing out the supplies cadre. The appointment of procurement specialists should be based on a certification ensuring that the specialists are fully familiar with the provisions and procedures of the PPA, and the procurement specialists should be eligible for career development and promotion based on merit as part of the overall public service performance appraisal system. The categorisation of procurement specialists should take place within the recently reformed grading system and should be based on a thorough review of the qualifications and practical experience of the public officials currently involved in procurement.

- In addition, a new procurement professional body (PPB) should be established and replace the $N B M M$. The PPB should be responsible for the training, promotion and quality assurance of the cadre of procurement specialists. The PPB should also appoint members to the PPAA.

\section{Public Service Pay and Pay Reform}

138. The reform of public service pay is vital for the rehabilitation of Government, particularly in terms of realising improvements in capacity and the delivery of public goods and services. In the case of Tanzania, the imperative and urgency for effective reform of pay and related incentives for public servants are underpinned by two major factors. First, current salary levels, especially for the technical and professional groups, are too low to sustain an acceptable level of employee motivation and performance. The second factor that impels public service pay reform emanates from the on-going vigorous pursuit of transforming the role of the state and the national economy which implies the need for more and better performing technical, professional and managerial staff. At present the Government is, and will be increasingly so, hard-pressed to recruit and retain such personnel because its pay levels are already most uncompetitive for these cadres.

139. From the on-set the reform of public service pay was a core component of the Civil Service Reform Project (CSRP). The gross distortions and inequities in the compensation structure had led to a situation where the morale of the public servants was low and on the decline, productivity and performance were low, and absenteeism, moonlighting and corruption were growing. The CSRP was launched with two basic objectives for the pay reform: (1) to rationalise the compensation structure by making it more transparent, equitable an efficient; and (2) to enhance public servants salaries to levels consistent with satisfactory performance motivation and productivity. Considerable progress has been made towards attainment of the first objective, and compensation structures have been simplified through the elimination of some allowances and benefits and consolidation of a simplified salary structure. ${ }^{51}$ With regards to the second objective, there has been a $90 \%$ increase in average public service pay in real terms between 1993 and 2000 . In the same period the minimum salary increased from Tshs 5,000 in FY92/93 to Tshs 41,000 in

\footnotetext{
${ }^{51}$ There are now 45 grades under four scales compared with the previous 196 grades under 23 scales.
} 
FY99/00. ${ }^{52}$ However, public service pay levels remain low in both absolute and comparative terms, especially compared with salaries offered in the private sector.

140. In 1999 the Government decided on a new public service pay policy. The medium term policy goals included:

- Enhancing pay for technical and professional staff to ensure that the government has a critical mass of appropriately skilled and experienced officials to ensure efficient and effective management of the economy. To this end, the pay structure for public servants was determined in comparison to pay levels in other sectors of the economy, and the minimum basic salary for university graduate entrants was given a special rise over the subsequent three years

- Developing a special (core) professional and managerial cadre comprising highly tasked and well compensated technical and professional officers

- Equitable share of the wage bill between services groups. On the basis of job-evaluation and regrading exercises, and a strategic overview of the public expenditure framework, a framework for ensuring equitable share of the wage bill among the various public services was defined

- Sustaining Public Service staff rationalisation and efficiency measures, by reducing the number of public employees and thus reducing the overall payroll. This was (and is) done through decentralisation by transfer of roles, functions, staff and resources to local authorities and executive agencies, and rigorous application of staffing norms in the ministries and departments

- Rationalisation of donors' compensation for Public Servants. The compensation practices and other incentive schemes used by donors for public servants working in development projects and programmes were rationalised and harmonised with effect from the FY 1998/99, so that hence forth the donors will top-up the public servants pay up to the level indicated in the medium tern pay targets for the relevant grade staff. Previously the excessive salaries paid to some civil servants deployed in development programmes had caused problems and discouraged the higher paid civil servants to return to their Government posts at the comparatively very low pay. levels

- Improving personnel management system and practices, by conducting extensive evaluation and regarding exercises and introducing an objective staff appraisal system

- Introduction of performance based compensation system, by ceasing automatic promotions and payment schemes; by issuing annual performance contracts to all Government officers, which will be the basis of annual staff appraisals; and by introducing a pilot scheme for performance-related pay

- Compensation system for executive agencies and other publicly funded institutions. Executive agencies and other (non-commercial) public funded institutions were accorded autonomy to determine their own compensation system within the overall framework provided by the CSD.

\section{Selective Accelerated Salary Enhancement}

141. Of direct relevance to the suggested reform of the procurement system, and in particular to the establishment of a cadre of procurement specialist, has been the introduction of the Selective Accelerated Salary Enhancement (SASE). Through this scheme pooled donor financing under the Performance Improvement Fund (PIF) of the PSRP complements the Pay Reform Strategy to systematically accelerate the pace of salary enhancement for key personnel in line with the

\footnotetext{
${ }^{52}$ Figures provided by the CSD.
} 
medium term pay targets. SASE replaced the prior practice of donors compensating public servants through local cost compensation (LCC), i.e. without overall coordination and pay limits.

142. The SASE scheme is selective in two ways. First, it targets personnel that have the greatest impact on service delivery. Second, the scheme is being implemented in phases starting with public service ministries, departments and agencies that have developed and adopted strategies, annual operational and action plans, etc. The criteria for selection of SASE beneficiaries in the relevant ministries are guided by the Operational Guidelines. All requests have to be submitted to the Inter-Ministerial Working Group (IMWG), a coordinating body with membership from all public sector reforms, which when evaluation the application will assess, inter alia, how the ministries have selected their nominees. So far approximately 1.510 personnel in four ministries and departments, the CSD, the President's Office-Planning and Privatisation, Ministry of Finance, and Ministry of Health have accessed SASE. Another seven ministries are currently in various stages of completing requirements to join, and by July 2004 all ministries, departments and agencies are expected to be included in the scheme.

143. They criteria for obtaining SASE support are:

- Positions with greatest impact on service delivery or quality strategic government outputs

- Valuation of the post as determined by the job-evaluation and re-grading exercise

- Degree of difficulty in attracting and retaining personnel in the specified posts and

- Location factor related to remoteness of specified posts or the extent to which the post supports the delivery of services in districts.

144. The SASE is of direct relevance to the establishment of an estimated cadre of procurement officials within the public service, as the scheme may be used to compensate and attract qualified individuals to some of the posts of procurement specialist. As the procurement specialist will be involved in the handling and disbursement of large public sums, it is important that they are duly compensated in order to avoid temptations of misbehaviour. Also, if procurement is to pose and attractive profession for the brightest individuals, the compensation provided will have to signal this.

It is recommended that the SASE scheme be utilised to ensure proper salary levels for key procurement professionals. This should be done within the on-going public pay reform and be linked to the suggested up-grading and certification process.

\section{Capacity Building Measures}

145. Currently the training offered to civil servants in public procurement is at best very sporadic and for the most non-existing. Almost everyone interviewed by the mission pointed to the lack of 
training and training options as a major problem. The implementation of the proposed procurement reforms is expected to generate an extensive demand for procurement training over and above the already limited availability, and the Government need to address this issue by implying both short, medium and long term measures.. Training for the reform of public procurement will not only cover the rules and regulations, it will also involve changes in ethical and cultural ways of doing procurement. Future procurement training should also include anticorruption measures as further deliberated below. On the short term, two immediate actions are suggested:

- First, a training needs assessment (TNA) should be conducted covering all tiers of Government including parastatals and all relevant specialised bodies (such as the CTB, PCB the Auditor General, etc.). The TNA must assess and specify the current capacity and the needs for capacity building within each institution, and will be crucial in the design and further development of a sound training programme

- Secondly, a survey of potential training institutions must be carried out. The mission visited a number of training institutions and obtained much material and information on already provided and planned procurement training. An overview of the training institutions is presented below. However, in order to ensure the involvement of the most capable institutions a thorough review should be carried out.

Figure 8 provides an overview of current procurement training institutions. 
Fig. 8: Overview of Procurement Training Institutions

\begin{tabular}{|c|c|c|c|c|c|c|c|c|c|}
\hline 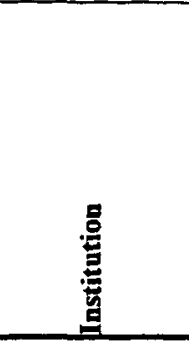 & 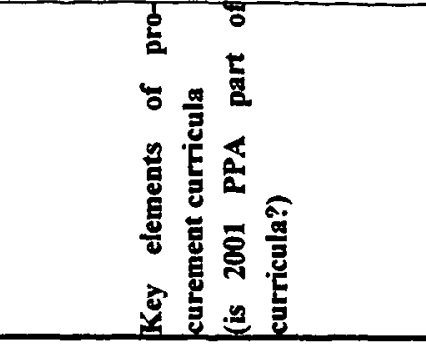 & 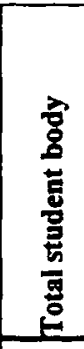 & 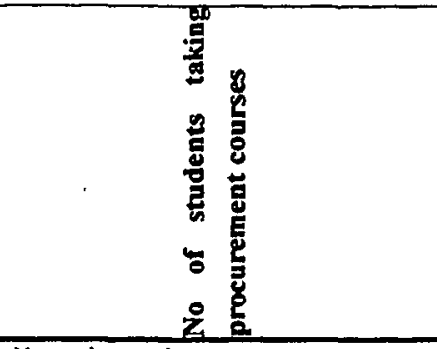 & 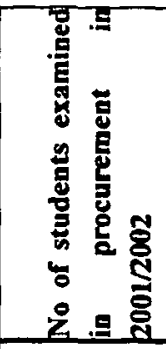 & 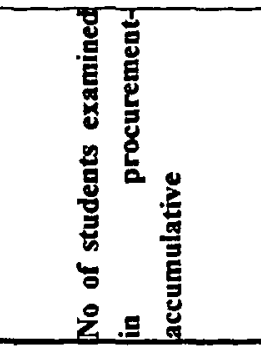 & 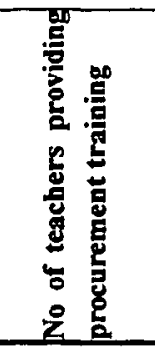 & 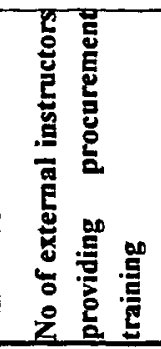 & 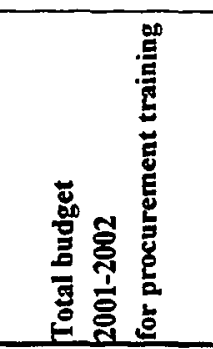 & 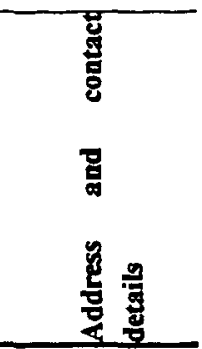 \\
\hline $\begin{array}{l}\text { National } \\
\text { Construction } \\
\text { Council }\end{array}$ & $\begin{array}{l}\text { Procurement of Engineering and Civil } \\
\text { Engineering Works. Training on PPA } \\
\text { is included }\end{array}$ & 502 & $\begin{array}{l}\text { No student at the moment } \\
\text { Courses are run when the need arise } \\
\text { and when government funds are } \\
\text { available }\end{array}$ & 40 & 164 & 4 & 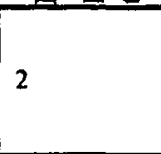 & Tsh $18,000,000$ & $\begin{array}{l}\text { P.0. Bi } \\
70039 \text { DSM } \\
\text { Julius Mamiro } \\
0741212414\end{array}$ \\
\hline $\begin{array}{l}\text { National Board } \\
\text { for Materials } \\
\text { Management }\end{array}$ & $\begin{array}{l}\text { Inventory Management, Physical } \\
\text { distribution, Purchasing Techniques } \\
\text { PPA is not included in the current } \\
\text { syllabus. The Board is writing a new } \\
\text { syllabus that include the act }\end{array}$ & 2657 & $\begin{array}{l}\text { Nil } \\
\text { The board is currently on supervisory } \\
\text { and regulatory functions. }\end{array}$ & 2924 & $\begin{array}{l}\text { Up to May '02 } \\
41.962\end{array}$ & $\mathrm{~N} / \mathrm{A}$ & N/A & Nil & $\begin{array}{l}\text { P.O. Box } \\
\text { 5993 DSM } \\
\text { C..Tesha } \\
0741337427\end{array}$ \\
\hline $\begin{array}{l}\text { Institute of } \\
\text { Procurement } \\
\text { and Supply }\end{array}$ & $\begin{array}{l}\text { Planning, legal aspects, public } \\
\text { procurement act, tender documents } \\
\text { and evaluations }\end{array}$ & 40 & 40 & 52 & $\begin{array}{l}\text { Nil } \\
\text { No Institution }\end{array}$ & 8 & 2 & Tsh $80,000,000$ & $\begin{array}{ll}\text { P.O. } & \text { Bi } \\
31141 \text { DSM } & \\
\text { Dr Masaburi } \\
0744434412\end{array}$ \\
\hline $\begin{array}{l}\text { Business } \\
\text { College }\end{array}$ & $\begin{array}{l}\text { Purchasing Techniques, Inventory } \\
\text { Management, Warehouse and } \\
\text { Distribution. PPA has not been } \\
\text { incorporated Management }\end{array}$ & 1104 & 05 & 01 & 8102 & 03 & 02 & Ths $8,500,000$ & $\begin{array}{l}\text { P.O. } \\
1968 \text { DSM } \\
\text { Mr Hyera } \\
0741331706\end{array}$ \\
\hline TIA & $\begin{array}{l}\text { Purchasing Techniques, Inventory } \\
\text { Management, Warehouse and } \\
\text { Distribution Management PPA has } \\
\text { not been incorporated }\end{array}$ & 83 & 83 & 5 & Nil & 12 & Nil & N/A & $\begin{array}{l}\text { PO.Box } \\
\text { Dar es-salaam- } \\
\text { Mrs Tumwindike } \\
07483617117\end{array}$ \\
\hline CIBDS & $\begin{array}{l}\text { International Business Management, } \\
\text { International Purchasing and Supply } \\
\text { Management } \\
\text { Training on PPA provided }\end{array}$ & N/A & N/A & N/A & $\mathrm{N} / \mathrm{A}$ & $\begin{array}{l}14 \\
\text { Procurement } \\
\text { Experts ITS } \\
\text { accredited }\end{array}$ & 14 & $\begin{array}{l}\text { For MLS } \\
\text { program expected } \\
\text { Tumover } \\
\text { USD 30,960 }\end{array}$ & $\begin{array}{l}\text { P.O. Box } \\
8677 \text { DSM } \\
\text { Mr Temba } \\
0741295985\end{array}$ \\
\hline
\end{tabular}




\section{Nature of the training}

146. It is suggested that the public servants in need of training be divided into three main categories:

1. Procurement specialist: This category of public servants is to constitute the new procurement cadre, and these are the persons, who will be involved in and in charge of procurement matters on a day-to-day basis. These include the staff of the CTB and all central and local government officials who will eventually be certified as procurement specialists

2. Specialist in need of targeted procurement training: This group will comprise individuals from the specialised bodies, which do not deal exclusively with procurement, but for which it is important to maintain a high degree of knowledge and experience with procurement related matters. The group will include for example: investigators from the PCB, who will be involved in investigation of corruption offences within procurement; officials from the Auditor General, who is responsible for the procurement auditing of procurement, and prosecutors from the Attorney General's Office who will eventually be responsible for prosecuting procurement related offences, etc.

3. Public servants or others periodically involved in the procurement process: This group comprises public servants, who do not have procurement as their main activity, but who nevertheless need to become familiar with the basic principles and rules of the PPA, including the ethical standards. The category includes the members of the tender boards at both central and local government level and the various external and internal experts charged with developing technical specifications, etc.

147. In addition, there also seem to be a need for training and sensitisation of the supply side, i.e. the private sector. This training should rightly be coordinated and conducted by the sector itself and could involve organisations like the NCC or others. As part of the capacity building of the supply side it is also important to further explore the option of designing certain contracts so that they are more easily accessible for local companies.

148. As the categorisation implies, the number of people to be trained is rather extensive. For the local government level alone, an estimated 1.800 officials will be in need of training. ${ }^{53}$ During a meeting with the head of investigation of the PCB it was indicated that approximately 60 investigators would require specialised training in procurement. In order to meet the training demands it is important that the training devised be targeted, well-planned and executed in a costefficient and value for money oriented manner. It is suggested that a Public Procurement Training Strategy (PPTS) be developed by the RA. The PPTS should be designed to deliver differentiated training for the above three groups. Where the first group will be in need of detailed theoretical and practical training in all aspects of procurement, the training for the second group should be

\footnotetext{
${ }^{53}$ Estimate from the President's Office/Regional and Local Government based on 15 persons from each of the 120 Local Government Authority units.
} 
directed towards their specific needs, for instance to conduct proper investigation. For the final group, shorter and more cursory courses could be organised.

149. The PPTS should also determine the mode of training. For the third group, which will encompass a rather large group of people a Training of Trainers (ToT) programme could pose a good and efficient model. For the second group, a solution would be to include procurement as a module within the already existing educational programmes for these groups of specialised officials. For the procurement specialist it might be considered to promote the establishment in a national technical university of an MBA program in procurement, an initiative, which has proven successful in other countries faced with the challenge of building up a cadre of procurement professionals from a narrow base. Over the longer term, the training function might be coordinated or discharged by the newly created procurement professional body in coordination with RA.

It is recommended that a Training Needs Assessment and a survey of potential training institutions be conducted. This should be followed up by the development of a comprehensive Procurement Training Strategy. The Public Procurement Training Strategy should be coordinated with the overall training strategy for the public service, and should also address how training will be funded (the choice is whether funds should be held centrally, and earmarked for procurement training, or be deemed part of the general training votes held by departments). In addition, the RA should maintain coordination functions over the training. A long-term measure should be the establishment of an $M B A$ program in procurement.

\section{Summary of Recommendations Regarding Organisation and Resources}

\section{Short term}

- Establish the Regulatory Authority (RA) as an autonomous regulatory body reporting directly to the Minister of Finance

- Decentralise procurement to ministerial level

- Change legal framework to include private sector representatives and representatives from the Procurement Professionals' Body (PPB) in the Public Procurement Appeals Authority (PPAA)

- Appoint members of PPAA and ensure that it becomes operational

- Provide RA full monitoring and supervisory powers vis-à-vis local government procurement

- Transform supplies units into procurement management units

- Conduct training needs assessment

- Conduct survey of potential training institutions

- Develop Public Procurement Training Strategy. 


\section{Medium term}

- Establish Information Management System linking RA with procuring entities

- Establish a new cadre of procurement specialists while phasing out supplies officer cadre.

- Conduct certification of procurement specialists

- Conduct information campaign on the new institutional set-up within procurement

- Develop initiatives for civil society involvement in procurement monitoring

- Replace National Board of Materials Management with PPB

- Introduce Selective Accelerated Salary Enhancement (SASE) scheme for key procurement staff

- RA coordinate and ensure quality of procurement training

- Implement procurement training programme targeting both public and private sector.

\section{Long term}

- Close Government Stores and introduce system based on framework agreements

- Establish MBA program in procurement

- Close Medical Stores Department and introduce framework agreements 


\section{4. AUDIT AND ANTI-CORRUPTION MEASURES}

\section{Corruption in Procurement}

150. It is generally recognised that corruption is widespread within the public procurement sector in Tanzania. ${ }^{54}$ The mission learned that corruption takes place during the process of selecting the contractor, consultant or vendor as well as during contract administration. Most people interviewed cited corrupt malpractices in the selection of consultants, appointment of suppliers, pre-qualification of contractors, tender evaluation, contract award, issuing variation orders, evaluation of claims, dissemination of information, certifying and making payments. Reportedly there is some variation as to where corruption in public procurement occurs. However, local government was identified as the area most infected by corrupt practices, whereas the CTB was generally viewed as a non-corrupt body.

151. The low salaries of public employees are commonly seen as a contributing factor to the corruption in public procurement. Also, public accountability is typically weak in the civil service and some parastatals. This is partly due to the opportunities created by monopoly of power and wide discretionary powers that some civil servants enjoy. The weak public accountability also results from lack of enforcement of the laws and principles of ethics. The institutions charged with enforcement and watchdog organizations that provide information on which detection and enforcement are based are weak and need to be strengthened to enable them to perform this complex task.

152. It is estimated that at the national level about 20 percent of the government expenditure on procurement is lost through corruption, mainly through kick-backs and bogus investments that have to be written off. ${ }^{55}$ Considering that public procurement accounts for about 70 percent of the entire government expenditure budget ${ }^{56}$, this translates to a loss of TShs 300 billion (USD 300 million) per year, enough to finance the combined annual recurrent budgets of the ministries of health and education. Clearly such a loss is economically unsustainable. Major losses occur in construction and supply contracts, which are the major avenues for corruption, particularly at the local government level. ${ }^{57}$

\footnotetext{
\$4 This is evident from the Report of the 1996 Presidential Commission of Inquiry Against Corruption, popularly known as the Warioba Report and the more recent Annual Report on the State of Corruption in Tanzania by ESRFFACEIT (Final Draft Report, Oct. 2002)

${ }^{55}$ S.J. Chavda, Challenges and the way forward in combating comption in the construction industry in Tanzania. Proceedings of Ministry of Works Workshop on Comuption Prevention in Construction Industry - April 2001.

${ }^{56}$ Tanzania's total annual expenditure budget is estimated at app. Tshs 2,0 trillion (equivalent to USD 2 billion). According to the NAO about Tshs $1,400-1,500$ billion or just over $70 \%$ is expended annually by the Government through public procurement.

${ }^{57}$ Current research by PCB reveals unaccounted losses of up to 60 percent in some construction projects.
} 
153. Transparency International (TI) has consistently ranked Tanzania among the most corrupt countries in the world. ${ }^{58}$ However, there has been a significant improvement in this ranking during the past five years (1998-2002) both in relative terms (ranking in relation to other countries) and qualitative terms (with the quantitative score improving from 1.9 in 1998 to 2.7 in 2002). Although TI warns against overstating the significance on year-to-year comparisons, it is significant to note that longer term trends in the scores are encouraging.

154. This positive development is cited to three main reasons. Firstly, most government ministries have taken deterrent measures to identify corrupt elements and expose or retire them "in public interest". 59 Secondly, the government has demonstrated a long-term commitment to eradicate corruption. In November 1999, the National Anti-Corruption Strategy and Action Plan (NACSAP) was issued by the Presidents Office. Combating corruption in procurement is one of seven priority areas of the NASCAP. Thirdly, there is increased awareness by the general public of the debilitating effect of corruption to the national economy. The general public knows that corruption diminishes public revenue, undermines fair trade, frustrates economic development and increases human suffering.

\section{Auditing}

155. Auditing of public procurement is exercised by the National Audit Office (NA.O). The NAO is an independent agency under the Ministry of Finance as described in the Public Finance Act (PFA) of 2001. The NAO is headed by the Controller and Auditor-General, who is appointed by the President. ${ }^{60}$ According to the PFA, the Controller and Auditor-General is responsible for auditing of all public expenditure $e^{61}$ and shall report on this to the National Assembly. The reports are to be submitted via the Minister of Finance. ${ }^{62}$

156. As a relatively new measure, ${ }^{63}$ the PFA requires the NAO to conduct value for money audits for the purposes of "establishing the economy, efficiency and effectiveness of any expenditures or use of resources by any Ministry of department". In addition, the NAO is urged to make recommendations to the Minister of Finance with the purpose of: preventing or minimising unproductive expenditure of public money; maximising the collection of public revenues; and averting loss of public resources by negligence, carelessness, theft, dishonesty, fraud, and corruption.

\footnotetext{
${ }^{58}$ Transparency International Comption Perceptions Index 2002

59 During the period 1996-2001, the Ministry of Works alone retrenched 755 employees and four were sent to court. Other institutions that retrenched or dismissed a large number of staff on allegations of corruption are the Tanzania Revenue Authority and the Police Force.

${ }^{60}$ PFA Article 26 (1)

${ }^{61}$ PFA Article 30 (1)

${ }^{62}$ PFA Article 30 (2)

${ }^{63}$ Introduced with the latest revision of the PFA in 2001, PFA Article 33.
} 
157. In recent years the NAO has received increased funding from the GoT to match its comprehensive powers and duties. However, it is widely recognized that the NAO still lacks capacity and skills for procurement auditing, with the result that auditing of public procurement is less comprehensive than may be necessary to ensure a high degree of compliance with the PPA and to combat corruption effectively.

Recommendation: In order to conduct adequate compliance auditing, it is essential that efforts of the NAO be strengthened. The auditing task is enormous and will increase as a result of the decentralization of administrative processes to regional and local government authorities. Therefore, the need to strengthen procurement audit capacity requires the urgent attention of the GoT. It is also important that the frequency of audits by NAO be increased and their scope widened. Ministries and other government agencies also need to strengthen their own internal controls and audit functions.

\section{Institutional Set-up for Fighting Corruption in Procurement}

158. The key government institutions responsible for combating corruption in Tanzania are: the PCB; the President's Office through the Ministry of Good Governance; the Ethics Commission; the Ethics Secretariat within the CSD and the CSD itself. Other government institutions playing a key role in the fight against corruption are the already mentioned NAO; the Commission for Human Rights and Good Governance; and the Director of Public Prosecution. These institutions are briefly described in more detail in Annex $\mathrm{V}$, which contains a detailed report on anticorruption measures with respect to public procurement.

159. A central issue, however, is the role of the RA vis-à-vis the above mentioned institutions, especially the PCB and the NAO. As illustrated below, the suggested monitoring and oversight mandate of the RA fits well into the already established institutional set-up. 
Fig. 9: Mandate and functions of key oversight institutions

\begin{tabular}{|l|l|}
\hline Institution & Mandate and functions \\
\hline RA & $\begin{array}{l}\text { Monitors the procurement environment in order to implement } \\
\text { proactive and/or corrective measures when necessary. The } \\
\text { monitoring ensures that rules and procedures are adhered to, } \\
\text { including the anti-corruption provisions of the PPA. If breaches of the } \\
\text { PPA anti-corruption provisions are detected, the RA should be } \\
\text { required to inform the PCB. Also, the RA shall subsequently assist } \\
\text { the PCB in its investigative efforts. }\end{array}$ \\
\hline PCB & $\begin{array}{l}\text { Investigates corruption offences within public procurement. When } \\
\text { investigation determines breach of the anti-corruption provisions of } \\
\text { the PPS, the PCB will refer the case to the Director of Public } \\
\text { Prosecution. }\end{array}$ \\
\hline NAO & $\begin{array}{l}\text { Conducts auditing of procurement with focus on both financial audit } \\
\text { but also issues of contract management, etc. In doing so, the NAO } \\
\text { shall be assisted by the RA, which due to its monitoring and } \\
\text { information gathering efforts, should be in a position to direct the } \\
\text { NAO towards cases in need of particular scrutiny. }\end{array}$ \\
\hline
\end{tabular}

160. The PCB and NAO have already taken the initiative to establish joint teams, which investigate corruption offences in procurement. It is suggested that the RA is involved in this initiative. Likewise, a technical audit unit for public procurement, the Contract Unit was established within the NAO in 2001. The auditors in this unit have all received targeted training in procurement auditing. At present a new unit, which will focus on value for money auditing, is being established. It is suggested that ways of cooperation between this unit and the RA are further explored.

In order to pool effort and expertise and thereby strengthen the overall monitoring and control, it is recommended that joint teams between the $R A, P C B$ and $N A O$ are established.

\section{Legal and Strategic Framework}

The Prevention of Corruption Act

161. The Prevention of Corruption Act (PCA) of 1971 provides the overall legal framework for anti-corruption interventions in Tanzania. The PCA has been amended on a number of occasions. One of the more important amendments was adopted in 1990 with the establishment of the PCB as an independent agency under the Office of Minister for Good Governance in the President's Office. The mission was provided with a document drafted by the PCB suggesting additional amendments to the Act, and these suggestions are briefly commented on below. 
162. The PCA in its present form contains four main parts: (i) Preliminary Provisions, providing definitions and interpretations; (ii) Prevention of Corruption Bureau, establishing the PCB; (iii) Corruption offences; and (iv) Miscellaneous Provisions, addressing issues such as burden of proof, special rules of evidence, powers of the Director General to authorise search and to prosecute, recovery of corruptly acquired assets, etc. The amendments suggested by the PCB add an extra chapter on electoral corruption practices.

163. The amendments suggested by the $\mathrm{PCB}$ contain a number of provisions of relevance to corruption within procurement. Below these amendments are listed, and the mission's comments added in italics. The amendments include provisions:

- Defining the power of the officers of the PCB, suggesting that the powers equal those of police officers above a certain rank

- Expanding the provisions on corrupt transactions, including bribery in procurement procedures, including contract award, withdrawing of tenders, and tender award. Notably the terminology used differ somewhat from the PPA, and it is suggested that standard procurement terminology is incorporated into the suggested amendments

- Expanding the provisions on public disclosure of assets by public officers

- Tightening the provisions on possession of unexplained property, which presuppose the commitment of an offence when the standard of living of a public servant exceeds present and past income

- Providing for penalty confiscation of assets acquired in a corrupt manner

- Defining the penalty for acts committed in conflict of interest

- Penalising abatement of corrupt actions and conspiracy

- Reversing the burden of proof, leaving the burden of proving any defence on the accused. This measure seems too excessive and in contradiction with established human rights principles warning against reversal of burden of proof in penal cases

- Confirming that local traditions and customs, as well as professional traditions and customs may not excuse breaches of the PCA

- Providing extensive protection of informers (whistleblowers). These provisions in fact seem too extensive, leaving little room for the accused to build a proper defence

- Empowering the courts to prohibit certain employment of up to seven years' duration of a person convicted of a corruption offence.

Overall, the Prevention of Corruption Act including the amendments suggested by the PCB provides a comprehensive framework for combating corruption. It is, however, suggested that certain suggested amendments be revoked or reformulated in order to avoid breach of fair trial principles.

The National Anti-Corruption Strategy and Action Plans

164. The NASCAP launched by the Government in 1999 was a result of a comprehensive consultative process. It recognizes that combating corruption requires a holistic approach that 
involves institutional reforms, coalition building and raising public awareness. The strategy identifies seven priority areas, including procurement:

- The Rule of law and legal framework: This component is intended to facilitate sector laws review and create conditions necessary for restoration of confidence in the judiciary and law enforcement agencies

- Financial discipline and management: The intention here is to reduce or eradicate siphoning of public funds by unfaithful officials and increase revenue collection to enable the financing of social services and facilitation of economic growth.

- Procurement: The intention is to ensure strict adherence to and transparent adrninistration of tendering and procurement procedures.

- Public education, awareness and sensitisation of their rights: To develop education programmes and create awareness of how corruption harms the economy and ultimately transforms the fabric and values of society.

- Public service reform (capacity building): To recognize that public officers are not "masters" but "servants" accountable for their actions and who, therefore, deserve a fair remuneration package.

- Whistle blowers and witness protection: Cognizant of the fact that informers and citizens who come forward to the law enforcement agencies and report on corruption incidences need to be protected, a programme would be developed to encourage citizens to cooperate.

- Media: To report corrupt elements without fear or favour and to publicize the harm they do to the innocent, the poor and the weak in Tanzania.

165. For each priority area, the strategy has identified several key actions to be undertaken in the short and medium-term by both the government and civil society. With respect to procurement there are 18 such actions and a number of these have already been or are being implemented. ${ }^{64}$ It is pertinent to note that the enactment of the PPA is considered one of the most important achievements of the strategy with respect to combating corruption in procurement. However, the challenge remains to put into practice and ensure implementation of the institutional and legal framework established by the PPA. The recent review conducted by ESRF-FACEIT ${ }^{65}$ identifies extensive misconduct and breaches of the PPA in the processing of tenders. This matches the observations of the CPAR mission. As already mentioned, the capacity of the CTB and the procuring entities to deliver efficient and high quality services is low due to shortage of qualified procurement staff. Furthermore, participation of the civil society in the government procurement process is needed in order to enhance fairness and transparency. The latter issue is addressed in more detail below.

\section{Review of Anti-Corruption sector strategies}

166. After the adoption of NACSAP all government ministries, as well as key government departments and agencies, were directed to prepare anti-corruption plans for their respective

\footnotetext{
${ }_{65}^{64}$ See Annex $V$ for a full overview of the actions planned for the public procurement sector.

${ }^{65}$ See note 55
} 
ministries, departments and agencies. These plans were published in September 2001 as NACSAP $(2001-2005)^{66}$ and cover 22 government ministries and four independent departments: the Civil Service Department, the Judiciary, the PCB and Tanzania Revenue Authority. NACSAP (2001 2005) does not contain action plans for local government authorities, as these plans are still under preparation. Implementation of the sector strategies is the responsibility of the sector ministries.

167. A review of the sector strategies reveals that corruption in procurement is identified as a problem within 14 government ministries and offices. ${ }^{67}$ Some of these ministries, notably those responsible for works, health and education, handle large procurement volumes per year. The corruption problems in procurement encountered by these ministries and offices relate to noncompliance with or abuse of procurement procedures, lack of transparency, loopholes/weaknesses in the procurement system, inefficiency, poor contract specifications and poor contract administration. In order to curb corruption some of the actions planned are to strengthen enforcement of procedures, strengthen staff capacity, enhance transparency and strengthen financial auditing.

168. The Permanent Secretaries of sector ministries report to the Chief Secretary through the Good Governance Coordination Unit (GGCU) on implementation of sector strategies and action plans. According to the GGCU, some progress has been made in the implementation of the respective sector action plans, albeit the infancy of the plans makes it is still too early to provide a proper impact assessment.

\section{Ethics and Integrity}

169. There are currently two sets of ethics rules governing public servants on Tanzania: the Code of Ethics and Conduct for the Public Service directed towards all public servants and the Leadership Code of Ethics ${ }^{68}$ addressed specifically to public service managers. An Ethics Commissioner heads the Civil Service Ethics Secretariat, which has the mandate to enforce the Leadership Code of Ethics. The Leadership Code applies to a specified group of public leaders and politicians, who must declare assets and liabilities on a regular basis, and also declare the source of their assets. The declared information is kept in a register, and a member of the public can upon written request to the Ethics Commission be allowed to review the declaration.

170. The Ethics Inspectorate within the CSD is primarily involved in the education and issues of ethical conduct among lower level public servants and non-government actors. The Inspectorate

\footnotetext{
${ }^{66}$ United Republic of Tanzania. The National Anti-Corruption Strategy and Sector Specific Action Plans for All Ministries and Independent Government Departments (2001-2005). Issued by the State House, President's Office (Sept. 2001).

${ }^{67}$ These are the ministries responsible for works; defence; health; education; agriculture; communication and transport; finance; foreign affairs, lands, energy and minerals; planning; water; science and technology; Vice President and Prime Minister's Offices.

${ }^{68}$ The Leadership Codes of Ethics is codified by law in the Public Leadership Code of Ethics Act of 1995
} 
has drafted and distributed the Code of Ethics and Conduct for the Public Service, which address such issues as: respect of human rights; diligent and disciplined performance; promotion of team work; excellence in service; responsibility and good stewardship; promotion of transparency and accountability; integrity; and political neutrality. Important provisions also of relevance to public procurement include the safeguarding of public property obliging the public servant to ensure that no damage, loss or misappropriation of public property occurs; the obligation of public servants to declare property when so requested; the prohibition against accepting bribes and excessive gifts; and the obligation to avoid situations of conflict of interest.

171. The greatest weakness of the Code of Ethics and Conduct for the Public Service lies in the lack of disciplinary measures and procedures. Thus, the code does not provide any information on ways of addressing misconduct and no review or appeals mechanisms are instituted. Instead breaches of the rules set forward are referred to the "Public Service Act, the National Security Act, the Prevention of Corruption Act or any other relevant law." This omission leaves that code of ethics as a rather weak instrument, and it is suggested that disciplinary measures are incorporated directly into the Code of Ethics and Conduct for the Public Service.

172. On a more specialised level and of direct relevance to public procurement is the Code of Conduct for Registered Materials Management Professionals issued by the NBMM. This code of conduct outlines the duties and responsibilities of registered material management professionals. It includes such measures as: the duty to maintain an unimpeachable standard of integrity; the duty to avoid any arrangement which might in the long-term prevent effective operation of fair competition; the prohibition to use information obtained in the line of duty for personal gain; the prohibition against arrangements which might prevent competitive bidding and unfair advantages to certain bidders; the prohibition against bribery and acceptance of gifts: etc. The code of conduct further establishes disciplinary measures, which include payment of fines and exclusion. A two-tier review mechanism is installed with the Ethics and Disciplinary Committee of the Board and the option of appeal to the Appeals Board.

173. While the Code of Conduct for Registered Materials Management Professionals serves as a well-developed standard for self-regulation, it is nevertheless recommended that the Code be replaced with a comprehensive ethics code for the new procurement profession. Such a code will serve as an important building block in establishing the new cadre as a profession within and beyond the civil service. It is important that the new code of ethics addresses ethical issues within all aspects of procurement and that disciplinary and enforcement measures are provided for.

It is suggested that disciplinary measures and procedures are incorporated in the
Code of Ethics and Conduct for the Public Service. It is further recommended that
a new code of ethics for public procurement professionals be drafted and its
content widely disseminated.




\section{Training}

\section{Training of $P C B$ investigators}

174. In an effort to ensure sufficient and efficient staff the PCB has employed a large number of new staff (about 300 new staff) during the past three years. Most of these employees were recruited as graduates with neither specific training nor experience relevant to their responsibilities in PCB. They therefore require substantial training. Currently the PCB has an inhouse orientation programme to familiarize newly recruited staff with their specific duties in the PCB. The programme comprises seminars, workshops and short courses focussing on organisational, administrative and investigative aspects of Bureau tasks. Some staff members have also received specialist training at the post-graduate level in selected institutions abroad in the areas of anti-corruption and investigation. However, such training is limited by the shortage of funds. In addition, very few PCB staff are familiar with corruption issues within procurement. The Bureau has therefore indicated an urgent desire to have a core group of about 60 investigators trained in procurement. The training required by the PCB should cover basic procurement principles and procedures and should integrate both technical and legal aspects of procurement. A proper understanding of basic procurement principles and procedures will enhance the skills of PCB staff in investigating corruption in procurement.

A specialised training scheme for PCB investigators should be developed in cooperation with the $R A$. The training should aim at providing a core group of $P C B$ investigators with both technical and practical tools for the investigation of procurement corruption. The option of involving a core group from the Prosecutors Office should also be explored.

\section{Monitoring}

\section{Monitoring public procurement - the involvement of civil society and the media}

175. In many countries the involvement of civil society, the media and the general public in the monitoring of public procurement has served as an important early warning and awareness raising mechanism. This section describes some of the elements, which may be considered for improving third sector involvement in public procurement in Tanzania. Where applicable, examples of specific actions taken are provided. 


\section{Access to information}

176. An important prerequisite for civil society and media monitoring of public procurement is the possibility of obtaining timely and reliable information about the procurement process. This requires that as much information as possible is made public and that publication is made without delay and in manner, which makes it easy accessible, also to interlocutors outside the government system. The mission noticed a general lack of adherence to the publication requirements of the PPA, especially with regards to the publication of contract awards.

177. A broader legal framework determining the rights of citizens to obtain information from the public sector is lacking. A draft Freedom of Information Act has been developed as part of a media law reform project. ${ }^{69}$ However, the act has not yet been passed by Parliament. The PPA Procurement of Goods and Works Regulations, Article 20 determines the right of "any person" to obtain information describing (briefly) the goods or works to be procured, and the names and addresses of pre-qualified suppliers or contractors during any stage of the procurement process.

\section{Example: Licitenet.com, Ecuador}

In Ecuador the national chapter of TI has developed an online database to inform the public about the process of public procurement in the country. The initiative is formed jointly by the private sector and civil society. A number of public institutions also assisted in the development of the database, including the State Attorney General and the Association of Municipalities. The general objective of the Licitinet database was to establish a website portal from which citizens can monitor the acquisition of goods and services by the public sector. Licitinet provides information on different procurement processes: current, closed and pending. A search can be made based on the date of bidding; name of the institution issuing the tender; place of execution; type of project or service; type of contract; or type of participant.

\section{Example: Russian Regional Integrity Initiative}

In Russia the national chapter of TI has developed a local integrity system, focusing on access to information, codes of conduct for public officials and public procurement. The integrity system is implemented in two model communities. The initiative is combined with a training programme for governmental institutions.

\section{Building capacity of NGOs}

178. Several of the people interviewed during the mission pointed to the lack of capacity among local NGOs as a deterring factor for civil society involvement in monitoring public procurement. At present the group of NGOs working in the area of anti-corruption is very limited and includes organisations such as the Tanzanian chapter of $\mathrm{TI}$, which is generally perceived as being weak and hampered by internal conflicts; FACEIT, which is also low in capacity; and the Economic and Social Research Foundation (ESRF), which is perceived as well-functioning and capable but

\footnotetext{
${ }^{69}$ Misa-Tan - Media Law Reform Project. The project has revised and developed draft legislation in a number of areas: Freedom of Information Act; amendments to the Broadcasting Services Act, 1993; Defamation and Privacy Act: Protection of Sources Act, 2002; amendments to the National Security Act, 1970; as well as a number of constitutional amendments relating to the media.
} 
over-stretched with work; etc. Most of the NGOs are based in Dar es Salaam with limited outreach and operation in the regional and rural areas. In addition, none of the NGOs encountered have developed particular activities targeting public procurement, and none had planned to do so.

Example of NGO activities: Guidelines and analysis of Public Procurement in Slovakia

In Slovakia, TI has established a working group on public procurement. The outcome of activities of this group is a practical instruction brochure for procurers and applicants in the system of public procurement "How to proceed in the public procurement process," as well as an analysis of the current system of public procurement - "Public procurement in Slovakia - some thoughts for further development."

\section{Involving the media}

179. The involvement of the media in creating public awareness on corruption constitutes one of the seven pillars of the NACSAP. The media serve as an important watchdog in exposing the negative effects of misconduct and corruption within procurement. Also, the media may serve as an important partner in efforts to strengthen public awareness on procurement issues. Unfortunately, the Tanzanian media are presently not fulfilling the watchdog role. The 2002 State of Corruption Report ${ }^{70}$ confirms that sound investigative journalism on corruption is very limited, likewise with procurement related journalism. Few of the media houses are even aware of the NACSAP, and among journalist the knowledge of procurement is virtually non-existing. This situation should be alleviated by the introduction of procurement training specifically designed for the joumalists. Ideally, procurement could constitute a module within a broader training programme on investigative journalism.

\footnotetext{
${ }^{70}$ See note 55 above.
} 


\section{Introducing whistleblowing mechanisms}

180. Whistleblowing is the popular term for the act of raising a concern about malpractice within an organisation. When introducing whistleblowing mechanisms focus remains on the responsibility of workers or citizens in general to raise concerns about malpractice, and the responsibility of those in charge to investigate and remedy such issues. As a means of allowing and encouraging citizens to blow the whistle on malpractices within public procurement, it is suggested that a hotline be established. The hotline could be operated by the RA or by the PCB, which already has a broader corruption hotline. Another, and often overlooked aspect, of whistleblowing is the protection and rights of the whistleblower and the introduction of a sound whistleblowing culture, where the whistleblower is seen as a witness and not as a complainant. The suggested amendments to the Prevention of Corruption Act prepared by the CTB include several provisions of protection of whistleblowers. ${ }^{71}$

\section{Example: The UK Public Interest Disclosure Act}

The UK Public Interest Disclosure Act came into force on 2nd July 1999. It encourages people to raise concerns about malpractice in the workplace and will help ensure that organisations respond by: (i) addressing the message rather than the messenger; and (ii) resisting the temptation to cover up serious malpractice. Through protecting whistleblowers from dismissal and victimisation in the following circumstances, the Act promotes the public interest.

The Act can be downloaded from the homepage of the British NGO Public Concern at Work, which is specialised in public interest whistleblowing: www.pcaw.co.uk

\footnotetext{
${ }^{71}$ However, as stated above, these suggestions seem to leave little for the accused to build his defence on as they do in fact prevent disclosure of relevant information to the accused. Thus, before adopting the suggestions by the PCB a proper analysis of the human rights aspects of such extensive protection of whistleblowers should be assessed.
} 
It is recommended that:

- the draft Access to Information Act be adopted within the nearest future. The Act should be widely disseminated among public servants, the media and civil society, and special joint training sessions introducing and explaining the consequences of the act should be organised for public servants and the media

- a capacity building scheme for involving NGOs in public procurement monitoring is developed and supported by the international donor community. The scheme must be designed to empower NGOs at both central and local level to understand and engage in the procurement processes. The scheme should include measures for introducing NGO staff to public procurement. It could also include a grant facility for procurement related projects within civil society

- a procurement training module for journalists be developed as part of a broader training scheme on investigative journalism

- a hotline for disclosure of misconduct within public procurement is established at the RA or is incorporated in the already existing corruption hotline operated by the PCB

- a legal framework protecting whistleblowers is introduced, while still respecting the human rights principles concerning fair trial

- a general information campaign about the responsibility and avenues of disclosing information on violations of the procurement procedures is implemented across Tanzania.

\section{Performance Indicators to Monitor Corruption in Procurement}

181. In February 2002 the GGCU of the President's Office issued a report on "Strategic Indicators for Monitoring Cross-Cutting Governance Trends. This report includes a series of indicators for monitoring public procurement developed by the GGCU with assistance from the World Bank:

1. Number and percentage of contracts awarded using methods that are less competitive than those set out in the approved procurement plan.

2. Total value of contracts awarded using methods that are less competitive than those set out in the approved procurement plan, and their value as a percentage of all public contracts awarded.

3. Number and percentage of public Contracts awarded without a bidding Procedure.

4. Total value of all public contracts awarded without a bidding procedure, and their value as a percentage of the total value of all public contracts awarded.

5. Number and percentage of approved contract variations that exceed the thresholds set out in the Public procurement Regulations

6. Total value of approved contract variations that exceed the thresholds set out in the Public Procurement Regulations, and their value as a percentage of the total value of the contracts to which they are related.

7. Number and percentage of contracts terminated early by MDAs after payments were made but before goods and services were delivered. 
8. Total value of payments issued against contracts terminated early by MDAs before goods and services were delivered and the value of this amount as a percentage of the total value of the contracts to which they are related.

9. Number and percentage of contracts abandoned by contractors after payments were received but before goods and services were delivered.

10. Total value of payments issued against contracts abandoned by contractors before goods and services were delivered, and the value of this amount as a percentage of the total value of the contracts to which they are related.

182. Annual reports on these indicators are to be forwarded by each MDA to the GGCU, which will then compile regular reports. However, the mission learned that the indicator reporting is not yet taking place.

183. The ten indicators provide quantified information in terms of number, value and percentage of: contracts awarded outside of normal bidding procedures; contracts awarded using less competitive methods than those set out in the approved procurement plan; contract variations that exceed threshold figures set out in the public procurement regulations; payments issued against terminated contracts before goods and services were received; and contracts abandoned by contractors after payments were made but before goods and services were received. Together the ten indicators provide an overall comprehensive picture of the performance of the procurement system in a specific organization. However, the focus remains on contractual and procedural measures, whereas there is little focus on more "soft" areas within procurement, such as training/ capacity building, and civil society involvement. Additional indicators could include:

- Number of applications to a potential procurement hotline (see below)

- Number of applications forwarded to the PCB for investigation

- Number of procurement cases prosecuted

- Number of procurement convictions

- Number of NGOs monitoring procurement processes

- Number of information activities regarding procurement being conducted

- Number of civil servants trained under the various procurement training prograrnmes

- Etc.

It is recommended that the procurement performance indicators developed by the GGCU and the World
Bank be broadened to also include indicators on investigation of procurement crimes, involvement of civil
society and training in public procurement. In addition, all the indicators should be adapted for
monitoring local government procurement. The adaptation should be carried out jointly by the RA, the
$G G C U$ and the President's Office/Regional and Local Government. 


\section{Summary of Recommendations for Audit and Anti-Corruption Measures}

\section{Short term}

- Adopt amendments to Prevention of Corruption Act as suggested by PCB. Revoke those amendments, which are in contradiction with fair trial principles

- Amend Code of Ethics for the Public Service to include disciplinary measures and enforcement mechanisms

- Adopt Access to Information Act

- Establish procurement hotline

- Strengthen the procurement audit capacity of the NAO and increase the frequency of audits.

\section{Medium term}

- Establish joint investigation and monitoring teams between the RA, the PCB and the NAO

- Develop and implement training for PCB investigators

- Draft new code of ethics for public procurement professionals

- Disseminate and conduct training on Access to Information Act

- Develop capacity building scheme for NGOs to enhance NGO monitoring of public procurement

- Introduce Legal framework for whistleblowing

- Develop and implement information campaign on procurement related whistleblowing

- Government adopt and use performance indicators on corruption in procurement

- Strengthen internal controls and audit functions of ministries and other government agencies.

\section{Long Term}

- Develop and implement procurement training for journalists. 



\section{5. PUBLIC SECTOR MANAGEMENT PERFORMANCE}

\section{Performance of the Public Procurement System}

184. The application of procurement methods is described in more detail above ${ }^{72}$, hence this chapter will focus on assessing the financial value of expenditures on public procurement and discussing the public procurement reform within the broader reform context in Tanzania.

\section{Value of procurement}

185. Because neither the MoF nor the CTB collect and publish data on the performance of the public procurement system, a reliable estimate of the value of expenditure on public procurement in Tanzania is difficult to make. However, Tanzania's total annual expenditure budget is estimated at app. Tshs 2.0 trillion (equivalent to USD 2 billion), and according to the NAO about Tshs $1,400-1,500$ billion or just over $70 \%$ is expended annually by the Government through public procurement.

\section{Public Sector Reform Programmes}

186. Since 1995, when Tanzania faced severe economic and financial crisis and a reform programme was introduced, macroeconomic stability has largely been achieved. Inflation declined from $28 \%$ in 1995 to single digits in early 1999. By June 2002, the inflation rate was down to $4.5 \%$. At the same time gross international reserves have more than doubled to reach four to five months of imports of goods and non-factor services. There has also been substantial structural reforms with a significant proportion of the 400 parastatals either privatised or divested.

187. A number of reform programmes have been ongoing in Tanzania since 1995. The programmes are primarily aimed at the alleviation of poverty through the equitable distribution of services to all sectors and sections of the community. Some programmes of relevance to procurement reform are briefly described below:

188. Public Financial Management Reform Programme (PFMRP): The PFMRP was established in 1998 to coordinate a number of complementary projects operating within the MoF. The PFMRP encompasses the Integrated Financial Management Accountability project (IFMAP), supported by SIDA. The project has focussed on establishing a financial management system in all ministries and regions; introduction of a common chart of accounts for budgeting and accounting purposes; introduction of a central payment system and establishment of effective control over expenditure commitments. The PFMRP is currently under revision with the purpose of incorporating the recommendations of the 2001 Country Financial Accountability Assessment. The CFAA made several recommendations on procurement reform, especially in the area of procurement auditing.

\footnotetext{
${ }^{72}$ Please refer to the chapter on procedures and practices
} 
189. Tax Administration Project (TAP): The Tanzanian Revenue Authority (TRA) is responsible for collection of all Government tax revenues including corporation tax, withholding tax, VAT, customs and excise duties. Collection efficiency has improved dramatically in recent years, and in the FY ending $30^{\text {th }}$ June 2002 , approximately $96 \%$ of budgeted tax revenues were collected. ${ }^{73}$ The TAP is supported by the Intemational Development Association (IDA) and several bilateral donors including DANIDA, DFID, the EU, FINIDA, GTZ, SIDA and USAID. The project aims at: increasing revenue collection without increasing tax rates; improving the legal framework; broadening the tax base; and improving administration infrastructure. Some issues of the TAP are dealt with in the section on Trade Practices as part of the chapter on Commercial Practice.

190. Public Service Reform Programme (PSRP): The PSRP is an eleven-year initiative divided into three inter-related phases. It aims at developing an efficient, performance-oriented public service operating to a published code of ethics. ${ }^{74}$ Key components of the first phase are medium term pay reform and the adoption of merit based recruitment procedures. As mentioned above, certain elements of procurement reform should be addressed under the PSRP, especially the establishment of a specialised procurement cadre.

191. Poverty Reduction Strategy (PRS): The PRS aims to address the key causes of poverty: low growth; lack of access to essential services and infrastructure; and weak governance. The PRS sets a framework, which prioritises objectives and sectors and identifies actions and their budget implications. Notably, one of the objectives of the PRS is to "minimize resource leakage and strengthen accountability". The identified actions under this objective include: to "make the Central Tender Board's results public through press release"; and "strengthen systems for more efficient cash management, procurement, payment and expenditure control, inventory, equipment and asset management, and timely audit reports".

192. Local Government Reform Programme (LGRP): The LGRP focuses on the decentralisation of the decision making process through greater empowerment of local authorities and with a strong focus on efficient and equitable service delivery. It includes five components: governance; local government restructuring; finance; human resource development; and institution and legal framework. A review of the LGRP in 2001 found that the initial timescales were too ambitious, especially in the area of fiscal decentralisation, where the MoF does not have confidence in the ability of local authorities to take over. Consequently fiscal decentralisation is now being introduced on a more gradual and selective scale in tandem with targeted financial management capacity building. The LGRP is of particular relevance to procurement reform, since some of the greatest weaknesses identified by the mission were in local government procurement. Ideally, the

\footnotetext{
${ }^{73}$ Figures originate from the draft final report for the "Revised Public Financial Management Reform Programme", Ministry of Finance, October 2002.

${ }^{74}$ For a brief review of the codes of ethics, please refer to the above chapter on Audit and Anti-Corruption Measures.
} 
majority of the reform measures suggested for local government procurement should be carried out under the auspices of the LGRP.

193. National Anti-Corruption Strategy and Action Plans (NACSAP): The NACSAP is described in detail above in chapter D on Audit and Anti-Corruption Measures. The strategy identifies seven priority areas including public procurement. Since procurement has been identified as one of the most corruption prone areas, those elements of procurement reform targeting corruption must be aligned and coordinated within the NACSAP.

194. Accountability, Transparency and Integrity Program (ATIP): The ATIP is designed as a comprehensive program, which will pool efforts and funds from a large group of donors. The Primary objective of the ATIP is to support the implementation of Tanzania's strategic framework for good governance. This will be done through: (i) strengthening the legal and judicial systems; (ii) enhancing public financial accountability; (iii) strengthening oversight and watchdog institutions (OWIs), particularly, supporting the drive to combat corruption; and (iv) improving coordination, management and monitoring and evaluation of Government's programs aimed at enhancing transparency and accountability. Procurement initiatives are funded as part of an established Project Preparation Facility, including: a feasibility study and pre-contract services associated with the refurbishment of the CTB facilities; general technical support to the CTB and more specifically for the restructuring and strengthening of the CTB and public procurement units; prepare a training needs assessment of procurement and design training course models for priority ministries. Some activities have already been implemented, including the finalisation of standard bidding documents. Another relevant aspect of the Preparation Facility relates to OWIs, which encompasses support to the PCB and capacity building of civil society organisations.

\section{Status of Public Financial Management}

195. In May 2001, the Government of Tanzania and donors jointly carried out a Country Financial Accountability Assessment (CFAA). Despite a number of significant improvements in financial accountability, the CFAA pointed to a number of deficiencies and a total of 170 recommendations were proposed. The CFAA noted that Tanzania has advanced in the areas of accounting and expenditure control, and that a sound system of formal rules for financial management has been put in place. However, the CFAA also noted that despite the improvements, the financial management framework is still characterized by:

- Inadequate macroeconomic forecasts

- Weak resource mobilisation, allocation and monitoring

- Inadequate strategy for debt management

- Expenditure base, which is too broad relative to funding prospective

- Failure to record and optimise external and internal revenue opportunities

- Low levels of public service capacity and performance 
- Inadequate financial accountability and discipline

- Weak cash planning and management

- Weak procurement procedures and practices

- Ineffective scrutiny and oversight.

196. The recommendations of the CFAA are currently being incorporated in the revised PFMRP as well as other relevant reform programmes in order to address outstanding weaknesses.

197. As for procurement a few of the recommendations of the CFAA have already been adhered to, namely the: development of Regulations of the PPA; and the preparation of procurement manual and standard documents. However, most of the recommendations of the CFAA have still not been met and are consequently repeatedly dealt with in this report. These include recommendations on capacity building measures, the establishment of a procurement cadre and development of a procurement support facility within the CTB. The fact that most of the recommendations of the CTB have not been followed up upon, may for some part be explained by the wish to wait for the detailed recommendations of the present CPAR. However, as in many other countries, Tanzanian reform efforts, may often be delayed under the pre-text of one review or the other, where sometimes reform should simply be initiated and then subject to subsequent review. In this case, the lack of follow-up on the CFAA recommendations may be seen as an indication of lack of resources and reform capacity within Government rather than the lack of political will. 


\section{C.6. E-PROCUREMENT}

198. There is no government wide information technology strategy in Tanzania. However, a communication and information strategy is included in the PFMRP and there is a management information systems component in the PSRP. A paper-based records management system is a subcomponent of this programme. This programme is aimed at improving basic record-keeping. In the longer term, it is the intention to computerise records management. These first steps of introducing information technology in a coordinated manner to the public administration could form the basis for later application of a system of e-procurement.

199. E-procurement as a term is used to describe a procurement system that utilises the possibilities created by electronic communication and office computers. As such an eprocurement system is governed by the same basic principles as a normal paper-based system. The main purpose of the system is to promote value for money in public spending, through the application of sound, transparent practices ${ }^{75}$. However an e-procurement system can offer a number of advantages over a normal paper based system of procurement. The main advantages are easy and cost effective access to information. Examples could be bidders access to advertisements, authorities access to legal documents and guidelines, and the access of oversight authorities to individual electronic procurement protocols and any documents on file.

200. It is not within the scope of this report to suggest technical solutions or promote any of the proprietary systems that are available on the market. However, for communication purposes it is presently a common viewpoint that communication through the Internet provides for a low cost and technically undemanding solution. As a consequence any computer in a public office that is connected to the Internet is ready to reap the benefits of e-procurement in its most simple forms. The Government already-has a web-site ${ }^{76}$ which could be utilised to host any Internet activities in the interim period, until a dedicated procurement web-site is established.

201. The different issues facing a country wishing to implement an e-procurement system can be outlined as follows:

\footnotetext{
${ }^{75}$ Supporting the development of e-procurement is one of the goals of the Global Procurement Agreement under the WTO. The WTO Working Group on Transparency in Public Procurement have recognized the special benefits in form of cost savings and increased transparency that e-procurement could offer developing countries, but also the barriers in form of access to the necessary technology and capacity that these countries face.

${ }^{76}$ www.tanzania.gov.tz
} 
Fig. 10: E-procurement issues

\begin{tabular}{|l|l|}
\hline Issue areas & Requirements \\
\hline Governance & $\begin{array}{l}\text { - Adapted legal framework } \\
\text { - Oversight organisation in place }\end{array}$ \\
\hline Human Resources & - Capacity to utilise system in place and well trained staff \\
\hline Institutions & $\begin{array}{l}\text { - Work flows adapted to system } \\
\text { - Uniform information(data) schemes applied } \\
\text { - Functioning market able to perform under new system }\end{array}$ \\
\hline Technology & $\begin{array}{l}\text { - Infrastructure in place } \\
\text { - Access to infrastructure established through office technology } \\
\text { - Necessary e-procurement software in place. }\end{array}$ \\
\hline
\end{tabular}

202. While access to information is the main stem of any procurement system e-procurement can be approached from different angles. The e-commerce approach includes setting up an electronic marketplace to improve the efficiency of the market and promote value for money. However, looking at the issues identified in the procurement environment of Tanzania it is evident that the more pressing problems of information dissemination and transparency should be prioritised. The different types of e-procurement systems, each with increasing level of sophistication and requirements are:

Fig. 11: Features and complexity of e-procurement systems

\begin{tabular}{|l|l|l|l|}
\hline Systems & Features & Complexity \\
\hline $\begin{array}{l}\text { slectronic information } \\
\text { system }\end{array}$ & $\begin{array}{l}\text { Supports dissemination of } \\
\text { information, monitoring and } \\
\text { statistics gathering but does not } \\
\text { offer any interactivity between } \\
\text { participants }\end{array}$ & $\begin{array}{l}\text { Low } \\
\text { Minimal } \\
\text { requirements. }\end{array}$ \\
\hline $\begin{array}{l}\text { Electronic purchasing } \\
\text { system }\end{array}$ & $\begin{array}{l}\text { Contains e-commerce features } \\
\text { such electronic formation of } \\
\text { contracts on pre-determined } \\
\text { terms. Suitable for } \\
\text { administration of large } \\
\text { framework agreements. }\end{array}$ & $\begin{array}{l}\text { Medium } \\
\text { Both technical, legal and } \\
\text { organisational requirement. }\end{array}$ \\
\hline $\begin{array}{l}\text { Electronic tendering } \\
\text { system }\end{array}$ & $\begin{array}{l}\text { Supports the entire procurement } \\
\text { cycle and eliminates the use of } \\
\text { paper entirely. Contains } \\
\text { functionality for formation of } \\
\text { complex contracts, auctioning } \\
\text { and complaints handling. }\end{array}$ & $\begin{array}{l}\text { High thorough legal and } \\
\text { and annot be seen outside the } \\
\text { organisational reforns that } \\
\text { cannot mature markets } \\
\text { context of a larger e- } \\
\text { government reform. }\end{array}$ \\
\hline
\end{tabular}


203. An electronic information system could be introduced in Tanzania, without more than minor changes in the legal framework and will not produce higher technological demands than a computer with Internet access in each of the procuring entities. On a longer term the system should develop into a full fledged business-to-government commercial marketplace, with facilities for online contracting and execution of the entire procurement process, from advertisement to handling of variations through electronic means ${ }^{77}$. The introduction of such a system may require quite substantial changes to the basic laws of contracting in Tanzania in areas such as electronic formation of contracts and signatures ${ }^{78}$.

204. Any recommendations in the field of e-procurement in Tanzania will be marked by the fact that credible data on the status of the organisational and technical requirements, mentioned above, are missing. To proper assess the preparedness of the country for the first steps of an eprocurement system, such data must be available. Of specific interest is the existing Integrated Financial Management System, which presently connects a number of central governement institutions. The system provides for a procurement module as an option, that should be assesed more closely.

205. The recommendations below reflect the fact that e-procurement is not a goal in it self, but only a means to reach those higher ranking goals of value for money and transparency. Eprocurement in its different forms enhance such other key recommendations as the establishment of a procurement journal, and increased focus on monitoring of the procurement processes.

\section{Recommendations}

\section{Short term}

- Introduce access to the Procurement Journal through the Internet utilising the existing Government web-site. This would reduce advertisement costs and make all tender notices, notices of extension and notices of award available for bidders and the public.

- Launch project to assess current status of the requirements for e-procurement, nature and size of any benefits expected, and the maturity of the private market.

\section{Medium term}

- Introduce online access to a centralized database of prices on commonly procured items. This would greatly improve the quality of tender documents.

- Support ongoing efforts to introduce technology (pc's and Internet access) to the entire public sector.

\footnotetext{
${ }^{77}$ Such systems have been implemented in countries such as USA, Canada, Brazil, Mexico and Chile.

${ }^{78}$ Guidance for the legal reforms required before a country can adapt electronic commerce can be found in the UNCITRAL Model Law for Electronic Commerce and the
} 
- Make tender documents available for download in electronic form. This would reduce time spent on post service and increase access for potential bidders while at the same time reducing costs.

- Access to administrative decisions from the CTB and relevant court decisions will help in shaping a common understanding of the main principles in sound procurement and will strengthen the effort to harmonize practices througbout the public sector.

- Establish isolated pilot projects in sectors most likely to benefit and where the listed requirements are most easily met.

\section{Long term}

- Enable public access to the procurement protocols that have now been entrenched in the Regulations ${ }^{79}$, thereby enlisting the public in the ongoing effort to enforce the rulles to the best of society as a whole.

\footnotetext{
${ }^{79}$ Regulations Article 20(2)
} 


\section{7. PERFORMANCE ON BANK-ASSISTED PROJECTS}

206. Parallel with the CPAR exercise the World Bank undertook an Independent Procurement Review (IPR) of 40 selected contracts in Health Sector Development Fund Projects; 34 under Integrated Roads Project (IRP-II), 25 in Agricultural Research Projects, 35 Social Action Fund Projects; and 14 contracts in Public Service Reform Projects. A total of 148 World Bank financed contracts were reviewed. 3 contracts originally selected under IRP-II (TANROADS) could not be reviewed due to non-availability of records and documents. In the Social Action Fund Project the contract register showed that the list provided was not complete, thus based on the register extra contracts were selected for review. The review was conducted during periods mutually agreed with the respective project implementing agencies and encompassed scrutiny of documents made available by the agency in their offices. The exercise included review of bid documents, evaluation reports, and correspondence with the World Bank and Tender Board committees (Central, Ministerial etc). In addition site visits were made on TANROADS, Agricultural Research, Social Action Fund and Health Sector Development Projects to observe ongoing Works and to monitor the utilisation of certain procured Goods. The observations arising out of the above have contributed to this report and are described in detail in the separate IPR report. Based on the results of the IPR, the following section of the report identifies general trends on the issues that affect performance on Bank assisted projects. Examples are provided where these represent such trends.

\section{Choice of procurement method and advertisement}

207. Owing to the absence of Procurement Plans, the choice of NCB over ICB and vice versa appears arbitrarily and is often not substantiated by the realities of the particular project regarding geography, tender packages and potential bidders. Furthermore cost estimates are often poor, leading to wrong conclusions of tender packaging and choice of procurement method.

208. Though World Bank guidelines encourage that the international community is notified through their respective embassies and trade commissions, tender advertisement is often restricted to local and East African newspapers. It is noted that in the absence of such publicity in most of the ICB tenders, the same set of contractors (including foreign) have been participating in most of the works contracts. This may be caused by a very limited number of players on the market, though a further opening of the market might be ensured by wider advertisement.

209. In order to encourage the domestic construction industry to participate in tenders, it is imperative that NCB packages are framed to suit the local firms' capacity and capability. The cost of tender documents, the value of bid security, etc. should be kept at a reasonable price level taking into account the local economic hardships and environment. In order to develop correct cost estimates, a centralized computerized cost data bank on Works and Goods, could be developed by the RA for reference and periodic updating by a qualified quantity surveyor. 


\section{Tender Openings}

210. The time allotted for bid submission from the date of tender availability is in some cases kept lower than the period recommended in the Guidelines / SBDs. This results in less response and non-participation. The rest of the bid opening requirements (such as bid opening on the date and time specified; rejection of bids received after the stipulated deadline; recording the names of bidders; the obligation to read out prices; the verification of bid security; along with the details such as value, form, validity etc.) are recorded and minutes of bid openings prepared. However, it was also observed that for Shopping contracts and Government purchase orders, where the procedure of selection by three quotations has been followed, the enquiries are often verbal and non-documented.

211. A copy of the tender opening record should be sent to the Bank for information. Since many bids are rejected due to the shortfalls in bid security validity it may be worthwhile to record the validity of the bid security also at the time of bid opening. Where the bid document stipulates that evaluation of the tender is on a lot by lot basis and not as a single lot, for the sake of transparency, bid prices can be read out lot wise and the minutes prepared accordingly. Thus the minutes will reflect the lot prices in which the award criteria are applied.

\section{Bid-and performance security}

212. There are several instances of: bid security not being presented in the right format; bid security amount falling short below the specified figure; bid security issued by non banking institutions; and security furnished not in the form of Banker's Cheque or certified Cheque but given in Bonds or personal cheques or other forms of collateral. Also, performance security is generally not extended up to the revised defects liability period whenever general extension of time has been granted.

\section{Pre-Qualification Documents:}

213. The loan agreement stipulates that a Pre-Qualification (PQ) exercise for Civil works over a certain value should be carried out. However, for some contracts no PQ is carried out, and for other contracts, in the absence of $\mathrm{PQ}$, only post qualification analysis was conducted. As noted above, the participants in most of the tenders regarding civil works and health sector development are more or less the same, and contracts are awarded over and over again to the same circle of firms.

\section{Tender documents}

214. Mostly the tender documents are in line with Bank SBDs. However, the technical specifications in some of the works contracts are of poor quality. As per the procurement guidelines, the cost of tender documents should be kept reasonable so as not to discourage qualified bidders from participation. Even for small value goods and works, tender document costs have been kept high. In the case of shopping of goods, quotations have been invited verbally or very brief request for quotations issued, lacking basic information like last date for submission of quotes, specified parameters, method of evaluation, delivery time, terms of payment, etc. It is 
noted that often a substantial percentage of the total project cost is incurred on procurement using shopping mode for goods. The lack of accountability in such purchases is a worrying factor. An annual inspection of all procured assets by a financial auditor for their utility and status should be undertaken as a part of their Annual Report, so that realistic value and depreciation of assets can be arrived at.

\section{Evaluation Reports}

215. The outputs of evaluation reports are not of desired quality. These reports do not in adequate detail analyse the evaluation parameters of equipments, offered work methodology, personnel capability and experience, etc., Post qualification criteria of bidders, especially in the case of Goods contracts are not examined and mentioned in the evaluation report. Comparative statements are not being properly prepared as prices are not compared on a common datum (some are inclusive of VAT and others are not). In addition, instances of rejection on un-documented qualification criteria are recorded.

216. In view of the prevailing confusion regarding what constitutes a material deviation, there have been instances where bids have been rejected for minor issues such as (i). original bid and copy not put in the same envelope, (ii) quoted price being lower than the Engineer's estimate, (iii) non submission of litigation history, (iv) unsigned CVs of personnel, (v) missing power of attorney, (vi) asking for terms of import/ export facility for plant and equipment etc.

\section{Keeping records}

217. A general lack of seriousness towards proper filing and preservation of records is being displayed in several implementing agencies. In many cases documents are missing or incomplete. Irrespective of the size and value of procurement, even for minor works or Shopping, there should be a brief contract or a detailed purchase order duly signed by an authorized signatory. Currently no such practice exists, even though this is required.

\section{Timeliness}

218. Time overruns with reference to recommended period for each activity is a common phenomenon in most of the contracts, in turn leading to cost overruns. In some cases the time allowed for bidding has been kept below the recommended period as if to convey a sense of urgency, after which considerable time has passed between the date of opening of tenders and award of contracts - even in cases of small value goods and works contract. The credibility of the implementing agency is lost when bidders are asked to keep extending the validity of their bids to cover the internal bureaucratic delays such as poor evaluation reports, and the long drawn process in obtaining approvals from Ministerial Tender Board, Regional Tender Board, Central Tender Board, which again leaves little time for Bank's approval. In some contracts, re-tendering has taken place because of such delays.

219. Delays have also been noted between the date of Bank/ CTB approval of contract award, the actual signing of the contract document, and the commencement of works. This is due to the 
delays occurring during negotiations and discussions with the respective bidders in obtaining confirmation that his bid conditions in spite of delay are still valid (mobilization of equipment, availability of proposed personnel, etc). It has been noted that in most of the civil works, the time assessed for construction has been estimated rather low and in the process there has been considerable time overrun - sometimes twice the estimated time. In view of such delays and lack of seriousness in adhering to the time period, the quality of works normally suffers and the performance control has been affected. In spite of clauses imposing liquidated damages in case of delays, no such claims have been made by the procuring entities. Possibly due to the lack of sufficient records or the realisation that their own inefficiency is to be blamed.

220. Delays have also been reported in the supply of goods due to constraints faced in the opening of Letters of Credit. In the absence of proper procurement planning and sequencing some of the consultancy contracts, especially the supervision consultancy contracts, had to be extended due to extensions granted in Works contracts.

\section{Recommended Supervision Plan}

221. The most urgent shortcomings on Bank financed projects to be addressed are:

- Poor procurement planning, leading to packaging of procurement in projects not supporting value for money and selection of wrong procurement method.

- Inadequate advertising, limiting the field of potential bidders, thereby reducing competition and value for money.

- Excess use of shopping method, reducing the portion of the project costs that are carried out through the preferred tendering methods.

- Lack of proper documentation of tender process and record keeping, hindering proper enforcement and audit of projects.

- Evaluation reports of uneven quality, leading to non-transparent application of award criteria.

- Unrealistic timeframes applied, leading to extensions of timeframes, which again increases costs.

222. In order to address these shortcomings a series of supervision measures are recommended:

- The importance of proper procurement planning, including packaging and choice of procurement method plays for a successful result must be emphasized by providing additional focus on substantiating the individual steps of the procurement plan. Higher quality in procurement planning would also address the problem of unrealistic timeframes by forcing the accounting officers to apply timeframes suited for that particular project. 
- The issue of inadequate advertisement should be seen in connection with the general recommendation that a procurement journal is established in Tanzania. Mandatory use of such a journal would certainly address the problems of potential bidders having to access different sources of information.

- The remarkably high percentage of procurement carried out by the shopping method should be examined more closely and all accounting officers should be required to substantiate why a shopping method was planned for, and not tendering.

- The poor record keeping could be addressed by stepping up the number of audits, and by requiring a signed list of the present contents of the procurement file as a prerequisite for Bank approval. 



\section{C.8. GENERAL RISK ASSESSMENT}

223. Any assessment of risk in a country's national public procurement system should be based on the stage of development of its legislative framework, the effectiveness of its regulatory institutions, the strength of its enforcement regime, the capacity of its institutional and human resources and the threat of corruption.

- Tanzania's legal framework has been thoroughly revised since the introduction of the new Public Procurement Act (2001), the Regulations (2001), the Standard Bidding Documents (2002) and the regulations on local government procurement to be issued early 2003. Some important steps still needs to be taken, such as the establishment of a credible complaints system through the formation of the Public Procurement Appeals Authority and the creation of a procurement journal, but the legal framework is largely up-to-date and in compliance with international standards.

- However, the on-going legal reforms have accentuated the problems that exist in the actual procurement procedures and practices. There is a huge gap between existing rules and the practices performed. This gap is caused in part by lack of capacity and knowledge and in part by corrupt behaviour that is allowed to flourish because of weak enforcement. The large gains that the country have made in reforming the legal framework will all be in vain if compliance with the new rules are not rigorously enforced.

- The enforcement regime, which underpins the procurement legislation, is particularly weak in Tanzania. Audits are very rarely carried out and never in adequate scale. External auditing is still in its infancy and current mechanisms for reviewing bidders' complaints are nonfunctioning. As a result, the accountability of public officials for the procurement decisions they make is undermined.

- While regulatory functions are vested in the CTB (albeit, mixed with executive functions) the oversight responsibility of the board is not clearly defined, particularly at local government level, and the authority of the CTB to ensure compliance is unclear. In addition, the CTB lacks both adequate budget and staffing to enable it carry out its responsibilities effectively.

- With a few exceptions, the public sector institutions, which conduct procurement, are illequipped for the task. Most ministries do not have dedicated organisational units to undertake procurement, and staff who handle the task invariably do so without training. The problems are only exacerbated at regional and local government level. The entire country lacks a planned training system for procurement.

- Corruption in Tanzania is widely recognized as being a real and widespread problem and appends itself particularly to public procurement, given the substantial expenditure, which all levels of administration make in this area. 
Measured against all of these parameters, the environment for conducting public procurement in Tanzania is one of high risk. However, Tanzania has demonstrated strong political will to implement all the above recommendations to improve its procurement system. The implementation risk is considered low and the prevailing high risk environment is expected to change rapidly to a less risky one. With the expected assistance from development partners, the proposed procurement reform is expected to be successful. 


\section{PRIVATE SECTOR}

\section{C.9. TRADE PRACTICES AND CUSTOMS}

\section{Trade Policies and Conditions in General}

224. Most sources agree that Tanzania's effort to reform and improve its trade environment has picked up speed over the last five years. The most important factors for this improvement are:

- Tariffs. As of July 1999 a five-tier structure for tariff rates on import duties was introduced. This reduced the simple average import duties from 18.3 percent in 1998 to 16.1 percent in 1999. The aggregated collectable duty to be exempted is estimated at 42 percent in 1999 down from 48 percent in 1998.

- Licences. Almost all export and import licenses have been eliminated in the process of liberalisation since the mid 1980s. Import licences are only required on goods deemed to be sensitive for health or for security reasons. However, in cases where licences are required, the set-up is weak due to comprehensive procedures demanding certifications not from one, but from a number of different institutions. Export permits are only required for goods that are monitored for environmental conservation or for national heritage purposes. Export restrictions are placed on a few foodstuffs for reasons of national food security, and there is an export ban on charcoal.

225. To issue Letters of Credit banks require as collateral either cash cover or landed property. The value of the security should either be $100 \%$ cash cover and the value of landed property should be at least $125 \%$ of the secured amount. Suppliers complain that the rates are too high and claim that this is one of major impediments in the import process. While this claim from suppliers may be a valid argument, banks on the other hand claim these rates are charged taking into consideration various factors such as:

- Weak legal environment

- High cost of capital

- High degree of risk

- Loan recovery problems

- Collateral recovery problems.

It is recommended that Government look into the possibilities of establishing a guarantee scheme or another support measure (excluding subsiy) that may lower the cost of obtaining letters of credit for suppliers 


\section{Custom Practices and Authorities in General}

226. Customs and Port Authorities in general have the reputation for being a hindrance for importers throughout Tanzania. Unpredictable and lengthy clearance delays and facility payments are said to be commonplace. There are numerous anecdotes to support this, e.g. it is mentioned by several importers that companies via facility payments can slow down the process of clearing the competitor's goods.

227. Most often legal action is not taken and penalties not imposed on importers that are "caught cheating". The institutions and companies that are to report irregularities and the authorities that are to enforce penalties when laws and regulations are broken often experience pressure from e.g. politicians not to impose penalties. It is vital that this issue be addressed if adherence with proper procedures is to improve.

228. On the side of importers, over-invoicing often takes place for goods that are exempted from duties and taxes to increase profit margins. In turn this is partly due to the fact that public authorities in some cases choose suppliers on the basis of their capacity to provide credit and postpone payments rather than on the basis of price. Under-invoicing, false labelling and incorrect description of goods on invoices are also frequently practiced by importers. Parts of the industry inspectors, Customs and Pre-Shipment Inspection (PSI) and Post Entry Audit (PEA) inspectors all confirm this, as do their statistical data.

229. The mission was also informed of a practice among some clearing agents, who inform importers that facility payments are necessary when in fact they are not. Receipts are of course not issued for facility payments and the importer therefore has no means to control the use of the funds provided for this purpose. The general professional level of the clearing agents is said to be low, and there is insufficient knowledge of the details of import regulations and procedures. As a consequence, importers are losing money since they do not always obtain the lowest possible tariff rates and due to the prolonged import procedures. There is a need for training of clearing agents in ethics, regulations, procedures and practices concerning the import process.

230. The Sub-Committee of the Shipping Industry Consultative Forum carried out a major study on import procedures and delays in import cargo clearance from the Dar Es Salaam Port in 2001. This involved active participation of all possible parties involved in imports including Government institutions, customs, inspection companies, importers, and clearing agents. The study was carried out with a very constructive attitude from all involved parties and has realistic and specific recommendations for practically all issues and steps in the process. It is essential that this work not be wasted. 
It is recommended:

- to establish procedures to ensure the follow-up on the suggested measures and recommendations in the study of the Sub-Committee of the Shipping Industry Consultative Forum.

- that measures be taken to intensify efforts to implement and enforce ethically correct practices as well as adherence with rules and regulations on the side of customs, importers and clearing agents. Legal action has to be taken and penalties imposed on importers that are "caught cheating". It is essential that the institutions or companies that are to report irregularities and the authorities that are to enforce penalties when laws and regulations are broken are protected from pressure from e.g. politicians

- to elaborate and implement an obligatory training programme for clearing agents.

\section{Import Procedures and Practices}

231. The issue in need of urgent attention is that of Pre-shipment Inspection (PSI). PSI was introduced almost 20 years ago to counteract lack of efficiency in Destination Inspection (DI) at that time. In principle PSI is a temporary measure, which should only be used until sufficient competence, organisation and ethics are in place for reverting to DI. It is generally recognised that due to a variety of factors, PSI is no longer the most efficient measure to ensure that goods are declared correctly. A major factor is the development of technology, which has left the PSI as an ineffective control instrument, especially if goods have been in transit on their way to the destination. Now many containers or seals can be opened and closed again with the right technology. Areas or countries with a shortage of inspection personnel provide a good environment for changing contents of containers before they are shipped to their final destination, and e.g. Dubai is well known for this. There is strong evidence that PSI is also inefficiently carried out in Tanzania, and the introduction of a Post Entry Audit (PEA) Programme in December 1999 to inspect the already inspected goods confirms this notion..

232. The results of the PEA support this view. When auditing only $15 \%$ of import declarations and consignments, the PEA has still lead to a significant growth in revenue collection. The figures below illustrate the increase in revenue collection following the introduction of PEA. 
Fig. 12: Annual TRA Customs Dept. Revenue Collection

- Budget vs. Actual 1997 to 2000

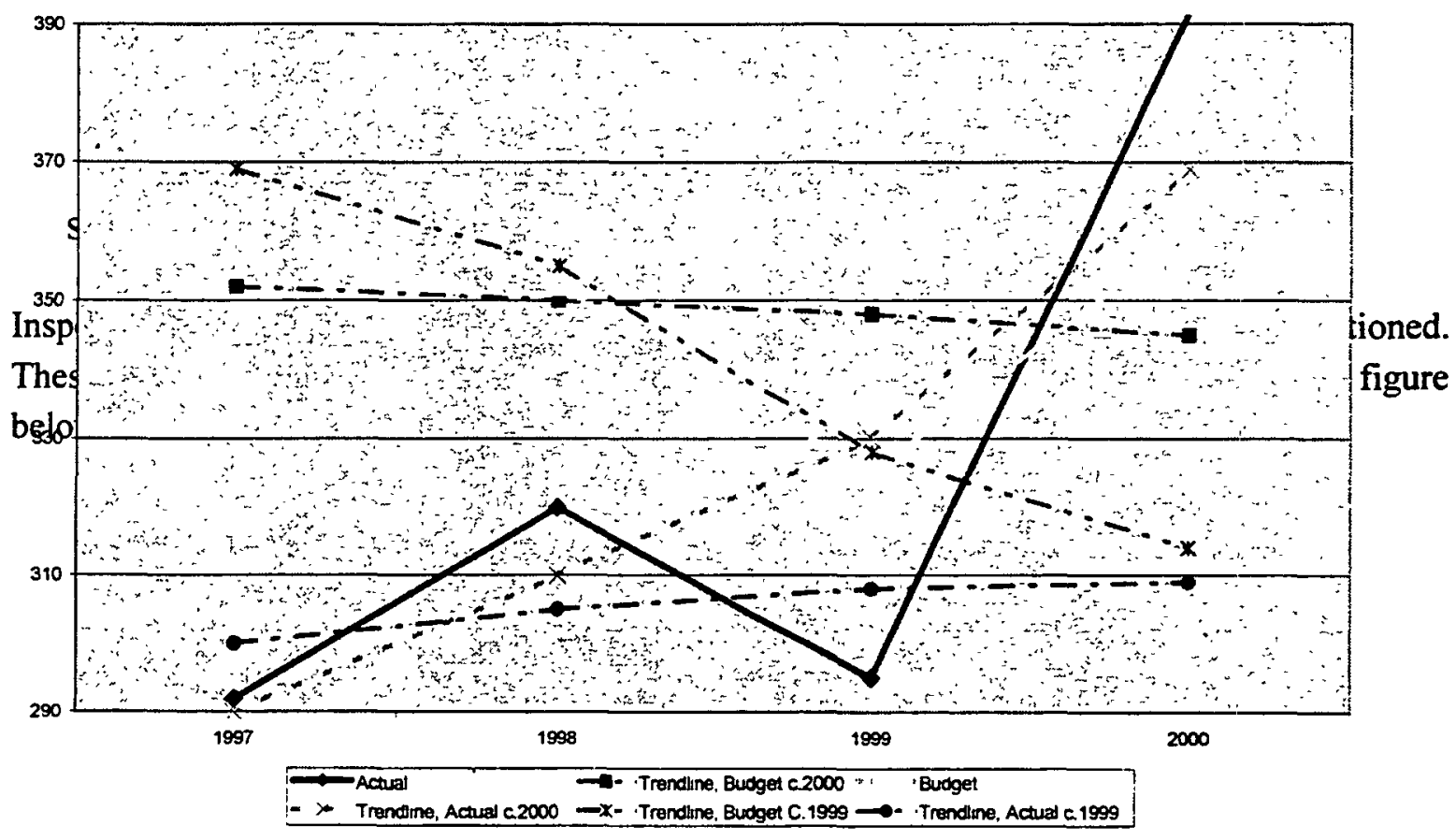


Fig. 13: TRA Customs Department Annual Revenues

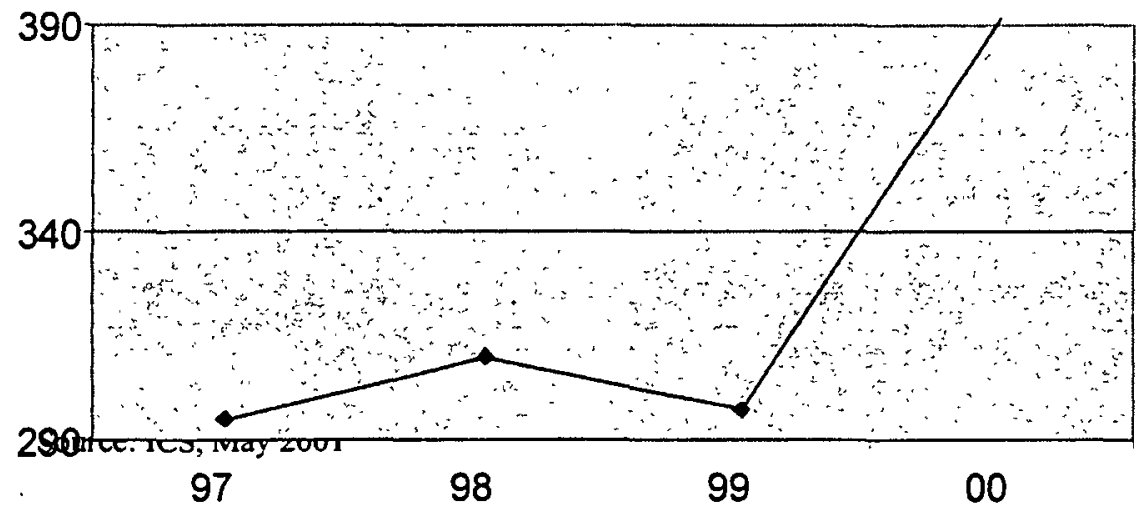

233. All indicators point towards an urgent need to move from PSI to DI. This is not a new issue. The need to move from PSI to DI is has been recognised but not acted upon. Two years ago, a plan was drawn up by the TRA and Ministry of Industry and Trade with the aide of SIDA and agreed upon with the aim of reforming customs, building capacity, introducing DI and terminating PSI as of 31 December 2002, Customs was to be reformed, capacity built and DI was to be introduced and PSI to end at 31 December 2002. To this day the first step of the plan has yet to be initiated. The Customs Department does not at present have the competence and capacity to implement and operate an overall DI system. ${ }^{80}$

It is recommended:

- to draw up an implementation plan for a shift from PSI to DI.

- to outsource implementation and operation of DI to a private inspection company, which should be identified via ICB. The outsourcing contract should have performance measurements where payment is depending on successful implementation.

- to instil in the outsourcing contract a requirement that customs officers are included in the team along with and on the same conditions as other employees of the inspection company. In connection with this, the contract should also require that the inspection company develop and implement a plan for building competence, capacity and ethic codes within the customs department with the aim of handing back the operation to customs when capacity is in place.

\footnotetext{
${ }^{80}$ However, at the workshop held in Dar Es Salaam on the 27. - 28. January 2003 the reforms including the move from PSI to DI were discussed and the workshop was informed that the reforms are now actually moving forward.
} 


\section{C.10. COMMERCIAL PRACTICES AND PROCUREMENT}

234. Tanzania embarked on the road towards liberalization in 1985 after almost two decades of central planning characterised by excessive government intervention in economic activities. Trade liberalisation, privatisation and investment promotion, tax, financial and civil servant reform followed and has been expanded since. The table below show the distribution of GDP by major business sectors.

Fig. 14: Gross domestic product by sector (mainland)

\begin{tabular}{|l|l|l|l|l|l|}
\hline & 1995 & 1996 & 1997 & 1998 & 1999 \\
\hline Agriculture, forestry \& fishing & 50.7 & 50.6 & 50.1 & 49.1 & 48.9 \\
\hline Mining \& quarrying & 1.4 & 1.5 & 1.7 & 2.0 & 2.1 \\
\hline Manufacturing & 7.9 & 8.0 & 8.1 & 8.4 & 8.3 \\
\hline Electricity \& water & 1.6 & 1.7 & 1.7 & 1.7 & 1.7 \\
\hline Construction & 3.8 & 3.9 & 4.1 & 4.3 & 4.5 \\
\hline Trade \& tourism & 15.7 & 15.6 & 15.8 & 15.9 & 16.1 \\
\hline Transport \& communication & 5.3 & 5.1 & 5.2 & 5.3 & 5.4 \\
\hline Financial \& business services & 10.3 .3 & 9.9 & 10.3 & 10.5 & 10.4 \\
\hline Public administration & 8.2 & 8.0 & 7.9 & 7.8 & 7.7 \\
\hline Imputed bank service charges & -4.8 & -4.2 & 5.0 & -5.2 & -5.1 \\
\hline GDP & 100.0 & 100.0 & 100.0 & 100.0 & 100.0 \\
\hline
\end{tabular}

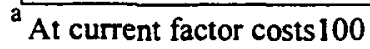

Source: The planning Commission, Economic Survey 1999/ The Economist Intelligence Unit Limited 2001/EIU Country Profile 2001

Agriculture is by far the most important sector followed by trade \& tourism, financial and business services and manufacturing.

235. Major exports are gold, cotton and coffee and major imports are consumer goods, machinery and industrial raw materials as shown in the table below. 
Fig. 15: Tanzania: External Trade

\begin{tabular}{|c|c|c|c|c|c|c|c|}
\hline & $1998^{a}$ & $1999^{2}$ & $2000^{2}$ & $2001^{\prime \prime}$ & $2002^{b}$ & $2003^{c}$ & $2004^{c}$ \\
\hline $\begin{array}{l}\text { Goods: exports fob (US\$ m) } \\
\text { Total } \\
\text { - Coffee } \\
\text { - Cotton } \\
\text { - Gold }\end{array}$ & $\begin{array}{l}589 \\
109 \\
48 \\
4\end{array}$ & $\begin{array}{l}553 \\
77 \\
27 \\
44\end{array}$ & $\begin{array}{l}663 \\
84 \\
38 \\
131\end{array}$ & $\begin{array}{l}776 \\
57 \\
34 \\
257\end{array}$ & $\begin{array}{l}884 \\
45 \\
39 \\
378\end{array}$ & $\begin{array}{l}972 \\
43 \\
51 \\
410\end{array}$ & $\begin{array}{l}1,068 \\
49 \\
60 \\
474\end{array}$ \\
\hline $\begin{array}{l}\text { Goods: imports cif (US\$ m) } \\
\text { Total } \\
\text { - Consumer goods } \\
\text { - Machinery } \\
\text { - Industrial raw materials }\end{array}$ & $\begin{array}{l}1,455 \\
311 \\
390 \\
154\end{array}$ & $\begin{array}{l}1,560 \\
327 \\
339 \\
159\end{array}$ & $\begin{array}{l}1,523 \\
381 \\
285 \\
165\end{array}$ & $\begin{array}{l}1,715 \\
363 \\
407 \\
205\end{array}$ & $\begin{array}{l}1,696 \\
404 \\
315 \\
175\end{array}$ & $\begin{array}{l}1,725 \\
422 \\
378 \\
186\end{array}$ & $\begin{array}{l}1,813 \\
455 \\
380 \\
173\end{array}$ \\
\hline $\begin{array}{l}\text { Volume and prices (\% change) } \\
\text { - Export volume of goods } \\
\text { - Import volume of goods } \\
\text { - Export prices } \\
\text { - Import prices } \\
\text { - } \\
\text { Terms of trade }(1990=100)\end{array}$ & $\begin{array}{l}9.8 \\
1.9 \\
-28.5 \\
6.8 \\
77.1\end{array}$ & $\begin{array}{l}18.6 \\
8.7 \\
-20.8 \\
-1.4 \\
61.9\end{array}$ & $\begin{array}{l}18.4 \\
0.1 \\
1.2 \\
-2.4 \\
64.2\end{array}$ & $\begin{array}{l}7.0^{b} \\
7.8^{b} \\
9.4^{b} \\
4.4^{b} \\
67.3^{b}\end{array}$ & $\begin{array}{l}6.0 \\
7.0 \\
7.4 \\
-7.6 \\
78.2\end{array}$ & $\begin{array}{l}6.0 \\
5.0 \\
3.7 \\
-3.1 \\
83.8\end{array}$ & $\begin{array}{l}6.0 \\
5.0 \\
3.6 \\
0.2 \\
86.7\end{array}$ \\
\hline
\end{tabular}

\section{Regulation of Competition and Conditions of Doing Business in Tanzania}

236. The Fair Trade and Competition Act has been adopted, and the business community in general expresses their satisfaction with the Act.. They also state, however, that its effect remains to be seen due to its recent nature. Overall the business community emphasizes three major issues when they are enquired about the obstacles to business development in Tanzania: The first issue is one of difficulties in activating the hidden value of assets owned by businesses wanting to providing collateral in lending. Land and property as credible collateral is hindered by complicated land ownership issues and an inefficient system of registration and retrieval of collateral.

237. Thus, the second issue relates to the high lending rates offered by the Tanzanian commercial banks. The table below shows the average lending rates for commercial banks in year 2002 . 
Fig. 16: Commercial Banks Lending rates for year 2002

\begin{tabular}{|l|r|r|r|r|r|r|r|r|r|r|r|}
\hline & \multicolumn{6}{|c|}{ Commercial Banks Lending rates for Year 2002 } & & \\
\hline & jan-02 & feb-02 & mar-02 & apr-02 & maj-02 & jun-02 & jul-02 & aug-02 & sep-02 & okt-02 & nov-02 \\
\hline & & & & & & & & & & & \\
\hline Lending rates & 16,85 & 16,55 & 16,65 & 16,47 & 16,38 & 16,40 & 16,66 & 16,45 & 15,86 & 15,83 & 16,96 \\
\hline Call Loans & 18,26 & 23,58 & 23,58 & 20,92 & 23,65 & 23,65 & 23,65 & 23,65 & 23,65 & 23,65 & 23,65 \\
\hline Short-erm (up to 1yr) & 14,55 & 15,59 & 14,35 & 14,44 & 14,82 & 14,83 & 14,70 & 15,26 & 14,76 & 14,37 & 14,47 \\
\hline Medium-term (1-2 yrs) & 17,12 & 17,25 & 17,70 & 16,74 & 16,56 & 16,59 & 18,28 & 15,69 & 14,45 & 15,56 & 16,21 \\
\hline Medium-lem (2-3 yrs) & 15,10 & 14,61 & 14,58 & 14,40 & 14,55 & 15,02 & 14,55 & 14,78 & 12,61 & 12,13 & 13,00 \\
\hline Long-term (3-5 yrs) & 16,29 & 15,94 & 17,15 & 17,50 & 17,62 & 17,18 & 17,38 & 17,86 & 17,45 & 16,30 & 17,45 \\
\hline Term Loans (over 5 yrs) & 21,21 & 19,37 & 19,46 & 19,24 & 18,37 & 18,38 & 18,40 & 18,68 & 20,02 & 20,79 & 23,67 \\
\hline
\end{tabular}

Source: Bank of Tanzania

238. Not only are lending rates high, but obtaining bid security can also be a major expense. The conditions for bid security are in general the same as with letters of credit. The value of the security should either be $100 \%$ cash cover and the value of the contract should be at least $125 \%$ of the secured amount. The causes of the high lending rates and costs of bid security are similar to those of obtaining letters of credit:

- Unstable legal environment

- High cost of capital

- High degree of risk

- Loan recovery problems

- Collateral recovery problems.

239. When asked regarding performance and bid bonds, banks claimed that they are merely facilitators of a contractual requirement between Contractors and suppliers. The requirement for a bond is normally contained in the contract between the Customer and the supplier and the bank is then required to facilitate. The suppliers concem is why the cost of such facility is high? Banks retorted that a bank which provides a performance guarantees must honour that guarantee according to its terms. It is not concerned with the relations between the supplier and the customer; nor with the question whether the supplier has performed his contracted obligations or not. In this regard this problem has to be addressed between the Clients and suppliers. However, there might be an opportunity for the Government to provide a framework that will cut the cost of this transaction in terms of a guarantee scheme or a similar mechanism.

240. The third issue is the issue of tax collection. Companies generally complain that they cannot obtain proper closure of their tax payments at the end of the year. The TRA does not respond to requests made by the companies as to whether the TRA will accept the tax accounts submitted by the companies. The common pattern is that the TRA after $4-5$ years will contact the company and demand to review all books, accounts, receipts, etc. and the company is then asked to document 
its activities for the whole period. This practice forces companies to put aside resources for such an exercise. This practice also leads to an unstable environment where many companies, especially Small and Medium-sized Enterprises (SMEs) are forced to operate with overheads twice the size of what is necessary for other countries in the region. The effect on competitiveness is obvious.

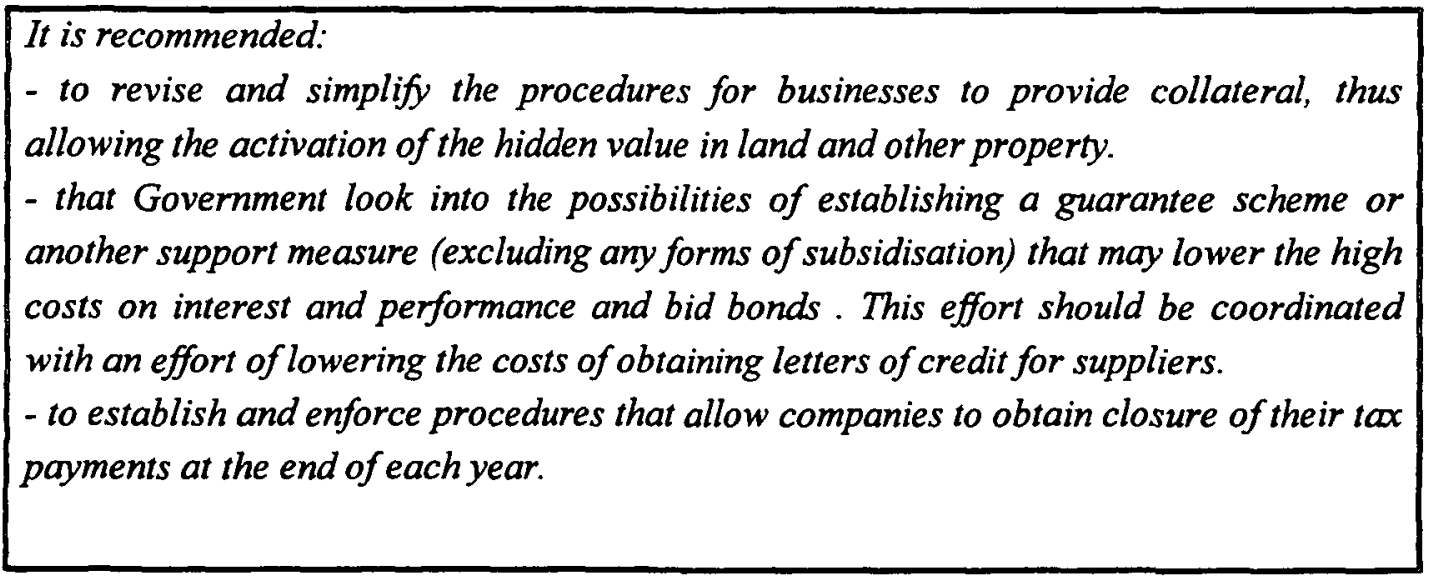

\section{Private Sector Procurement}

241. Procurement practices in the private sector are generally weak, especially within the SME segment. A continuous effort to build procurement capacity within companies would improve the competitiveness of the private sector. However, some companies, and among them ex-parastatals, have very strong procurement practices both for national and international procurement and purchasing.

242. The procurement methods, competencies and first and foremost hands-on experience within these companies seem to be much stronger than in most training institutions. This knowledge base could be utilised by the training institutions by inviting experienced procurement officers from the private sector to serve as guest lecturers. A similar approach could be adopted towards those government agencies, which also possess state-of-the-art experience.

243. Furthermore, some private companies have developed incentive schemes for procurement officers where part of the salary depend on the officer's ability to cut cost by obtaining the best quality at the lowest price. These incentive schemes could be of interest for the public sector as a measure to improve procurement efficiency. 
It is recommended:

- that training institutions incorporate experienced procurement officers from the private and public sector as trainers in their courses.

- to examine incentive schemes for procurement officers in the private sector and establish a pilot project where such incentive schemes are tested in the public sector.

\section{C.11. PRIVATE SECTOR PERFORMANCE ON PUBLIC PROCUREMENT CONTRACTS}

244. Inadequate performance in terms of suppliers not delivering the assets they were contracted for is to be expected when corruption is widespread in procurement. This is due the fact that money spent on facility payment must be recovered somewhere else in the business process. The IPR and its site visits aimed at verifying procured assets does, however, not point towards substandard deliveries being systemic and pervasive. Irregularities are reported, but not as a systemic observation. 


\section{ZANZIBAR}

245. This chapter describes the set-up and implementation of public procurement in Zanzibar. The focus is on providing an overview of the key aspects and problems currently facing Zanzibar in reforming its public procurement system. The chapter has to be read in conjunction with the rest of the report covering Tanzania mainland. Thus, most of the recommendations and principles described in other parts of this report may also apply to Zanzibar. As will be noted, the Zanzibari procurement system is less developed than that in Tanzania mainland. Thus, the recommendations made imply a measure of prioritisation, which should be taken into consideration by the Zanzibar Government.

\section{Brief Background}

246. Zanzibar consists of the two islands of Unguja and Pemba and 14 smaller isolated islets. It has a total area of $2,332 \mathrm{sq} . \mathrm{km}$. and an estimated population of one million people. Zanzibar became united with Tanganyika in April 1964 to form the United Republic of Tanzania. Within the Union, Zanzibar has its own government, the Revolutionary Government of Zanzibar. The Government of Zanzibar is in control of all isle affairs except defence, foreign and home affairs. The latter are controlled by the Union government. Laws passed by the National Assembly of Tanzania mainland are valid for Zanzibar only in specifically designated union matters. Zanzibar's House of Representatives has jurisdiction over all non-union matters. There are currently 76 members in the House of Representatives, including 50 elected by the people, 10 appointed by the president of Zanzibar, 5 ex-officio members, and an attorney general appointed by the president. The Zanzibari court system parallels the legal system of the union, and all cases tried in Zanzibari courts, except for those involving constitutional issues and Islamic law, can be appealed to the Court of Appeals of the union.

247. Zanzibar has developed its own Poverty Reduction Strategy Paper (PRSP), securing some support from the international community. Thus, it is planned that $4,5 \%$ of PRSC funds will go to Zanzibar, stressing the need for increased focus on public expenditure and as part hereof, on public procurement. At present, public procurement accounts for app. $40 \%$ of the state budget, which in the FY01/02 totalled Tshs 86.400 billion. By virtue of the constitutional independence of Zanzibar, matters of public expenditure and public procurement are a prerogative of the Government of Zanzibar. 


\section{Legal Framework}

248. The Act to Establish the Central Tender Board in Zanzibar and Other Related Matters (CTBA) came into effect on 1 July 2002. Prior to the enactment of the CTBA, procurement in Zanzibar was governed by the Treasury Instructions of 1965 and the Trade Act No. 4 of 1989 . The latter established the CTB. However, Article 49 of the CTBA, repeals the procurement provisions of the previous legal framework. The CTBA, which both establishes a CTB and addresses issues of the procurement process, is based on the Public Procurement Act of Tanzania mainland. Unfortunately, the CTBA is seriously flawed, and a review of the Act reveals the following main shortcomings:

249. Role of the CTB: The CTBA provides extensive powers to the CTB. Thus, the CTB is endowed with both regulatory and executing functions. This poses a serious threat to the functioning of the board. Experience from Tanzania mainland has shown that, while the wish by the MoF to retain control over Government procurement might be understandable and justifiable, the functioning of the procurement system might easily be weakened by the very same control measures. In this case the Zanzibar CTB will become a bottleneck whereby the efficiency and credibility of the entire procurement system is at risk.

250. Appeal: The CTBA Articles 45-48 describes the complaints and appeals procedures. According to these provisions, the review shall be carried out:

- First, by written decision by the Accounting Officer of the Ministry ${ }^{81}$

- Second, the complaint may be forwarded to the CTB for administrative review

- Third, disputes not settled by the CTB shall be referred to the Minister of Finance. The decisions of the Minister is final, unless the complainant seeks judicial review within the court system.

The inclusion of the Minister of Finance, by which a political level within the appeals process is inserted constitutes a serious flaw of the CTBA. By this measure, the risk of (accusations of) conflict of interest increase substantially. In this case, the Minister fulfils a function, which should rightly be awarded to a regular Appeals Body. This Appeals Body should be independent from the Ministry of Finance and Economic Affairs (MoFEA), and should be allowed to review all aspects of the complaints, including the review carried out by the CTB and the Accounting Officer in question.

251. Regulations: One of the most serious flaws of the legal framework is the lack of Regulations supporting the CTBA. Thus, Article 44 of the CTBA prescribes the development of Regulations and calls for yearly review of the thresholds set forth by the Regulations. The

\footnotetext{
${ }^{81}$ Only the ministry level is mentioned here, and not parastatals or other procuring entities.
} 
Regulations are also supposed to describe the practical application of such critical issues as conditions for selection of procurement method and contents of bidding documents. However, the Regulations have never been issued, leaving the CTBA non-operational. The mission learned that the MoFEA had originally commissioned a local consultancy company based in Dar es Salaam to draft the Regulations, but this process was halted due to the recognized deficiencies in the Act.

252. The review of the CTBA reveals a number of defaults, whereby a general overhaul of the Act is recommended. The mission discussed this matter with the MoFEA, which agreed to the observations made, while noting that the adoption of amendments or even a new Act might prove difficult since the present Act has only recently passed through Parliament. As an interim measure, providing a legal base for procurement while the CTBA is amended, it is suggested that the MoFEA issue instructions authorising the ministries/Accounting Officers to approve all contracts. This would at least legalise the current practices.

It is recommended that the CTBA be revised to reflect standards of a sound procurement system, including:

- the removal of executing functions from the CTB

- establishing a credible appeals mechanism by removing the Minister of Finance from the appeals process

- seeking further harmonization of the procurement systems of Zanzibar and mainland Tanzania, which could also facilitate joint activities, including capacity building, training, exchange of experience and pooling of resources.

It is further recommended that Regulations should be developed in tandem with the amendment of the CTBA, and both instruments should be issued at the same time.

As an immediate measure, the MoFEA should issue intermediary instructions to provide a minimum legal framework for the procurement currently being carried out.

\section{Procedures and Practices}

253. The procedures and practices of procurement in Zanzibar are marred by the lack of a proper legal framework. Thus, at present procurement, apart from donor funded procurement, is conducted on an ad hoc basis leaving extensive discretion to the Accounting Officers in the Ministries. While some of the procuring entities are applying the rules of the now void Treasury Instructions, others have simply adopted their own procedures.

254. The most commonly used practice is competitive quotation (shopping). By this measure, procurement is carried out by requesting three quotations from suppliers previously known by the procuring entity. Usually, the relevant Head of Department will identify the three potential bidders, and pre-qualification is rarely used, as the ministry/Head of Departments claim to know 
the local market and the suppliers. There is no registration of bidders, though some Accounting Officers and Heads of Departments claim to maintain their own lists of potential suppliers. The potential supplier usually approaches the ministry either in person or by sending his profile to the ministry. Some ministries like the Ministry of State Regional Administration and Local Government claim to check the suppliers before they are added onto the list.

255. When, as part of competitive quotation, the decision should be based on quality and price applying the principle of the economically most advantageous tender, the mission learned that more often than not contract award is based on which supplier can provide credit. This has established a largely arbitrary and non-transparent environment, which in addition is far from cost-efficient and value for money-oriented.

256. The heavy reliance on credits by most ministries is related to the complete lack of procurement planning and to the general shortcomings in budgeting, including cash budgeting, and fund disbursements. Budget planning in general was only introduced in 2001. Under the current system, ministries are provided with monthly cash releases ${ }^{82}$ from the MoFEA. However, without planning and budgeting, the ministries are regularly in lack of cash, leaving them to procure on credit often at excessive rates.

257. Only when projects are funded by donors, who have their own standards and procedures, is actual tendering carried out. These are also the only instances where any advertisement takes place. Due to donor requirements and lack of capacity some ministries like the Ministry of Water, Energy, Construction and Lands use procurement agents for large, international procurements.

258. The variety of un-coordinated and arbitrary procedures and practices is highlighted by the mixed feedback provided on the issue of decentralization. While some ministries conduct procurement without involving or even reporting to the MoFEA, in other instances the MoFEA caries out procurement directly for the ministries. ${ }^{83}$

259. The mission was informed that standard contracts have been developed for works, but not for supplies and services. Though, none of the persons interviewed were able to provide a copy of the standard contracts. In some cases, contracts are not signed at all, and instead delivery is based on a so-called "gentlemen agreement." Post-contract negotiations are common practice.

260. The enforcement is weak as illustrated by the lack of disciplinary and penal measures and actions. Another sign of a weak enforcement culture is the lack of complaints by bidders. Bidders refrain from complaining since they do not expect that it will yield any results, but also because they risk being barred (on non-legal basis) from bidding for future contracts.

\footnotetext{
${ }^{82}$ The Ministry of Health informed that it receives monthly releases in the amount of Tshs 30-80 million.

${ }^{83}$ Both the Ministry of Health and Social Welfare and the Ministry of State Regional Administration and Local Government confirmed this practice.
} 
261. There is a general information void when it comes to the procurement system. Several ministries visited were not even aware of the CTBA let alone the provisions of the Act. And nothing seems to have been done or even planned to provide information about the CTBA. When the CTBA has been properly amended, it would be advisable to ensure proper dissemination of the new legal framework and its implementation.

262. All in all, the review of procedures and practices portrays a situation of complete disorganisation. The review has identified arbitrary applications of principles and standards, high risk of and indeed situations of conflict of interest. This, in turn, leaves room for fraud and corruption to flourish. In order to amend the situation, the new legal framework must be in place and capacity building at all levels provided.

It is recommended that efforts to introduce sound procedures and practices for procurement are stepped up. A pre-requisite for this is the development of a sound legal framework, after which targeted capacity building and technical assistance should be provided. This should include, as first step, a targeted training programme focusing on key institutions and individuals.

\section{Organisation and Resources}

263. The organisation and resources of procurement in Zanzibar mirrors the situation as described for the legal framework and procedures and practices. Hence, the organisation may only be characterised as fragmentary and resources as scarce. Some key issues are described in more detail below.

264. As mentioned above, the CTB was established by the Trade Act of 1989. Under the 1965 Treasury Instructions, all contracts above Tshs 1 million were required to be approved by the CTB, but the Treasury Instructions were suspended in the early 1990es without any replacement procedures. When the Treasury Instructions were suspended, ministries stopped forwarding the tenders for approval by the CTB and instead went via the Principal Secretary or through the ministerial tender board. Consequently, the CTB soon lost its functions. The CTBA of 2002 reestablishes the CTB. Though, in reality the members of the CTB are not yet appointed. The Act provides the board with extensive powers of both regulatory and executing character: ${ }^{84}$

- Overseeing and monitoring the conduct of procurement by procuring entities

- Advising the Government on all matters regarding procurement and the operation of the Government's procurement system

- Approving the issue of tender or the use of alternative procurement methods

${ }^{84}$ CTBA Article 7 
- Receiving tender and holding tender openings, reviewing tender evaluations and recommendations made by procuring entities and authorizing awards of contracts

- Reviewing all requests for variations

- Reviewing and approving sales by tender.

265. As in Tanzania mainland, where a key recommendation is the division of regulatory and executive functions and the transformation of the CTB into a purely regulatory body, the CTB of Zanzibar should undergo a similar transformation. Thus, a Regulatory Authority for Zanzibar (RAZ) should be established as an autonomous body under the auspices of the MoFEA.

266. In addition to the CTB, the CTBA establishes tender board for ministries (Ministry Tender Committee) and for parastatals. There are currently no ministerial tender boards in place, and thus no prior experience, neither organisational nor human, with such arrangements. This has to be taken into account when decentralisation is being structured. Thus, decentralisation must be matched with extensive capacity building, in particular at ministerial level, as well as the introduction of an information management system similar to that suggested for the mainland.

267. As described in the legal framework section, the current appeals system for procurement is flawed. The CTBA does not provide for a proper appeals authority, in that the Minister of Finance serve as the point of final administrative review. To mend this situation it is suggested that Zanzibar establish a public procurement appeals authority along the same lines as that of Tanzania mainland.

268. The lack of capacity, both in human and institutional terms, pose the greatest challenge to the development of a sound procurement system in Zanzibar. Only a very limited number of public officials have experience with regular procurement, ${ }^{85}$ and there is an extensive need for sensitisation and training in procurement, which might very well be carried out in cooperation with mainland institutions. Thus, a training programme should be developed including the same features as for the mainland.

\footnotetext{
${ }^{85}$ Mainly those who have worked with donor-funded projects, which includes officials from the Ministry of Health and Social Welfare; Ministry of Trade, Industries, Marketing and Tourism; Ministry of Water, Construction, Energy and Land. The latter informed the mission that it currently employs 4 procurement experts in the department of works.
} 
Recommendations:

- The CTB should be reformed into a purely regulatory body (RAZ)

- Ministerial tender boards and PMUs should be established

- Full decentralisation to MDAs should be carried out, though paired with extensive capacity building measures.

- Zanzibar should establish a public procurement appeals body along the same lines as that in Tanzania mainland.

- A capacity building programme for organizational and human development should be designed and implemented

\section{Anti-corruption}

269. Most people interviewed in Zanzibar during the course of this study pointed to widespread corruption in public procurement. They stated that there is both petty and grand corruption in procurement, which, like in Tanzania mainland, can be attributed to several factors, notably poverty, weak accountability, greed, conflict of interest, undue political influence and weaknesses in procurement procedures. Generally, however, corruption is less talked about by the general public in Zanzibar than in the mainland.

270. Fighting corruption in Zanzibar is mainly the responsibility of two government institutions: the Police Force and the Ministry of State for Constitutional Affairs and Good Governance.

271. The Police Force handles corruption through the Anti-Corruption and Fraud Squad. The Squad was constituted in its present form in 1985 by transferring the then Anti-Corruption Squad from the office of the Chief Minister to the Police Force and merging it with the Fraud Investigation Section. It has powers to investigate and prosecute corruption cases under the penal code. It also advises the Government on matters relating to corruption, bribery and fraud in public expenditure. The Squad is not directly financed by the Zanzibar Government since the Police Force is under the jurisdiction of the Ministry of Home Affairs of the Union Government. It has a staff strength of about 20 police officers, but it is poorly equipped and lacks specialist training in investigating corruption.

272. The Ministry of State for Constitutional Affairs and Government, which is under the Office of the President, was established in 2000 to strengthen the level of governance in Zanzibar as a means of enhancing social, political and economic development. Its portfolio includes promotion of human rights and good governance and it has the responsibility of coordinating all good governance activities. 
273. Realising that existing legislative measures are inadequate to combat corruption, the Ministry has initiated steps to review the legal framework for fighting corruption. In September 2002 it appointed a committee to draft a leadership code of ethics and a new law for combating corruption in a more comprehensive manner. The intention is to establish institutions similar to the PCB and Ethics Commission of the mainland. The Ministry hope to secure the approval of the House of Representatives for the new bills by July 2003.

\section{Recommendations:}

- An anti-corruption strategy and action plan for Zanzibar should be developed including public procurement as an element

- As part of the strategy development, a review of the current legal framework should be conducted

- Procurement training for 2-3 investigators from the Anti-corruption and Fraud Squad should be provided

- Collaboration and coordination with the anti-corruption institutions of Tanzania mainland should be strengthened, especially with the PCB

- Sensitisation of the civil society, media, business community and general public on corruption matters should be initiated.

\section{The Private Sector in Zanzibar}

274. Zanzibar's economy is based primarily on the production of cloves ( $90 \%$ grown on the island of Pemba), the principal foreign exchange earner. Thus, agriculture contributes about to $75 \%$ of foreign exchange earnings, employs about $60 \%$ of the labour force and provides $30 \%$ of tax revenues. Exports have suffered with the downturn in the clove market. Tourism is an increasingly promising sector, and a number of new hotels and resorts have been built in recent years. The Government of Zanzibar has been more aggressive than its mainland counterpart in instituting economic reforms and has legalized foreign exchange bureaus on the islands. This has loosened up the economy and dramatically increased the availability of consumer commodities. Furthermore, with external funding, the government plans to make the port of Zanzibar a free port. Rehabilitation of current port facilities and plans to extend these facilities will be the precursor to the free port. The island's manufacturing sector is limited mainly to import substitution industries, such as cigarettes, shoes, and processed agricultural products. In 1992, the government designated two export-producing zones and encouraged the development of offshore financial services. Zanzibar still imports much of its staple requirements, petroleunn products, and manufactured articles. The figure below shows the gross domestic product per sector. 
Fig. 17: Gross domestic product by sector (Zanzibar)

(\% of total)

\begin{tabular}{|l|l|l|l|l|l|}
\hline & $\mathbf{1 9 9 6}$ & $\mathbf{1 9 9 7}$ & $\mathbf{1 9 9 8}$ & $\mathbf{1 9 9 9}$ & $\mathbf{2 0 0 0 ^ { \mathbf { 2 } }}$ \\
\hline Agriculture, forestry \& fishing & 29.1 & 26.6 & 25.3 & 25.9 & 24.7 \\
\hline Mining \& quarrying & 2.6 & 2.5 & 2.4 & 2.2 & 2.8 \\
\hline Manufacturing \& handicrafts & 5.7 & 5.7 & 5.7 & 5.6 & 5.6 \\
\hline Electricity \& water & 12.0 & 12.7 & 13.7 & 14.4 & 14.5 \\
\hline Construction & 10.5 & 10.5 & 8.4 & 7.6 & 8.4 \\
\hline Wholesale \& retail trade, restaurants \& hotels & 18.9 & 20.6 & 22.6 & 22.7 & 23.1 \\
\hline Transport \& communications & 4.6 & 4.0 & 4.1 & 4.3 & 4.4 \\
\hline Finance \& insurance & 3.3 & 2.1 & 2.4 & 3.1 & 3.1 \\
\hline Public administration & 15.9 & 15.5 & 15.6 & 15.2 & 14.8 \\
\hline Imputed bank service charges & -2.6 & -0.3 & -0.1 & -1.0 & -1.3 \\
\hline GDP & 100.0 & 100.0 & $\mathbf{1 0 0 . 0}$ & $\mathbf{1 0 0 . 0}$ & $\mathbf{1 0 0 . 0}$ \\
\hline
\end{tabular}

${ }^{2}$ Provisional data. ${ }^{b} 1985$ prices at factor cost.

Source: BoT, Economic and Operations Report/The Economist Intelligence Unit Limited 2001/EIU Country Profile 2001.

275. There has been a steady movement towards liberalisation of the economy in Zanzibar and although there are still restrictions on e.g. foreign investments in some areas, these are few and limited in scale. However, the stability or static nature of the different sectors suggest an economy that is still highly regulated and insufficiently liberalised to generate change and growth on its own.

Import and Export Procedures and Practices

276. Contrary to Tanzania, Zanzibar does not have PSI, as the Government was hesitant to approve this measure when it was introduced in the mainland. Thus, the current system is based on DI. The mission observed that goods are valued by the WTO Transaction Value, tariffs are transparent, and while clearing agents must be used licensing is not said to be problematic. Also, INCOTERMS are known and used, mainly CIF and FOB.

277. Both custom clearance and release is reportedly conducted effectively by the Customs and by the clearing agents. The procedure takes approximately three days. In case of re-export to the mainland, the clearing agents complain that clearing goods is a large problem taking two to three weeks even after clearance by the Zanzibari authorities.

278. The delay in re-export from Zanzibar to Tanzania mainland may partly be explained by the reports of extensive smuggling taking place via the Zanzibari ports as evidenced by inspection results and general literature. This caused the government to drop the export-processing zones. Despite this, smuggling is said to have increased due the recent economic down turn (GDP has dropped from 238 USD per head in 1998 to 222 USD in 2000) and following the establishment of Maruhubi as a free port. Reportedly the smuggling via Zanzibar mainly concerns imported 
foodstuffs and consumer goods, which are illegally re-exported to the main land (some are never counted as imports). The practice is well established as the "Zanzibar loophole".

It is recommended that destination inspection be outsourced to a private inspection agency for a predefined period of time. This could both counteract smuggling and provide credibility to the Zanzibar inspection regime and eventually lead to a decrease in the time required for customs clearance of re-export to the mainland.

\section{Summary of Recommendations for Zanzibar}

\section{Short term}

- Issue intermediary instructions to provide minimum legal framework for procurement

- Revise the legal framework, i.e. the CTBA to reflect standards of a sound procurement system

- Draft and issue Regulations

- Reform the CTB to a purely regulatory body

- Develop anti-corruption strategy and action plan for Zanzibar

- Review of the current legal framework of relevance to anti-corruption

- Train 2-3 investigators from the Anti-corruption and Fraud Squad

\section{Medium term}

- Establish ministerial tender boards and PMUs

- Decentralise procurement to level of MDAs and parastatals

- Establish a Public Procurement Appeals Body

- Develop and implement procurement training programme for key institutions and individuals.

- Strengthen collaboration and coordination with the anti-corruption institutions of Tanzania mainland

- Initiate sensitisation of the civil society, media, business community and general public on corruption matters

- Outsource destination inspection to a private inspection agency

\section{Long term}

- Develop and implement a capacity building programme for organizational and human development in procurement 


\section{E. RECOMMENDED ACTION PLAN}

279. The previous chapters sets out a series of recommendations designed to address the various weaknesses in the public procurement environment in Tanzania. This chapter briefly discusses which measures are to be taken by the Government and others, as well as the issue of timing and funding of the procurement reform. A table inserted at the end of the chapter provides a schematic overview of all recommended actions, their timing, as well as identification which party is responsible for overseeing the implementation of each action.

\section{Measures to be the Taken by the Government}

280. It is clear that the primary responsibility for implementing the planned procurement reforms lies with the Tanzanian authorities at State, Regional and local authority levels. In particular, it is incumbent upon the Ministry of Finance to bring forward the reform at national level and ensure the effectiveness of the reformed Regulatory Authority. Likewise, the President's Office/ Regional and Local Government will face a great challenge in securing that local govemment procurement is thoroughly reformed.

\section{Measures to be Taken by the Bank and Other Financiers}

281. The finalization of the CPAR should be seen by all parties concerned not as an end-point but as the beginning of a process. Based on the Bank's experience in other countries, it may take several years to implement procurement reform successfully. Even when the first reforms have taken hold, continuous development will still be required. Throughout this process, the Bank will maintain an active dialogue with the Tanzanian authorities, through periodic visits by public procurement reform specialists and through its staff based in Tanzania, to promote effective reform of public procurement and will provide technical assistance, if required.

282. The Bank will continue holding procurement training seminars for the staff of implementation agencies responsible for Bank-financed projects. Previous Bank seminars held in Tanzania have been successful in making public officials aware of the benefits of a transparent and competitive procurement system and in increasing familiarity with international procurement practices.

\section{Technical Assistance}

283. The Tanzanian Government will need Technical Assistance to implement this reform program in a timely and effective manner. The immediate need is for assistance towards the 
design and implementation of a comprehensive capacity building scheme aimed at increasing knowledge and skills at both central and local levels.

284. Most of the development partners expressed willingness to provide technical assistance towards the implementation of the proposed reforms. DFID is in fact already working with the Government to map out detailed implementation plans which will be used to solicit funding from development partners. The ATIP will be the main financing instrument for implementing the reforms while the PRSC will be the main monitoring instrument.

\section{Timetable}

285. The time-bound Action Plan which follows this narrative covers the main recommendations made by this report. The actions were all discussed and agreed with the Task Force and a variety of other stakeholders at the Government organised workshop in Dar es Salaam on 27-28 January, 2003 and has been accepted by all the parties.

\section{Funding Procurement Reform}

286. The main source of finance in the short term for the technical assistance which Tanzania will need to implement the recommendations contained in this report is likely to be DFID, which has already earmarked funds for Technical Assistance for Public Procurement in Tanzania.

287. Subject to reaching agreement with the World Bank on the recommendations and Action Plan contained in this report, other development partners including: AfDB, DANIDA,USAID, SIDA, EU are also considering financing part of the sizeable scope of activities, which the reform program entails.

\section{Monitoring and Follow-up Plan}

288. The Government workshop on 27-28 January, 2003 agreed to transform the Government Task Force to a Steering Committee for implementing the Reform Program and recommended that new terms of reference (TOR) be drafted. The Steering Committee will be responsible for ensuring that reform efforts are brought forward until the Regulatory Authority (RA), which remains to be established, reaches a development where it can take over that task. It is important that these TOR clearly identify, when the RA should be expected to take over as the key coordinator of reform. In the meantime, the CTB will be the implementing agency under the leadership of the Steering Committee. Until then the CTB should be tasked with the development of a preliminary monitoring plan, including a detailed set of indicators of the performance of the public procurement system at all levels of administration, supported by a plan for collecting the necessary data. 
289. The Task Force should meet at least quarterly and, in advance of each meeting, the key implementing entities should submit reports detailing progress made in the previous quarter against the recommendations and proposing a work program for the coming quarter, to be agreed by the Task Force.

290. A schematic overview of the actions to be taken is presented below. 


\section{CPAR ACTION PLAN}

\begin{tabular}{|c|c|c|c|c|c|}
\hline Section of the report & Actions & $\begin{array}{l}\text { Short term } \\
(<12 \text { months })\end{array}$ & $\begin{array}{l}\text { Medium term } \\
(12-24 \text { months) }\end{array}$ & $\begin{array}{l}\text { Long term } \\
(>24 \text { months })\end{array}$ & Responsible \\
\hline \multirow[t]{7}{*}{$\begin{array}{l}\text { Legal and Regulatory } \\
\text { Framework }\end{array}$} & Issue Local Government Authority Regulations & 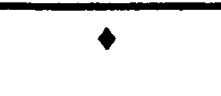 & & & $\begin{array}{c}\text { GoT/RA/Presidents' Office } \\
\text { - RALG }\end{array}$ \\
\hline & $\begin{array}{l}\text { Support the distribution and enforcement of the newly developed } \\
\text { Standard Documents issued by the CTB. }\end{array}$ & $\bullet$ & & & RA \\
\hline & Establish the Public Procurement Appeals Authority. & $\bullet$ & & & GoT/MoF \\
\hline & $\begin{array}{l}\text { Introduce necessary amendments to the PPA to form the Reformed } \\
\text { Central Tender Board (RA) }\end{array}$ & $\bullet$ & & & GoT/MoF \\
\hline & $\begin{array}{l}\text { Establish mandatory time limits for the main steps in the procurement } \\
\text { process and review existing time limits }\end{array}$ & & $\bullet$ & & $\overline{\mathrm{RA}}$ \\
\hline & Introduce an effective ban on both pre- and post-contract negotiations & & $\bullet$ & & GoT \\
\hline & Ensure adequate remedies for misprocurement. & & & + & GoT \\
\hline \multirow[t]{8}{*}{$\begin{array}{l}\text { Procedures and } \\
\text { Practices }\end{array}$} & $\begin{array}{l}\text { Enforce the requirement for advertisement of tenders in generally } \\
\text { available media until the procurement journal is operational. }\end{array}$ & $\bullet$ & & & $\mathrm{RA}$ \\
\hline & Enforce existing rules on application of pre-qualification & $\bullet$ & & & RA \\
\hline & Increase monitoring of the bid opening process. & $\bullet$ & & & $\mathrm{RA}$ \\
\hline & $\begin{array}{l}\text { Increase audits of evaluation reports to ensure correct application of } \\
\text { award criteria. }\end{array}$ & $\bullet$ & & & RA/NAO \\
\hline & $\begin{array}{l}\text { Strengthen the quality of procurement planning through monitoring } \\
\text { and capacity building }\end{array}$ & & $\bullet$ & & $\mathrm{RA}$ \\
\hline & $\begin{array}{l}\text { Issue guidelines for use of quotations and strengthen enforcement of } \\
\text { the existing rules concerning equal treatment of bidders. }\end{array}$ & & $\bullet$ & & $\mathrm{RA}$ \\
\hline & Establish a government funded procurement journal. & & 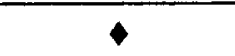 & & GoT/RA \\
\hline & $\begin{array}{l}\text { Consider mandatory pre-qualification for certain tenders to enforce the } \\
\text { proper use of pre-qualification. }\end{array}$ & & & $\bullet$ & GoT/RA \\
\hline
\end{tabular}




\begin{tabular}{|c|c|c|c|c|c|}
\hline Section of the report & Actions & $\begin{array}{l}\text { Short term } \\
(<12 \text { months })\end{array}$ & $\begin{array}{l}\text { Medium term } \\
\text { (12-24 months) }\end{array}$ & $\begin{array}{l}\text { Long term } \\
\text { (>24 months) }\end{array}$ & Responsible \\
\hline & Enforce existing rules on proper record keeping & $\bullet$ & & & GoT/RA \\
\hline & $\begin{array}{l}\text { Increase quality in technical specifications to reduce need for } \\
\text { variations }\end{array}$ & $\bullet$ & & & $\overline{R A}$ \\
\hline & $\begin{array}{l}\text { Establish deterrence by enforcing existing rules on punishment for } \\
\text { misprocurement }\end{array}$ & $\bullet$ & & & $\mathrm{RA}$ \\
\hline & $\begin{array}{l}\text { Establish awareness of legal framework and execute a general program } \\
\text { of monitoring, audit and enforcement, with specific annual goals }\end{array}$ & $\bullet$ & & & $\overline{R A}$ \\
\hline \multirow[t]{12}{*}{$\begin{array}{l}\text { Organisation and } \\
\text { Resources }\end{array}$} & $\begin{array}{l}\text { ORGANISATION } \\
\text { Change PPA to establish the RA as an autonomous regulatory body }\end{array}$ & $\bullet$ & & & GoT \\
\hline & Decentralise procurement to level of MDAs and parastatals & $\bullet$ & & & GoT \\
\hline & $\begin{array}{l}\text { Establish Information Management System linking RA with procuring } \\
\text { entities }\end{array}$ & & $\bullet$ & & RA \\
\hline & $\begin{array}{l}\text { Change legal framework to include private sector representatives and } \\
\text { representatives from the PPB in the PPAA }\end{array}$ & $\bullet$ & & & GoT \\
\hline & Appoint members of the PPAA and ensure it becomes operational & $\bullet$ & & & Appointing bodies \\
\hline & $\begin{array}{l}\text { Provide RA with full monitoring and supervisory powers vis a vis local } \\
\text { government procurement }\end{array}$ & & $\bullet$ & & GoT/RA/PO-RALG \\
\hline & Transform Supplies Units into PMUs & $\bullet$ & & & GoT (all procuring entities) \\
\hline & $\begin{array}{l}\text { Conduct information campaign on the new organisational set-up within } \\
\text { procurement }\end{array}$ & & $\bullet$ & & $\mathrm{RA}$ \\
\hline & $\begin{array}{l}\text { Develop initiatives for civil society involvement in Procurement } \\
\text { monitoring }\end{array}$ & & $\bullet$ & & $\overline{R A}$ \\
\hline & $\begin{array}{l}\text { Close Government Stores and introduce system based on framework } \\
\text { agreements }\end{array}$ & & & $\bullet$ & GoT/MoF \\
\hline & Close MSD and introduce framework agreements & & & $\bullet$ & $\mathrm{GoT} / \mathrm{MoH} / \mathrm{MoF}$ \\
\hline & $\begin{array}{l}\text { RESOURCES AND CAPACITY } \\
\text { Replace supplies officers with a new cadre of procurement specialists }\end{array}$ & & & & CSD \\
\hline
\end{tabular}




\begin{tabular}{|c|c|c|c|c|c|}
\hline Section of the report & Actions & $\begin{array}{l}\text { Short term } \\
(<12 \text { months })\end{array}$ & $\begin{array}{c}\text { Medium term } \\
\text { (12-24 months) }\end{array}$ & $\begin{array}{l}\text { Long term } \\
(>24 \text { months) }\end{array}$ & Responsible \\
\hline & in the civil service rating system & & $\bullet$ & & \\
\hline & Conduct certification of procurement specialists & & $\bullet$ & & $\overline{\mathrm{CSD} / \mathrm{PPB}}$ \\
\hline & Replace National Board of Materials Management (NBMM) with PPB & & $\rightarrow$ & & MoW/ NBMM/RA \\
\hline & Introduce SASE scheme for key procurement staff & & $\rightarrow$ & & CSD \\
\hline & Training needs assessment (TNA) across central and local government & $\bullet$ & & & RA/PO- RALG \\
\hline & Survey of potential procurement training institutions & $\bullet$ & & $\bar{c}$ & RA \\
\hline & Develop Public Procurement Training Strategy & $\bullet$ & & & $\overrightarrow{R A}$ \\
\hline & Coordinate and ensure quality of procurement training & & $\bullet$ & & $\overline{\mathrm{RA}}$ \\
\hline & $\begin{array}{l}\text { Implement procurement training programme for public and private } \\
\text { sector }\end{array}$ & & $\bullet$ & & $\begin{array}{l}\text { RA / selected training } \\
\text { institutions/ NCC/ private } \\
\text { sector institutions }\end{array}$ \\
\hline & Establish MBA program in procurement & & & - & $\mathrm{RA} / \mathrm{MoHE}$ \\
\hline \multirow[t]{7}{*}{$\begin{array}{l}\text { Audit and Anti- } \\
\text { Corruption Measures }\end{array}$} & $\begin{array}{l}\text { LEGAL MEASURES } \\
\text { Adopt amendments to Prevention of Corruption Act as suggested by } \\
\text { PCB. Revoke those amendments, which are in contradiction with fair } \\
\text { trial principles }\end{array}$ & $\bullet$ & & & GoT \\
\hline & $\begin{array}{l}\text { Amend Code of Ethics for the Public Service to include disciplinary } \\
\text { measures and enforcement mechanisms }\end{array}$ & $\bullet$ & & & CSD \\
\hline & Adopt Access to Information Act & $\bullet$ & & & GoT \\
\hline & Draft new code of ethics for public procurement professionals & & $\bullet$ & & RA/PPB \\
\hline & Introduce Legal framework for whistleblowing & & $\bullet$ & & GoT/PCB \\
\hline & $\begin{array}{l}\text { CAPACITY, MONITORING AND INFORMATION } \\
\text { Establish procurement hotline }\end{array}$ & $\bullet$ & & & RA/ PCB \\
\hline & $\begin{array}{l}\text { Develop and implement information campaign on procurement reiated } \\
\text { whistleblowing }\end{array}$ & & $\bullet$ & & $\mathrm{RA}$ \\
\hline
\end{tabular}




\begin{tabular}{|c|c|c|c|c|c|}
\hline Section of the report & Actions & $\begin{array}{l}\text { Short term } \\
(<12 \text { months })\end{array}$ & $\begin{array}{c}\text { Medium term } \\
\text { (12-24 months) }\end{array}$ & $\begin{array}{l}\text { Long term } \\
(>24 \text { months) }\end{array}$ & Responsible \\
\hline & Disseminate and conduct training on Access to Information Act & & $\bullet$ & & $\begin{array}{l}\text { Journalists' Association/ } \\
\text { NGOs }\end{array}$ \\
\hline & $\begin{array}{l}\text { Strengthen the audit capacity of the NAO and increase the frequency } \\
\text { of audits }\end{array}$ & $\bullet$ & & & NAO \\
\hline & $\begin{array}{l}\text { Strengthen internal controls and audit functions of ministries and other } \\
\text { government agencies. }\end{array}$ & & $\bullet$ & & GoT/NAO \\
\hline & $\begin{array}{l}\text { Establish joint investigation and monitoring teams between the RA, the } \\
\text { PCB and the NAO }\end{array}$ & & $\bullet$ & & $\mathrm{RA} / \mathrm{PCB} / \mathrm{NAO}$ \\
\hline & Develop and implement training for PCB investigators & & $\bullet$ & & $\begin{array}{l}\text { RA/training institutions/ } \\
\text { PCB }\end{array}$ \\
\hline & $\begin{array}{l}\text { Develop capacity building scheme for NGOs to enhance NGO } \\
\text { monitoring of public procurement }\end{array}$ & & $\bullet$ & & GoT/RA \\
\hline & $\begin{array}{l}\text { Government adopt and use performance indicators on corruption in } \\
\text { procurement }\end{array}$ & & $\bullet$ & & GoT/GGCU \\
\hline & Develop and implement procurement training for journalists & & & $\bullet$ & $\begin{array}{l}\text { RA/ Journalist Training } \\
\text { Institution } \\
\end{array}$ \\
\hline \multirow[t]{7}{*}{ E-Procurement } & Provide access to the Procurement Journal through the Internet & $\bullet$ & & & $\mathrm{RA}$ \\
\hline & Launch project assessing climate for e-procurement & $\bullet$ & & & $\mathrm{RA} / \mathrm{MoF}$ \\
\hline & Develop centralized database of prices on commonly procured items & & $\bullet$ & & $\overline{\mathrm{RA}}$ \\
\hline & Support ongoing efforts to introduce IT in the entire public sector. & & 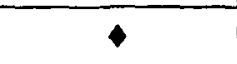 & & GoT/CSD \\
\hline & $\begin{array}{l}\text { Make tender documents, CTB decisions and relevant court decisions } \\
\text { available for electronic downloading }\end{array}$ & & 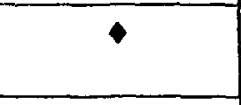 & & RA \\
\hline & Establish pilot projects & & $\bullet$ & & GoT \\
\hline & Enable public access to the procurement protocol & & & $\bullet$ & GoT \\
\hline \multirow[t]{2}{*}{$\begin{array}{l}\text { Trade practices and } \\
\text { Customs }\end{array}$} & $\begin{array}{l}\text { Looking into the possibilities of establishing a guarantee scheme or } \\
\text { another support measure (excluding subsidisation) that may lower cost } \\
\text { of obtaining letters of credit for suppliers. }\end{array}$ & & - & & GoT \\
\hline & Intensify the ef fort to implement and enforce ethically correct practices & 4 & & & MOF/TRA \\
\hline
\end{tabular}




\begin{tabular}{|c|c|c|c|c|c|}
\hline Section of the report & Actions & $\begin{array}{l}\text { Short term } \\
\text { (<12 months) }\end{array}$ & $\begin{array}{c}\text { Medium term } \\
\text { (12-24 months) }\end{array}$ & $\begin{array}{l}\text { Long term } \\
\text { (> } 24 \text { months) }\end{array}$ & Responsible \\
\hline & $\begin{array}{l}\text { as well as adherence with rules and regulations on the side of customs, } \\
\text { importers and clearing agents. Legal action has to be taken and } \\
\text { penalties imposed on importers that are "caught cheating" }\end{array}$ & & & & \\
\hline & $\begin{array}{l}\text { Elaborate and implement an obligatory training programme for } \\
\text { clearing agents }\end{array}$ & & 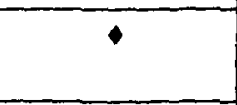 & & TRA \\
\hline & Draw up an implement a plan for a shift from PSI to DI & $\bullet$ & & & MoF/TRA \\
\hline & $\begin{array}{l}\text { Outsource implementation and operation of Destination Inspection to a } \\
\text { private inspection company }\end{array}$ & & + & & MOF/TRA \\
\hline & Hand back the operation to customs when capacity is in place & & & - & MoF/TRA \\
\hline \multirow{4}{*}{$\begin{array}{l}\text { Private Sector } \\
\text { Commercial Practices } \\
\text { and Procurement }\end{array}$} & Improve businesses access to collateral & - & & & GoT/MoTI \\
\hline & $\begin{array}{l}\text { Look into the possibilities of establishing a guarantee scheme or } \\
\text { another support measure (excluding any forms of subsidisation) that } \\
\text { may lower the high interest as well as performance and bid bond costs }\end{array}$ & - & & & GoT/MoTI \\
\hline & $\begin{array}{l}\text { Establish and enforce procedures that allow companies to obtain } \\
\text { closure of their tax payments at the end of each year }\end{array}$ & $\cdot$ & & & MoF/TRA \\
\hline & $\begin{array}{l}\text { Incorporate experienced procurement officers as trainers in their } \\
\text { training institutions procurement courses }\end{array}$ & & $\bullet$ & & $\begin{array}{l}\text { Procurement training } \\
\text { institutions }\end{array}$ \\
\hline \multirow[t]{6}{*}{ Zanzibar } & $\begin{array}{l}\text { LEGAL FRAMEWORK, PROCEDURES \& ORGANISATION } \\
\text { Issue intermediary instructions to provide minimum legal framework } \\
\text { for procurement }\end{array}$ & $\bullet$ & & & MoFEA \\
\hline & $\begin{array}{l}\text { Revise the legal framework, i.e. the CTBA to reflect standards of a } \\
\text { sound procurement system }\end{array}$ & $\bullet$ & & & GoZ/MoFEA \\
\hline & Draft and issue Regulations & 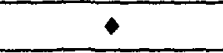 & & & MoFEA \\
\hline & Reform the CTB to a purely regulatory body & + & & & GoZ/MoFEA \\
\hline & Establish ministerial tender boards and PMUs & & $\div$ & & All line ministries \\
\hline & Decentralise procurement to level of MDAs and parastatais & & - & & GoZ/MoFEA \\
\hline
\end{tabular}




\begin{tabular}{|c|c|c|c|c|c|}
\hline Section of the report & Actions & $\begin{array}{l}\text { Short term } \\
(<12 \text { months })\end{array}$ & $\begin{array}{l}\text { Medium term } \\
\text { (12-24 months) }\end{array}$ & $\begin{array}{l}\text { Long term } \\
\text { (>24 months) }\end{array}$ & Responsible \\
\hline & Establish a Public Procurement Appeals Body & & 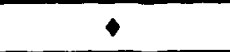 & & GoZ \\
\hline & $\begin{array}{l}\text { Develop and implement a capacity building programme for } \\
\text { organizational and human development in procurement }\end{array}$ & & & $\bullet$ & RAZ \\
\hline & $\begin{array}{l}\text { Develop and implement procurement training programme for key } \\
\text { institutions and individuals. }\end{array}$ & & $\bullet$ & & $\begin{array}{l}\text { RAZ/ Training institutions } \\
\text { (also mainland) }\end{array}$ \\
\hline & $\begin{array}{l}\text { ANTI-CORRUPTION } \\
\text { Develop anti-corruption strategy and action plan for Zanzibar }\end{array}$ & - & & & GoZ/MoSCAGG \\
\hline & Review of the current legal framework of relevance to anti-corruption & 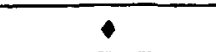 & & & MoSCAGG \\
\hline & $\begin{array}{l}\text { Training for } 2-3 \text { investigators from the Anti-corruption and Fraud } \\
\text { Squad }\end{array}$ & 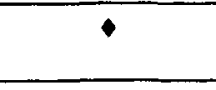 & & & RAZ/PCB \\
\hline & $\begin{array}{l}\text { Strengthen collaboration and coordination with the anti-corruption } \\
\text { institutions of Tanzania mainland }\end{array}$ & & $\bullet$ & & GoZ/MoSCAGG \\
\hline & $\begin{array}{l}\text { Initiate sensitisation of the civil society, media, business community } \\
\text { and general public on corruption matters }\end{array}$ & & $\bullet$ & & RAZ \\
\hline & $\begin{array}{l}\text { PRIVATE SECTOR } \\
\text { Outsource destination inspection to a private inspection agency }\end{array}$ & & - & & GoZ \\
\hline
\end{tabular}





\section{F. ANNEXES}

$\begin{array}{ll}\text { Annex I } & \text { List of People Met } \\ \text { Annex II } & \text { List of Documents Consulted } \\ \text { Annex III } & \text { List of Task Force Members/Government Procurement Task Force } \\ \text { Annex IV } & \text { Detailed Breakdown of Supplies Officers in Public Service } \\ \text { Annex V } & \text { Anti-Corruption Initiatives } \\ \text { Annex VI } & \text { NACSAP Action Plan for Public Procurement } \\ \text { Annex VII } & \text { Checklist Comparing National Competitive Bidding Procedures } \\ & \text { And World Bank Policy }\end{array}$



ANNEX I

\section{LIST OF PEOPLE MET}

\section{Tanzania mainland:}

\begin{tabular}{|c|c|c|}
\hline Name & Title & Institution/ Company \\
\hline Mr. N.S.D. Nkinga & Secretary & $\begin{array}{l}\text { Central Tender Board, Ministry } \\
\text { of Finance }\end{array}$ \\
\hline Mr. G.J. Rubibira & $\begin{array}{l}\text { Ag. Chief Engineer, Contracts } \\
\text { Control Unit }\end{array}$ & Ministry of Works \\
\hline Mr. Marmo & Acting Chief Executive & TANROADS \\
\hline Mr. Ambrose R. M. Gamba & Senior Procurement Engineer & TANROADS \\
\hline Mr. Kicheri & Deputy Internal Auditor & TANROADS \\
\hline Mr. E. K. Shuli & $\begin{array}{l}\text { Assistant Auditor General } \\
\text { (Ministries) }\end{array}$ & National Audit Office \\
\hline Mr. P. Lyimo & Permanent Secretary & Ministry of Finance \\
\hline Mr. Nyamtara D. Mukome & $\begin{array}{l}\text { Programme Support Services } \\
\text { Officer }\end{array}$ & $\begin{array}{l}\text { Ministry of Finance/ European } \\
\text { Development Fund Support } \\
\text { Unit }\end{array}$ \\
\hline Mr. M. J. Kamba & Principal State Attorney & Attorney General's Chambers \\
\hline Mr. Hussein H. Bachoo & Supplies officer & Attorney General's Chambers \\
\hline Mrs. Caroline M. Mdundo & Programme Administrator & Attorney General's Chambers \\
\hline Mr. Patrick N. Kassera & Deputy Commissioner & Tanzania Revenue Authority \\
\hline Mr. S.S. Yusufu & $\begin{array}{l}\text { Deputy Commissioner for } \\
\text { Customs \& Excise, Dar es } \\
\text { Salaam }\end{array}$ & Tanzania Revenue Authority, \\
\hline Mr. H. J. Shamumoyo & Outcome Manager, Legal & $\begin{array}{l}\text { Local Government Reform } \\
\text { Programme/ President's Office, } \\
\text { Regional Administration and } \\
\text { Local Govermment }\end{array}$ \\
\hline Mrs. Selina A. Mkony & Programme Manager & $\begin{array}{l}\text { Public Service Reform } \\
\text { Programme/ Civil Service } \\
\text { Department of the President's } \\
\text { Office }\end{array}$ \\
\hline Mr. George D. Yambesi & Director of Policy Development & $\begin{array}{l}\text { Civil Service Department of the } \\
\text { President's Office }\end{array}$ \\
\hline Mr. Wilyam Kleiman & Chief Technical Adviser & $\begin{array}{l}\text { Civil Service Department of the } \\
\text { President's Office }\end{array}$ \\
\hline Mr. Peter Miyansi & Director Record \& Achirve & $\begin{array}{l}\text { Civil Service Department of the } \\
\text { President's Office }\end{array}$ \\
\hline Mr. David Sawe & Director Management Services & $\begin{array}{l}\text { Civil Service Department of the } \\
\text { President's Office }\end{array}$ \\
\hline Mr. Eugene Mayowera & $\begin{array}{l}\text { Ag. Director Management } \\
\text { Services }\end{array}$ & $\begin{array}{l}\text { Civil Service Department of the } \\
\text { President's Office }\end{array}$ \\
\hline Mrs. A. Nyondo & Director Ethics & $\begin{array}{l}\text { Civil Service Department of the } \\
\text { President's Office }\end{array}$ \\
\hline Mr. C.J. Ngutunyi & Head of Administration & $\begin{array}{l}\text { Civil Service Department of the } \\
\text { President's Office }\end{array}$ \\
\hline Mrs. Agnes Meena & $\begin{array}{l}\text { Assistant Director Policy } \\
\text { Development }\end{array}$ & $\begin{array}{l}\text { Civil Service Department of the } \\
\text { President's Office }\end{array}$ \\
\hline Mr. Samson K. Fimbo & $\begin{array}{l}\text { Director, Human Resource } \\
\text { Development Division }\end{array}$ & $\begin{array}{l}\text { Civil Service Department of the } \\
\text { President's Office }\end{array}$ \\
\hline F.A. Mandara & Secretary & Ethics Secretariat \\
\hline Mrs. Susanne Frederiksen & Counsellor/Aid Accountability & DANIDA \\
\hline Mr. E. N. Warsanga Shayo & $\begin{array}{l}\text { Director of Administration and } \\
\text { Personnel }\end{array}$ & Ministry of Health \\
\hline Mr. Golden E. Masinga & Senior Supplies Officer & Ministry of Health \\
\hline
\end{tabular}




\begin{tabular}{|c|c|c|}
\hline Name & Title & Institution/Company \\
\hline Mr. S. Ndandala & Senior Supplies Officer & Ministry of Health \\
\hline Mr. Mwanukuzi & Head of Physical Planning Unit & $\begin{array}{l}\text { Ministry of Education and } \\
\text { Culture }\end{array}$ \\
\hline Mr. Sambega & $\begin{array}{l}\text { Secretary of the Ministerial } \\
\text { Tender Board }\end{array}$ & $\begin{array}{l}\text { Ministry of Education and } \\
\text { Culture }\end{array}$ \\
\hline Mr. G. R. Bakula & $\begin{array}{l}\text { Quantity Surveyor - Physical } \\
\text { Planning Unit }\end{array}$ & $\begin{array}{l}\text { Ministry of Education and } \\
\text { Culture }\end{array}$ \\
\hline Mr. Hubert Mrango & $\begin{array}{l}\text { Director, Eternal Sector } \\
\text { Division }\end{array}$ & $\begin{array}{l}\text { President's Office / Planning } \\
\text { and Privatization }\end{array}$ \\
\hline Mrs. Grace L. Mosha & Senior Economist & $\begin{array}{l}\text { President's Office / Planning } \\
\text { and Privatization }\end{array}$ \\
\hline Mr. Jeremy Orton & Programme Officer & DFID \\
\hline Mr. Iain Alexander & $\begin{array}{l}\text { Procurement and Contracts } \\
\text { Manager }\end{array}$ & DFID \\
\hline Mr. Jan Erik Rasmussen & $\begin{array}{l}\text { First Secretary, Infrastructure } \\
\text { and Energy }\end{array}$ & NORAD \\
\hline Mr. Edward G. Hoseah & Director of Investigations & $\begin{array}{l}\text { President's Office / Prevention } \\
\text { of Corruption Bureau (PCB) }\end{array}$ \\
\hline Mr. Oscar B. Hosea & Civil Engineer & $\begin{array}{l}\text { President's Office / Prevention } \\
\text { of Corruption Bureau (PCB) }\end{array}$ \\
\hline Dr. Vincent Kihiyo & $\begin{array}{l}\text { Director, Research Control and } \\
\text { Statistics }\end{array}$ & $\begin{array}{l}\text { President's Office/Prevention of } \\
\text { Corruption Bureau }\end{array}$ \\
\hline Mr. Msemo & Director of Procurement & Medical Stores Department \\
\hline Mr. Mayaya & Coordinator & $\begin{array}{l}\text { President's Office / Good } \\
\text { Governance Coordination Unit }\end{array}$ \\
\hline Mr. Mathias Chitunchi & Assistant Coordinator & $\begin{array}{l}\text { President's Office / Good } \\
\text { Governance Coordination Unit }\end{array}$ \\
\hline Mr. Geofrey E. Mungure & Senior Procurement Officer & Central Government Stores \\
\hline Mr. Heny B. Njuguna & $\begin{array}{l}\text { Chief Consultant, Transport and } \\
\text { Infrastructure }\end{array}$ & $\begin{array}{l}\text { Eastern and Southern African } \\
\text { Management Institute - ESAMI, } \\
\text { Arusha }\end{array}$ \\
\hline Mr. B.C. Muhegi & Registrar & Contractors Registration Board \\
\hline Mr. Magesa C. Bairi & $\begin{array}{l}\text { Assistant Registrar, Registration } \\
\text { Services }\end{array}$ & Contractors Registration Board \\
\hline Mr. Emmanuel Taseni & Principal Research Officer & Contractors Registration Board \\
\hline Mr. Clemence P. Tesha & Registrar & $\begin{array}{l}\text { National Board for Materials } \\
\text { Management (NBMM) }\end{array}$ \\
\hline Mr. Douglas Arbucle & $\begin{array}{l}\text { Executive Officer/ Assistant } \\
\text { Programme Officer }\end{array}$ & USAID \\
\hline Mr. Aziz Kilonge & Procurement Agent & USAID \\
\hline Mr. Jimmi R. Msaki & Aid Program Assistant & USAID \\
\hline Mrs. Gudrun Leirvaag & Programme Officer & SIDA \\
\hline Mr. Remmy N. F. Temba & Executive Director & $\begin{array}{l}\text { Centre for International } \\
\text { Business Development Service } \\
\text { Ltd. (CIBDS) }\end{array}$ \\
\hline Aloyce P. Mushi & Chairman & $\begin{array}{l}\text { Tanzania Association of } \\
\text { Consultants }\end{array}$ \\
\hline Mr. Severinus M. Hyera & Principal & $\begin{array}{l}\text { College of Business Education, } \\
\text { Dar es Salaam }\end{array}$ \\
\hline Ms. Itika Hilda Mafwenga & $\begin{array}{l}\text { Vice Principal / Director of } \\
\text { Studies }\end{array}$ & $\begin{array}{l}\text { College of Business Education, } \\
\text { Dar es Salaam }\end{array}$ \\
\hline Mr. Ben Andrew Mukiramweni & Chief Economist & $\begin{array}{l}\text { Tanzania Private Sector } \\
\text { Foundation (TPSF) } \\
\end{array}$ \\
\hline Mr. Samson Chemponda & Economist & $\begin{array}{l}\text { Tanzania National Business } \\
\text { Council (TNBC) }\end{array}$ \\
\hline Geir Sundet & Specialist in Governance & UNDP \\
\hline Mr. Peter N. M. Mangunguli & Director & Central Government Stores \\
\hline Mr. Geoffrey Elisa Mungure & Senior Procurement Officer & Central Government Stores \\
\hline Mr. Deogratius B. Kumalija & Purchasing Officer & Central Government Stores \\
\hline
\end{tabular}




\begin{tabular}{|c|c|c|}
\hline Name & Title & Institution/Company \\
\hline $\begin{array}{l}\text { Mr. Magelan L. Sakinoi } \\
\text { (MCIPS) }\end{array}$ & $\begin{array}{l}\text { Deputy Comissioner for } \\
\text { Procurement \& Office Services }\end{array}$ & Tanzania Revenue Authority \\
\hline Mr. Craig Harebottle & $\begin{array}{l}\text { Finance \& Administration } \\
\text { Manager }\end{array}$ & D.T. Dobie \& Company (T) Ltd \\
\hline Mr. Keelapudi M. Reddy & $\begin{array}{l}\text { Procurement Advisor, Tax } \\
\text { Administration Project }\end{array}$ & Tanzania Revenue Authority \\
\hline $\begin{array}{l}\text { Mr. Kesogukewele M.I.M. } \\
\text { Msita, }\end{array}$ & Executive Secretary & National Construction Council \\
\hline Mr. Julius G. Mamiro & Chief consultant & National Construction Council \\
\hline Mirs. Beatrice M. Mutabazi & Deputy Director & Tanzania Bureau of Standards \\
\hline Mr. V.P. (Verne) Kulyk & General Manager & Cotecna Inspection S.A. \\
\hline Mr. Fred Chatelin & Operations Manager & Cotecna Inspection S.A. \\
\hline Mr. Patrick N. Kassera & $\begin{array}{l}\text { Deputy Commissioner, Income } \\
\text { Tax Department (Up-Country } \\
\text { Regions and Technical } \\
\text { Services) }\end{array}$ & Tanzania Revenue Authority \\
\hline Mr. Walid Juma & $\begin{array}{l}\text { Deputy Commissioner, Internal } \\
\text { Audit }\end{array}$ & Tanzania Revenue Authority \\
\hline Ms. J.M. Kiwelu & Manager & CRDB Bank Ltd \\
\hline Mrs. Martha S. Kalipeni & Manager, International Banking & CRDB Bank Ltd \\
\hline Anderson Y.L. Mlabwa & Director of Credit & CRDB Bank Limited, \\
\hline Gothalm C.K. Mbele & Head of Finance & Tanzania Bancorp Ltd. \\
\hline Isaac Dallushi & Chairman & $\begin{array}{l}\text { Tanzania Chamber of } \\
\text { Commerce, Industry and } \\
\text { Agriculture }\end{array}$ \\
\hline Poul Makanza & Director Corporate Affairs & Tanzania Cigarette Company \\
\hline Henry Mpande & Ass. Operations Manager & $\begin{array}{l}\text { ICS, Inspection \& Control } \\
\text { Services Ltd. }\end{array}$ \\
\hline David Christian & General manager & $\begin{array}{l}\text { ICS, Inspection \& Control } \\
\text { Services Ltd. }\end{array}$ \\
\hline C. Mui & Executive Secretary & $\begin{array}{l}\text { Tanzania Civil Engineers } \\
\text { Contractors Association }\end{array}$ \\
\hline S.l. Kishimbo & Chairman & $\begin{array}{l}\text { Tanzania Civil Engineers } \\
\text { Contractors Association }\end{array}$ \\
\hline Salum Dhiyebi & Honorary Treasurer & $\begin{array}{l}\text { Tanzania Civil Engineers } \\
\text { Contractors Association }\end{array}$ \\
\hline M. Njiu & $\begin{array}{l}\text { Managing Director and Former } \\
\text { Chairman of the Association of } \\
\text { Consulting Engineers Tanzania }\end{array}$ & Inter Consult Ltd \\
\hline A.O. Mkamba & Registrar & Engineers Registration Board \\
\hline Mr. Rutahiwa & $\begin{array}{l}\text { Regional Administrative } \\
\text { Secretary }\end{array}$ & $\begin{array}{l}\text { Office of the Regional } \\
\text { Administrative Secretary - } \\
\text { Mwanza Region }\end{array}$ \\
\hline Mr. Wambura & Regional Stores Officer & $\begin{array}{l}\text { Central Government Stores - } \\
\text { Mwanza Region }\end{array}$ \\
\hline Mr. Lutego & $\begin{array}{l}\text { Head of Tanzania Building } \\
\text { Agency - Mwanza Region }\end{array}$ & $\begin{array}{l}\text { Tanzania Building Agency } \\
\text { Mwanza Regional Building } \\
\text { Agency }\end{array}$ \\
\hline Mr. Leonard B. Bihondo & Lord Mayor & Mwanza City Council \\
\hline Mr. L. Kalokola & City Treasurer & Mwanza City Council \\
\hline Mabula Mageta & Counsellor - Igoma Ward & Mwanza City Council \\
\hline Justus Nyanza & Counsellor - Korani Ward & Mwanza City Council \\
\hline Dismas Masunu & Counsellor - Butimba Ward & Mwanza City Council \\
\hline Mary Hewa & Deputy Mayor & Mwanza City Council \\
\hline Paschal Kabuhwa & Public Relation Officer & Mwanza City Council \\
\hline P. Banuti & Mwanza City Director & Mwanza City Council \\
\hline D. Mulongo & City Economist & Mwanza City Council \\
\hline Ms Ngusa & City Planning Officer & Mwanza City Council \\
\hline
\end{tabular}




\begin{tabular}{|c|c|c|}
\hline Name & Title & Institution/ Company \\
\hline Tizeba & City Engineer & Mwanza City Council \\
\hline A.K. Magogo & Council Chairman & Korogwe District Council \\
\hline Hon. Joel Sendera, MP & Councillor & $\begin{array}{l}\text { Korogwe District Council / East } \\
\text { Constituency }\end{array}$ \\
\hline Hon. Musa Lupan, MP & Councillor & $\begin{array}{l}\text { Korogwe District Council / } \\
\text { Korogwe West }\end{array}$ \\
\hline Tolla S. Michael & Councillor & Korogwe District Council \\
\hline Hon. S-Y Kallaghe, & Councillor & Korogwe District Council \\
\hline Hon. Jaffai Ngude & Councillor & $\begin{array}{l}\text { Korogwe District Council/ } \\
\text { Dindira Ward }\end{array}$ \\
\hline Marian Shemaladi & Councillor & $\begin{array}{l}\text { Korogwe District Council/ } \\
\text { Bungu }\end{array}$ \\
\hline Hon. Halima J. Musa & Councillor & $\begin{array}{l}\text { Korogwe District Council / } \\
\text { Mombo. }\end{array}$ \\
\hline Hon. Theresia Gawile, MP & Councillor & $\begin{array}{l}\text { Korogwe District Council / } \\
\text { Special seats - Female }\end{array}$ \\
\hline Ms Esther Mbigili & (DED) & Korogwe District \\
\hline Dr. B.J. Ngoli & (DMO) & Korogwe District \\
\hline $\begin{array}{l}\text { Mr M.A. Magati (District } \\
\text { Engineer }\end{array}$ & (Works) & Korogwe District \\
\hline Mr Joseph Masanja & District Treasurer & Korogwe District \\
\hline Grace R. Mbamku & District Planning Officer & Arumeru District \\
\hline D.M. Rugangila & Dado & Arumeru District \\
\hline P.M. Mollel & ANRO & Arumeru District \\
\hline Billy Nsigemjura & $\mathrm{Ag} \mathrm{DT}$ & Arumeru District \\
\hline Eng. Mohamed B. Loisengei & District Water Eng. & Arumeru District \\
\hline R.L. Mnyungi & District Engineer - Works & Arumeru District \\
\hline P.S.M. Ngaponsa & District Trade Officer & Arumeru District \\
\hline Jonathan P. Kiama & District Legal Officer & Arumeru District \\
\hline David A- Kaale & District Manpower M. Officer & Arumeru District \\
\hline Solomon N. Ayo & Councillor & $\begin{array}{l}\text { Arumeru District Council/ } \\
\text { Songoro Ward }\end{array}$ \\
\hline Joram Simeon Lomayani & Councillor & $\begin{array}{l}\text { Arumeru District Council/ } \\
\text { Moiyo Ward }\end{array}$ \\
\hline Peter Kyunahi & Councillor & $\begin{array}{l}\text { Arumeru District Council / } \\
\text { Segla Singish Ward }\end{array}$ \\
\hline Thomas L. Mollel & Councillor & Arumeru District Council \\
\hline Akundael L. Nanjaro & Councillor & Arumeru District Council \\
\hline Zablon Ole Muterian & Councillor & $\begin{array}{l}\text { Arumeru District Council/ } \\
\text { Olkokola }\end{array}$ \\
\hline Penina \& Kivuyo Olturumet & Councillor & Arumeru District Council \\
\hline Nemburis ? Kimbele & Vice Chairman & Arumeru District Council \\
\hline $\begin{array}{l}\text { William T. Massary - Mburuma } \\
\text { Ward }\end{array}$ & Councillor & Arumeru District Council \\
\hline Elly H. Mija - Soko II & Councillor & Arumeru District Council \\
\hline Samuel urasa Nkaranga Ward & Councillor & Anumeru District Council \\
\hline Michael S. Mrema & Councillor & $\begin{array}{l}\text { Rombo District Council/ Olele } \\
\text { Ward }\end{array}$ \\
\hline Protas M. Lyakurwa & Councillor & $\begin{array}{l}\text { Rombo District Council / } \\
\text { Mengwe Manda Ward }\end{array}$ \\
\hline Michael I. Laswai & Councillor & $\begin{array}{l}\text { Rombo District Council / } \\
\text { Mokala }\end{array}$ \\
\hline $\begin{array}{l}\text { Tarsilla E. Kimarion } \\
\text { (K(Kinsach }\end{array}$ & Councillor & Rombo District Council \\
\hline Rowani Selasini Makiidi & Councillor & Rombo District Council \\
\hline Mr J.P. Kilonzo & & Rombo District \\
\hline Mr Lukumaijm & District Industrial ?? & Rombo District \\
\hline A.R. Kamuda?? & 4th trade officer & Rombo District \\
\hline Dr Makashi I M & $\mathrm{Ag} \mathrm{DMO}$ & Rombo District \\
\hline
\end{tabular}




\begin{tabular}{|l|l|l|}
\hline Name & Title & Institution/ Company \\
\hline N.A. Musamnyati & $\begin{array}{l}\text { District Education Statistics \& } \\
\text { Logistics Officer (AG DEO) }\end{array}$ & Rombo District \\
\hline M. Bikombo & District Internal Auditor & Rombo District \\
\hline W. Sahu?? & & Rombo District \\
\hline Nyander N.S.S. & & Rombo District \\
\hline
\end{tabular}

\section{Zanzibar:}

\begin{tabular}{|c|c|c|}
\hline Name & Title & Company \\
\hline Mr. J.B. Raphael & Principal Secretary & $\begin{array}{l}\text { Ministry of Finance \& } \\
\text { Economic Affairs }\end{array}$ \\
\hline Mrs. J.A. Meze & Deputy Principal Secretary (E) & $\begin{array}{l}\text { Ministry of Finance \& } \\
\text { Economic Affairs }\end{array}$ \\
\hline Mr. A.K. Shaaban & Deputy Principal Secretary (EA) & $\begin{array}{l}\text { Ministry of Finance \& } \\
\text { Economic Affairs }\end{array}$ \\
\hline Mr. Salum K. Nassor & $\begin{array}{l}\text { Commissioner for Stock } \\
\text { Verification }\end{array}$ & $\begin{array}{l}\text { Ministry of Finance \& } \\
\text { Economic Affairs }\end{array}$ \\
\hline Mr. Hussein S. Khatib & $\begin{array}{l}\text { Commissioner for Stock } \\
\text { Verification }\end{array}$ & $\begin{array}{l}\text { Ministry of Finance \& } \\
\text { Economic Affairs }\end{array}$ \\
\hline Mr. Ame B. Ame & Accountant General & $\begin{array}{l}\text { Ministry of Finance \& } \\
\text { Economic Affairs }\end{array}$ \\
\hline Mr. Yussuf B. Hija & Planning, ZPC & $\begin{array}{l}\text { Ministry of Finance \& } \\
\text { Economic Affairs }\end{array}$ \\
\hline Mr. Sharif A. Shauri & Budget Officer & $\begin{array}{l}\text { Ministry of Finance \& } \\
\text { Economic Affairs }\end{array}$ \\
\hline Mrs. Janet E. Lutansuka & Stock verification officer & $\begin{array}{l}\text { Ministry of Finance \& } \\
\text { Economic Affairs }\end{array}$ \\
\hline Mr. Othman Tuma & Stock verification officer & $\begin{array}{l}\text { Ministry of Finance \& } \\
\text { Economic Affairs }\end{array}$ \\
\hline Dr. Omar Makame Shauri & Principal Secretary & Ministry of Health \\
\hline Mrs. Mwaka A. Said & $\begin{array}{l}\text { Director of Planning and } \\
\text { Administration }\end{array}$ & Ministry of Health \\
\hline Dr. T.F. Thani & Director of Curative Services & Ministry of Health \\
\hline Mr. Faffar A, Mussa & Chief Supplies Officer & Ministry of Health \\
\hline Mr. Mohammed Kafir & Chief Pharmacist & Ministry of Health \\
\hline Mr. Juma R. Kassu & Chief Accountant & Ministry of Health \\
\hline Mr. Hamid Juma & Sub-accountant & Ministry of Health \\
\hline Mr. Hassan H. Wambi & Principal Secretary & $\begin{array}{l}\text { Ministry of State Regional } \\
\text { Administration and Local } \\
\text { Government }\end{array}$ \\
\hline Mr. M.V. Simai & Director of Planning & $\begin{array}{l}\text { Ministry of State Regional } \\
\text { Administration and Local } \\
\text { Government }\end{array}$ \\
\hline Mr. R.R. Mohid & UDLANTA & $\begin{array}{l}\text { Ministry of State Regional } \\
\text { Administration and Local } \\
\text { Government }\end{array}$ \\
\hline Mr. Hamad B. Hamad & KMKM & $\begin{array}{l}\text { Ministry of State Regional } \\
\text { Administration and Local } \\
\text { Government }\end{array}$ \\
\hline Mr. Ahmed A. Khamis & Chief Accountant & $\begin{array}{l}\text { Ministry of State Regional } \\
\text { Administration and Local } \\
\text { Government }\end{array}$ \\
\hline Mr. M.O. Jaffar & $\begin{array}{l}\text { Chief Accountant, Fire and } \\
\text { Rescue }\end{array}$ & $\begin{array}{l}\text { Ministry of State Regional } \\
\text { Administration and Local } \\
\text { Government }\end{array}$ \\
\hline Mr. M.R. Mirani & Officer, Fire and Rescue & $\begin{array}{l}\text { Ministry of State Regional } \\
\text { Administration and Local } \\
\text { Govemment }\end{array}$ \\
\hline
\end{tabular}




\begin{tabular}{|l|l|l|}
\hline Name & Title & Company \\
\hline Mr. F.A. Han & JKU & $\begin{array}{l}\text { Ministry of State Regional } \\
\text { Administration and Local } \\
\text { Government }\end{array}$ \\
\hline Mr. M.M. Ali & JKU & $\begin{array}{l}\text { Ministry of State Regional } \\
\text { Administration and Local } \\
\text { Government }\end{array}$ \\
\hline Mr. F.J. Hawab & Volantia & $\begin{array}{l}\text { Ministry of State Regional } \\
\text { Administration and Local } \\
\text { Government }\end{array}$ \\
\hline Mr. H.M. Bakari & MAFUNZO & $\begin{array}{l}\text { Ministry of State Regional } \\
\text { Administration and Local } \\
\text { Government }\end{array}$ \\
\hline Mr. Ali Bashir & $\begin{array}{l}\text { Ministry of State Regional } \\
\text { Administration and Local } \\
\text { Government }\end{array}$ \\
\hline Salma Masoud Ebrahim & Director of Trade & $\begin{array}{l}\text { Ministry of Trade, Industry, } \\
\text { Marketing \& Tourism }\end{array}$ \\
\hline Juma M. Ahmed & Fanzibar Ports Corporation \\
\hline Khamis S Ali (Shaib) & Director & Quality Building Contractors \\
\hline Mahmoud M. Mousa & Operation Manager & Wings \& Wheels Company \\
\hline
\end{tabular}


ANNEX II

\section{LIST OF DOCUMENTS CONSULTED}

\begin{tabular}{|c|c|c|c|c|c|}
\hline No. & Title & $\begin{array}{c}\text { Issued } \\
\text { by }\end{array}$ & Place & $\begin{array}{l}\text { Month/ } \\
\text { Year }\end{array}$ & $\begin{array}{c}\text { Type of } \\
\text { document }\end{array}$ \\
\hline 1. & $\begin{array}{l}\text { An Act to Regulate Public Procurement in the } \\
\text { Government of the United Republic and for the } \\
\text { Related Matters }\end{array}$ & GoT & Tanzania & $\begin{array}{l}\text { Feb/ } \\
2001\end{array}$ & Legal \\
\hline 2. & $\begin{array}{l}\text { Public Procurement (Selection and Employment } \\
\text { of Consultants) Regulations, } 2001 \text { (Government } \\
\text { Notice No. 137) and Procurement of Goods and } \\
\text { Works Regulations, } 2001 \text { (Government Notice } \\
\text { No. 138) }\end{array}$ & GoT & Tanzania & 2001 & Legal \\
\hline 3. & $\begin{array}{l}\text { Code of Procedure for Tendering for Civil and } \\
\text { Building Works in Tanzania }\end{array}$ & GoT & Tanzania & 2000 & Legal \\
\hline 4. & $\begin{array}{l}\text { The Local Government Finance Act, } 1982-\text { No. } \\
9 \text { of } 1982 \text { - Arrangement of Regulations }\end{array}$ & GoT & Tanzania & $\begin{array}{c}\text { Oct } / \\
2000\end{array}$ & Legal \\
\hline 5. & $\begin{array}{l}\text { The Local Government (District Authorities) } \\
\text { Act, } 1982\end{array}$ & GoT & Tanzania & $\begin{array}{l}\text { June/ } \\
2000\end{array}$ & Legal \\
\hline 6. & $\begin{array}{l}\text { Translation of the Local Authority Financial } \\
\text { Memorandum } 1997-\text { Tendering and } \\
\text { Contractual Procedures and Specific Contract } \\
\text { Procedures for Construction and Engineering }\end{array}$ & NCC & Tanzania & 2002 & Legal \\
\hline 7. & $\begin{array}{l}\text { The Local Government Finance Act, } 1982 \text { - No. } \\
9 \text { of } 1982 \text { - Regulations - Selection and } \\
\text { Employment Regulation of Consultants (Draft) }\end{array}$ & GoT & Tanzania & $\begin{array}{l}\text { Oct/ } \\
2002\end{array}$ & Legal \\
\hline 8. & $\begin{array}{l}\text { An Act to Establish the Medical Stores } \\
\text { Department for the Procurement, Storage and } \\
\text { Distribution of Medical Supplies and to Provide } \\
\text { for other Matters Connected or Incidental to the } \\
\text { Establishment and Management of the } \\
\text { Department. }\end{array}$ & GoT & Tanzania & $\begin{array}{l}\text { Sept/ } \\
1993\end{array}$ & Legal \\
\hline 9. & $\begin{array}{l}\text { The Medical Stores Department Act, } 1993 \text { - No. } \\
13 \text { of } 1993 \text { - Regulations }\end{array}$ & GoT & Tanzania & $\begin{array}{l}\text { Sept/ } \\
1996\end{array}$ & Legal \\
\hline 10. & The Contractors Registration Act, 1997 & GoT & Tanzania & $\begin{array}{l}\text { April/ } \\
1997 \\
\end{array}$ & Legal \\
\hline 11. & $\begin{array}{l}\text { National Board for Materials Management Act, } \\
1981\end{array}$ & GoT & Tanzania & $\begin{array}{l}\text { April } \\
1981\end{array}$ & Legal \\
\hline 12. & The Central Tender Board Act & GoZ & Zanzibar & 2002 & Legal \\
\hline 13. & $\begin{array}{l}\text { An Act to Establish The Central Tender Board } \\
\text { in Zanzibar and other Related Matters }\end{array}$ & GoZ & Zanzibar & 2002 & Legal \\
\hline 14. & $\begin{array}{l}\text { An Act to Make Provisions which are Essential } \\
\text { for the Smooth and Effective Working of The } \\
\text { Financial Machinery of Government and other } \\
\text { Matters Connected Therewith }\end{array}$ & GoZ & Zanzibar & 2001 & Legal \\
\hline 15. & The Zanzibar Constitution (Amendment) Act & GoZ & Zanzibar & 1989 & Legal \\
\hline 16. & $\begin{array}{l}\text { Proposed Draft for the Repeal and Replacement } \\
\text { of the Prevention of Corruption Act No. } 16 \text { of } \\
1971 \text { and the Current Prevention of Corruption } \\
\text { Act. }\end{array}$ & GoT & Tanzania & 2002 & Legal \\
\hline 17. & $\begin{array}{l}\text { Agreement and Schedule of Conditions of } \\
\text { Building Contract (With Quantities) }\end{array}$ & & Tanzania & 2000 & \\
\hline 18. & $\begin{array}{l}\text { Report on The Survey of Application of The } \\
\text { Public Procurement Act in The Construction }\end{array}$ & & Tanzania & 2002 & \\
\hline
\end{tabular}




\begin{tabular}{|c|c|c|c|c|c|}
\hline No. & Title & $\begin{array}{c}\text { Issued } \\
\text { by }\end{array}$ & Place & $\begin{array}{c}\text { Month/ } \\
\text { Year }\end{array}$ & $\begin{array}{l}\text { Type of } \\
\text { document }\end{array}$ \\
\hline & Sector & & & & \\
\hline 19. & $\begin{array}{l}\text { Standard Tendering Documents - Procurement } \\
\text { of Goods - International Competitive Tendering }\end{array}$ & GoT & Tanzania & $\begin{array}{l}\text { June/ } \\
2002\end{array}$ & Guide \\
\hline 20. & $\begin{array}{l}\text { Standard Prequalification Document - } \\
\text { Procurement of Works - International } \\
\text { Competitive Tendering }\end{array}$ & GoT & Tanzania & $\begin{array}{l}\text { June/ } \\
2002\end{array}$ & Guide \\
\hline 21. & $\begin{array}{l}\text { Standard Tendering Document - Procurement of } \\
\text { Works - National Competitive Tendering } \\
\text { (Smaller Works Contracts) }\end{array}$ & GoT & Tanzania & $\begin{array}{l}\text { June/ } \\
2002\end{array}$ & Guide \\
\hline 22. & $\begin{array}{l}\text { Guidelines on The Evaluation of Technical and } \\
\text { Financial Proposals and Preparation of } \\
\text { Evaluation Reports - Selection and } \\
\text { Employment of Consultants }\end{array}$ & GoT & Tanzania & $\begin{array}{l}\text { Junel } \\
2002\end{array}$ & Guide \\
\hline 23. & $\begin{array}{l}\text { Standard Request for Proposals - Selection and } \\
\text { Employment of Consultants }\end{array}$ & GoT & Tanzania & $\begin{array}{l}\text { June/ } \\
2002\end{array}$ & Guide \\
\hline 24. & $\begin{array}{l}\text { Standard Tendering Documents - Procurement } \\
\text { of Works - Smaller Contracts - International } \\
\text { Competitive Tendering }\end{array}$ & GoT & Tanzania & $\begin{array}{l}\text { June/ } \\
2002\end{array}$ & Guide \\
\hline 25. & $\begin{array}{l}\text { Tender Evaluation Guidelines - Procurement of } \\
\text { Goods or Works }\end{array}$ & GoT & Tanzania & $\begin{array}{l}\text { June/ } \\
2002\end{array}$ & Guide \\
\hline 26. & $\begin{array}{l}\text { Standard Tendering Documents - Procurement } \\
\text { of Health Sector Goods - (Pharmaceuticals, } \\
\text { Vaccines and Condoms) }\end{array}$ & GoT & Tanzania & $\begin{array}{l}\text { Junel } \\
2002\end{array}$ & Guide \\
\hline 27. & $\begin{array}{l}\text { Comments of NBMM on } \\
\text { Effectiveness/Shortfall and Suggestions on } \\
\text { Improvements Required on Public Procurement } \\
\text { Act. No. } 3 \text { of } 2001\end{array}$ & NBMM & Tanzania & $\begin{array}{l}\text { July/ } \\
2002\end{array}$ & Note \\
\hline 28. & $\begin{array}{l}\text { The National Anti-Corruption Strategy and } \\
\text { Action Plan for Tanzania }\end{array}$ & GoT & Tanzania & $\begin{array}{l}\text { Nov/ } \\
1999 \\
\end{array}$ & $\begin{array}{c}\text { Strategy } \\
\text { paper }\end{array}$ \\
\hline 29. & $\begin{array}{l}\text { Procurement Manual for Local Government } \\
\text { Authorities }\end{array}$ & NCC & Tanzania & $\begin{array}{l}\text { June/ } \\
2002 \\
\end{array}$ & Manual \\
\hline 30. & Invitation to Quote - Supply of Generators & & Tanzania & $\begin{array}{l}\text { Oct } \\
2000 \\
\end{array}$ & \\
\hline 31. & $\begin{array}{l}\text { Standard Tendering Procedure for Works } \\
\text { Contracts }\end{array}$ & & Tanzania & 2000 & \\
\hline 32. & $\begin{array}{l}\text { Ministry of Finance -Central Tender Board - } \\
11^{\text {th }} \text { Ordinary Central Tender Board Meeting }\end{array}$ & CTB & Tanzania & $\begin{array}{l}\text { Aug/ } \\
2002\end{array}$ & $\begin{array}{c}\text { Minutes of } \\
\text { meeting }\end{array}$ \\
\hline 33. & $\begin{array}{l}\text { Ministry of Finance -Central Tender Board - } \\
12^{\text {t }} \text { Ordinary Central Tender Board Meeting }\end{array}$ & CTB & Tanzania & $\begin{array}{l}\text { Oct/ } \\
2000\end{array}$ & $\begin{array}{c}\text { Minutes of } \\
\text { meeting }\end{array}$ \\
\hline 34. & $\begin{array}{l}\text { Ministry of Finance - Central Tender Board - } \\
13^{\text {th }} \text { Ordinary Central Tender Board Meeting }\end{array}$ & CTB & Tanzania & $\begin{array}{l}\text { Oct } \\
2000\end{array}$ & $\begin{array}{c}\text { Minutes of } \\
\text { meeting }\end{array}$ \\
\hline 35. & $\begin{array}{l}\text { Report on the Survey of Application of the } \\
\text { Public Procurement Act in the Construction } \\
\text { Sector }\end{array}$ & NCC & Tanzania & $\begin{array}{l}\text { Aug/ } \\
2002\end{array}$ & Report \\
\hline 36. & $\begin{array}{l}\text { Strategic Indicators for Monitoring Cross- } \\
\text { Cutting Governance Trends }\end{array}$ & $\begin{array}{l}\text { MoF/ } \\
\text { WB }\end{array}$ & Tanzania & $\begin{array}{l}\mathrm{Feb} / \\
2002\end{array}$ & Note \\
\hline 37. & $\begin{array}{l}\text { Tanzania's Third Phase Government Fight } \\
\text { Against Corruption: A Brief on Achievements } \\
\text { and Challenges 1995-1999 }\end{array}$ & GoT & Tanzania & $\begin{array}{l}\mathrm{Feb} / \\
1999\end{array}$ & Brief report \\
\hline 38. & $\begin{array}{l}\text { The State of Corruption in Tanzania - Annual } \\
\text { Report } 2002 \text { - Final Draft Report }\end{array}$ & $\begin{array}{c}\text { ESRF/ } \\
\text { FACEIT }\end{array}$ & Tanzania & $\begin{array}{l}\text { Oct/ } \\
2002\end{array}$ & Report \\
\hline 39. & Misa -Tan: Media Law Reform Project & MLRP & Tanzania & $\begin{array}{l}\text { Nov/ } \\
2002\end{array}$ & Note \\
\hline
\end{tabular}




\begin{tabular}{|c|c|c|c|c|c|}
\hline No. & Title & $\begin{array}{c}\text { Issued } \\
\text { by }\end{array}$ & Place & $\begin{array}{l}\text { Month/ } \\
\text { Year }\end{array}$ & $\begin{array}{c}\text { Type of } \\
\text { document }\end{array}$ \\
\hline 40. & $\begin{array}{l}1^{\text {st }} \text { Quaterly Monitoring Report - January- } \\
\text { March } 2002\end{array}$ & GoT & Tanzania & 2002 & Report \\
\hline 41. & $\begin{array}{l}\text { Strategic Management and Good Governance } \\
\text { Reporting: Monitoring and Controlling the } \\
\text { Legal and Judicial Processes Relating to Cases } \\
\text { of Comuption, Fraud, Embezzlement, Graft, } \\
\text { Nepotism, etc. }\end{array}$ & GoT & Tanzania & $\begin{array}{l}\text { Nov/ } \\
2002\end{array}$ & Note \\
\hline 42. & $\begin{array}{l}\text { A Tool-Kit for Good Governance at Village } \\
\text { Level }\end{array}$ & UNDP & Tanzania & $\begin{array}{l}\text { Nov' } \\
2001\end{array}$ & Draft note \\
\hline 43. & $\begin{array}{l}\text { Presidents Office - Regional Administration } \\
\text { and Local Government - Terms of Reference - } \\
\text { Preparation of Handbook for Village } \\
\text { Governments }\end{array}$ & GoT & Tanzania & - & ToR \\
\hline 44. & Public Expenditure Tracking Pilot Project & - & - & - & $\begin{array}{l}\text { Project } \\
\text { proposal }\end{array}$ \\
\hline 45. & $\begin{array}{l}\text { Public Procurement Reform - For Good } \\
\text { Governance and Capacity Development }\end{array}$ & - & - & $\begin{array}{l}\text { Oct } \\
2002\end{array}$ & Paper \\
\hline 46. & $\begin{array}{l}\text { The National Anti - Corruption Strategy and } \\
\text { Sector Specific Action Plans for all Ministries } \\
\text { and Independent Government Departments }\end{array}$ & GoT & Tanzania & $\begin{array}{l}\text { Ded } \\
2002\end{array}$ & $\begin{array}{l}\text { Strategy } \\
\text { plan }\end{array}$ \\
\hline 47. & $\begin{array}{l}\text { Public Service Reform Programme - Internal } \\
\text { Memorandum - PSRP Training Plan (2002 - } \\
2002)\end{array}$ & GoT & Tanzania & $\begin{array}{l}\text { June/ } \\
2002\end{array}$ & $\begin{array}{l}\text { Memorand } \\
\text { um }\end{array}$ \\
\hline 48. & $\begin{array}{l}\text { Public Service Management and Employment } \\
\text { Policy }\end{array}$ & GoT & Tanzania & - & $\begin{array}{l}\text { Policy } \\
\text { paper }\end{array}$ \\
\hline 49. & Public Service Medium Term Pay Policy & GoT & Tanzania & $\begin{array}{l}\text { Jan/ } \\
1999 \\
\end{array}$ & $\begin{array}{l}\text { Policy } \\
\text { paper }\end{array}$ \\
\hline 50. & Overview of Various Cardre and Pay Scale & $\mathrm{CSD}$ & Tanzania & - & Note \\
\hline 51. & $\begin{array}{l}\text { Selective Accelerated Salary Enhancement } \\
\text { (SASE) }\end{array}$ & WB & - & - & Note \\
\hline 52. & $\begin{array}{l}\text { Journal of the Tanzania Public Service Reform } \\
\text { Programme - First Issue } 2002\end{array}$ & GoT & Tanzania & 2002 & Journal \\
\hline \multicolumn{6}{|c|}{ 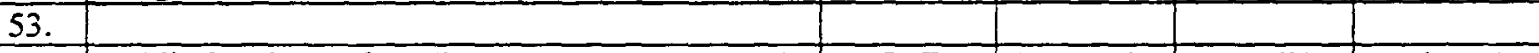 } \\
\hline 54. & $\begin{array}{l}\text { Public Service Reform Programme - Strategy \& } \\
\text { Action Plan, } 1999-2004 \text { - Volume } 1\end{array}$ & GoT & Tanzania & $\begin{array}{c}\text { April/ } \\
1999 \\
\end{array}$ & Action plan \\
\hline 55. & $\begin{array}{l}\text { Revised Public Financial Management Reform } \\
\text { Programme }\end{array}$ & GoT & Tanzania & $\begin{array}{r}\text { Oct/ } \\
2002 \\
\end{array}$ & $\begin{array}{l}\text { Gvt. } \\
\text { programme }\end{array}$ \\
\hline 56. & $\begin{array}{l}\text { The State of Corruption in Tanzania Annual } \\
\text { Report } 2001 \text { - Evaluation of the Controller and } \\
\text { Auditor General Reports } 1997-2000\end{array}$ & $\begin{array}{c}\text { ESRF/ } \\
\text { FACEIT }\end{array}$ & Tanzania & $\begin{array}{l}\text { May/ } \\
2002\end{array}$ & Report \\
\hline 57. & $\begin{array}{l}\text { Audit of Local Government Accounts for the } \\
\text { Year ended } 31^{\text {st }} \text { December, } 2000\end{array}$ & NAO & Tanzania & - & $\begin{array}{l}\text { Audit } \\
\text { report }\end{array}$ \\
\hline 58. & $\begin{array}{l}\text { Audited Accounts and Management Audit } \\
\text { Report on the Financial Statements on the } \\
\text { Tanzania National Roads Agency (Tanroads) } \\
\text { for the Year ended } 30^{\text {th }} \text { June, } 2001\end{array}$ & NAO & Tanzania & - & $\begin{array}{l}\text { Audit } \\
\text { report }\end{array}$ \\
\hline 59. & Tanzania - Foreign Trade Barriers & & - & - & Note \\
\hline 60. & $\begin{array}{l}\text { Tanzania Assistance Strategy - Tanzania } \\
\text { Country Profile - Volume. I }\end{array}$ & GoT & Tanzania & - & $\begin{array}{l}\text { Strategy } \\
\text { paper }\end{array}$ \\
\hline 61. & $\begin{array}{l}\text { Government Note on Partnership Issues - } \\
\text { Statement by the Ministry of Finance }\end{array}$ & GoT & Tanzania & $\begin{array}{l}\mathrm{Dec} / \\
2002 \\
\end{array}$ & Statement \\
\hline 62. & $\begin{array}{l}\text { Brief on Governance to the Consultative Group } \\
\text { Meeting }\end{array}$ & GoT & Tanzania & $\begin{array}{l}\mathrm{Dec} / \\
2002 \\
\end{array}$ & Note \\
\hline
\end{tabular}




\begin{tabular}{|c|c|c|c|c|c|}
\hline No. & Title & $\begin{array}{c}\text { Issued } \\
\text { by }\end{array}$ & Place & $\begin{array}{l}\text { Month/ } \\
\text { Year }\end{array}$ & $\begin{array}{c}\text { Type of } \\
\text { document }\end{array}$ \\
\hline 63. & $\begin{array}{l}\text { Joint Statement on the Poverty Reduction } \\
\text { Budget Support Facility and the Harmonization } \\
\text { with the World Bank PRSC }\end{array}$ & $\begin{array}{l}\text { Consult } \\
\text { Group } \\
2002 \\
\end{array}$ & 一 & 2002 & Statement \\
\hline 64. & $\begin{array}{l}\text { Economic and Social Research Foundation } \\
\text { (ESRF) - Enhancing aid Relationships in } \\
\text { Tanzania: Report of the Independent Monitoring } \\
\text { Group }\end{array}$ & $\begin{array}{l}\text { Independ } \\
\text { ent } \\
\text { Monitori } \\
\text { ng Group }\end{array}$ & - & $\begin{array}{l}\text { Nov/ } \\
2002\end{array}$ & Report \\
\hline 65. & $\begin{array}{l}\text { Statement by the IMF Representative } \\
\text { Consultative Group Meeting for Tanzania }\end{array}$ & $\mathrm{IMF}$ & Tanzania & $\begin{array}{l}\text { Decl } \\
2002\end{array}$ & Statement \\
\hline 66. & $\begin{array}{l}\text { External Financing Requirements Note - } \\
\text { Prepared by the World Bank for the } \\
\text { Consultative Group Meeting for Tanzania }\end{array}$ & WB & Tanzania & $\begin{array}{l}\text { Ded/ } \\
2002\end{array}$ & Note \\
\hline 67. & $\begin{array}{l}\text { Transfers to Public Institutions -Draft Final } \\
\text { Report Volume Il }\end{array}$ & PWC & 一 & $\begin{array}{l}\text { Sep/ } \\
1998\end{array}$ & Report \\
\hline 68. & $\begin{array}{l}\text { Local Government Reform Programme. } \\
\text { Medium Term Plan and Budget - June } 2002 \text { - } \\
\text { June } 2005\end{array}$ & GoT & Tanzania & $\begin{array}{l}\text { June/ } \\
2002\end{array}$ & $\begin{array}{l}\text { Governmen } \\
\text { tal } \\
\text { programme }\end{array}$ \\
\hline 69. & $\begin{array}{l}\text { Korogwe: Comprehensive Council Health Plan } \\
\text { for the Year 2003-01-09 }\end{array}$ & & Tanzania & $\begin{array}{l}\text { Nov/ } \\
2002 \\
\end{array}$ & \\
\hline 70. & $\begin{array}{l}\text { Selection and Employment Regulation of } \\
\text { Consultants }\end{array}$ & & Tanzania & 2002 & \\
\hline 71. & Policy Paper on Local Government Reform & GoT & Tanzania & $\begin{array}{l}\text { Oct/ } \\
1998\end{array}$ & $\begin{array}{l}\text { Policy } \\
\text { paper }\end{array}$ \\
\hline 72 . & $\begin{array}{l}\text { Announcer a Biannual Bulletin of TBS - } \\
\text { Vol.XXI - No. } 1\end{array}$ & TBS & Tanzania & $\begin{array}{l}\text { Jan. - } \\
\text { June/ } \\
2002 \\
\end{array}$ & Joumal \\
\hline 73. & Tanzania Bureau of Standards (TBS) in Context & TBS & Tanzania & - & Brochure \\
\hline 74. & $\begin{array}{l}\text { Tanzania Bureau of Standards - The TBS Test } \\
\text { House }\end{array}$ & TBS & Tanzania & 2002 & Brochure \\
\hline 75. & Tanzania Buyers Guide & TBS & Tanzania & $\begin{array}{l}\text { July/ } \\
2002\end{array}$ & Guide \\
\hline 76. & $\begin{array}{l}\text { Contractors Registration Board -Procedures and } \\
\text { Criteria for Registration of Contractors }\end{array}$ & $\mathrm{CRB}$ & Tanzania & $\begin{array}{l}\text { March/ } \\
2000\end{array}$ & $\begin{array}{l}\text { Procedures } \\
\text { guide }\end{array}$ \\
\hline 77. & $\begin{array}{l}\text { Contractors Registration Board - Annual Report } \\
\text { and Accounts for the Year ended } 31^{\text {st }} \text { December, } \\
2000\end{array}$ & CRB & Tanzania & $\begin{array}{l}\mathrm{Dec} / \\
2000\end{array}$ & Report \\
\hline 78. & $\begin{array}{l}\text { The Code of Conduct for Registered Materials } \\
\text { Management Professionals }\end{array}$ & NBMM & Tanzania & $\begin{array}{l}\text { Oct/ } \\
1994\end{array}$ & $\begin{array}{l}\text { Code of } \\
\text { conduct }\end{array}$ \\
\hline 79. & $\begin{array}{l}\text { Code of Ethics and Conduct for the Public } \\
\text { Service }\end{array}$ & GoT & Tanzania & - & $\begin{array}{l}\text { Code of } \\
\text { ethics }\end{array}$ \\
\hline 80. & $\begin{array}{l}\text { The Contractors Registration Act, } 1997- \\
\text { Arrangement of Sections }\end{array}$ & GoT & Tanzania & $\begin{array}{l}\text { June/ } \\
1997 \\
\end{array}$ & Legal \\
\hline 81. & $\begin{array}{l}\text { National Construction Council-Report on the } \\
\text { Survey of Application of the Public } \\
\text { Procurement Act in the Construction Sector }\end{array}$ & NCC & Tanzania & $\begin{array}{l}\text { Aug/ } \\
2002\end{array}$ & Report \\
\hline
\end{tabular}




\begin{tabular}{|c|c|c|c|c|c|}
\hline No. & Title & $\begin{array}{l}\text { Issued } \\
\text { by }\end{array}$ & Place & $\begin{array}{l}\text { Month/ } \\
\text { Year }\end{array}$ & $\begin{array}{c}\text { Type of } \\
\text { document }\end{array}$ \\
\hline 82. & $\begin{array}{l}\text { Contractors Registration Board - Contractors } \\
\text { Annual Return Forms }\end{array}$ & $\overrightarrow{\mathrm{CRB}}$ & Tanzania & - & Form \\
\hline 83. & $\begin{array}{l}\text { Contractors Registration Board - List of } \\
\text { Registered Contractors, List of Deleted } \\
\text { Contractors }\end{array}$ & CRB & Tanzania & $\mathrm{Jan} / 2002$ & $\begin{array}{l}\text { Reference } \\
\text { list }\end{array}$ \\
\hline 84. & $\begin{array}{l}\text { The Contractors Registration Act (Act No.17 of } \\
\text { 1997) } \\
\text { By-Laws - } 1999\end{array}$ & GoT & Tanzania & $\begin{array}{l}\text { Oct/ } \\
1999\end{array}$ & Legal \\
\hline 85. & $\begin{array}{l}\text { National Construction Council - Directory of } \\
\text { Construction Materials } 2002\end{array}$ & $\mathrm{NCC}$ & Tanzania & 2002 & $\begin{array}{l}\text { Reference } \\
\text { document }\end{array}$ \\
\hline 86. & $\begin{array}{l}\text { Tax Administration Project (Credit } 3184-\text { TA) } \\
\text { - IDA Supervision Mission - 18-29 September, } \\
2000\end{array}$ & - & Tanzania & $\begin{array}{l}\text { Sep/ } \\
2000\end{array}$ & $\begin{array}{c}\text { Mission } \\
\text { report }\end{array}$ \\
\hline 87. & $\begin{array}{l}\text { Tax Administration Project (Credit 3184-TA) - } \\
\text { IDA Supervision Mission - April 23 - May 4, } \\
2001\end{array}$ & - & Tanzania & 2001 & $\begin{array}{l}\text { Mission } \\
\text { report }\end{array}$ \\
\hline 88. & $\begin{array}{l}\text { External Review of the Medical Stores } \\
\text { Department - Report Prepared by an External } \\
\text { Review Team }\end{array}$ & $\begin{array}{l}\text { External } \\
\text { review } \\
\text { team }\end{array}$ & Tanzania & $\begin{array}{l}\text { Nov/ } \\
1998\end{array}$ & Report \\
\hline 89. & $\begin{array}{l}\text { Discussion between the Government and the } \\
\text { Private Sector: Follow -Uj Actions on Key } \\
\text { Issues and Problems }\end{array}$ & - & - & - & Note \\
\hline 90. & $\begin{array}{l}\text { Key Planning Variables \& Assumptions - } \\
\text { Ministry of Finance }\end{array}$ & GoT & Tanzania & $\begin{array}{l}\text { Oct/ } \\
2002\end{array}$ & \\
\hline 91. & $\begin{array}{l}\text { PSI \& PE Audit Programme Review, January to } \\
\text { December } 2000\end{array}$ & ICS & Tanzania & $\begin{array}{l}\text { May/ } \\
2001\end{array}$ & Note \\
\hline 92. & Tanzania Trade Summary & $\begin{array}{l}\text { Dept. of } \\
\text { Commer } \\
\text { ce }\end{array}$ & USA & 2000 & Note \\
\hline 93. & $\begin{array}{l}\text { Private Sector Development in Tanzania } \\
(1992 / 1993 \text { to } 2008)\end{array}$ & GoT & Tanzania & $\begin{array}{l}\text { Dec/ } \\
2002\end{array}$ & Note \\
\hline 94. & $\begin{array}{l}\text { Consultative Group Frormal Session, December } \\
\text { 2002, Joint Statement by Development Partners } \\
\text { on Private Sector Development }\end{array}$ & WB & Tanzania & $\begin{array}{l}\text { Dec/ } \\
2002\end{array}$ & Note \\
\hline 95. & $\begin{array}{l}\text { Tanzania Investment Report, Report on the } \\
\text { Study of Foreign Private Capital Flows in } \\
\text { Mainland Tanzania }\end{array}$ & $\begin{array}{l}\text { Bank of } \\
\text { Tanzania }\end{array}$ & Tanzania & $\begin{array}{l}\text { Dec/ } \\
2001\end{array}$ & Report \\
\hline 96. & $\begin{array}{l}\text { The Shipping Industry Consultative Forum - } \\
\text { Report of the Sub-Committee on the Study on } \\
\text { Delays in Import Cargo Clearance from Dar Es } \\
\text { Salaam Port }\end{array}$ & $\begin{array}{l}\text { Tanzania } \\
\text { Central } \\
\text { Freight } \\
\text { Bureau }\end{array}$ & Tanzania & $\begin{array}{l}\text { Feb/ } \\
2001\end{array}$ & Report \\
\hline 97. & $\begin{array}{l}\text { Towards a Policy for Small and Medium } \\
\text { Enterprises in Tanzania }\end{array}$ & GoT & Tanzania & $\begin{array}{l}\text { Sep/ } \\
1999\end{array}$ & Report \\
\hline 98. & $\begin{array}{l}\text { Small and Medium Enterprise Development } \\
\text { Policy - Final Draft }\end{array}$ & MolT & Tanzania & 2002 & Note \\
\hline 99. & Tanzania Chamber of Commerce, Industry and & TCCIA & Tanzania & - & Legal \\
\hline
\end{tabular}




\begin{tabular}{|c|c|c|c|c|c|}
\hline No. & Title & $\begin{array}{c}\text { Issued } \\
\text { by }\end{array}$ & Place & $\begin{array}{l}\text { Month/ } \\
\text { Year }\end{array}$ & $\begin{array}{l}\text { Type of } \\
\text { document }\end{array}$ \\
\hline & Agriculture (TCCIA) Constitution & & & & \\
\hline 100. & $\begin{array}{l}\text { Government of Tanzania Civil Service } \\
\text { Benchmark Job Evaluation Study }\end{array}$ & KPMG & - & $\begin{array}{l}\text { Dec/ } \\
1998\end{array}$ & Report \\
\hline 101. & Poverty reduction strategy $2001 / 2002$ & GoT & Tanzania & $\begin{array}{l}\text { Nov/ } \\
2002\end{array}$ & $\begin{array}{l}\text { Draft } \\
\text { progress } \\
\text { report }\end{array}$ \\
\hline 102. & Tanzania Comoros & EIU & - & 2001 & $\begin{array}{l}\text { Country } \\
\text { profile }\end{array}$ \\
\hline 103. & $\begin{array}{l}\text { The Constitution of the United Republic of } \\
\text { Tanzania }\end{array}$ & GoT & Tanzania & 1977 & Legal \\
\hline 104. & $\begin{array}{l}\text { Building value through Public Procurement: a } \\
\text { focus on Africa }\end{array}$ & $\begin{array}{l}\text { UNCTA } \\
\text { D/WTO }\end{array}$ & - & - & $\begin{array}{l}\text { Research } \\
\text { paper }\end{array}$ \\
\hline 105. & Syllabus review report & NBMM & Tanzania & - & Report \\
\hline 106. & $\begin{array}{l}\text { Tanzania - Country Procurement Assessment } \\
\text { Report }\end{array}$ & WB & - & $\begin{array}{l}\text { Sept/ } \\
1996\end{array}$ & Report \\
\hline 107. & $\begin{array}{l}\text { UNCITRAL Model Law on Procurement of } \\
\text { Goods, Construction and Services with Guide to } \\
\text { Enactment }\end{array}$ & $\begin{array}{l}\text { UNCITR } \\
\text { AL }\end{array}$ & - & - & Legal \\
\hline 108. & $\begin{array}{l}\text { The materials management professional stage } \\
\text { syllabus }\end{array}$ & NBMM & Tanzania & - & Syllabus \\
\hline 109. & $\begin{array}{l}\text { Revised syllabus for the pre-foundation stage in } \\
\text { material management }\end{array}$ & NBMM & Tanzania & - & Syllabus \\
\hline 110. & $\begin{array}{l}\text { Revised syllabus for the foundation stage in } \\
\text { materials management }\end{array}$ & NBMM & Tanzania & - & Syllabus \\
\hline 111. & Research proposal guide & NBMM & Tanzania & - & Guide \\
\hline
\end{tabular}




\section{ANNEX III}

\section{LIST OF TASK FORCE MEMBERS}

\section{GOVERNMENT PROCUREMENT TASK FORCE}

\begin{tabular}{|c|c|c|c|}
\hline NAME & ORGANIZATION & ADDRESS & TELEPHONE \\
\hline N.S.D. NKINGA & $\begin{array}{l}\text { Ministry of Finance/ } \\
\text { Central Tender Board }\end{array}$ & $\begin{array}{l}\text { P.O. BOX } 9111 \\
\text { Dar es Salaam }\end{array}$ & 21133466 \\
\hline SALUM K. NASSOR & $\begin{array}{c}\text { Ministry of Finance and } \\
\text { Economic Affairs, } \\
\text { Zanzibar }\end{array}$ & $\begin{array}{l}\text { P.O. BOX } 1154 \\
\text { Zanzibar }\end{array}$ & $\begin{array}{c}0747-412368 \\
0242-2231171\end{array}$ \\
\hline MTIMILA M.S. MTIMILA & $\begin{array}{c}\text { Ministry of Industry and } \\
\text { Trade }\end{array}$ & $\begin{array}{l}\text { P. O. BOX } 9503 \\
\text { Dar es Salaam }\end{array}$ & $\begin{array}{l}0744-305215 \\
0741-214312\end{array}$ \\
\hline GOSBERT J. RUBIBIRA & Ministry of Works & $\begin{array}{l}\text { P. O. BOX } 9423 \\
\text { Dar es Salaam }\end{array}$ & $0744-279501$ \\
\hline GOLDEN E. MASINGA & Ministry of Health & $\begin{array}{l}\text { P. O. BOX } 9083 \\
\text { Dar es Salaam }\end{array}$ & $0744-610061$ \\
\hline MICHAEL J. KAMBA & $\begin{array}{l}\text { Attorney General's } \\
\text { Chambers }\end{array}$ & $\begin{array}{l}\text { P. O. BOX } 9050 \\
\text { Dar es Salaam }\end{array}$ & $0744-376053$ \\
\hline P.N. KASSERA & $\begin{array}{c}\text { Tanzania Revenue } \\
\text { Authority }\end{array}$ & $\begin{array}{l}\text { P.O. BOX } 9131 \\
\text { Dar es Salaam }\end{array}$ & $\begin{array}{c}2113186 \\
0744-444822\end{array}$ \\
\hline OSCAR B. HOSEA & $\begin{array}{c}\text { Prevention of Comption } \\
\text { Bureau (PCB) }\end{array}$ & $\begin{array}{l}\text { P. O. BOX } 4865 \\
\text { Dar es Salaam }\end{array}$ & $0741-261903$ \\
\hline GEOFFERY.E. MUNGURE & $\begin{array}{c}\text { Central Government } \\
\text { Stores }\end{array}$ & $\begin{array}{l}\text { P.O. BOX } 9150 \\
\text { Dar es Salaam }\end{array}$ & $0744-281839$ \\
\hline AMBROSE R. M. GAMBA & TANROADS & $\begin{array}{l}\text { P.O. BOX } 11364 \\
\text { Dar es Salaam }\end{array}$ & $0748-359215$ \\
\hline EDWARD I.M. MWANYALLA & $\begin{array}{c}\text { TTCL, Director Facilities } \\
\text { and Support }\end{array}$ & $\begin{array}{l}\text { P. O. BOX } 9070 \\
\text { Dar es Salaam }\end{array}$ & $0748-448888$ \\
\hline ENG. DR. E. SIMKOKO & $\begin{array}{c}\text { Engineers' Registration } \\
\text { Board }\end{array}$ & $\begin{array}{l}\text { P.O. BOX } 14942 \\
\text { Dar es Salaam }\end{array}$ & $\begin{array}{c}022- \\
2136208 / 2122836 \\
0744-333622\end{array}$ \\
\hline JULIUS MAMIRO & $\begin{array}{c}\text { National Construction } \\
\text { Council }\end{array}$ & $\begin{array}{l}\text { P. O. BOX } 70039 \\
\text { Dar es Salaam }\end{array}$ & $0741-212414$ \\
\hline MODESTUS LUKONGE & $\begin{array}{l}\text { Architects and Quantity } \\
\text { Surveyors }\end{array}$ & $\begin{array}{l}\text { P.O. BOX } 72673 \\
\text { Dar es Salaam }\end{array}$ & 2117546 \\
\hline EMMANUEL TASENI & $\begin{array}{c}\text { Contractors' Registration } \\
\text { Board }\end{array}$ & $\begin{array}{l}\text { P.O. BOX } 13374 \\
\text { Dar es Salaam }\end{array}$ & $\begin{array}{c}21131169 / 0744- \\
386756\end{array}$ \\
\hline ALOYSE PETER MUSHI & $\begin{array}{c}\text { Tanzania Association of } \\
\text { Consultants }\end{array}$ & $\begin{array}{l}\text { P. O. BOX } 4668 \\
\text { Dar es Salaam }\end{array}$ & $\begin{array}{c}0742-782605 \\
2180170\end{array}$ \\
\hline RAJABU R. HATIBU & $\begin{array}{l}\text { University of Dar es } \\
\text { Salaam }\end{array}$ & $\begin{array}{c}\text { P. O. BOX } 35091 \\
\text { Dar es Salaam }\end{array}$ & $\begin{array}{c}2410693 / 0744- \\
272028\end{array}$ \\
\hline YUSSUF BALOZI HIJA & $\begin{array}{c}\text { Zanzibar Ports } \\
\text { Corporation }\end{array}$ & $\begin{array}{l}\text { P. O. BOX } 263 \\
\text { Zanzibar }\end{array}$ & $\begin{array}{c}024-2232857 / 0747- \\
434681\end{array}$ \\
\hline ABDI KHAMISI FAKI & Zanzibar Revenue Board & Zanzibar & \\
\hline
\end{tabular}




\section{ANNEX IV}

\section{DETAILED BREAKDOWN OF SUPPLIES OFFICERS IN PUBLIC SERVICE}

\begin{tabular}{|l|l|l|}
\hline Scheme Level & Salary Grade & Pay Rate $\quad$ (Tanzanian shillings) \\
\hline Supplies Assistant & TGS 2 & $(61,150-66,650)$ \\
\hline Supplies Officer (III) & TGS 3 & $(80,960-87,310)$ \\
\hline Supplies Officer (II) & TGS 4/5 & $(89,310-96,080) /(99,080-106,080)$ \\
\hline Supplies Officer (I) & TGS 6/7 & $(109,240-117,320) /(121,840-133,520)$ \\
\hline Senior Supplies Officer (III) & TGS 7/8 & $(121,840-133,520) /(139,380-151,460)$ \\
\hline Senior Supplies Officer (II) & TGS 8/9 & $(139,380-151,460) /(157,650-172,330)$ \\
\hline Senior Supplies Officer (I) & TGS 9/10 & $(157,650-172,330) /(179,100-200,500)$ \\
\hline Principal Supplies Officer (III) & TGS 11/12 & $(210,280-235,560) /(242,700-264,210)$ \\
\hline Principal Supplies Officer (II) & TGS 12/13 & $(242,700-264,210) /(272,800-297,310)$ \\
\hline Principal Supplies Officer (I) & TGS 14 & $(306,240-336,300)$ \\
\hline
\end{tabular}

Schemes by Funding Type

\begin{tabular}{|c|c|c|c|c|c|}
\hline Scheme & Cent. Govt & Regions & Loc. Govt & Loc. Govt & Total \\
\hline & MDAs & & CG funded & LG funded & employees \\
\hline 0822 Supplies Officer (III) & 101 & 4 & 37 & 9 & 151 \\
\hline 0823 Supplies Officer (II) & 76 & 7 & 17 & 5 & 105 \\
\hline 0824 Supplies Officer (I) & 66 & 1 & 10 & 3 & 80 \\
\hline 0825 Senior Supplies Officer (III) & 32 & 2 & 3 & 1 & 38 \\
\hline 0826 Senior Supplies Officer (II) & 13 & 1 & 1 & 1 & 16 \\
\hline 0827 Senior Supplies Officer (I) & 5 & 3 & & & 8 \\
\hline 0829 Principal Supplies Officer (II) & 1 & & & & 1 \\
\hline 0830 Principal Supplies Officer (I) & 1 & & & & 1 \\
\hline 0840 Assistant Stores Officer (II) & 146 & 8 & 41 & 8 & 203 \\
\hline 0841 Assistant Stores Officer (I) & 132 & 11 & 36 & 4 & 183 \\
\hline 0842 Stores Officer (III) & 53 & & 8 & 2 & 63 \\
\hline 0843 Stores Officer (II) & 22 & & 7 & & 29 \\
\hline 0844 Stores Officer (I) & 5 & 1 & 5 & & 11 \\
\hline 0845 Senior Stores Officer (II) & 1 & & 3 & & 4 \\
\hline 0846 Senior stores Officer (I) & 3 & & 3 & & 6 \\
\hline 0847 Principal Stores Officer & & & 2 & & 2 \\
\hline Grand Total & 657 & 38 & 173 & 33 & 901 \\
\hline
\end{tabular}




\title{
ANNEX V
}

\section{ANTI-CORRUPTION INITIATIVES}

\author{
by \\ Professor A.S. Mawenya \\ Consultant \\ P.O. Box 564, Dar es Salaam, Tanzania \\ e-mail-: dpl@ectz.com
}

December 2002 



\section{INTRODUCTION: STATE OF CORRUPTION IN PUBLIC PROCUREMENT}

Public procurement is an area that is prone to wide-spread corruption in Tanzania. This is evident from the Report of the Presidential Commission of Inquiry Against Corruption, popularly known as the Warioba Report ${ }^{1}$, published in 1996 and the more recent Annual Report on the State of Corruption in Tanzania. ${ }^{2}$ According to these reports and according to most people interviewed during the course of this assessment there is both petty and grand corruption in public procurement and contracting. This corruption takes place during the process of selecting the contractor, consultant or vendor as well as during contract administration. Most people interviewed cited corrupt malpractices in the selection of consultants, appointment of suppliers, pre-qualification of contractors, tender evaluation, contract award, issuing variation orders, evaluation of claims, dissemination of information, certifying and making payments. They claimed that corrupt malpractices are most rampant in local government procurement.

There are many factors that have contributed to corruption in public procurement. The main reasons cited by the people interviewed are poverty, weak accountability, greed, weaknesses and loopholes in existing procurement procedures particularly at the local government level, collusion, favouritism, conflict of interest and undue political influence.

Low salaries compel some public servants to engage in petty corruption in order to earn additional income and make ends meet. On the other hand big-budget projects are a special target for grand corruption. They can be used by greedy politicians and unscrupulous high ranking public officials as conduits for embezzling and defrauding public funds. ${ }^{3}$

Public accountability is typically weak in the civil service and some parastatal organizations. This is partly due to the opportunities created by monopoly of power and wide discretionary powers that some civil servants enjoy. Weak public accountability also results from lack of enforcement of the laws and principles of ethics. The legal institutions charged with enforcement and watch-dog organizations that provide information on which detection and enforcement are based are weak; they need to be strengthened to enable them perform this complex task.

The annual loss of public revenue through procurement corruption is difficult to quantify. However the loss can be enormous. It is estimated that at the national level about 20 percent of the government expenditure on procurement is lost through

\footnotetext{
${ }^{1}$ United Republic of Tanzania. Report of the Presidential Commission of Inquiry Against Comuption, 1996

${ }^{2}$ ESRF-FACEIT. The State of Corruption in Tanzania Report 2002, Final Draft Report (Oct. 2002)

${ }^{3}$ A number of large office blocks constructed at exorbitant prices by parastatal organizations in Dar es Salaam have no economic justification of the investment made, as they remain partially occupied or uncompleted.
} 
corruption, mainly through kick-backs and bogus investments that have to be written off ${ }^{4}$. Considering that public procurement accounts for about 70 percent of the entire government expenditure budget this translates to a loss of TShs 300 billion (US\$300 million) per year, enough to finance the combined annual recurrent budgets of the ministries of health and education. Clearly such a loss is economically unsustainable. Major losses occur in construction and supply contracts; they are the major avenues for corruption, particularly at the local government level ${ }^{5}$.

Most people interviewed stated that the level of corruption, though still high, has declined since the publication of the Warioba Report. They attributed this positive and encouraging development to three main reasons. Firstly, after the publication of the Warioba Report most government ministries took immediate deterrent measures to identify corrupt elements and expose or retire them "in public interest". 6 Secondly the government has demonstrated a long-term commitment to eradicate corruption. It has initiated long term measures of enhancing transparency, professionalism and accountability in public procurement by reviewing the legal and institutional framework. ${ }^{7}$ Thirdly, there is increased awareness by the general public of the debilitating effect of corruption to the national economy. The general public knows that comuption diminishes public revenue, undermines fair trade, frustrates economic development and increases human suffering.

Transparency International (TI) has consistently ranked Tanzania among the most corrupt countries in the world. ${ }^{8}$ However, there has been a significant improvement in this ranking during the past five years (1998-2002) both in relative terms (ranking in relation to other countries) and qualitative terms (with the quantitative score improving from 1.9 in 1998 to 2.7 in 2002). Although TI warns against overstating the significance on year to year comparisons, it is significant to note that longer term trends in the scores are encouraging.

Eradicating corruption is a declared goal of the Government in its efforts to promote good governance. The government has a policy of zero tolerance in the fight against corruption and its approach has three distinct levels of attack. This review focuses on on-going anti-corruption initiatives at these three levels. The first level is the legal environment in which laws and institutions are created to combat corruption in society. The second level is the national strategy and action plans that provide the national

\footnotetext{
${ }^{4}$ S.J. Chavda, Challenges and the way forward in combating comption in the construction industry in Tanzania. Proceedings of Ministry of Works Workshop on Corruption Prevention in Construction Industry - April 2001.

${ }_{6}^{5}$ Current research by PCB reveals unaccounted losses of upto 60 percent in some construction projects.

${ }^{6}$ In the Ministry of Works alone 755 employees were retrenched and four sent to court. Other institutions that retrenched or dismissed a large number of staff on allegations of comuption are the Tanzania Revenue Authority and Police Force.

${ }^{7}$ Five Acts that are relevant to public procurement have been passed by Parliament: the Public Finance Act No 6 of 2001, Public Procurement Act No 3 of 2001, Engineers Registration Act No 15 of 1997, Architects and Quantity Surveyors Registration Act No 16 of 1997 and Contractors Registration Act No 17 of 1997

${ }^{8}$ Transparency International Corruption Perceptions Index 2002
} 
framework of intervention against different causes of both petty and grand corruption. The third level is coalition building in the fight against corruption among key stakeholders in the government, civil society and private sector. This is critical because no single entity, on its own, can overcome the power of corrupt elements in society without involving other stakeholders.

\section{REVIEW OF INSTITUTIONAL SET UP}

The key government institutions that are responsible for combating corruption in Tanzania are the Prevention of Corruption Bureau (PCB), the President's Office through the Ministry of Good Governance, the Ethics Secretariat and the Civil Service Department. Other government institutions that play a key role in the fight against corruption are the National Audit Office, the Commission for Human Rights and Good Governance and the Director of Public Prosecution. These institutions are briefly described below. Appendix 1 gives more detailed information concerning the mandate, powers, organizational set up and main activities of these institutions.

\section{(i) Prevention of Corruption Bureau}

The PCB is the most important institution in the fight against corruption. It has a long history that goes back to the Prevention of Corruption Act of 1971 and subsequent formation of the Anti-Corruption Squad in 1975. It was constituted in its present form in 1991 following amendments to the Anti-Corruption Act and the Economic and Organized Crime Control Act No 13 of 1984.

The PCB has powers to receive, investigate and prosecute corruption cases. It is headed by a Director-General who is appointed by the President and assisted by four departmental directors, who are also appointed by the President. The four departments that constitute the PCB are:

- Investigation Department, which is responsible for identifying, investigating and prosecuting corruption cases

- Research, Control and Statistics Department, which is primarily responsible for research

- Liaison and Community Education Department, which is responsible for creating awareness among the public on corruption; and

- Administration and Personnel Department, which is responsible for administration and human resources development.

Although the PCB does not have a formal mandate to coordinate other government institutions, it functions as a focal point for government efforts to fight corruption by giving advice on matters pertaining to corruption and receiving cases forwarded to it by 
other agencies. The Bureau has offices in every region and district and a reasonably large staff establishment of about 500 to effectively cover the whole country.

The operations of the Bureau are focused on the core functions of prevention, investigation and prosecution and provision of awareness and advisory services. Since 1998 there has been a substantial rise in the number of corruption cases reported to the Bureau signifying the enhanced confidence that the public has in the Bureau. The number of corruption cases reported rose from 432 in 1998 to 1461 in 2000 and 3611 in 2001. During the first five months of this year (January - May 2002) the number of reported corruption cases was 4842 .

However, the process of prosecuting cases by the Bureau is slow. Although all cases reported to the Bureau are fully investigated it takes a long time to bring genuine cases of corruption to court for prosecution.

\section{(ii) President's Office}

The President's Office, through the Minister of State for Good Governance and Chief Secretary, is the focal point of the government for combating corruption.

The PCB, and most of the specialized institutions dealing with corruption fall under the President's Office. These include the Ethics Secretariat, the Commission for Human Rights and Good Governance and the Civil Service Department.

The Chief Secretary is assisted by the Good Governance Coordinating Unit (CGCU). This unit was established in 2001 and its main function is to coordinate the implementation of anti-corruption and governance related issues among on-going government reform programmes. The Unit has a skeleton staff of only two people - the Coordinator and one assistant - whose main activity is to facilitate the implementation, coordination and monitoring of the national anti-corruption strategy and action plans.

\section{(iii) Ethics Secretariat}

Public leaders are required to abide to ethical standards prescribed by the Public Leadership Code of Ethics Act No. 13 of 1995. The Ethics Secretariat is the institution charged with the enforcement of this Act.

The Secretariat is established by section 132 of the Constitution of the United Republic of Tanzania as an extra-ministerial department of the government under the office of the President. Its mandate is to ensure that political leaders and senior officials in government and parastatal organizations do not use their official positions in illegal acquisition of wealth, bribery, nepotism, patronage, etc. 
The main activities of the Secretariat are to receive declarations of assets from public leaders, receive complaints and advise the government on matters relating to the conduct and behaviour of public leaders. It has a total staff of 26 people, all of whom are based in Dar es Salaam, and works closely with the PCB. It has plans to establish zonal offices upcountry in order to be closer to the people.

\section{(iv) Civil Service Department}

The Civil Service Department (CSD) is a central player in promoting good governance. It facilitates the on-going government reforms by providing human resources and developing procedures, directives, norms and incentives that prescribe the civil service working environment. It has developed a code of ethics to regulate the conduct and behaviour of public servants ${ }^{9}$ and established a special unit - The Ethics Inspectorate Unit - to enforce the code. The unit is headed by a Director who reports to the Permanent Secretary of the CSP. It has a small staff strength of four people.

\section{(v) The Commission for Human Rights and Good Governance}

The CHRGG became operational in March 2002, following a constitutional amendment passed in 2001. The Commission functions as an ombudsman and has powers that cover a wide range of activities for promoting and protecting human rights and good governance.

(vi) National Audit Office

The National Audit Office, formerly the office of the Controller and Auditor General plays a critical role in combating corruption. As the agency responsible for auditing government income and expenditure it acts as the watchdog over financial integrity and the credibility of financial management. Reports of the Controller and Auditor General have always exposed corruption malpractices in the expenditure of public funds. They have exposed non-transparent decision making that is clearly not in the public interest. They have also made recommendations to curb the diversion of public resources for private gain.

NAO is headed by the Controller and Auditor General who is assisted b a Deputy Controller and Auditor General. It has a total staff strength of 394.

\footnotetext{
${ }^{9}$ United Republic of Tanzania. Code of Ethics and Conduct for the Public Service (June 1999)
} 


\section{(vii) Director of Public Prosecution}

The Director of Public Prosecution (DPP) plays a very crucial role in the fight against corruption. Seeking the DPP's consent is required in order to bring most cases of corruption to court. The PCB is required to seek DPP's permission to prosecute all cases of corruption except those that involve receiving or giving bribes. The DPP reviews such requests and decides which cases should be prosecuted, and he has the prerogative to declare a nole proseque. Only when the DPP is satisfied that there is a case to answer may the PCB take the case to court.

\section{NATIONAL ANTI-CORRUPTION STRATEGY}

The National Anti-Corruption Strategy ${ }^{10}$ launched by the Government in 1999 was a result of a comprehensive consultative process. It recognizes that combating corruption requires a holistic approach that involves institutional reforms, coalition building and raising public awareness.

The strategy identifies seven priority areas, including procurement, and provides an integrated framework for fighting corruption based on these areas. The seven priority areas are:

- The Rule of law and legal framework: This component is intended to facilitate sector laws review and create conditions necessary for restoration of confidence in the judiciary and law enforcement agencies

- Financial discipline and management: The intention here is to reduce or eradicate siphoning of public funds by unfaithful officials and increase revenue collection to enable the financing of social services and facilitation of economic growth.

- Procurement: The intention is to ensure strict adherence to and transparent administration of tendering and procurement procedures.

- Public education, awareness and sensitisation of their rights: To develop education programmes and create awareness of how corruption harms the economy and ultimately transforms the fabric and values of society.

- Public service reform (capacity buildings): To recognize that public officers are not "masters" but servants accountable for their actions and who, therefore, deserve a fair remuneration package.

- Whistle blowers and witness protection: Cognizant of the fact that informers and citizens who come forward to the law enforcement agencies and report on

\footnotetext{
${ }^{10}$ United Republic of Tanzania. National Anti-Corruption Strategy and Action Plan (November 1999).
} 
corruption incidences need to be protected, a programme would be developed to encourage citizens to cooperate.

Media: To report corrupt elements without fear or favour and to publicize the harm they do to the innocent, the poor and the weak in Tanzania.

For each priority area, the strategy has identified several key actions to be undertaken in the short and medium-term by both the government and civil society. With respect to procurement there are eighteen such actions and a number of these have already been or are being implemented.

It is pertinent to note that the enactment of the public finance and public procurement acts is one of the most important achievements of the strategy with respect to combating corruption in procurement. This has enhanced confidence by the general public in the government procurement system. Implementation of these acts has resulted in increased transparency, enhanced competitiveness and fairness in the procurement system.

However, these benefits are not matched by efficiency in the processing of tenders. The capacity of the government and procurement agencies to deliver efficient and high quality services is low due to shortage of qualified procurement staff. Furthermore, participation of the civil society in government procurement process is needed in order to enhance fairness and transparency.

\section{SECTOR STRATEGIES}

After the adoption of NACSAP all government ministries, as well as key government departments and agencies, were directed to prepare anti-corruption plans for their respective ministries, departments and agencies. These plans were published in September 2001 as NASCAP $(2001-2005)^{11}$ and cover 22 government ministries and four independent departments. The departments are the Civil Service Department, Judiciary, PCB and Tanzania Revenue Authority. NASCAP (2001 - 2005) does not contain action plans for the local government, as these plans are still under preparation. Implementation of the sector strategies is the responsibility of sector ministries.

A review of the sector strategies reveals that

- Procurement corruption is a problem in 14 government ministries. These are the ministries responsible for works, defence, health, education, agriculture, communication and transport, finance, foreign affairs, lands, energy and

11 United Republic of Tanzania. The National Anti-Cornuption Strategy and Sector Specific Action Plans for All Ministries and Independent Government Departments (2001-2005). Issued by the State House, President's Office (Sept. 2001). 
minerals, planning, water, science and technology, Vice President and Prime Minister's Offices. Some of these ministries, notably those responsible for works, health and education, handle large procurement volumes per year

- Procurement corruption problems encountered by these ministries relates to non-compliance with or abuse of procurement procedures, lack of transparency, loopholes/weaknesses in the procurement system, inefficiency, poor contract specifications and poor contract administration.

- In order to curb corruption some of the actions planned are to strengthen enforcement of procedures, strengthen staff capacity, enhance transparency and strengthen financial auditing. Other planned actions such as decentralization of the procurement system and preparation of standard procurement guidelines, are beyond the jurisdiction of the respective ministries and may therefore not be implemented.

Permanent Secretaries of sector ministries report to the Chief Secretary through the GGCU on implementation of sector strategies and action plans. On quarterly basis every ministry, government department and agency is required to file one page report containing the following information

- Number of complaints/reports received in the quarter

- Number of officials who have been issued with reprimands, suspended, dismissed or have had their cases referred to the PCB or the Police.

- A self assessment on the achievement of a maximum of five targets or outputs set for the quarter; and

- The five targets or outputs set for the next quarter

According to the GGCU some progress has been made in the implementation of the respective sector action plans. However, considering that the compilation of most action plans was only recently completed it is perhaps too early to assess their impact. It is also clear that there are changes in the implementation and a continuous review of these plans is necessary in order to reflect these changes.

\section{CODES OF CONDUCT}

Corruption often thrives in the absence of a public service work ethics or lack of understanding of the principles of public accountability and responsibility. Integrity in public life and public service develops through:

- legislation, regulations and codes of conduct,

- $\quad$ professionalism among public officials, and

- societal values that respect meritocracy, honesty and professionalism. 
Together, these establish and foster a tradition of ethical public life and an atmosphere in which most politicians and public servants are assumed to be honest. This, however, is not the case in Tanzania due to serious shortcomings in each of the above areas.

At the macro level there are two codes of conduct that apply to civil servants and public leaders. These are the Code of Ethics and Conduct for the Public Service and the Leadership Code of Ethics. Both codes are relatively new developments ushered in by the third phase government whose campaign platform during the 1995 elections was to eradicate corruption. They are positive developments that have enhanced public confidence and credibility of the third phase government; however it is probably too early to assess their impact.

At the micro level there are several codes of ethics regulating the conduct and behaviour of professionals, particularly in the legal, medical, accounting and engineering fields. Most of these codes are based on voluntary enforcement by the respective professional associations, except a few statutory ones that are enforced by regulatory bodies.

Some of the professional codes of conduct are as old as the professions themselves. Appendix 2 gives a selected list of codes of ethics that are relevant to professionals that regularly perform procurement tasks (engineers, architects, quantity surveyors, purchasing officers and accountants). They have similar features that emphasize discipline and diligence, professionalism, transparency and accountability, integrity and excellence. However their impact in curbing corruption is insignificant. On the other hand there are no codes of conduct among trade associations to regulate the behaviour and conduct of business practitioners in the private sector.

Codes of conduct are important in curbing corruption because they create an ethical environment among public servants, political leaders and professionals. It is important however to bear in mind the following crucial issues:

- $\quad$ The ethical environment should be clearly defined at the macro level, from which the micro-level reforms and changes shall develop.

- The ethical environment must be owned, policed and constantly monitored throughout the public sector

- Changes in the ethical environment should go hand in hand with credible efforts to make the private sector more accountable through selfregulation. 


\section{TRAINING}

In an effort to ensure sufficient and efficient staff the PCB has employed a large number of new staff (about 300 new staff) during the past three years from a wide range of professional disciplines, notably law, engineering, accountancy, commerce, economics and sociology. Most of these employees were recruited as fresh graduates with neither specific training nor experience relevant to their responsibilities in PCB. They therefore require substantial training.

Currently the PCB has an in-house orientation programme whose purpose is to familiarize newly recruited staff with their specific duties in PCB. The programme comprises seminars, workshops and short courses that focus on organizational, administrative and investigative aspects of the Bureau. Some staff have also received specialist training at the post-graduate level in selected institutions abroad in the areas of anti-corruption and investigation. However, such training is extremely limited by the shortage of funds. In addition, very few PCB staff understand procurement. The Bureau has therefore indicated an urgent desire to have a core group of about 60 staff trained in procurement.

The training required by PCB should cover basic procurement principles and procedures and should integrate both technical and legal aspects of procurement. A proper understanding of basic procurement principles and procedures will enhance skills of PCB staff in investigating procurement corruption.

\section{PERFORMANCE INDICATORS}

Over and above the initiatives to enhance capacity and to improve the legal and institutional framework for combating corruption there is a need to develop reliable instruments for assessing the level and form of corruption in procurement. These instruments would measure both perceived and experienced corruption. However, given the complexity and perverse nature of corruption it is difficult to develop precise measurable indicators. Hence the use of these indicators should go hand in hand with perceptive judgements based on relevant unquantifiable information.

\section{World Bank performance indicators}

Appendix 3 lists ten indicators suggested by the World Bank for monitoring public procurement. These indicators provide, on an annual basis, quantified information in terms of number, value and percentage of

(i) Contracts awarded outside of normal bidding procedures 
(ii) Contracts awarded using less competitive methods than those set out in the approved procurement plan

(iii) Contract variations that exceed threshold figures set out in the public procurement regulations

(iv) Payments issued against terminated contracts before goods and services were received

(v) Contracts abandoned by contractors after payments were made but before goods and services were received

Together the ten indicators provide an overall comprehensive picture of the performance of the procurement system in a specific organization. However the following specific comments are pertinent:

- All ten indicators are easy to measure from available data, provided that accurate records of relevant information are kept.

- A close scrutiny of the indicators shows that if their values are high then there are problems in the procurement system. This should justify further investigation to determine the root causes of the problem, and corrupt practices, though not directly implied may be possible causes of the problem and must be investigated.

- All ten indicators refer to post-contract evaluation in the sense that they provide aggregated historical information on completed contracts. This information, though useful for future planning, has limited value in solving potential problems in on-going contracts.

\section{Suggestions}

In addition to performance indicators of the overall procurement system specific indicators that can give an early warning of potential corrupt malpractices in public procurement are needed. The main focus of such indicators should be on

(i) exploring factors within the internal operations of the public sector that facilitate or encourage corrupt practices

(ii) identifying forms of interaction in corruption between public employees and private sector practitioners

(iii) systematic analysis and follow-up of complaints received from bidders, the general public and media.

A good public procurement system must have in-built mechanisms for giving an early warning of suspicious circumstances that may lead to corruption in the process of contract procurement. Some of these circumstances are highlighted below: 
- Contract award that by-passes normal procurement procedures: Find out whether the circumstances claimed to justify such a procedure really exist. If they do not, the real reason is to cover up and facilitate corruption.

- Misleading bid information: One ploy is to publish notification of bidding information in obscure circulation sources that are not easily accessible even though they satisfy the advertising requirements.

- Unnecessarily stringent pre-qualification conditions: Establishing excessively stringent or unnecessary pre-qualification requirements and then allowing only selected firms to bid can further restrict bidder competition. In particular, if the standards and criteria for pre-qualification are arbitrary such pre-qualification is simply a ploy of accommodating favoured bidders at the exclusion of competent ones.

- High proportion of provisional sums and prime cost items in the build up of the tender price: This is an indirect way of by-passing competitive bidding. It leaves too much discretion to the supervising consultant to decide on prices and mode of supply of such items during contract implementation stage.

- Delayed bid opening: Delaying the opening of bids, for any reason, are strong grounds to suspect corrupt practices in procurement. It may permit late submission of favoured bids.

- Undeclared bid evaluation criteria: The final opportunity to distort the outcome of competitive bidding is at the bid evaluation stage. If the intention is to steer the award to a favoured bidder, the evaluation process offers almost unlimited opportunities. The evaluators can invent entirely new criteria for deciding what is best and then apply them subjectively to get the desired results. They are often aided in this process by issuing bidding documents that are deliberately vague and obscure about the requirements to be met and how the selection decision will be made.

\section{ZANZIBAR}

Most people interviewed in Zanzibar during the course of this assessment pointed to wide-spread corruption in public procurement. They stated that there is both petty and grand corruption in procurement which, like in Tanzania mainland, can be attributed to several factors, notably poverty, weak accountability, greed, conflict of interest, undue political influence and weaknesses in procurement procedures. Generally, however, corruption is less talked about by the general public in Zanzibar than it is in the mainland.

Fighting corruption in Zanzibar is mainly the responsibility of two government institutions: the Police Force and the Ministry of State for Constitutional Affairs and Good Governance. 
The Police Force handles corruption through the Anti-corruption and Fraud Squad. The Squad was constituted in its present form in 1985 by transferring the then AntiCorruption Squad from the office of the Chief Minister to the Police Force and merging it with the Fraud Investigation Section. It has powers to investigate and prosecute corruption cases under the penal code. It also advises the government on matters relating to corruption, bribery and fraud in public expenditure.

The Squad is not directly financed by the Zanzibar government since the Police Force is under the jurisdiction of the Ministry of Home Affairs of the Union Government. It has a staff strength of about 20 police officers, but it is poorly equipped and lacks specialist training in investigating corruption.

The Ministry of State for Constitutional Affairs and Government, which is under the Office of the President, was established in 2000 to strengthen the level of governance in Zanzibar as a means of enhancing social, political and economic development. Its portfolio includes promotion of human rights and good governance and it has the responsibility of coordinating all good governance activities.

Realizing that existing legislative measures are inadequate to combat corruption, the Ministry has initiated steps to review the legal framework for fighting corruption. In September 2002 it appointed a committee to draft a leadership code of ethics and a new law for the combating corruption in the island in more comprehensive manner. The intention is to establish institutions similar to the PCB and Ethics Commission of the mainland. The Ministry's target is to secure House of Representative's approval for the new bills by July 2003 .

\section{MANAGEMENT INFORMATION SYSTEM}

Information is an overriding consideration in institutional management. Managers at all levels require information for the purpose of generating reports, monitoring performance, forecasting, planning and making decisions. A management information system (MIS) is a computer based network that integrates the collection, processing and transmission of information.

The institutions involved in combating corruption in Tanzania use both manual filing systems and desk computers to record raw data. Transaction data required by managers for processing is then accessed from these records. A detailed diagnosis of the information needs of these institutions, which is a pre-requisite to the implementation of a successful MIS, was not carried out during the course of this assessment. 


\section{RECOMMENDATIONS}

The following recommendations are put forth:

(i) Ensure that there is full transparency at all stages of the procurement process: No information should be withheld to bidders with respect to decisions made or results of evaluations carried out at any stage of the tendering process.

(ii) Introduce an anti-corruption declaration in procurement contracts: Bidders who have won procurement contracts should be required to sign a declaration to the effect that they have not in any way indulged in corrupt malpractice to influence the award of the contract to them.

(iii) Strengthen financial control and monitoring of construction projects through technical and value for money auditing: Conventional financial audits alone are insufficient to determine the level of corruption and/or magnitude of misappropriated funds in construction projects. Actual expenditure incurred has to be ascertained with the value of actual (physical) works constructed.

(iv) Enforce adherence to professional code of ethics by procurement officers and professionals at all levels: Public accountability is weak in the civil service partly due to lack of enforcement of the laws and principles of ethics.

(v) Provide training in basic principles and procedures of public procurement to $P C B$ staff in order to enhance their skills in investigating procurement corruption: Few PCB staff understand procurement. This puts them at a great disadvantage when faced with issues relating to procurement corruption.

(vi) Promote and strengthen self-regulation initiatives aimed at curbing procurement corruption and enhancing accountability and integrity by professionals: Many professional associations have codes of ethics to regulate the professional conduct of their members. These associations should be facilitated to enforce their ethical codes in order to promote professional integrity among their members.

(vii) Encourage business and trade associations in the private sector to develop codes of ethics to regulate the conduct of their members and enhance corporate governance: Such codes will enhance credibility of members of the business community. Fear of being sanctioned will help to reduce corruption malpractice among members of the business community.

(viii) Create transparent avenues for the civil society and general public to monitor procurement contracts: Civil society and the media should have access to information concerning public procurement contracts. 
(ix) Publish names of focal persons responsible for monitoring corruption in government ministries, departments and agencies for general information to the public: The existence of focal points for monitoring corruption and implementation of NACSAP in government ministries, departments and agencies is unknown to the general public. People with corruption related complaints should know whom to approach confidentially or otherwise in the respective sector ministries and government agencies.

Appendix 2: Boards and professional associations regulating the conduct of various professional personnel that normally carry out public procurement

\begin{tabular}{|l|l|l|c|}
\hline & \multicolumn{1}{|c|}{$\begin{array}{c}\text { Professional } \\
\text { Cadre }\end{array}$} & \multicolumn{1}{|c|}{ Regulatory Organ } & Remarks \\
\hline 1. & $\begin{array}{l}\text { Accountants and } \\
\text { Auditors }\end{array}$ & $\begin{array}{l}\text { i. National Board of Accountants } \\
\text { and Auditors } \\
\text { ii. Tanzania Association of } \\
\text { Accountants and Auditors }\end{array}$ & Statutory \\
\hline 2. & Engineers & $\begin{array}{l}\text { i. Engineers Registration Board } \\
\text { ii. Institution of Engineers Tanzania } \\
\text { iii. Association of Consulting } \\
\text { Engineers Tanzania }\end{array}$ & Soluntary \\
\hline 3. & Architects & $\begin{array}{l}\text { i. Architects and Quantity Surveyors } \\
\text { Registration Board } \\
\text { ii. Architectural Association of } \\
\text { Tanzania }\end{array}$ & Voluntary \\
\hline 4. & $\begin{array}{l}\text { Quantity } \\
\text { Surveyors }\end{array}$ & $\begin{array}{l}\text { i. Architects and Quantity Surveyors } \\
\text { Registration Board } \\
\text { ii. Tanzania Institute of Quantity } \\
\text { Surveyors }\end{array}$ & Soluntary \\
\hline 5. & $\begin{array}{l}\text { Supplies and Materials } \\
\text { Management Officers }\end{array}$ & $\begin{array}{l}\text { i. National Board of Materials } \\
\text { Management } \\
\text { ii. Tanzania Institute of Supplies and } \\
\text { Materials Management }\end{array}$ & Voluntary \\
& Voluntary \\
\hline
\end{tabular}


ANNEX VI

\section{NACSAP ACTION PLAN FOR PUBLIC PROCUREMENT}

\begin{tabular}{|c|c|c|c|c|c|c|c|}
\hline \multirow[t]{2}{*}{ PROBLEM } & \multirow{2}{*}{$\begin{array}{c}\text { MINISTRY } \\
\text { (Departments) }\end{array}$} & \multirow{2}{*}{$\begin{array}{l}\text { WHO } \\
\text { BENEFITS }\end{array}$} & \multirow{2}{*}{$\begin{array}{l}\text { WHO } \\
\text { LOSES }\end{array}$} & \multirow{2}{*}{$\begin{array}{c}\text { ACTIONS } \\
\text { ALREADY TAKEN }\end{array}$} & \multicolumn{2}{|c|}{ ACTIONS TO TAKE } & \multirow{2}{*}{$\begin{array}{l}\text { EXPECTED RESULT } \\
\text { AND BY WIEN } \\
\text { (1)=short-term Dec.2000 } \\
\text { (2)=Medium-term } 2005 \\
\text { (3)=Long-term on-going }\end{array}$} \\
\hline & & & & & Government & Clvil Society & \\
\hline $\begin{array}{l}\text { PROCU- } \\
\text { REMENT }\end{array}$ & $\begin{array}{l}\text { - Central Tender } \\
\text { Board } \\
\text { - Ministry of } \\
\text { Works. } \\
\text { - Ministry of } \\
\text { Defence. } \\
\text { - All other } \\
\text { Ministries. } \\
\text { - Pension Funds. } \\
\text { Professional } \\
\text { Registration } \\
\text { Board }\end{array}$ & $\begin{array}{l}\text { The Comupt } \\
\text { decision } \\
\text { maker and the } \\
\text { dishonest } \\
\text { supplier/ } \\
\text { tenderer }\end{array}$ & $\begin{array}{l}\text { The } \\
\text { honest } \\
\text { supplier/ } \\
\text { Tenderer } \\
\text { and the } \\
\text { public. }\end{array}$ & $\begin{array}{l}\text { - Drafted New Procurement } \\
\text { Law \& Regulation. } \\
\text { - Improved Monitoring of } \\
\text { tendering practice within } \\
\text { Central \& Regional Tender } \\
\text { Boards, as well as Ministerial } \\
\text { Committees. } \\
\text { - Replacement of corrupt } \\
\text { members of public } \\
\text { procurement \& tender bodies. } \\
\text { - Close follow-up of source of } \\
\text { quotations/bids received. } \\
\text { - Introduction of "box" for } \\
\text { tender/quotation submission. } \\
\text { - All valid quotations/bids to be } \\
\text { sealed and opened only by } \\
\text { tender Committee. } \\
\text { - Office supplies being acquired } \\
\text { from Government stores } \\
\text { Department or their appointed } \\
\text { agents. } \\
\text { - Registration boards for } \\
\text { Contractors and Consultants } \\
\text { formed. }\end{array}$ & $\begin{array}{l}\text { - Approve/Pass the Law } \\
\text { - Monitoring \& replacement of corrupt } \\
\text { elements to continuc. } \\
\text { - Establish cadre of procurement } \\
\text { specialists in Central \& Regional } \\
\text { Tender Committees } \\
\text { - Tenure of membership of tender boards } \\
\text { to be limited. } \\
\text { - Make public tender results } \\
\text { - Introduce appeals mechanism relating } \\
\text { to tender awards. } \\
\text { - Make public economic justification of } \\
\text { major "investment" projects. } \\
\text { - Publicise all contracts of significant } \\
\text { implication. } \\
\text { - Minimise bureaucratic intervention in } \\
\text { procurement. } \\
\text { - Reduce procedures for small values } \\
\text { purchases } \\
\text { - Arrange periodic open motings } \\
\text { between panellists drawn from donors, } \\
\text { civil society, private sector and } \\
\text { Regional Tender Boards or Ministerial } \\
\text { Tender Committees. } \\
\text { - Prepare black-list of suppliers of goods } \\
\text { and services. } \\
\text { - All tendering to be open to public by } \\
\text { press advertisement. }\end{array}$ & $\begin{array}{l}\text { - Voice well-researched } \\
\text { comments on all tender awards } \\
\text { through a coalition of } \\
\text { procurement specialists. } \\
\text { - Arrange public workshops on } \\
\text { procurement procedures } \\
\text { - In depth surveys of public } \\
\text { contract and awarding } \\
\text { officials, firms. } \\
\text { - Monitoring entire bidding } \\
\text { process \& give quotation in } \\
\text { bids } \\
\text { - Design participatory } \\
\text { workshops for consensus and } \\
\text { collective action in } \\
\text { procurements }\end{array}$ & $\begin{array}{l}\text { - Lower tender prices on goods } \\
\text { \& services - (1). } \\
\text { - Savings in public expenditure } \\
\text { on goods \& services - (1) } \\
\text { - Honest supplier/tenderer will } \\
\text { be solvent - (2) } \\
\text { - Promotes competition through } \\
\text { transparency - (2) } \\
\text { - Economy in government } \\
\text { acquisitions - (3) } \\
\text { - Fair contract awards - (3) } \\
\text { - Increased transparency in } \\
\text { procedures for } \\
\text { tendering - (3) } \\
\text { - Enhanced efficiency in } \\
\text { procurement by keeping to a } \\
\text { minimum bureaucratic } \\
\text { interventions - (2) } \\
\text { - Less fraud in concessions and } \\
\text { contracting - (2) }\end{array}$ \\
\hline
\end{tabular}


ANNEX VII

\section{Annex A - Checklist comparing National Competitive Bidding Procedures and World Bank Policy}

\begin{tabular}{|c|c|c|c|}
\hline & Yes & No & Bank Policy \\
\hline $\begin{array}{l}\text { 1. Are there eligibility restrictions based on } \\
\text { nationality of bidder and/or origin of goods (other } \\
\text { than primary boycotts)? }\end{array}$ & & $\mathrm{X}$ & Not allowed \\
\hline $\begin{array}{l}\text { 2. Are there primary boycotts, which are established } \\
\text { by law? }\end{array}$ & $\mathrm{X}$ & & $\begin{array}{l}\text { Only primary boycotts are } \\
\text { acceptable }\end{array}$ \\
\hline $\begin{array}{l}\text { 3. Are bidding opportunities advertised in the local } \\
\text { press? }\end{array}$ & $\mathrm{X}$ & & Required \\
\hline $\begin{array}{l}\text { 4. Are prospective bidders allowed at least } 30 \text { days } \\
\text { for bid preparation (except for commodities/small } \\
\text { goods contracts)? }\end{array}$ & $\overline{\mathrm{X}}$ & & Required \\
\hline $\begin{array}{l}\text { 5. Are contractors/suppliers pre-qualified for } \\
\text { large/specialized contracts? }\end{array}$ & $\mathrm{X}$ & & Required \\
\hline $\begin{array}{l}\text { 6. Are minimum experience, technical and financial } \\
\text { requirements (for pre- or post-qualification) } \\
\text { explicitly stated in the documents? }\end{array}$ & $\mathrm{X}$ & & Required \\
\hline $\begin{array}{l}\text { Registration should not be used as a substitute } \\
\text { for advertisement when open competition is } \\
\text { required. However, when advertising for civil } \\
\text { works, borrowers could indicate the required } \\
\text { minimum category of contractor specified in } \\
\text { the registration system. }\end{array}$ & & $\mathrm{X}$ & Required \\
\hline $\begin{array}{l}\text { 7. Is an invitation to pre-qualify advertised for each } \\
\text { procurement involving large or complex potential } \\
\text { contracts? }\end{array}$ & $\mathrm{X}$ & & Required \\
\hline $\begin{array}{l}\text { 8. Are joint ventures with local firms required for } \\
\text { foreign firms' eligibility? }\end{array}$ & & $\mathrm{X}$ & Not allowed \\
\hline $\begin{array}{l}\text { 9. Are joint venture partners jointly and severally } \\
\text { liable? }\end{array}$ & $\mathrm{X}$ & & Required \\
\hline
\end{tabular}




\begin{tabular}{|c|c|c|c|}
\hline \multicolumn{4}{|c|}{$\begin{array}{c}\text { Annex A - Checklist comparing National Competitive Bidding } \\
\text { Procedures and World Bank Policy }\end{array}$} \\
\hline $\begin{array}{l}\text { 10. Are there set limitations to the number of firms } \\
\text { who can bid for a contract? }\end{array}$ & & $\mathrm{X}$ & Not allowed \\
\hline 11. Are parastatals allowed to bid? & $\mathrm{X}$ & & $\begin{array}{l}\text { Acceptable only if they (i) } \\
\text { are financially } \\
\text { autonomous, (ii) operate } \\
\text { under commercial law, } \\
\text { and (iii) are independent } \\
\text { from borrower and its } \\
\text { purchasing/contracting } \\
\text { authority. }\end{array}$ \\
\hline $\begin{array}{l}\text { 12. Are bidders required to register with a local or } \\
\text { federal authority as a prior condition for bidding? }\end{array}$ & $\mathrm{X}$ & & $\begin{array}{l}\text { Should be discouraged. } \\
\text { Acceptable only if } \\
\text { registration criteria, } \\
\text { process and cost } \\
\text { reasonable/efficient and } \\
\text { qualified foreign firms are } \\
\text { not precluded from } \\
\text { competing. }\end{array}$ \\
\hline 13. Are extensions to bid validity allowed? & $\mathrm{X}$ & & $\begin{array}{l}\text { Acceptable only if } \\
\text { justified by exceptional } \\
\text { circumstances. }\end{array}$ \\
\hline $\begin{array}{l}\text { 14. Are there restrictions on the means of delivery of } \\
\text { bids? }\end{array}$ & & $\mathrm{X}$ & $\begin{array}{l}\text { Not allowed, except when } \\
\text { bidders have to submit } \\
\text { physical samples. Then } \\
\text { they can be required to } \\
\text { deliver bids by mail, by } \\
\text { courier, by hand, etc. }\end{array}$ \\
\hline $\begin{array}{l}\text { 15. Is preference given to suppliers or contractors } \\
\text { based on region or locality of registration, small } \\
\text { size, ethnic ownership, etc.? }\end{array}$ & $\mathrm{X}$ & & Not allowed \\
\hline $\begin{array}{l}\text { 16. Are there restrictions on sources of labour and } \\
\text { material? }\end{array}$ & & $\mathrm{X}$ & $\begin{array}{l}\text { Not allowed, except for } \\
\text { unskilled labour, if } \\
\text { available locally. }\end{array}$ \\
\hline
\end{tabular}




\section{Annex A - Checklist comparing National Competitive Bidding Procedures and World Bank Policy}

\begin{tabular}{|c|c|c|c|}
\hline $\begin{array}{l}\text { 17. Is public bid opening required? Does it occur } \\
\text { immediately or closely following the bid } \\
\text { submission deadline? }\end{array}$ & $X$ & & Required \\
\hline $\begin{array}{l}\text { 18. Is a "two envelope" bid opening procedure } \\
\text { permitted for procurement of goods or works?" }\end{array}$ & & $\mathrm{x}$ & $\begin{array}{l}\text { Should be discouraged. } \\
\text { Allowed only if (i) } \\
\text { domestic law precludes } \\
\text { use of one envelope and } \\
\text { (ii) provided adequate } \\
\text { safeguards against } \\
\text { retaining second envelope } \\
\text { unopened are incorporated } \\
\text { in the two envelope } \\
\text { procedures and effective } \\
\text { bid protest mechanisms } \\
\text { are already in place for the } \\
\text { due processing of bid } \\
\text { complaints. }\end{array}$ \\
\hline $\begin{array}{l}\text { 19. Is automatic rebidding required if too few bids are } \\
\text { received? }\end{array}$ & $\mathrm{X}$ & & $\begin{array}{l}\text { Acceptable, provided all } \\
\text { responsive bidders are } \\
\text { allowed to bid, the process } \\
\text { is efficient and no serious } \\
\text { delays result. }\end{array}$ \\
\hline 20. Is "bracketing" used in bid evaluations?" & & $\mathrm{X}$ & Not allowed \\
\hline Are bid evaluation criteria other than price allowed? & $\mathrm{X}$ & & $\begin{array}{l}\text { Only if quantified in } \\
\text { monetary terms }\end{array}$ \\
\hline $\begin{array}{l}\text { 21. Is award made to lowest evaluated qualified and } \\
\text { responsive bidder? }\end{array}$ & $\mathrm{X}$ & & Required \\
\hline
\end{tabular}

\footnotetext{
${ }^{1}$ All technical envelopes are opened first and, after review, price envelopes of all or only qualified/responsive bids are opened in the second round.

${ }^{2}$ Rejection of bids outside a range or "bracket" of bid values.
} 


\section{Annex A - Checklist comparing National Competitive Bidding Procedures and World Bank Policy}

\begin{tabular}{|c|c|c|}
\hline $\begin{array}{l}\text { 22. Are price negotiations conducted with "winning" } \\
\text { bidders prior to contract signature? }\end{array}$ & $\mathrm{X}$ & $\begin{array}{l}\text { Not allowed, except where } \\
\text { the bid price is } \\
\text { substantially above market } \\
\text { or budget levels and then } \\
\text { only if negotiations are } \\
\text { carried out to try to reach } \\
\text { a satisfactory contract } \\
\text { through reduction in scope } \\
\text { and/or reallocation of risk } \\
\text { and responsibility which } \\
\text { can be reflected in a } \\
\text { reduction in Contract } \\
\text { Price. (See Guidelines } \\
\text { para } 2.60 \text { ) }\end{array}$ \\
\hline 23. Are price adjustment provisions generally used? & $\mathrm{X}$ & $\begin{array}{l}\text { Not required but } \\
\text { recommended for works } \\
\text { contracts of one year or } \\
\text { more in duration when } \\
\text { domestic inflation rate is } \\
\text { high. }\end{array}$ \\
\hline $\begin{array}{l}\text { 24. Are the terms and conditions used in goods and } \\
\text { works procurement generally appropriate for the } \\
\text { size and nature of contract intended? }\end{array}$ & $\mathrm{X}$ & $\begin{array}{l}\text { Required (to be acceptable } \\
\text { they should be balanced, } \\
\text { reasonable, and clearly } \\
\text { address the most } \\
\text { important issues that lead } \\
\text { to problems during } \\
\text { performance, e.g. risk } \\
\text { allocation, payment, } \\
\text { inspection, } \\
\text { completion/acceptance, } \\
\text { insurance, warrantees, } \\
\text { changes, contract } \\
\text { remedies, force majeure, } \\
\text { governing law, } \\
\text { termination, etc.) }\end{array}$ \\
\hline $\begin{array}{l}\text { 25. Are contract scope/conditions modified during } \\
\text { implementation? }\end{array}$ & $\bar{X}$ & $\begin{array}{l}\text { Acceptable, but the } \\
\text { Bank's approval is } \\
\text { required for changes in } \\
\text { those contracts that were } \\
\text { subject to prior review } \\
\text { under the Loan } \\
\text { Agreement. }\end{array}$ \\
\hline
\end{tabular}




\section{ANNEX B - QUESTIONNAIRE ON PUBLIC PROCUREMENT SYSTEM}

\begin{tabular}{|c|}
\hline Section A - Legal Framework \\
\hline GENERAL FEATURES \\
\hline $\begin{array}{l}\text { 1. Identify predominant legal system (i.e. Common/Civil Law; Socialist; other) } \\
\text { Common Law (although Islamic courts are present on Zanzibar for certain cases) }\end{array}$ \\
\hline $\begin{array}{l}\text { 2. Identify form of government (i.e. federal or centralized) } \\
\text { Tanzania is a union republic with centralized government, with some autonomy for The } \\
\text { Revolutionary Government of Zanzibar. }\end{array}$ \\
\hline $\begin{array}{l}\text { 3. Does the Constitution (if there is one) contain any provision directly bearing on public sector } \\
\text { procurement? (If so, describe) } \\
\text { No }\end{array}$ \\
\hline $\begin{array}{l}\text { 4. Is the country a signatory (or planning to become one) to the Agreement on Government } \\
\text { Procurement of the World Trade Organization? } \\
\text { No }\end{array}$ \\
\hline $\begin{array}{l}\text { 5. Does the basic contract law contain any provision directly bearing on public sector } \\
\text { procurement? (If so, describe) } \\
\text { No }\end{array}$ \\
\hline $\begin{array}{l}\text { 6. Is there a separate body of law, which regulates public sector procurement, or is it governed } \\
\text { by regulations issued under an organic finance act? } \\
\text { Yes, the Public Procurement Act (2001) with supporting regulations for both central and } \\
\text { local government procurement covers all public procurement. }\end{array}$ \\
\hline $\begin{array}{l}\text { 7. Is the system clear, comprehensive and consistent? Does it cover all essential aspects with no } \\
\text { unduly complicated, unnecessary, conflicting or outdated regulations? Are rules found in } \\
\text { various distinct sources or within a well-coordinated legal framework? } \\
\text { Yes, the legal framework is consistent and thorough. }\end{array}$ \\
\hline $\begin{array}{l}\text { 8. Is the hierarchy of the sources of procurement rules well established? } \\
\text { Yes, with the enactment of the new Procurement Act in } 2001 \text { previous unclarities have been } \\
\text { removed. }\end{array}$ \\
\hline $\begin{array}{l}\text { 9. What is the scope of coverage for the procurement legal framework? Does it cover sub- } \\
\text { national government? Does it include coverage of all government procurement including } \\
\text { security and military procurement? } \\
\text { All public procurement is covered by the Act, with the exception of procurement by } \\
\text { parastatals not receiving government "subsidy" and procurement of a sensitive nature by the } \\
\text { military and security forces. }\end{array}$ \\
\hline $\begin{array}{l}\text { 10. Are there separate procurement rules established for parastatals? Describe. } \\
\text { No }\end{array}$ \\
\hline $\begin{array}{l}\text { 11. Is the procurement function decentralized? If so, describe basic structure, name the main } \\
\text { decentralized procuring entities and indicate their role, rights, and responsibilities. } \\
\text { No, the Central Tender Board is the central body responsible for all procurement at the } \\
\text { central government level, handling all large procurements. Below certain thresholds, tender } \\
\text { boards of individual ministries etc. handle procurement activities. }\end{array}$ \\
\hline
\end{tabular}


12. Is there an entity(ies) with oversight responsibilities for procurement functions throughout public administration (e.g., with primary regulatory powers, responsible for harmonization of rules and monitoring of compliance)? If so, identify and describe responsibilities and structure.

Yes, the Central Tender Board is presently both the central executing body and the central policy and monitoring body.

13. Is there a Central Tender Board or a similar institution? What are its duties and responsibilities?

The Central Tender Board is presently both the central executing body and the central policy and monitoring body. The CTB is an autonomous board, within the Ministry of Finance.

14. Does the system allow/facilitate the introduction of new and innovative techniques and contracting practices without compromising basic principles?

Even though the Procurement Act and Regulations are quite detailed, there is adequate room for adaptation of new techniques within the overall legal framework.

15. Are there rules/procedures regarding bidder suspension and debarment? Yes, tender boards can debar bidders based on previous performance/irregularities.

16. Is the country a member of regional trade/customs agreements? (If so, specify) Yes, the SADC Trade Protocol where member countries of SADC are supposed to phase-in intra-SADC preferential tariff treatment over a period of eight years starting the year 2000. The EAC members (including Tanzania) intent to harmonise their tariff and customs regimes and to enact a Common Exterial Tariff in 2004.

17. Are there primary/secondary boycotts? (Specify) No

18. Are there provisions regarding preferences for particular categories of suppliers of goods, works and services? (Specify) Yes, but only in local government procurement, where preference can be given to local works contractors.

19. Are there arbitration rules applicable to procurement contracts? Are they consistent with international rules such as those embodied in the UNCITRAL Model Law on Arbitration? (Highlight major differences)

Standard terms for public contracts often contain arbitration clauses, but without such specific agreement public contracts are subject to the legal procedures of the courts. The Arbitration Rules of the National Construction Council, which are largely in line with the Model Law, is often referred to.

20. Are there laws or regulations governing policies and procedures for awarding concessions/contracts for private sector provision/operation of power, water or other infrastructure facilities? (BOO, BOT, etc.) Do any general conditions of contract apply as a matter of law or regulation? No, the Procurement Act applies.

\section{BASIS OF TRANSPARENCY}

1. Is there a legal or regulatory requirement for public disclosure of procurement legal texts? Yes, legal texts are published in the Government Gazette. 
2. Are there mandatory requirements for maintaining written records of procurement? To what extent are they available to the general public?

Yes, a comprehensive procurement protocol is mandatory. The content of the protocol is not available to the public as there is no freedom of information act.

3. Are requirements for advertisement of contracting opportunities adequate? Does the country have a national gazette (or other similar publication) published in a timely fashion? Is it easily available to the general public?

Advertisement is only through newspapers. The Government Gazette does not carry advertisements of procurement opportunities. For large contracts, advertisement in the newspapers is adequate, but the country does not have a centralized media where all procurement opportunities can be accessed.

4. Are requirements regarding public bid opening, if any, appropriate?

Yes, the Procurement Act and Regulations contains adequate rules.

5. Are negotiations after bid opening or award selection allowed? Do the rules on negotiated procurement, if any, provide the basis for a fair and transparent process?

Pre-contract negotiation is allowed as long as they do not "substantially" change the terms of contract. There are no rules on how such negotiation should proceed.

6. Are conditions for use of various procurement methods clearly established? Is there an explicit requirement that open competitive bidding is the preferred or default method?

Yes, competitive bidding is the proffered method, but a large number of loosely defined exceptions leave room for interpretation and irregularities.

7. Is there a requirement for public notice of contract awards?

Yes, in the Government Gazette.

8. Are there clear and appropriate requirements for bid and contract securities?

Yes, in the Standard Terms of Contract published by the Central Tender Board.

9. Are qualification requirements for bidders, if any, fair and appropriate for the purpose of the contract?

Comprehensive and adequate qualification requirement are contained in the standard prquilification documents published by the Central Tender Board.

10. Do requirements for bid examination and evaluation provide the basis for a rational and fair process?

Yes

11. Are summaries of information about public procurement published (e.g. number of bids received, number of contracts awarded, names of successful bidders)? If so, describe scope and frequency.

Very rarely, even though it is required in the Regulations.

12. Does government hold regular meetings with the business community to discuss public procurement issues?

No

13. Is there a conflict of interest policy in effect? (If so, describe its essential features). Yes, the Anti-Corruption legislation specifically outlaws decisions made by public employees in conflict of interest. 
14. Are there laws on bribery of government officials and are they enforced? Do government bidding documents and contracts contain anti-bribery and anti-corruption conditions?

Yes, bribes are covered by the Anti-Corruption legislation, which is enforced by the Prevention of Corruption Bureau. The standard contract terms published by the Central Tender Board do contain an anti-bribery pledge.

\section{BASIS OF ACCOUNTABILITY}

1. Are government employees expected to follow a published code of ethics? If so, describe its basic features.

Yes, two codes of ethics exist. The Code of Ethics and Conduct for the Public Service directed towards all public servants, and the Leadership Code of Ethics addressed specifically to public service managers. Apart from comprehensive ethics requirements, the latter also determines that public leaders and politicians must declare assets and liabilities on a regular basis, including the source of their assets. The Code of Ethics and Conduct of the Public Service contains a number of ethics provisions. Of relevance to procurement are in particular the provisions on safeguarding of public property obliging the public servant to ensure that no damage, loss or misappropriation of public property occurs; the obligation of public servants to declare property when so requested; the prohibition against accepting bribes and excessive gifts; and the obligation to avoid situations of conflict of interest.

2. Is there an accessible and secure process for bidders to report bribes by others and solicitation/extortion of bribes by government officials?

The Prevention of Corruption Bureau (PCB) operates a hotline, where aggrieved bidders may report corruption related violations. Reports can also be made anonymously. However, the PCB lacks expertise to follow-up and investigate procurement related corruption.

3. Do bidders have adequate access to administrative or judicial review/appeal?

No, the Public Procurement Appeals Authority mentioned in the Procurement Act (2001) has not yet been formed.

4. Are there measures/initiatives to curb/control corruption, e.g. anti-corruption statutes and/or bodies, whistle-blower statutes, comprehensive reforms of the civil service/judiciary, regional initiatives, provisions in the criminal law, anti-bribery provisions, etc.? (If so, describe) The Prevention of Corruption Act of 1971 with subsequent amendments provides a rather comprehensive framework for combating corruption. The law is currently under revision, and it is expected that the amendments will lead to the introduction of whistleblower mechanisms. Also, the amendments suggested by the PCB also expand the provisions on public disclosure of assets by public officers. Both the Prevention of Corruption Act and the PPA contains antibribery provisions. The problem remains the enforcement of these provisions. 


\section{Section B - Trade/Customs Practices}

1. Are foreign firms engaged in trade with the country required to use a local agent?

There is no legal provision-requiring firm to use a national agent for products or services rendered in Tanzania. However some multi-nationals appoint agents or local representatives to safe guard quality, and prevent infringement of patents or copyrights, provide maintenance and distribute spare parts. All importers use clearing agents.

2. Is there evidence of any trade malpractice affecting public sector procurement? No.

3. Is inspection conducted according to generally established procedures? Are there indications that the inspection is not effective?

Tanzania has pre-shipment inspection (PSI) and this is in general conducted according to generally established procedures. However, there is strong evidence that PSI due to external factors, i.e. development of technology, is inefficient, and the introduction of a Post Entry Audit Programme in December 1999 to inspect the already inspected goods confirms this notion - $15 \%$ of goods are subjected to post shipment audit.

4. Do pre-shipment/post-shipment inspection, if any, unduly increase the procurement lead time? The combination of pre-shipment inspection and post entry audits for $15 \%$ of all imported goods increase the lead-time for that part of the imports. It is recommended to move quickly towards Destination Inspection. Customs and Port Authorities in general have the reputation for being a hindrance for importers throughout Tanzania. Unpredictable and lengthy clearance delays and facility payments are said to be commonplace

5. Is counter-trade used? Barter agreements? For what percentage of the country's total trade? Generally no, although it cannot be excluded that counter-trade is used in special cases, i.e. weapons import.

6. Are the ICC's INCOTERMS generally understood and commonly used in the Country? Are other trade terms used?

Yes, they are general practice and generally understood by all parts involved in imports and exports.

7. Are licensing and customs procedures generally transparent and efficient?

Licensing procedures are transparent however they are not efficient due to certificates needed before the final approval is granted. For example before issuing some licences traders are required to obtain certification from Ministry of Health, Ministry of tourism, Radiation Commission, Contractors registration board, TBS, TPRI just to mention a few. 
8. Are "facilitation" payments normally necessary to clear goods through customs, obtain work permits for expatriate labour, process monthly payment certificates/invoices?

Facility payments are said to be commonplace. There are numerous anecdotes to support this, e.g. it is mentioned by several importers that companies via facility payments can slow down the process of clearing the competitor's goods.

9. Are staff familiar with shipping and other trade documents? With documentary credits? With customs, yes. The general professional level of the clearing agents is said to be low, and there is insufficient knowledge of the details of import regulations and procedures.

\section{Section C - Financial/Budgetary Framework}

1. Are banks capable of issuing Letters of Credit?

Yes

2. Are banks generally creditworthy?

Yes

3. Can bid, performance and advance payment securities be obtained easily? What formats are permitted? Bank guarantees? Bonds? Other? Provide details on cost, if available.

Obtaining bid security is extremely costly. The conditions for bid security are in general the same as with letters of credit. The value of the security should either be $100 \%$ cash cover and the value of the contract should be at least $125 \%$ of the secured amount. The causes of the high lending rates and costs of bid security are: Unstable legal environment, High cost of capital, High degree of risk, Loan recovery problems, and Collateral recovery problems.

4. Are the requirements for issuance of bid, performance, and other securities to suppliers/contractors reasonable?

Suppliers/contractors do not in general find the requirements reasonable. However, the high costs as described above can place national suppliers in a position where they are not able to compete for tenders that are put out internationally although they would otherwise be competitive.

5. Do suppliers/contractors have reasonable access to credit? Access as such is no problem, but costs are as described above are very high. Commercial lending rates are high as well (16.96\% in November 2002).

6. Do implementing agencies obtain budgetary authorizations for contract payments falling due beyond the current financial year? Generally, yes.

7. Are major projects or programs clearly identified in government budget estimates?

Yes 
8. What procedures are followed to ensure the procuring entity obtains budget authorization prior to inviting bids?

There are no procedures of ensuring that procuring entities do not invite tenders before budget authorization but the system would not allow payment to the contractor. Thus inviting tenders before budget authorization would be done at the entity's own risk.

9. Do procuring entities reliably receive the monies authorized? Or is the budget subject to revision during the year by a restrictive cash release system?

The budget is usually subject to revision depending on the quarterly cash releases

\section{Section D - Public Sector Procurement of Goods/Works}

\section{GENERAL RISK ASSESSMENT}

1. Is staff working in public sector procurement area held in high regard?

Procurement is not viewed as a profession and is not recognized as such within the public sector. At present, procurement is either carried out by supplies officers, who often lack training and skills, or by other professionals, such as civil engineers, who have experience with procurement, but for whom it is not a key task.

2. Are pay levels for staff working on procurement comparable to that for other public and private sector technical specialists?

Payments vary, but generally public service pay is lower than that of the private sector.

3. Does a code of ethics exist that staff working in procurement are expected to follow?

No. The only code of ethics with some relevance is the Code of Conduct for Registered Materials Management Professionals issued by the National Board of Materials Management. This code provides a rather comprehensive ethics framework for the materials management profession, but since materials management only covers limited aspects of procurement, the code does not address all aspects of procurement.

4. Are the authorities relating to procurement clearly delegated to the entities carrying out the process? Are the applicable procedures clearly defined?

Delegation is described the PPA and procedures in the Regulations. 
5. Are procurement decisions overridden by higher governmental agencies? If so, by whom? To what degree is the procurement decision-making process independent and based on transparent criteria?

Procurement decisions are generally independent, although there are reports of political interference especially at local government level. Also, there has been some cases of high profile, where high level officials have been accused of interfering in large scale contracts. At the level of the Central Tender Board transparency is relatively high. Tenders are advertised, tender openings are public and some contracts awarded are also published. However, at lower levels transparency requirements are not stringently followed.

6. Does the highest level of government encourage/support/enforce compliance with existing procurement regulations? Are violations investigated and procurement/other responsible officials held accountable?

Enforcement seems to be a major problem. Though the Government is officially promoting and supporting an anti-corruption agenda there are still reports of even high-level linkage to corruption cases within procurement. Violations are seldom investigated as the investigating authorities, like the PCB and the police, lack resources and expertise, and it is very difficult to find examples of public officials being held accountable for corruption offences.

7. Are there indications suggesting price-fixing in open bidding?

No

\section{ORGANIZATION}

1. Is appropriate information on procurement adequately disseminated (i.e. procurement staff are aware of updated rules and thresholds, and other issues relevant to their assigned. responsibilities)?

Information on procurement is generally lacking. Especially at local government authority level, where even awareness about the Public Procurement Act is low. There are no formal measures, such as newsletters or other up-dates providing procuring entities with up-dated information.

2. Are the procurement and supply management functions clearly distinguished? No. The Public Procurement Act only mentions procurement experts, and leaves it open as to the educational background of these experts.

3. Is contracting authority reasonably delegated (i.e. there are no unnecessary levels of approvals or cumbersome procedures)?

Procuring entities complain that the thresholds set are too low and that the approval required by the CTB provides for too cumbersome a procedure. It has been recommended that procurement be decentralised to the level of ministries, departments, agencies and parastatals leaving the CTB as a purely regulatory authority.

4. Are the thresholds for contracting authorities regularly updated?

There has since the introduction of the Procurement Act in 2001 not been any updates. 
5. Do procuring entities have internal quality and control mechanisms? Are they regularly audited?

There is a general lack of internal quality and control mechanisms and external auditing is infrequent

6. Are procurement staff experienced in international procurement?

Some ministries and parastatals possess staff experienced in international procurement. This experience is typically acquired through work on donor-financed projects. However, at regional and local government authority level the experience with international procurement is virtually non-existing.

7. Do adequate formal and on-the-job training programs exist for entry- and higher-level staff that contribute to proper professional career development? Does knowledge of procurement lead to career advancement?

No

8. Are there additional training resources in the country that are currently utilized or that could be utilized to complement Government/donor-administered programs (e.g. universities and private institutions)?

Several universities, business schools and private institutes have voiced their interest in providing procurement training, and some are currently organising forthcoming training events. However, a systematised effort is lacking and there is a great need for a comprehensive Government strategy on training and capacity building within procurement.

9. Did previous training programs (if any) lead to an obvious improvement in the quality/productivity of procurement work?

Some donors have conducted limited and selective training for staff responsible for procurement on donor funded projects, and there is evidence that these staff members are generally proficient in the donor requirements for procurement-especially World Bank rules. However, there have been problems in terms of retaining the staff members, and several have left the public sector and have sought employment in the private sector, where payment levels are higher.

10. Do procurement staff have adequate project/contract management capabilities? A few do, but generally there is an overall lack of project/ contract management capabilities.

11. Are procurement agents used? Under what circumstances? How are they selected? Describe normal basis for compensation and contract duration Yes, often for donor funded tenders and for some government funded complex tenders. They are selected according to the rules on selection of consultants on a unit fee basis, typically with a contract duration corresponding with the planned duration of the specific tender to be performed.

12. Is procurement monitoring and administration computerized? How adequately do procurement entities track the key steps in the procurement process and collect appropriate project-related cost and schedule information?

Computerized monitoring is very rare in government-funded projects. Generally, recording and filing of information is of low standard. 


\section{PROCUREMENT PLANNING}

1. Are project implementation units adequately staffed with trained procurement, planning, scheduling, expediting and cost estimating personnel?

No, there is a chronic shortage of adequately trained staff with knowledge of the new legal framework.

2. Is overall planning for complex goods, works and other contracts done in sufficient detail to produce realistic project definition, achievable completion schedules, and accurate cost estimates? No, poor quality in all planning stages is a major problem.

3. Is the early technical and financial planning well coordinated so that projects are fully funded when work needs to begin, based on accurate cost estimates? No, lack of accurate information affects quality of planning.

4. Are appropriate methodologies used to plan multiple inter-related procurement activities on large projects (e.g. the critical path method)? Rarely for government funded and run projects.

5. Are project components appropriately packaged for procurement purposes? No, often the packaging does not take into account the structure of the market and the available bidders.

6. Are completion schedules generally met for goods, works and consultant services contracts? If not, what is the major cause for slippage? Is sufficient time generally allowed for external reviews/clearances?

No. Poor planning and poor specifications often cause delays. Delays caused by external reviews/clearance are not reported.

7. Do procurement units regularly conduct market surveys to update their knowledge of prevailing prices for goods and works? Generally not, even though some do.

8. Are procedures and methodologies for planning procurement of recurrent items (i.e. inventory control, forecasting of future requirements, classification, coding, accounting/financial management, spare parts management, and delivery systems) adequate? Stores Managers and Supplies Managers handle these tasks, but general procurement planning is perceived to be of low quality. 


\section{DOCUMENT PREPARATION}

1. Do standard documents exist for goods, works and other types of contract? List. Are other international contract formats used? If so, identify.

Yes, the Central Tender Board have in November 2002 issued a number of mandatory standard documents (listed in main report) covering goods, works and services/consultant procurement. These standard documents are based on World Bank standard documents and until they are disseminated, a number of other standard documents based largely on donor documents are in use. In addition the National Construction Council have issued standard documents specifically for use in local government works procurement.

2. Are these documents, if any, readily adaptable to specific contract situations (i.e. by modifications made through a Bid Data Sheet, Special Conditions of Contract or similar)? Yes, all available standard documents allow for adaptation.

3. Are there separate documents for international and national competitive bidding not financed by the Bank? Yes

4. Do Instructions to Bidders (ITBs) contain all information necessary to prepare responsive bids and clearly understand evaluation criteria and their method of application? Yes

5. Do they contain other necessary information, such as eligibility requirements, basis of bid, language and currency of bids, common currency for purposes of evaluation, source and date of the exchange rate, etc.? Are sample forms and other appropriate sections of the documents provided? Yes

6. Are bidders required to provide bid security in an appropriate amount as a condition of responsiveness of their bid? Yes, if the procuring entity desires it.

7. Is pre- or post-qualification provided for? Yes, both options are available.

8. Are qualification criteria appropriate and clearly described? Yes, but only in the standard documents, not in the Act or Regulations.

9. Are conditions of contract equitable? Do they provide adequate coverage for most important commercial and legal issues (for the method of procurement, size, nature and type of contract used) and provide adequate protection to the Government, without putting undue risk on bidders? Yes, the standard terms appear equitable.

10. Are standard purchase orders used for shopping? Yes 


\section{PRE-QUALIFICATION}

1. Is pre-qualification carried out when appropriate? What types of contracts is it used for? Works? Goods? Other?

No, even though the Act provides for pre-qualification and requires it when appropriate, often pre-qualification is not carried out.

2. Is the pre-qualification process fair and transparent? Are decisions made promptly? Are foreign firms allowed to apply?

Yes, the described procedures are adequate.

3. Are standard pre-qualification documents used? Do they clearly and completely describe all the prerequisites for submitting responsive applications for pre-qualification? Is financial information routinely requested and critically evaluated to assess an applicant's financial capacity to perform?

Yes, the standard documents issued by the Central Tender Board, specifically the "standard pre-qualification document" for work are adequate.

4. Do procuring entities verify prior to contract award if a successful bidder continues to meet pre-qualification requirements? No

5. Are suppliers required to have a local agent in order to qualify to bid for goods or services? No

6. Do procuring entities maintain updated lists of qualified suppliers and contractors and updated market information on commonly procured goods, including spares and consurnables? Is supplier and contractor performance routinely evaluated and are any standing lists of prequalified suppliers and contractors updated and modified based on this information. Can newcomers readily apply and be qualified?

Some procuring entities maintain internal lists. There are no common rules for the administration procedures of such lists. The quality of the administration and information in these list vary, and as a consequence hereof, the bidders can expect very different levels of treatment from different procuring entities.

7. Is the procedure for registration of domestic contractors fair, providing timely access to the bidding process to all potentially qualified bidders? Are bidders should be allowed to register by mail and, if the conditions in the country allow, through the internet?

Is registration permanently opened to bidders for registration or update, is there a deadline imposed in relation to a specific bidding process? Is the time taken for registration reasonable? Bidders for works are required to be registered with the National Board of Construction in different classes based on capacity. The registration process appears cumbersome but fair, and there are no complaints of excessive time taken for processing. 


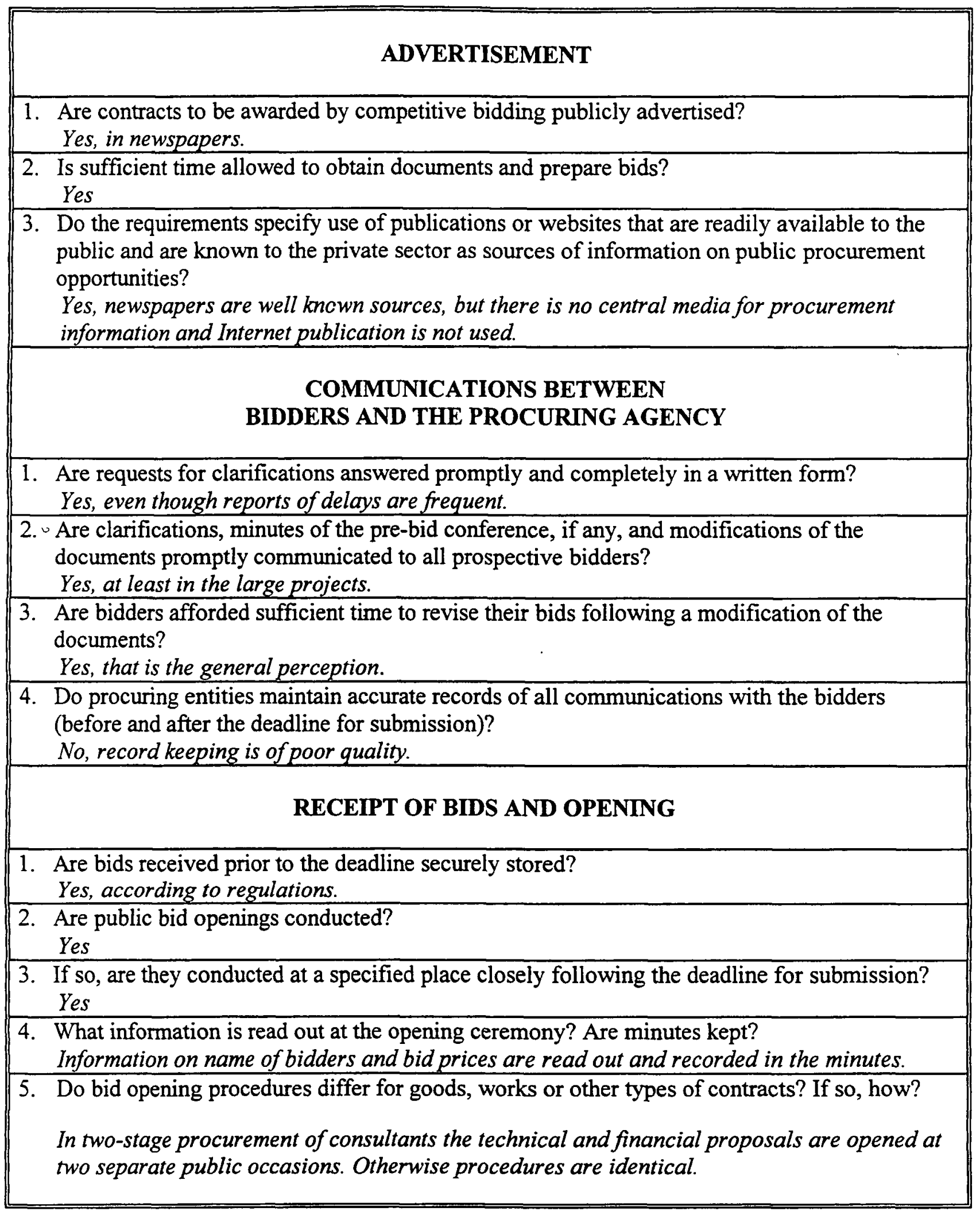




\section{BID EXAMINATION AND EVALUATION}

1. Are evaluations conducted by qualified evaluating committees?

Yes, often consultants are employed to do the evaluation

2. Are evaluating committees appointed ad hoc for each evaluation? Yes

3. Is responsiveness determined on the basis of the documentary requirements described in the documents and according to established practice? Yes

4. Are bid evaluations carried out thoroughly and on the basis of the criteria specified in the documents?

Often non-advertised criteria are applied due to lack of quality in the bidding documents.

5. Is the successful bidder's qualification to perform the contract determined solely on the basis of the criteria stated in the documents? (See above) If not, what other criteria are considered? No, often non-advertised and non-admissible criteria are applied, such as previous performance.

6. Are evaluations normally completed within the original bid validity period? No, there are widespread complaints of long evaluation and award periods.

7. Are bid evaluation reports prepared containing all essential information (i.e. a clear and complete description of the evaluation process, including the reasons for rejecting any bid as non-responsive, how the stated evaluation criteria were applied, and how the successful bidder's qualifications were verified)? The rules require such reports, but they are often not completed.

8. Describe any significant differences between goods and works procurement relating to the above.

The issue of non-advertised criteria is even more outspoken for works procurement, where quality in the bidding documents is of high importance.

\section{CONTRACT AWARD AND EFFECTIVENESS}

1. Are contracts required to be awarded to the lowest evaluated responsive bidder who has been determined to be qualified to perform the contract satisfactorily? Yes

2. Are negotiations conducted with bidders, before or after selection? Yes, often pre-contract negotiations are performed due to poor quality in technical specifications.

3. Are additional Government approvals required before contracts can be made effective? The Auditor-General must approve all contract terms.

4. Is performance security required in a reasonable amount and in a reasonable format? Yes 
5. Describe any differences between goods and works relating to the above.

Negotiations are more widespread in works procurement, which often are of a more complex nature than goods procurement.

\section{CONTRACT ADMINISTRATION}

1. Are there manual or computerized procurement and/or contract monitoring systems? No

2. Are suppliers and contractors generally paid on time? What is the normal time lapse from invoice submission to final payment? Yes, payment is mostly on time, with a time lapse of approx 30 days from invoicing.

3. Are there appropriate procedures to monitor delivery of goods and services to verify quantity, quality and timeliness?

No general procedures in place. Practices differ from entity to entity.

4. Are contract changes or variations handled promptly in accordance with the contract conditions and established practice (i.e. change/variation orders are given and/or confirmed in writing, constructive change orders are avoided, unit rates in the contract are honoured but the supplier or contractor is allowed to agree to any new unit rates introduced and the completion schedule for each change or variation, etc.)?

Variations are often handled informally without observing contract terms.

5. Do procuring entities normally make a good faith attempt to resolve disagreements through informal negotiations?

Yes

6. If this fails, are the resulting disputes handled in accordance with the contract conditions? No, there is a general tendency to rely on informal negotiations and ignore actual contractual terms.

7. Are supplier and contractor claims handled fairly based on a clear recognition of both parties' obligations under the contract?

Yes, but only through negotiations.

8. Are contract managers/administrators skilled in resolving problems in a timely manner and dealing with unforeseen circumstances arising during the life of the contract? Do they adequately document all actions of contractual import taken by the purchase/employer during implementation?

There are knowledgeable contract managers in some of the bigger ministries and agencies such Ministry of Works and TANROADS but generally contract managers have inadequate knowledge of the legal framework and the basic principles of dispute settlement.

9. Are contractual remedies utilized only when appropriate and in accordance with the contract conditions?

Generally contract remedies are not applied.

10. Are contracts generally completed on schedule and within the originally approved contract price? Or are cost and time overruns frequent? If so, in which sectors and for which particular kinds of contracts? Are fair final acceptance procedures used and certificates issued in a timely fashion?

Delays are frequent, but are often the result of poor planning and specifications. 
11. Are contracts generally administered in a fair and equitable manner (e.g. the purchaser/employer grants extensions of time when delays are attributable to its untimely action, fair compensation is provided to offset additional costs caused by its mistakes, etc.) Yes

12. Are under-inspection, over-inspection and/or improper rejection of goods, materials or methods of carrying out the works a common problem? No

13. Are disruptions of the supplier's or contractor's orderly performance common? No

14. Can any of the improper contract administrative practices identified above, be attributable to a problem identified in the local procurement environment? Specify Yes, the poor quality of planning and technical specifications is often the cause of improper administrative practices and opens opportunities for corruption.

15. Are procurement evaluations/audits conducted? If so, describe scope, frequency, who carries them out, etc. No, procurement audits are not performed, neither on central or local levels.

\section{RECORD KEEPING}

1. For contracts to be awarded on the basis of competitive bidding, does the procuring entity maintain a complete record of the process? This would include e.g. copies of all public advertisements, pre-qualification documents (if used), the pre-qualification evaluation report documenting any decisions not to pre-qualify certain potential bidders, the bidding documents and any addenda, a record of any pre-bid meetings, the bid opening minutes, the final bid evaluation report (including a detailed record of the reasons used to accept or reject each bid, copies of bids, appeals against procedures or award recommendations, a signed copy of the final contract and any performance and advance payment securities issued, etc.

The Regulations require that a procurement protocol with all relevant information be maintained. However, this rarely happens, and the requirement is not enforcea'.

2. Are adequate contract administration records maintained? (These would include contractual notices issued by the supplier, contractor, purchaser or employer; a detailed record of all change or variation orders issued affecting the scope, quantities, timing or price of the contract; records of invoices and payments; certificates of inspection, acceptance and completion; records of claims and disputes and their outcome; etc.) The Regulations require that a procurement protocol with all relevant information be maintained. However, this rarely happens, and the requirement is not enforced.

3. For small contracts or purchase orders for goods procured using shopping procedures, is a database maintained showing the current market price for commonly needed items? No, procuring entities conduct ad hoc surveys, which often leads to poor quality in cost assessment.

4. Are periodic reports prepared on overall procurement activities? By and for whom? Yes, by the Central Tender Board for the Ministry of Finance. 


\section{Section E - Public Sector Selection of Consultants}

1. Are procuring entities capable of carrying out a professional selection process for consultant services? Do they administer consultant contracts effectively? Yes. The rules are contained in the Regulations on selection and employment of consultants supported by standard documents (based on World Bank documents) issued by the Central Tender Board.

2. Is the winning consultant firm normally chosen by comparing competitive proposals submitted by a list of qualified firms? Where do implementing agencies obtain the information necessary to develop lists? Specify what other methods are used and when they are used.

Short lists are compiled on the basis of expressions of interest following public advertisement.

3. Do requests for proposals clearly describe the selection process and evaluation criteria? Yes, this is normally the case.

4. Do the Terms of Reference describe the requirements of the assignment clearly and completely, including background, scope and objectives, deliverables, time frame, anticipated staff-time, and government contributions?

No on government funded projects there is a general issue of low quality in the description of requirements and specifications.

5. Is selection based only on technical considerations or also on price? Normally the split is $80 \%$ on the technical criteria and $20 \%$ on price.

6. Are technical criteria detailed and appropriate and their relative weights reasonable? Yes

7. If price is also a selection factor, are technical evaluations completed before opening and consideration of price proposals? Are the relative weights chosen for each factor appropriate? Yes

8. Are there standard conditions of contract? Are they fair and equitable to the consultant? Do they adequately protect the interests of the client?

Yes, standard terms (based on World Bank documents) are issued by the Central Tender Board.

9. What form of compensation is used? Unit rates? Lump sum based on milestones? Other?

All forms are available, depending on the nature of the contract, but mostly unit rates are used.

10. Are consultants required to submit proposal, performance and/or advance payment securities? No normally not. 
11. Is there a conflict of interest policy provision included in the conditions of contract? (If so, describe)

Yes, the standard terms of contract contain both an obligation for the consultant to disclose any conflicts of interest and anti-bribery pledges.

12. Are evaluations conducted by committees with appropriate expertise?

Yes, the relevant tender board is responsible for appointing the committee member in accordance with the Regulations.

13. Are general criteria broken down into appropriate detailed criteria agreed by the evaluating committee before conducting the evaluation?

Yes, this is normally the case.

14. Are all criteria applied consistently, fairly and impartially by the evaluators? Are the individual score sheets kept as part of the procurement record? Yes, this is normally the case

15. Are evaluations conducted individually by each member of the committee and the results averaged?

No, committees reach a common position through negotiations.

16. Are new factors or weights added after the issuance of the request for proposals which are considered during the evaluation?

No, this is not the general perception.

17. Are evaluation reports prepared containing essential details of the process, results, and matters to be taken up during contract negotiations?

Such reports are mandatory, but are often not available due to poor enforcement of rules and inadequate filing system.

18. Are evaluations normally completed within the time originally requested for the validity of proposals?

Yes, but drawn out evaluation and award periods are common.

\section{Section F - Procurement Performance}

\section{STATISTICS}

1. What are the approximate annual values of public procurement for goods, works, and consultant services, respectively? If possible, distinguish between procurement for projects and ongoing programs. Statistics were not available

2. What are the approximate percentages of goods, works, and consultant services financed by external donors? Statistics were not available

3. What percentage of public procurement follows competitive bidding procedures? Other methods? Statistics were not available

4. What percentage of competitively bid procurement is donor financed? Statistics were not available 


\section{GENERAL EXPERIENCE}

1. Are government organizations generally perceived by suppliers/contractors/consultants/the public as fair and efficient in their procurement practices?

No, there is a perception of widespread corruption in the public service.

2. Which of the following factors are considered to be problems by persons familiar with public procurement in the country?

\begin{tabular}{|l|l|}
\hline Yes & No \\
\hline & $\mathrm{x}$ \\
\hline
\end{tabular}

Inappropriate or outdated laws and regulations

Poor compliance with and enforcement of existing laws

Poor information about procurement needs

Shortage of experienced professional staff

Poor training of procurement staff

Low pay for procurement staff

Poor procurement training

Weak procurement planning

Poor procurement methods and procedures

Lack of good standard procurement documents

Poor technical specifications (Goods only? Works?)both

Cumbersome contract approval procedures

Lack of clear delegation of contracting authority

Interference by higher level officials

Inadequate appeals mechanism

Lack of anti-corruption measures and enforcement

\section{EXPERIENCE WITH WORLD BANK-ASSISTED PROJECTS}

1. How many Bank projects have been completed in the country? Are now underway? In which sectors?

A total of 130 projects have been completed since the Bank started lending to Tanzania in 1963.

There are currently 22 projects under implementation, with a total commitment of US\$1.3 billion and 7 projects under preparation

2. Which organizations have been responsible for procurement on these projects?

Various implementing agencies have been responsible for procurement. In most of the projects, special project implementation units were created with a procurement specialist as one of the staff.

3. What thresholds for ICB, IS, NS, and prior review for goods, works, and consultant services are currently in effect for ongoing projects? Are they the same for all projects? How long have they been in effect?

The thresholds for ICB have normally been US\$150,000 for works and US\$100,000 for goods. For IS and NS the threshold is normally US\$30,000. For consultant services the threshold for QCBS has been US\$100,000. Prior review thresholds are US\$150,000 for works, US\$100,000 for goods, US\$100,000 for firms and US\$50,000 for individual consultants 
4. Do project audits/completion reports/supervision reports indicate significant procurement problems? Have any cases of misprocurement occurred? Describe.

The problems include: poor procurement planning; inadequate advertising; excess use of shopping method; lack of proper documentation of tender process and record keeping; evaluation; and unrealistic implementation

5. Have procurement issues caused serious implementation delays, cost overruns, disbursement delays? Describe. Yes, serious cost overruns have been experienced in works contracts due to implementation delays.

6. Does the Bank receive a large number of complaints about procurement procedures, selection decisions in the country? No

7. Are contracts generally awarded within the planned, usual time frame that would be required for similar operations by other experienced and efficient organizations? No

8. Are there serious problems or conflicts between national and/or local practices and World Bank guidelines which should be addressed on an interim basis pending implementation of recommended long-term action plans? No 


\section{Section G - Private Sector Procurement}

1. Is there a reasonably well-developed private sector which freely trades goods and procures works and other services?

A fairly well developed private sector has developed since Tanzania embarked on the road towards trade liberalisation in 1985. Major sectors are trade \& tourism, financial \& business services, manufacturing and to a certain extent construction.

2. Does the private sector compete actively in opportunities advertised by the government? Is this evidenced by number of bids/proposals received when open competition is sought? Yes, the private sector does compete actively in opportunities advertised by the government. Open competition is common practice when the central Government

3. Do private sector companies feel comfortable in exercising their right to complain or seek remedies under the public procurement system (to the extent the system provides for this right)?

The private sector does not feel uncomfortable about complaining under the public procurement system, but they do not on the other hand see any use of doing so. The private sector does not find it transparent. where to complain and the general perception is that it involves a substantial effort with an absolute minimal chance of a result.

4. What is the performance record of private sector companies on.government contracts? (Is there evidence of deliberate under pricing, poor performance on government contracts or excessive price increases after contract award during performance)?

The IPR done simultaneously with the CPAR and its site visits aimed at verifying procured assets does not point towards substandard deliveries being systematic and pervasive. Irregularities are reported, but not as a systematic observation.

5. Is there evidence that private sector companies are aware of requirements and have the capacity to submit acceptable bids/proposals (i.e. understand the system)? Are many bids/proposals rejected for procedural reasons?

In general, the larger companies have the capacity whereas there is a need to develop professional business practices in SME's. The rate of proposals rejected for procedural reasons are not alarming

6. Has there been any experience with private sector contracts for the provision, operation, maintenance of infrastructure for various public services (BOO/BOT/BOOT/etc.)? Describe. No experience. 
7. Do private sector companies have access to commercial loans at a reasonable interest rate? Commercial lending rates are high, $16.96 \%$ nov-02. Not only are lending rates high, but also obtaining bid security is a major expense. The conditions for bid security are in general the same as with letters of credit. The value of the security should either be $100 \%$ cash cover and the value of the contract should be at least $125 \%$ of the secured amount. The causes of the high lending rates and costs of bid security are similar to those of obtaining letters of credit: Unstable legal environment, High cost of capital, High degree of risk, Loan recovery problems, Collateral recovery problems.

8. Are bonds commonly used? If so, is there a regulatory authority overseeing the activities of bonding companies? Is there a mechanism to suspend companies that have not honoured their obligations to pay or execute bonds? Is there a satisfactory track record of calling of bonds? Bonds are not commonly used, as the cost is high. The issue is the same as with bid security and letters of credit mentioned above in question 7.

\section{SECTION H - EMERGING AREAS OF INTEREST}

1. Is military expenditure covered by the public procurement systems laws and regulations? Briefly describe coverage and exceptions. Yes, except for procurement of sensitive goods and services. There are presently no guidelines defining the split between sensitive and non-sensitive procurement.

2. Does the public procurement system and accompanying control environment (including the financial accountability system) control the flow of funds so as to ensure that funds budgeted for valid expenditures are not diverted to finance illicit activities (e.g. money laundering, terrorism)?

3. Does the country have policies aimed at promoting environmentally and socially responsible procurement? Briefly describe coverage or initiatives that will contribute to such procurement practices. No specific policies are in place. 